


W.

15:

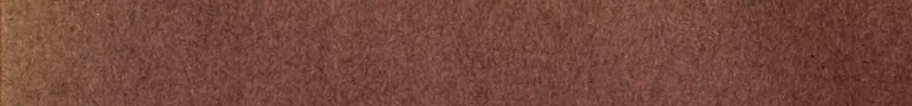

S

W.

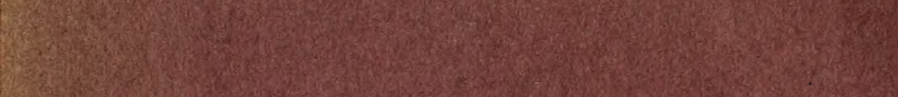

20.

W

(1) 8

When

3i)

3.

4.

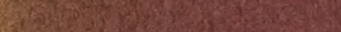

H.

$\frac{1}{3}$ 
$L-6$ 



\section{DIE ABSTAMMUNG}

\section{DER}

\section{ALTESTEN HAUSTIERE.}

PHYLOGENETISGHE STUDIEN DEER DIE ZOOLOGISCHE HARKUNRT DER IN PRAHISTORISCHER ZEIT RROOREENEN WAUSTIER-ARTEN NBQST UNTER-

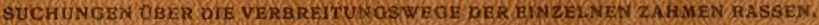

Now:

\section{DR. CONRAD KELLER}

O. PROEESSOR DER SEEAIELLEN $20010 \mathrm{GM}$ AM EIOGLNOSSISOHEN ROL XIECHNKUM 15. 20 ructs?

WERATSEEGEBEN

DURGH DIE

\section{STIFTUNG VON SCHNYDER VON WARTENSEE.}

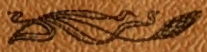

Zngicil 1002

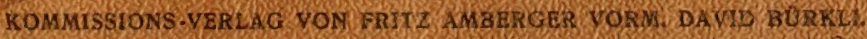<smiles>[18OH]</smiles> 



\section{DIE ABSTAMMUNG}

DER

\section{ÄLTESTEN HAUSTIERE.}

PHYLOGENETISCHE STUDIEN ÜBER DIE ZOOLOGISCHE HERKUNFT DER IN PRÄHISTORISCHER ZEIT ERWORBENEN HAUSTIER-ARTEN NEBST UNTERSUCHUNGEN ÜBER DIE VERBREITUNGSWEGE DER EINZELLNEN ZAHMEN RASSEN.

VON

\section{DR. CONRAD KELLER}

O. PROFESSOR DER SPEZIELLEN ZOOLOGIE AM EIDGENÖSSISCHEN POI.YTECHNIKUM IN ZÜRICH.

HERAUSGEGEBEN

DURCH DIE

STIFTUNG VON SCHNYDER VON WARTENSEE.

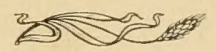

ZÜRICH 1902

DRUCK UND KOMMISSIONS-VERLAG VON FRITZ AMBERGER VORM, DAVID BÜRKLI. 


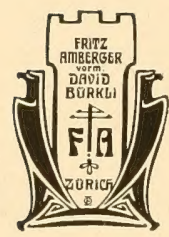




\section{VORWORT.}

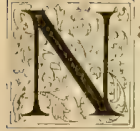
ach den erfolsereichen inläufen, welche das Situdium der Haustierwelt vor vierzig Jahren grenommen hat, sollte man erwarten, dass der Ausbau dieses zoologisclien Wissenszweiges heute nahezu vollendet sei.

Dem ist jedoch nicht so. Ein Blick in die einschlägige Litteratur belehrt uns im Gegenteil, dass bezüglich der Abstammung der allerwichtigsten I Iausticr-Rassen cinc ausserordentliche Verwirrune herrscht.

Leider hat die moderne Schulzoologie den Gergenstand gründlich vernachlässigt - gewiss nicht zu ihrem Vorteil! Sind doch gerade bei den der Domestikation unterworfenen Tieren die phylogenetischen Probleme in der allerpositivsten Weise zu fassen und die Gesetze der Umbildung ticrischer Formen am klarsten zu ïberblicken.

Mehr Interesse für die hier zu crörternden Abstammungsfragen brachte man aus den Kreisen der Landwirte entgegen.

Die wissenschaftliche Tierproduktionslehre hat seit Jahren dic Notwendigkeit einschläniger Untersuchungen hervoruchoben, da solche der Praxis die nötige Sicherheit des züichterischen Vorgehens gewähren müssen. Die Zootechniker haben auch wohl versucht, dem Stiefkind der Zoologie, der I lausticreschichte, nakh Krätiten aufzuhelfen. Aber diese Kräfte waren sehr häufig unzureichend und führten zum Dilettantismus - rühmliche Ausnahmen immerhin zugegeben. Nicht jeder Zootechniker befand sich eben in der glücklichen Lage eines H. von Nathusius, der richtig sah, weil er tüchtiger Praktiker und Zoologe zugleich war. So entstand oft mehr Verwirrung als Klarheit in Fragen, die selbst für den geschulten Zoologen zu den allerschwierigsten gehören. 
Die ethnographische und kulturgeschichtliche Forschung, die an Acm Vorgang der Haustierwerdung ein lebhaftes Interesse haben musste, kam über eine gewisse Stufe der Erkenntnis niemals hinaus. Sie Jahren habe ich in meinen Vorarbeiten zu diesem Gegenstand betomt, dass verschiedene Forschungsmethoden zusammenwirken müssen, un äher den Lropung der ältesten Hausticre ins Klare zu kommen. L'm den Ausuangspunkt mit Sicherheit zu crmitteln,

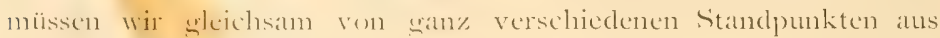
nach rückwärts visieren.

Den Gegenstand zu erschöpfen, kann nicht in meiner Absicht liegen; dem Einzelnen ist dies kaum möglich, es bedarf dazu der Mitwirkung Vieler. Ueberdies ist die Schwierigkeit der Materialbeschaffung viel grösser als man glaubt. Ich bin mir derselben um so vollkommener bewusst, da ich auf weiten Gebieten der alten Welt gesammelt habe und namentlich auch dic Haustierwelt der wichtigsten afrikanischen Kulturkreise aus eigener Anschauung kennen lernte.

Neine Arbeit soll eine der Gegenwart entsprechende Grundlage schaffen, auf welcher ein weiterer Ausbau möglich ist. Ich beschränkte mich auf die Abstammung der alten Haussäugetiere, da bezüglich der Hausvögel, insbesondere Huln und Taube, seit den sorgfältigen Untersuchungen Darwin's die Herkunft klargelegt ist. Hinsichtlich der wichtigsten, in prähistorischer Zeit entstandenen Haustierarten vertrete ich da und dort Ansichten, die von den herrschenden Meinungen abweichen; meine Resultate verdanke ich Methoden, die ich zum Teil erst schaffen musste.

Dass ich mich auf die wichtigsten und allerältesten Haustiere beschränkte, hat einen doppelten Grund. Einmal ist deren Phylogenese am dunkelsten geblieben und am schwicrigsten zu ermitteln. Sodam hat der Mensch seme wichtigsten Erwerbungen in der Tierwelt bereits in vorhistorischer Zeit gemacht; was nachträglich hinzukam, erscheint von sekundärer Bedeutung.

Zürich, am 1. September 1902.

Prof. Dr. C. Keller. 


\section{INHALTS - UEBERSICHT.}

Seite

1. Historische Einleitung . . . . . . . . . 1-6

11. Die Methoden der Rassenforschung und der Haustier-Phylogenie . . T-1\%

1II. Die antike Kunst im Dienste der Haustiergeschichte . . . . $18-23$

IV. Der Vorgang der Haustierwerdung . . . . . . . 24-34

V. Die Haushunde . . . . . . . . . . . 35-8n

VI. Die Hauskatze . . . . . . . . . . . $81-87$

VII. Pferd und Esel . . . . . . . . . . $88-99$

VIII. Die Hausschweine . . . . . . . . . . . 100-115

IX. Die Hausrinder (Bos taurus und l3os indicus) . . . . 116-16S

x. Das Hausschaf . . . 169-19s

XI. Die Hausziege . . . . . . . . . . 199-204

XII. Das Kamel . . . . . . . . 210-215

Uebersicht über die Stammesverhältnisse der ältesten Haustiere . . . 216-21;

Nachtrag zum Kapitel ${ }_{\text {HHausrinder }}{ }^{2}$. . . . . . . . . 218

Rückblick . . . . . . . . . . 219-232

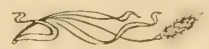





\section{IISTORISCHE INLEITL NC.}

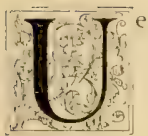

eber die Ilerkunft der I laustiere hatte man bereits im klassischen Altertum die vollkommen richtige Vorstellung, dass sie aus dem Wildstande in den Dienst des Menschen herüber genommen wurden und die aristotelische \%eit betrachtete allgemein . Isien als das Stammland der wichtigsten Arten.

Vergleichen wir damit, was noch im Jahr 1835 der Münchener Zoologe Andreas Wagner in einem angesehenen wissenschaftlichen Sammelwerk behauptet. $\left.{ }^{1}\right)$ Nach diesem Autor hängt die Frage der Domestikation aufs innigste mit dem primitiven Zustand des Menschengeschlechts zusammen; keine der frühesten Urkunden der Völker weiss etwas von 'Tierzähmung, sie alle sprechen von einem höheren, besseren Zustand des jugendlichen Menschengeschlechts, das eine vollkommene Herrschaft über die ganze Welt der Tiere ausübte. Mit dem Fall des Menschen ging diese Gewalt verloren und nur ein kleiner Teil der Tiere, der zu seiner Existenz unumgänglich nötig war, blieb ihm noch ferner überlassen.

Ich habe absichtlich diese Gegenüberstellung grewhit, um zu zeigen, wie wenig Fortschritte die Kenntnis der Haustiergeschichte während zwei Jahrtausenden zu verzeichnen hat. Jener Standpunkt mag ja nicht allseitige Billigung erfahren haben, aber dass er überhaupt noch im ersten Irittel des 19. Jahrhunderts in einem ernsthaften Werke ausgesprochen werden durfte, ist für den Stand der Dinge bezeichnend.

Es bedeutet dies ein Rückgang hinter das 18. Jahrhundert, da bereits Buffon auf einem wissenschaftlich ganz richtigen Boden stand, indem er für eine Reihe alter Haustiere (Pferd, Esel, Kamel, Ziege, Schaf und Hund) eine Herkunft aus dem Orient nachzuweisen versuchte und eine entsprechende wilde Stammart als Ausgangspunkt ansah, denn er sagt, dass die Natur noch weitere Arten in Reserve habe, die der Mensch mit einiger Anstrengung in seinen Dienst herüberziehen könnte (il ne tiendrait qu'à nous d'assujettir et de faire servir à nos besoins). ${ }^{2}$ ) Der letztere Gedanke ist später namentlich in Frankreich mit Begeisterung aufgegriffen und durchzuführen versucht

1) F. Ch. D. zon Schreber. Die Säugetiere. Fortsetzung von Andreas Hagner. VI. Teil. 1835. Pag. 4.

3) Histoire naturelle, t. XII. 1764. 
worden. Der Erfolg entsprach allerdings nicht den gehegten Erwartungen. Man übersah eben. dass eine allzu extensive menschliche Wirtschaft nur zu einer Zersplitterung der Kräfte fülıren musste.

Aehnliche Ansichten bezüglich der Herkunft unserer ältesten Haustiere vertraten im 18. Jahrhundert Gïldenstädt und Pallas, so dass schliesslich die Neigung immer mehr hervortrat, dieselben ganz allgemein aus Asien herzuleiten. Dieser Strömung trat dann $G$. Cuvier insofern entgegen, als er wenigstens für die Hausrinder einen europäischen Ursprung nachwies. Im übrigen war Cuz'zer's Einfluss der Entwicklung der Haustier-Geschichte nichts weniger als günstig. Es hängt dies mit seinen allgemeinen theoretischen Anschaungen zusammen. Als entschiedener Vertreter der Artbeständigkeit waren ihm die wandelbaren Haustiere in höchstem Grade unbequem; wenn er auch zugiebt, dass die Einwirkung des Menschen Abänderungen hervorriefen, die in der freien Natur niemals entstehen konnten, so drückt doch der grosse Schöpfer der vergleichenden Anatomie die Variationsgrenze in einer subjektiven Weise derart herunter, dass er in oflenbaren Widerspruch mit den Thatsachen gelangt. In seinem berühmt gewordenen "Discours préliminaire", den er seinen "Recherches sur les ossements fossiles" vorausschickt, durchgeht er kurz die Variationen (pag. 60 und 61). Bei der halb domestizierten Katze beschränken sie sich auf einige Aeusserlichkeiten, Unterschiede im Skelett sind dagegen nicht vorhanden. Bei den Rindern sind diese Verïnderungen schon grösser, aber wiederum rein äusserlich: grösserer oder kleinerer Wuchs, mehr oder weniger lange Hörner, die auch fehlen können, eine grössere oder geringere Menge Fett auf dem Rücken - das ist alles. Schafe und P'ferde verhalten sich ähnlich, einzig der Hund zeigt stärkere Einwirkungen, aber auch hier wird an dem gegenseitigen V'erhältnis der Knochen nichts geändert (. dans toutes ces variations les relations des os restent les mémes" !).

Während die vergleichende Anatomie als Führerin in den so schwierigen Rassenfragen prädestiniert war, hat seltsamer Weise ihr Schöpfer durch seine Autorität dieselben in der ersten Hälfte des 19. Jahrhunderts völlig lahm gelegt und nur so erklärt sich die retrograde Stellung, die sich beispielsweise bei Andreas Wagner bemerkbar macht.

In Frankreich blieb eine mächtige Gegenströmung nicht aus. Isidore Geoffroy S\%. Hilaire, den Traditionen seines Vaters folgend und wie dieser auf dem Boden der Entwicklungslehre stehend, bekämpfte mit Erfolg die Ansichten von Curier und bereitete in seinem Werk Acclimatation et domestication des animax utiles", das von 1849 bis 1860 vier Auflagen erlebte, den Boden für unsere modernen Anschauungen über die Abstammung der Haustiere vor.

Indem er von denselben Art für Art vornimmt. weist er in überzeugender Weise nach, dass die V ariationen nicht allein äusserliche, oberflächliche sind, wie Cuvier wollte, sondern dass sie auch die beständigsten 
inmeren Organe wie das Skelett beeinflussen. Im Jahr 1859 stellte er in den "Comptes Rendus" eine Liste von 47 Haustieren auf, die ihrer Entstehung nach verschiedenalterig sind und von denen er 14 Arten als in vorhistorischer Zeit entstanden erklärt.

Zum ersten Mal erfolgen eingehendere Angaben über die Urheimat und die Verbreitungswege für die einzenen Haustierspezies. Die Methode. die Is. Geoffroy St. Hilaire zur Anwendung bringt, ist zunächst die rein zoologische, doch vermisst man die vergleichend-anatomische frundlage allzusehr und Irrtümer mussten da und dort unterlaufen. Daneben werden die Thatsachen der Kulturgeschichte in ausgiehigster Weise herangezongen. womit zweifellos wertvolle Winke gewonnen und vielfach richtige Perspektiven erzielt wurden. Die orientalische, beziehungsweise asiatische Herkunft der ältesten Haustiere gelangt zu stärkster Betonung: „L'Orient, particulièrement l'Asie, est la patrie primitive des animaux domestiques et, sans exception, de tous ceux, dont la domestication est la plus ancienne".')

In jener Periode beschäftigte sich sodann L. Fitzinger eingehender mit der Abstammung und Verbreitung der Ilaustierrassen. Seine Arbeiten sind vorzugsweise in den Sitzungsberichten der Akademie der $\mathrm{W}$ issenschaften in Wien niedergelegt, später (1876) schrieb er ein besonderes Werk über die Hunderassen und ihre Abstammung. In rasse-geographischer Ilinsicht ist viel brauchbares Material zusammengetragen, die Methode zur Auffindung der Stammformen jedoch verfehlt. Fitzing ver verfährt rein deskriptiv, indem er sich an rein äusserliche Merkmale hält, anatomische Analysen dagegen fast gar nicht anwendet. Die Art, wie er Bastarde von ungekreuzteı Formen ausscheidet, trägt den Stempel der Willkürlichkeit an sich; die Zahl seiner Stammformen ist durchweg zu hoch, das Ab. stammungsbild viel zu verwickelt. Seine wissenschaftlichen Anschauungen haben daher keinen tieferen Einfluss auszuüben vermocht. Seine bis ins einzelne gehende Nomenclatur der Rassen ist zwar von manchen Autoren später zum Teil angenommen worden, basiert aber wiederum auf willkürlichen Annahmen. In seinen späteren Arbeiten Iässt er die inzwischen von anderen angebahnten Fortschritte bezüglich der Haustierstammarten so gut wie unberücksichtigt.

Ein bedeutungsvoller Wendepunkt beginnt mit der Entdeckung der l'fahlbauten.

Im Winter 1853/54 führte der ausnahmsweise niedrige Wasserstand des Zürichsees zur Auffindung der ersten prähistorischen Station in Obermeilen, bald nachher kamen auch an verschiedenen anderen Stellen ähnliche alte Seedörfer zum Vorschein. Neben anderen Fundstücken förderte man aus dem Schlamm zahlreiche Haustierüberreste zu 'Tage, welche in Ludwig. Rïtimeyer einen geistvollen Bearbeiter fanden.

1) Is. Geoffroy St. Hilaire. Animaux utiles. 1861. Pag. 256. 
Schon 1860 erschien dessen erste Veröffentlichung in den, Mitteilungen der antiquarischen Gesellschaft in Zürich ", bald nachher folgte die klassische "Fauna der Pfahlbauten" (1862), womit Rätineyer zum eigentlichen Begründer der modernen wissenschaftlichen Haustiergeschichte wurde und ganz neue Streiflichter auf das genetische Verständnis unserer Rassen zu werfen vermochte. Seine minutiösen vergleichend-anatomischen Analysen im Verein mit weiten geistigen Gesichtspunkten überholten alle seine Vorgånger, Cuvier nicht ausgenommen. Ausserdem fielen diese Untersuchungen in eine besonders empfängliche Zeit hinein. Darzin hatte kurz vorher sein Werk über den Ursprung der Arten veröffentlicht und trat darin mit allem Nachdruck für die Umbildung und Entwicklung der organischen Wesen ein. Rütimeyer konnte als erster die Richtigkeit dieser Lehre an einem speziellen Beispiel darthun, indem er den primitiven Charakter der Haustiere der Pfahlbauperiode gegenüber der Gegenwart nachwies und eine Umbildung thatsächlich konstatierte. Es war somit die prähistorische Forschung, die in V'erbindung mit anatomischen Methoden ganz neue Ausblicke eröffnete. Im Jahre 1867 folgte als Ausbau der neugewonnenen Ideen der "Versuch einer natürlichen Geschichte des Rindes", der für unsere zahmen Rinderformen die breiteste phylogenetische Grundlage bot.

In England war es namentlich Charles Darwin, der die von Rütimeyer betretene Bahn in vollstem Umfange zu würdigen verstand und bei seinen eigenen Untersuchungen dessen anatomische Methode befolgte. In dem bekannten und vielbenutzten Werk über "Variieren der Tiere und Pllanzen im Zustande der Domestikation", das 1868 in erster Autlage ausgegeben wurde. lässt sich der bedeutende Fortschritt erkennen. den die Geschichte der Haustiere in weniger als einem Dezennim gemacht hatte. Das Buch enthält neben einer ausserordentlichen Fülle von Thatsachen über die geographische Verbreitung der einzelnen Haustiere auch phylogenetische Ergebnisse, die neu und eigenartig sind - es mag hier nur auf die Stammesgeschichte der Kaninchen- und Tauben-Rassen hingewiesen werden.

Von dieser Periode ab macht sich eine regere Thätigkeit bemerkbar, die bald auf den Gesamtbestand der I Iaustierwelt, bald auf einzelne Arten gerichtet ist.

Ich erwähne zunächst Theophil Studer, der vorzugsweise die prïhistorische Seite bebaute und die reichen Haustierrelikte der westschweizerischen P'fahlbauten, welche infolge der Juragewässerkorrektion zu Tage traten, eingehender untersucht hat. Er konnte nicht allein die von Rütimeyer gewomnenen Resultate bestätigen, sondern auch in mancher Hinsicht erweitern.

In Deutschland hat Alfred Achring in einer Reihe verdienstvoller Arbeiten an der Iland prähistorischer Funde unsere Kenntnisse über die Abstammung der Haustiere gefördert: ich erinnere an seine eingehenden Studien über diluviale Pferde und deren Beziehungen zu unseren heutigen 
Rassen, an seine Forschungen üher den I $r$, eine wichtige (quelle zahmer Rinder, dann über die prähistorischen Hausschweine Norddeutschlands und über altweltliche und altamerikanische Hunde.

Einen andern Weg betrat Fuluw Kühn durch die $187+$ erfolgte Schaffung eines Haustiergartens im landwirtschaftlichen Institut der Universität Halle. Hier sollte dem Abstammungsproblem auf physiologischem Wege nachgegangen werden und durch Kreuzungsversuche der zahmen Rassen mit verschiedenen Wildformen die Affinitat festgestellt werden. Einen Ueberblick

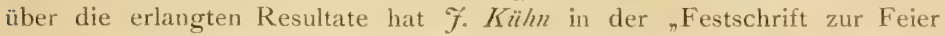
des 25-jahrigen Bestehens des landwirtachaftlichen Institutes" 1s8s gegreben.

Ausserhalb Europa floss das Material zur Rassenkenntnis fremder Gebiete etwas spärlicher, als man bei der raschen Aufeinanderfolge grosser Expeditionen hätte erwarten dürfen. Die verschiedenen Reisenden haben den Gegenstand allzusehr vernachlässigt. Doch giebt es rühmliche Ausnahmen: R. Hartmann machte eingehendere Erhebungen über die Haussäugetiere der Nilländer $(1864) ; G$. Schweinfurth und $O$. Baumann haben unsere Kenntnisse afrikanischer Haustiere in erfreulicher Weise erweitert.

Daneben finden wir zahlreiche Forscher, deren Thatigkeit darauf gerichtet ist, einzelne Haustierspezies in monographischen Untersuchungen zu behandeln. Geradezu vorbildlich sind in dieser Richtung die "Vorstudien für Geschichte und Zucht der Haustiere", worin schon 1864 Hermann z'on Nathusius die Rassen des Schweines nach ihrer Verwandtschaft und Abstammung untersucht hat. Es ist zu bedauern, dass die Zootechniker der späteren 7,eit hinsichtlich umsichtiger Iandhabung der Methode diesem Muster vorurteilsfreier Untersuchung so selten gefolgt sind.

An monographischen Arbeiten über das Rind sind die verschiedenen Veröffentlichungen von M. Wilckens hervorzuheben. Er ist der Begründer der früher übersehenen Brachycephalus-Rasse geworden, nahm aber bezüglich der Stammform der Rinder eine etwas schwankende Stellung ein.

Eine ebenso eingehende wie sachkundige Durcharbeitung der früher ganz ungenügend bekannten I Iausinder ()steuropas lieferte Leopold Idametz in einer Reihe von Publikationen und es wäre zu wünschen, dass auch die westeuropäischen Rassen in ähnlicher Weise erforscht würden. Für die nordeuropäischen Rinder ist dies zum Teil geschehen, indem E. O. Arenander mit einer einlässlichen Studie über die hornlosen Rinder hervortrat, deren Stellung in der Stammgeschichte er freilich nicht zutreffend beurteilte.

Die Vorgeschichte der Hunderassen ist an der Hand prähistorischer Materialien, besonders von Feitteles, Woldrich, Anutschin, Strobel und Studer aufzuklären versucht worden. während Max Silber die asiatischen und afrikanischen Haushunde nach ihrer geographischen Verbreitung in besonderen Monographien bearbeitet hat.

Die Hauskatze ist mit Rücksicht auf ihre Abstammung von Martorelli in neue Beleuchtung zu setzen versucht worden. 
Einc schöne Studie über rezente Pferde, namentlich über diejenigen Russlands, hat Tscherski geliefert. Der österreichische Zoologe $L$. von Lorenz-Liburnau hat die Abstammungsverhältnisse unserer Hausziegen einer erneuten und verdienstvollen Untersuchung unterzogen.

Dem mag hinzugefügt werden, dass ich seit einem Dezennium dem Haustierproblem in seinem ganzen Umfange nachzugehen bestrebt war und in meinen Veröffentlichungen die Bildungsherde und Wanderstrassen einzelner Arten verfolgte. Ich wies auf Grund neuer Untersuchungen auf die Notwendigkeit hin, die V'erhältnisse der Nachbarkontinente zu befragen, um deren Einwirkung auf den Haustierbestand Europas besser zu ermitteln.

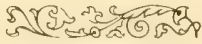




\section{I)II: MIETHODL N \\ DOER R ISSENEARSCIUNG LND I)IER HAUSTIER-PHYLOGENIE.}

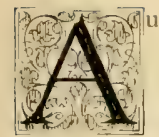

f keinem Gebiet der Zoologie ist eine genaue und kritische Orientierung über die einzuschlagenden Wege der phylogenetischen Forschung so notwendig, wie gerade in der Haustiergeschichte. Der schwankende, unsichere Zustand in den herrschenden . Inschauungen rührt zum grossen Teil davon her, dass man in der Methode nicht kritisch genug war. Jeder geht seine eigenen Wege: Der Naturforscher kümmerte sich häufig zu wenig um die Thatsachen der Kulturgeschichte und Ethnographie: Kulturhistoriker und Sprachforscher glaubten oft genug, die schwierige Materic ohne Beihülfe der anatomischen Forschung bewältigen zu können und mussten naturgemäss auf Abwege geraten; die Prähistorie verliess sich allzusehr auf ihre Ergebnisse, ohne dieselben von andern Standpunkten zu beleuchten. Kein Wunder, dass da und dort sogar der Dilettantismus sich auf unser Feld wagte, um als schwerwiegendes Argument die "feste Ueberzeugung“ ins Feld zu führen.

Diesem Zustand muss ein für allemal ein Ende gemacht werden und wir müssen völlige Klarheit darüber besitzen, wie hier methodisch vorgegangen werden soll.

Denn an das rassengeschichtliche Studium knüpfen sich eine grosse Zahl rein wissenschaftlicher Fragen, die uns Aufschluss zu geben haben über den grossen Vorgang der Umbildung in der organischen Welt —. Fragen, deren Beantwortung wohl nirgends so klar gewonnen werden kann, wie auf dem Feld der Haustierwerdung. Auch in den grossen Tagesfragen der Vererbungsphysiologie, die immer noch nicht zur Ruhe kommen wollen, wird der definitive Entscheid wohl von Seite der Haustiergeschichte fallen müssen.

Das Studium derselben hat aber nicht nur einen rein akademischen Wert; man beginnt vielmehr einzusehen, dass ihm auch eine eminent praktische Bedeutung innewohnt.

Halten wir stets daran fest, dass jede Haustier-Rasse ein Produkt geschichtlicher Entwicklung ist: ihre morphologischen Eigenschaften bilden den sinnlich wahrnehmbaren Ausdruck für bestimmte physiologische Leeistungen. Diese gestalten sich aber beim Haustier grossenteils zu wirtschaftlichen Leistungen. 
Die Ausbildung von Rassen konnte nur langsam vor sich gehen und es bedurfte der zürchterischen Intelligenz von vielen menschlichen Generationen, um ein bestimmtes Zuchtziel zu erreichen. Eine grosse Summe von Kulturarbeit des Menschen erscheint somit im Haustier niedergelegt.

Indem wir Rassengeschichte treiben, unsere heutigen Rassen also nach rückwärts verfolgen, um zuletzt beim Ausgangspunkt, d. h. bei der wilden Stammform anzulangen, gewinnen wir einen Ueberblick über den Weg, den die züchterische Praxis eingeschlagen hat, sowie über den Gesamterfolg der dabei verwendeten Kulturarbeit. Damit ist ein geistiger und ein praktischer Gewinn erzielt. Das Ergebnis muss notwendigerweise der Methode der Züchtung eine grössere Sicherheit verleihen. An die Stelle des Herumtastens und der blossen Zufallsgriffe tritt der positive Anhalt für züchterische Bestrebungen. Ohne Kenntnis der Rassengeschichte bleibt die Tierproduktion auf unsicherer Basis.

Daher die Erscheinung, dass fast in allen neueren Schriften über wissenschaftliche Tierzucht die Rassengeschichte eine starke Betonung erfährt. Auch hat man in zootechnischen Kreisen den anerkennenswerten Versuch - fügen wir hinzu mit wechselndem Glück - unternommen, der Abstammung der heutigen Rassen nachzugehen.

Der wissenschaftlichen \%oologie fällt die Aufgabe zu, an Hand zuverlässiger Methoden den landwirtschaftlichen Kreisen Unterstützung zu leihen und namentlich den Wust; der von unberufener Seite in das Gebiet der Rassengeschichte hineingeschleppt wurde, gründlich zu beseitigen!

Da heisst es, jeden Fortschritt scharf unter die Loupe der Kritik nehmen, wobei besonders bei den schon in vorgeschichtlicher Zeit entstandenen Haustierformen mit der grössten Umsicht operiert werden muss.

Die herkömmlichen Methoden der theoretischen Zoologie reichen hier nicht mehr aus, denn es tritt im Entwicklungsgange eines Haustieres ein wesentlicher Faktor hinzu, der bei freilebenden Arten nicht in Frage kommt - es ist der Mensch, der den Gang der Dinge beherrscht, seine Haustiere umbildet und die Verbreitung derselben besorgt, so dass die Migration im engsten Zusammenhang mit den Wanderungen der Völker steht, die ihr lebendes Inventar nach den neuen Wohnsitzen mitnehmen.

Wir werden daher unter allen Umständen auch die Verbreitungsgeschichte des Menschen, sowie seinen Kulturbesitz in den einzelnen Kulturkreisen zu untersuchen haben, um Winke für die Herkunft der einzelnen zahmen Arten zu gewinnen.

Die Anwendbarkeit unserer Methoden beruht im Ferneren auf zwei Voraussetzungen, deren Richtigheit vorerst zu prüfen wäre.

Die eine Toraussetzung nimmt als Ausgangspunkt irgend einer zahmen Art eine Wildform an, die erst mit dem Auftreten des Menschen gezähmt werden konnte. Dagegen kamn wohl kein Einwand erhoben werden. Es sind zunächst vergleichend-anatomische Gründe, die direkte Belege dafür 
liefern, dass die Wildform die Vorstufe zum Haustier bildet: die Annahme wird aber auch durch Dokumente der antiken Kunst bestätigt und endlich sehen wir ja noch in der Gegenwart am Beispiel des afrikanischen Strausses den Vorgang sich abspielen, wie eine freilebende Art allgemeiner in den Hausstand des Menschen übertritt.

Die zweite Voraussetzung geht dahin, dass bei den allermeisten Haustieren die zugehörige wilde Stammform heute noch fortlebt. Diese Annahme schien aus dem Grunde zulässig, weil die Domestikation doch erst auf einer gewissen Entwicklungsstufe des Menschen stattgefunden hat und manche Völker heute noch hinter dieser Stufe zurückbleiben. Der Zeitraum, der die Gegenwart von der Zeit des ersten Erscheinens zahmer Tierarten in der Umgebung des Menschen trennt, ist nicht gross genug, um das völlige Erlöschen der zugehörigen WVildformen herbeizuführen. Es ist natürlich schwer, zuverlässige Daten über das Alter der ältesten Haustiere zu gewinnen. Die Nachtorschungen, die ich nach dieser Richtung an altägyptischen Haustieren angestellt habe, führten zu dem Ergebnis, dass die frühesten Spuren dort bis in das 6. Jahrtausend v. Chr. zurückverfolgt werden können. Rind, Schaf und Esel traten in den I Iausstand ein, da die Bewohner Urägyptens von der Steinzeit in die vorpharaonische Negadahzeit übergingen. Wir werden uns nicht allzuweit von der Wirklichkeit entfernen, wenn wir jene Kulturstufe um etwa 8000 Jahre von der Gegenwart zurückdatieren. Dieser Zeitraum genügt nicht, um Wildformen zum Erlöschen zu bringen, wie wir gerade an der Hand ägyptischer Dokumente nachweisen können.

Immerhin hat es nicht an Widersprüchen gegen unsere zweite Voraussetzung gefehlt. Der fleissige, aber nicht immer sehr kritische Zoologe L. Fitzinger schrieb noch 1876: "Die Behauptung, dass unmöglich alle "Individuen einer Art gezähmt werden können, entbehrt jedes historischen "Beweises und wird durch die erlaubte Annahme einer langen Dauer der "Zähmungsperiode bedeutend entkräftet. Um diesen Einwurf vollkommen "ungültig zu machen, bedarf es nur der so einleuchtenden Annahme, dass "jene Individuen, die sich der Domestikation entzogen haben, durch all,mähliche Ausrottung vom Schauplatz entfernt wurden, eine Annahme, "die so natürlich erscheint, dass man sie schon längst gebilligt hat."

Wenn diese so sicher hingeworfene Behauptung Fitzinger's wirklich jene allgemeine Billigung erfahren hätte, wie der Autor glaubhaft machen will, dam müssten wir es natürlich aufgeben, nach den wilden Stammformen unserer tierischen Hausgenossen zu suchen.

Es ist von grundsätzlicher Bedentung, die unhaltbaren Annahmen von Fitzinger an der Hand von Thatsachen zu widerlegen.

Ich will zunächst die lange Dauer der Domestikation nicht verwerfen. Der Mensch hat nur langsam und nach vielen missglückten Versuchen Tiere seiner Umgebung dauernd an den Hausstand gewöhnen können. 
Auf den ersten Wurf wurde kein Haustier gewonnen. Vielorts mochte man für zweckmässig finden, um bei den mangelhaften Verkehrswegen einer starken Inzucht vorzubeugen, ab und zu wieder frisches Blut aus dem Wildstande einzuführen. Was Plinius und Columella hierüber berichten, ist wohl nicht ganz von der Hand zu weisen.

Dagegen ist es durchaus falsch, wenn man glaubt, die Wildformen seien nach und nach ausgemerzt worden. Für ein geographisch beschränktes Areal, das stark kultiviert wurde, mag das richtig sein. Sehen wir doch ïberall den Wildstand zurückgehen, wo die höhere Kultur sich ausbreitet und intensive Wirtschaft betrieben wird. Daneben giebt es noch Erdräume genug, wo der nicht domestizierte Rest einer Art bequem fortleben kann. Und ein solcher Rest muss geblieben sein, da ja der Mensch nur einen Bruchteil der Individuen zähmen konnte.

Merkwürdigerweise scheint Fitzinger die längst vor 1876 erschienenen Untersuchungen von Nathusius nicht gekannt zu haben, denen zufolge das ostasiatische Hausschwein, das schon zur Pfahlbauzeit nach Europa gelangte, von dem heute noch in Asien wildlebenden Bindenschwein abstammt, während unser Schwarzwild das karpfenrückige Landschwein Mitteleuropas geliefert hat. Die Steppenrinder Osteuropas und die Niederungsrinder im Norden Deutschlands sind Abkömmlinge des Ur (Bos primigenius), welcher zuerst im mykenischen Kulturkreis gezähmt wurde, als Wildform aber noch lange neben seinen zahmen V'erwandten fortlebte, da er 1627 endgültig verschwand.

Für die Windhundgruppe konnte ich die gemeinsame Stammform im abessinischen Wolfe nachweisen, der heute noch als Wildhund in den oberen Nilländern vorhanden ist.

Das afrikanische Mähnenschaf lieferte schon vor Beginn des alten Reiches ein eigentümliches Hausschaf, die wilde Stammart musste im Nilthal der Kultur weichen, hat sich aber auf weiten Gebieten Afrikas bis zur Gegenwart behauptet, wie dies auch für die wilde Stammform der asiatischen Schafe gilt.

Also kann auch die zweite Voraussetzung ohne Bedenken angenommen werden.

Wollen wir die Urheimat irgend eines Haustieres aufsuchen, so machen wir sehr bald die Erfahrung, dass eine einzige Methode nicht genügt, es sind, will man Täuschungen vermeiden, stets Kontroll-Methoden einzuführen; das Ergebnis erlangt erst dann die nötige Sicherheit, wenn es von möglichst verschicdenen Standpunkten aus beleuchtet werden kann. Nirgends rächt sich die Einseitigkeit der Methode rascher als auf dem Gebiet der Haustiergeschichte: die heillose Verwirrung, die bis zur Gegenwart besteht, ist lediglich auf methodische Missgriffe zurückzuführen.

Die Unklarheit in der Rassengeschichte des Hundes ist ein Beispiel, wozu die einseitige Anwendung der prähistorischen Forschungsmethode geführt hat. Noch klassischer ist die Verwirrung in der Geschichte des 
Rindes; die Zähmung desselben ist offenbar sehr früh erfolgt, es gehört neben dem IJund zu den allerältesten IIaustieren. Die Abstammung semer Rassen ist von zahlreichen Forschern auf sehr verschiedenen Wegen aufzuklären versucht worden, sodass wir gegenwärtig folgende Lösung dieses allerdings recht verwickelten P’roblems aufzählen können:

1. Unsere europäischen Rinderrassen sind nach ihrer Herkunft völlig unklar; die wilde Stammform ist unbekannt (Wilckens).

2. Unsere zahmen Rinder sind auf cine cinzige Stammform zurückzuführen; als solche muss der erst in geschichtlicher \%eit erloschene Ur (Bos primigenius) angesehen werden (Cuvier, Nehring-).

3. Unsere europäischen Rinder stammen aus ciner cinzigen Quelle und diese Stammquelle ist ein ungehörntes Rind (Bos akeratos. LAnsicht von Arenander]).

4. Die Rinderrassen Europas sind teils aus Hochasien, teils aus Nordamerika (!), teils aus Zentralafrika eingewandert und müssen auf zior Stammformen zurückgeführt werden (Kaltenegger).

5. Unsere Rinderrassen lassen sich von zwei wilden Stammformen ableiten, von denen aber nur eine in Europa zu suchen ist (Rütime')er, feller.).

6. Der europäische Rinderbestand hat zuci verschiedene Stammquellen.

Die den Ausgangspunkt bildenden Wildrinder waren beide in Europa heimisch (Adametz.)

Grösser kann die Verwirrung wohl kaum gedacht werden, da hier der monophyletische, der diphyletische und selbst der tetraphyletische standpunkt zum Ausdruck kommt, von denen ja nur einer der richtige sein kanm.

Es mag daher nicht überflüssig sein, einen prüfenden Blick auf die zur Anwendung gelangten Methoden zu werfen und dabei genau zu untersuchen, wo diese versagen können. Wir werden sie passend in die beiden Kategorien der Hülfs-Methoden und der eigentlich naturwissenschaftlichen Methoden unterbringen. Erstere haben in Fragen der Haustiergeschichte stets nur eine beratende, niemals aber eine entscheidende Stimme.

\section{A. HÜILS-METHODEN.}

Die kulturgeschichtliche Methode. Sie ist frühzeitig zur Anwendung gekommen, erfreute sich einer gewissen Beliebtheit und wird heute noch stets mit Nutzen verwendet. Sie geht von der Anschauung aus, dass die Völker schon frühzeitig Wanderungen unternommen haben, wobei ihr Kulturbesitz, am sichersten der Hanstierbesitz weiter verbreitet wurde. Erscheinungen aus der geschichtlichen Zeit legen uns diese Annahme auch für die Urzeit ausserordentlich nahe. Die Kulturgeschichte giebt uns genauere Aufschlüsse über den Umfang des Kulturbesitzes; sie weist uns auch die Wege, auf denen die Kultur sich ausgebreitet hat. Das sind naturgemäss 
auch die Wege, die bei der Migration zahmer Tiere eingeschlagen wurden. An der Hand dieser Methode haben wir die im Prinzip jedenfalls richtige Vorstellung in uns aufgenommen, dass der Ursitz unserer europäischen Iaustiere nicht notwendig auf unserem Boden zu suchen ist, sondern dass die Möglichkeit der Einwanderung aus einem Nachbarkontinent vorliegt.

Um die Mitte des 19. Jahrhunderts gelangte die kulturgeschichtliche Methode sehr ausgiebig zur Verwendung; namentlich war es Isidore Gcoffroy St. Hilaire, der unter dem Einfluss der arischen Einwanderungstheorie fast alle europäischen Haustiere aus Asien einwandern liess. Das war nun allzu schematisch verfahren, zahme Rassen sind zweifellos aus Asien nach Europa gelangt, aber ich habe seither in mehreren Veröffentlichungen nachgerviesen, dass in viel grösserem Umfang als bisher zugegeben wurde, der Nachbarkontinent Afrika Elemente an die europäische Haustierwelt abgegeben hat. Inderseits hatten die Kulturaniregungen, die von aussen her kamen, die natürliche Folge, dass passendes Wildmaterial in Europa domestiziert wurde.

Die kulturgeschichtliche Methode, es muss dies ausdrücklich betont werden, ist stets zu Rate zu ziehen, sie half uns die allgemeinen Grundlagen der Haustiergeschichte aufbauen, sie giebt uns heute noch wertvolle Winke über die Verbreitungswege. Bei dem Mangel jeder naturwissenschaftlichen Kontrolle wird sie jedoch versagen, sobald es sich um speziellere Untersuchung der einzelnen Rassen handelt. Es lässt sich nicht verkennen, dass gerade in der Neuzeit entschiedener Nissbrauch derselben Verwirrung gebracht hat.

Die sprachuissenschaftliche Mcthode. Sie stellt sich die Aufgabe, mit Rücksicht auf unsere Zwecke den Sprachschatz der verschiedenen Vöker zu untersuchen, um so Anhaltspunkte über die Verbreitungswege der einzelnen Haustiere zu gewinnen. Man hoffte auf diesem Wege der Urheimat auf die Spur zu kommen. Gewisse Sprachwurzeln sollen auf die Wurzeln der Haustiere hinweisen. Das klingt theoretisch ganz schön, aber in der Anwendung darf diese Methode nur mit der grössten Umsicht aufgenommen werden. In philologischen Kreisen legt man auf dieselbe ein ganz unberechtigtes Gewicht, seit Victor Heln mit unleugbarem Erfolg sie gehandhabt hat, übersieht dabei, dass eine naturwissenschaftliche Kontrolle absolut notwendig ist, ansonst nur Verwirrung angerichtet wird. Ein klassisches Beispiel, auf welche Abwege der einseitig sprachwissenschaftliche Standpunkt geführt hat, liefert das 1897 von Baranski veröfentlichte Werk: "Die vorgeschichtliche Zeit im Lichte der Haustierkultur“. Mit einer Ausdauer, die einer besseren sache würdig wäre, sucht der genannte Iutor in fast allen Sprachen der alten Welt Sprachwurzeln heraus und gelangt schliesslich mit einer beispiellos kühnen Phantasie zu Wurzeln der I Iaustierrassen, die uns ebensosehr überraschen wie erheitern!

Beispielsweise tindet er eine alte Wurzel für P'ferd heraus, die .al“ 
lautet und sich in ala, pal, gal, kal, keval, endlich in das französische cheval verwandelte. Für unser Rind finden wir neben der Wurzel "ur" von welcher gur, bur, thur, taur abzuleiten ist, noch eine andere Wurzel "ab", die übergeht in aba, ob, oba und vermutlich in unserem gemütlichen Wort "Loba" enthalten ist!

Das sind Verirrungen, die uns am besten auf die ohnehin nicht sehr zuverlässige sprachwissenschaftliche Methode verzichten lassen.

\section{B. NATURWISSENSCHAFTLICHE METHODEN.}

Die vergleichend-anatomische Methode. Dieselbe ist als streng naturwissenschaftliche Forschungsmethode weitaus am zuverlässigsten. Sie arbeitet mit Hülfe des anatomischen Vergleiches, stellt den Grad der Umbildung fest und schliesst auf eine umso engere Verwandtschaft, je grösser die anatomische Uebereinstimmung erscheint. Frühere Forscher, so namentlich Is. Geoffroy St. Hilaire und besonders L. Fitzinger haben sich zu exklusiv an die rein äusserlichen morphologischen Verhältnisse gehalten, wodurch fehlerhafte Resultate entstanden. Es ist daher unumgänglich notwendig, auch die innere Organisation zu analysieren.

Es ist dabei durchaus nicht gleichgültig, welche Organsysteme zur wissenschaftlichen Analyse herangezogen werden. Wir werden uns vielmehr an diejenigen zu halten haben, die der Variation am wenigsten unterliegen. Am besten hält man sich bei Rassenstudien an das Skelett, kann sich sogar einfach auf Schädeluntersuchungen beschränken. Das Ideal, das die Inthropologen anstrebten, aber bisher nicht erreichten, auf Grund der Schädelanalysen ein sicheres Urteil über die Rassenzugehörigkeit zu gewinnen, ist thatsächlich für unsere Haustier-Rassen verwirklicht. Eine Schädeluntersuchung genügt, um das asiatische Schwein von demjeniggen europäischer Herkunft zu unterscheiden; um die orientalische oder occidentale Rasse eines Pferdes zu ermitteln oder ein zahmes Primigenius-Rind vom Brachyceros-Rind zu trennen. Es ist das Verdienst von Ludwig Riutimeyer, die vergleichend-anatomische Methode in die Rassengeschichte eingeführt zu haben, um damit die glänzendsten Erfolge zu erzielen. Er gilt daher mit Recht als Begründer der wissenschaftlichen Rassenlehre.

Wir dürfen indessen nicht verschweigen, dass die vergleichend-anatomische Methode trotz ihrer Zuverlässigkeit nicht frei von Fehlerquellen ist, wenn sie für sich allein angewendet wird. Jeder Anatom weiss, dass die sogenannten Konvergenz-Erscheinungen, wie sie ja nicht selten auftreten, Verlegenheiten bereiten können. Auf zoologischem Gebiet führten sie mehr als einmal zu unrichtigen Schlüssen. Derartige KonvergenzErscheinungen können auch bei unseren Haustieren auftreten.

Die Rassen sind anfänglich anatomisch verschieden, schlagen aber bei der weiteren Entwicklung selbst im Skelettbau eine Bahn ein, die scheinbar einem gremeinsamen Ziele zusteuert. 
Ein recht überraschendes Beispiel hat $T h$. Studer für die Hunderassen nachgrewiesen. Wo sich einzelne Reihen zu Zwergformen entwickeln, da beginnt der Schädel die typischen Rassenmerkmale zu verlieren und nimmt eine eigentümliche Form an, die sich dem jugendlichen Schädel nähert. Ware die verschiedene Genese nicht ermittelt. so müsste der anatomische Befund auf eine gemeinsame Abstammung schliessen. Die Rasse ist in Schädel der Zwergform einfach verwischt. Die Konvergenz kann eine teilweise sein, wie Erscheinungen beim afrikanischen Zebu-Rind lehren. Bei manchen Formen macht sich eine Konvergenz zum europäischen PrimigeniusRind bemerkbar, die aus rein mechanischen Gründen erklärbar wird.

Fü sich allein verwendet, kann die anatomische Methode vollkommen richtig gehandhabt sein und doch Unklarheiten übrig lassen. Ein Forscher kann durch das Studium der Schädelumbildungen eine Entwicklungsreihe der Rassen gefunden haben, die sich allgemein durch die Formel A-B-C-I ausdrücken lässt, für ihn ist A das Anfangsglied, I) das Endglied. Nun kehrt ein anderer die Reihe einfach um, so dass sie lautet D-C-B-A. Dann ist I) das Anfangsglied, A das Endglied. Hier bedarf es eben gewisser Kontroll-Methoden. Uebertragen wir obiges auf einen konkreten Fall. Bezüglich der Stammverhältnisse beim Rind sind Lehring und Arenander zu einer monophyletischen Auffassung gelangt. Ersterer findet durch anatomischen Vergleich, dass der grossgehörnte Bos primigenius als Ausgangsform zu betrachten ist. Kultureinflüsse einerseits, ungünstige Existenzbedingungen anderseits haben wesentliche Veränderungen im Schädelbau hervorgerufen. Die brachyceren Rinder sind nach Vchring Kümmerformen: der Körper wird kleiner, das Gehörn kürzer, kann sogar ganz fehlen. Logischerweise stehen dam die namentlich im Norden Europas so häufig auftretenden hornlosen Rinder (Bos taurus akeratos) am Ende der Entwicklungsreihe. In jüngster Zeit hat Arenander die Reihe einfach umgekehrt; für ihn ist das hornlose Rind (Bos akeratos) die Ausgangsform, von welcher aus sich im Laufe der Zeit die kurzhörnigen Rinder entwickelten; durch stärkere Entwickiung des Gehörus gingen letztere in eine langhörnige Rasse, wie sie besonders in Osteuropa auftritt, über. Hier müssen eben Kontroll-Methoden herangezogen werden und diese belehren bald genug, dass selbst für den Fall, dass die monophyletische Abstammung zulässig wäre, die Annahme von Arcnander unmöglich den Thatsachen entsprechen kann. Das Gesamturteil über den Wert der vergleichendanatomischen Methode mag dahin zusammengefasst sein, dass sie ihrer Zuverlässigkeit wegen in erster Linie als Führerin in der Rassengeschichte zu dienen hat. Sie kann in manchen Fälen für sich allein schon zum Ziele führen, in anderen Fällen reicht sie vollkommen aus und muss durch andere Methoden ègänzt werden, namentlich wo Konvergenzerscheinungen zu vermuten sind.

Handelt es sich um die geographische Herkunft eines Haustieres, um 
die Rekonstruktion des Weges, den eine Rasse genommen hat, so reicht sie nicht mehr aus, sondern kann nur in Verbinclung mit weiteren Forschungsmethoden sichere Ergebnisse liefern.

Die prähistorische Methode. Gerade unsere wichtigsten Haustiere sind sehr alt, ihre Entstehung reicht in die vorgeschichtliche Zeit zurück. Es ist dies vollkommen verständlich, denn jedes Volk muss vorerst eine gesicherte materielle Basis schaffen, bevor es eine geschichtliche Bedeutung erlangen kann. Die historische Zeit setzt somit eine höher entwickelte wirtschaftliche Stufe voraus. Diese Thatsache lässt sich sehr deutlich auf dem Boden alter Kulturen, besonders in Altägypten verfolgen; anderseits haben ja reine Jägervölker niemals eine wirklich geschichtliche Bedeutung erlangt.

Die Fäden der Entwicklung einzelner Rassen müssen daher über die geschichtliche Zeit hinaus verfolgt werden, da sie sich mit ihren Antängen im Dunkel der Urgeschichte verlieren. Die vorgeschichtlichen Haustierfunde, so lückenhaft sie auch sein mögen, werden von der allergrössten Bedeutung; die scheinbar wertlosen Knochen, die in den alten Pfahlbauniederlassungen autgefunden wurden, gewahren die wichtigsten Einblicke in die damaligen Kulturverhältnisse, sie ermöglichten dem scharfblickenden Ludwig Rütimeyer, die Fauna jener Periode, von der uns kein Historiker etwas berichtet, bis ins Einzelne zu rekonstruieren.

Und die Knochenfunde im Schutte der untergegangenen altrömischen Kolonien im Norden der Alpen lassen uns abermals ein Entwicklungsglied erkennen, das zwischen den primitiven Iaustier-Rassen der Pfahlbauperiode und den hochgezüchteten Formen der Gegenwart vermittelt.

Die prähistorische Methode in Verbindung mit der anatomischen gewäbrt die genauesten Erggebnisse über das zeitliche Auftreten zahmer Tiere auf einem bestimmten Areal. Es ist zu bedauern, dass die archäologischen Ausgrabungen in Griechenland, Mesopotamien und Oberägypten bisher nicht sorgfältiger auf Knochenfunde geachtet haben, da gerade in jenen alten Kulturgebieten die wichtigsten Aufschlüsse zu erwarten sind.

Die physiologische Methode. Die Fähigkeit fruchtbarer Kreuzung von Tierformen gilt in der Zoologie bekanntlich als ein Kriterium naher Verwandtschaft. Daher wurde, um die Beziehungen der zahmen Tiere zu Wildformen zu vermitteln, der Versuch gemacht, unsere zahmen Rassen mit den als Stammformen vermuteten wilden Arten zur Fortptlanzung zu bringen. Je leichter es gelingt, fruchtbare Nachkommen zu erzeugen, um so wahrscheinlicher ist es, dass die zur Kreuzung. verwendete Wildform Anteil an der Bildung der zahmen Rasse hatte.

Diese Methode ist stets als ein wichtiges IJülfsmittel bei der Entscheidung von Abstammungsfragen sozusagen unbeanstandet zugelassen worden. Nachdem sie früher wiederholt in Frankreich und England zur Verwendung gelangte, hat später in Deutschland besonders F. Kühn in Halle derartige Zuchtversuche im grossen Stile durchgeführt. Es standen 
ilm zu diesem Zwecke die grossartigen Mittel eines Haustiergartens im landwirtschaftlichen Institut der Universität zur Verfügung.

Mir scheint jedoch die Schlussfolgerung, dass eine zahme Rasse von einer Wildform abstamme, wenn sich das Keimplasma jener mit dauerndem Erfolg in das Keimplasma dieser letztern einfügt, nicht ohne Weiteres zulässig. Die Resultate solcher Zuchtversuche, so interessant sie nach anderer Richtung sein können, dürfen in der Rassengeschichte nur mit grosser Reserve zur Entscheidung von Abstammungsfragen herangezogen werden; jedenfalls wird eine weitere Kontrolle nötig. Beispielsweise lässt sich unsere Hausziege mit Erfolg mit dem Steinbock paaren. Die Nachkommen, die sogenannten Bastardsteinböcke, sind fruchtbar. Da diese Fruchtbarkeit umbeschränkt zu sein scheint, wurde mehrfach der Versuch unternommen, die Bastarde in den Alpen anzusiedeln. Dennoch wäre der Schluss ungerechtfertigt, dass der Steinbock an der Abstammung unserer Hausziege beteiligt sei. Unsere europäischen Iausziegen enthalten sicher kein Steinbockblut, sondern stammen von der 'Bezoarziege ab.

Dic ethographische Methode. In gewissem Sinne nimmt sie eine Mittelstellung zwischen naturwissenschaftlicher und kulturgeschichtlicher Forschungsweise ein. Sie holt aus dem Kulturbesitz räumlich getrennter, aber zeitlich neben einander lebender Völker speziell den Haustierbesitz heraus, um ihn vergleichend zu untersuchen. Der Kreis der zu untersuchenden Völker kann dabei nicht gross genug gezogen werden. Ich hege die Ueberzeugung und habe ihr in früheren Arbeiten schon Ausdruck gegeben, dass man auf dem Gebiet der llaustiergeschichte unmöglich ein abschliessendes Urteil erlangen kann, wenn man sich nur auf das kleine Areal von Europa beschränkt. Wir müssen uns so ziemlich in der ganzen alten Welt umsehen, wenn wir ein Bild der Rassenzuwanderungen für unseren Kontinent gewinnen wollen.

Mit dieser ethnographischen Methode werden wir sofort zur Ueberzengung geführt, dass in gewissen hochkultivierten Gebieten zahllose Kreuzungen den Rassencharakter schliesslich verwischen und diese daher für unsere Zwecke ganz unbrauchbar werden. Daneben giebt es wieder andere. die von den Wellen einer fortschreitenden Kultur sozusagen unberührt bleiben; abseits vom Weltverkehr gelegen, hat sich der Haustierbestand ungemein konservativ gestaltet, so dass merkwürdige Rassen-Inseln alter Haustierformen erhalten blieben. Gerade diese, die als ältere zu Tage tretende Schichten der Haustierkultur aufzufassen sind, werden von der grössten Bedeutung. Gebirgsländer, ausgedehnte Steppen und ozeanische Insein erscheinen besonders reich an solchen lebenden Relikten. In unseren Alpen sind beispielsweise nur wenig veränderte Reste des Torfschafes und des Torfschweines aufgefunden worden, die gegenwärtig allerdings in ihrer Existenz bedroht erscheinen. In den den Bergen von Albanien gelang es Adametz, das noch fast unveränderte Pfahlbaurind nachzuw eisen. Vermutlich 
leben dort auch andere sehr alte Haustiere. Eine genauere I)urchforschung der Inseln des Mittelmeeres dürfte einen auffallend stationären Zustand der Rassen ergeben. Naterialien, die ich aus Sardinien erhielt, ergaben überraschende Thatsachen. Viel ist von aussereuropäischen Gebieten, namentlich von Asien und Afrika zu erwarten. Hat man doch eigentlich erst begonnen, in jenen Regionen den Schatz von Thatsachen zu heben und doch treten uns schon einzelne verblüffende Erscheinungen entgegen. So ist das Langhorn-Rind der Altägypter, das ausgestorben schien, für verschiedene Regionen des heutigen Innerafrika nachgewiesen. Das eigentümliche Hausschaf des alten Reiches, das später im Nilthal durch asiatische Schafe verdrängt wurde, schien erloschen. Es fehlt vollständig im Nilthal, wurde aber kürzlich am oberen Niger entdeckt, wo es sich fast unverändert bis heute erhalten hat.

Wir können auch die alten Kulturvölker zum Vergleich heranziehen und mit Hülfe der Archäologie deren I Jaustierbesitz ermitteln. Die PalaeEthnographie von Mesopotamien. Aegypten und (iriechenland gab uns dice wertvollsten Aufschlüsse. Man könnte hier wohl von einer besonderen archïolugisshon. Methode reden. Sie verwendet nicht osteologisches. Material wie die prähistorische Forschung, sondern hält sich an bildliche Darstellungen. Der Gegenstand ist wichtig genug, um ihm hier einen besonderen Abschnitt zu widmen.

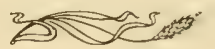




\section{IDIE ANTIKE KUNST IM DIENSTE DER HILSTIIRGIESCHICHTE.}

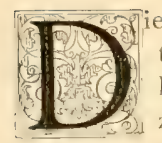

Umrisse einer Entwicklungsgeschichte der bildenden Kunst treten uns Dank dem Bienenfleiss der Forscher in der zweiten Hälfte des 19. Jahrhunderts, der ein umfangreiches Material zusammenbrachte. ziemlich deutlich entgegen. I)ie I rgeschichte vermochte den (jegenstand von der historischen seite zu durchdringen: die vergleichende Välkerkunde brachte wichtige ethologische Ergiinzungen.

Für unsere Zwecke erscheint es bedeutungsvoll, dass die ersten Anfänge einer bildenden Kunst erheblich früher bemerkbar sind als die ältesten Versuche in der Kunst der Haustiergewinnung. Manche haben sogar die Kunstleistungen geradezu als eine allgemeine Aeusserung des sozialen Organismus erklären wollen, was wohl zu weitgehend ist. Immerhin steht fest, dass in der Gegenwart überraschend gute Bildereien bemerkt werden bei ganz verschiedenen menschlichen Rassenelementen, deren wirtschafiliche Stufe noch keine wirklichen Haustiere kennt. Die Eskimozeichnungen sind zu einer gewissen Berühmtheit gelangt; die Felszeichnungen der Buschmänner lassen eine gute Gabe der Naturbeobachtung erkennen. Der Urbewohner Europas unternahm schon während der älteren Steinzeit, da noch kein einziges Haustier vorhanden war, die ersten, wem auch noch etwas umbeholfenen Versuche, Bildereien herzustellen. Die einst vielverlachte "I Iöhlenkunst" wird heute ernst genommen, wenn auch die Kritik und die Zweifelsucht in einzelnen Fällen Verdachtmomente herausgriff.

Auf jener primitiven Wirtschaftsstufe, wo der Mensch auf die Jagd angewiesen ist, wird der Kreis seiner Vorstellungen beherrscht von den Gegenständen der Nahrung, d. h. von der Wildauna der Umgebung, daher zeichnet er die grösseren Jagdtiere seiner Ileimat wenigstens in Umrissen, während Pflanzenteile nur selten zur Darstellung gelangen. Es sind die lebensvollen, freibeweglichen Geschöpfe, welche die Phantasie des primitiven Menschen vorwiegend beschäftigen.

Wo nun die wirtschaftliche Entwicklung in neue Bahnen einlenkt, der Mensch in einzelnen Kulturkreisen die Wildarten zum Teil als zahme Geschöpfe bleibend an seine Uingebung kettet und daher nicht mehr auf die Erträge der Jagd allein angewiesen ist, da tritt auch ein neues Motiv der bildenden Kunst auf. 
Die Haustiere beginnen im Fühlen und Denken des Menschen eine hervorragende sitellung einzunchmen: die kïnstlerische I)arstellung grebt das jagdbare Tiere nicht auf, aber sie entlehnt nun mit Vorliebe die Motive aus der I Iaustierwelt.

Altägypten liefert ein klassisches Beispiel. Die Malerei und Plastik, in der ägyptischen Kunst kaum von einander zu trennen, führen uns in wundervoll erhaltenen Werken besonders während der klassischen Kunstepoche im alten Reich die Haustiere in allen möglichen Situationen vor, so dass wir die genauesten Einblicke in die Landwirtschaft erlangen. Auch Altassyrien ist nicht arm an trefflichen Darstellungen.

Auch jetzt noch steht das tierische Objekt neben der menschlichen Figur im Vordergrund, die Pflanzenwelt geht ganz nebenher. Assvrische und mykenische Künstler leisten in der Tierplastik schon hervoragendes, aber als Landschafter sind sie herzlich unbedeutend.

In der ägyptischen Kunst ist es ebenso. Im alten Reich ist die Landschaft stets unbeholfen, so treftlich die Leistungen in der Tierdarstellung sind: erst im neuen Reich lässt sich ein Fortschritt erkennen. Zwar ist die bekannte Jagd des Ramses, welche in Medinet Habu eingraviert ist, bezüglich der landschaftlichen Szenerie eine eigentliche Sudelei, während in Deir el Bahri bessere Werke erscheinen, aut denen z. B. die Sykomore mit einiger Sorgfalt behandelt ist; die Zeichnung ist immerhin noch schablonenhaft und daher steif. Durch die Haustierdarstellungen der antiken Kunst gewinnen wir einen Einblick in den Bestand, den alte Völker besassen, wir lernen den Wechsel der Rassen, sowie ihre Verbreitung bis ins einzelne kennen. Auf die Lehre von der Umbildung der einzelnen Rassen fallen nicht selten helle Sitreitlichter. Dazu ist allerdings eine detaillierte zoologische Kenntnis der Rassen erforderlich - das Wissen der Archaeologen muss hier versagen. Die Angaben mancher sonst ganz verdienstvoller archaeologischer Forscher müssen daher stets mit Vorsicht aufgenommen werden, Wo beispielsweise von einem Wildstier die Rede ist, bleibt man oft im Unklaren, ob darunter der Wisent oder der Ur gemeint ist; ein Wildstier wird gelegentlich als Büffel, ein Wildschaf als Antilope, ein Pferd als Esel oder ein Schaf als Ziege aufgeführt. Dass Kunsthistoriker sich streiten, ob in einer antiken Darstellung eine Wildform oder eine zahme Art vorliege, kann nicht überraschen, denu solche Dinge vermag in manchen Fällen nur das geübte Auge des Zoologen zu entscheiden.

Man kann die Frage aufwerfen, inwieweit antike Tierdarstellungen verwertbar sind, da zoologische Ergebnisse nur dann Anspruch auf Zuverlässigkeit erheben können, wenn jene Figuren der Wirklichkeit entsprechen.

Diese notwendige Voraussetzung trifft nun glücklicherweise gerade für die älteste Kunst in hohem Grade zu, weil diese ein eminent naturalistisches Gepräge besitzt. Anfänglich hat eben die Kunstdarstellung den einzigen Zweck, die Tierszenen so wiederzugeben, wie sie gesehen wurden, sei es 
durch Zeichnung oder durch die Plastik, in letzterem Falle meist als Basrelief, weil es sich der Zeichnung am meisten nähert.

Später änderte sich die Sachlage, namentlich weil der religiöse V́orstellungskreis die naturalistische Auffassung beeintlusst und damit vom Realismus abdrängt. I)ie Figuren werden stilisiert und mit phantastischen Zuthaten versehen, wodurch sie für die naturvissenschaftliche Betrachtungsweise völlig wertlos werden.

Aus diesem Grunde ist mit den zahlreichen Tierfiguren des kaukasischen Kunstkreises gar nichts anzutangen; ebenso wird der Zoologe an den geflügelten Stieren mit Menschenköpfen, wie sie die technisch gut ausgebildete Kunst in Assyrien darzustellen beliebte, vollkommen teilnahmslos vorbeigehen.

Ohne Zweifel haben wir von der Archaeologie in Zukunft noch wichtige Aufschlüsse zu erwarten, aber schon das was vorliegt, ist fruchtbar geworden. In den alten Kulturgebieten Mesopotamiens haben die Arbeiten eines Layard, Bolta, Razulinson, Smith, Rassam, de Sarzec u. a. schon zahlreiche Fundstätten aufgedeckt, von denen einzelne wie Birs Nimrud, Khorsabad und Kujundschik viel genamnt sind. Die chaldäische, sowie die altbabylonische Kunst vermochte bisher nur eine mässige Zahl von Tierdarstellungen zu liefern; vielleicht ändert sich das Verhältnis später. Viel ergiebiger erscheint die spätere assyrische Kunstperiode; auffallenderweise setzt sie sozusagen ohne Jugendstadium in voller Entwicklung ein. Bei scharf ausgesprochener Eigenart lassen einzelne Skulpturen neben technischer Vollendung eine bemerkenswerte Feinheit der Naturbeobachtung erkennen. Es sind vormeist Bildereien an den assyrischen Königspalästen, zu deren Herstellung allerdings nur die begabtesten Künstler herangezogen worden sein dürften. Es sind uns vorzügliche Darstellungen von Pferden, Wildrindern, Schafen und namentlich grossen, doggenähnlichen Hunden erhalten: auch das Schwein fehlt nicht.

Parallel mit dieser Kunst entwickelte sich eine solche von grosser Originalität und achtunggebietender Höhe im Nilthal während der I'haraonenzeit; ob sie an der Wurzel mit der mesopotamischen Kunst zusammenhängt, lässt sich wohl vermuten, aber zur Zeit noch nicht mit genügender Sicherheit entscheiden. Das höfische Leben in Memphis, dem Mittelpunkt des alten Reiches, war den künstlerischen Bestrebungen wohl gesinnt; die soziale Stellung des Künstlers war eine bevorzugte. Die Kunst gewinnt hier im Gegensatz zu dem Zweistromland einen gewissen demokratischen Charakter, da immer und immer wieder Szenen aus dem häuslichen Leben des Volkes zur 1)arstellung gelangen. Bei dem nüchternen Sinn der Pharaonenleute und der Monotonie des Landes darf man keinen grossen Schwung der Phantasie erwarten; dafür erreicht die altägyptische Kunst mit einfachen Mitteln eine grosse Klarheit und Durchsichtigkeit der Idee. die der Künstler ausdrücken will. Bei der auffallenden /uneigung zur Tierwelt, 
die ja zum förmlichen Tierkult führte, kanı es nicht überraschen, wenn auf den zahlreichen Wandmalereien und Basreliefs der Grabkammern die Tierdarstellungen einen breiten Raum einnehmen. Wenn auch anfänglich die volle Freiheit fehlt, vielmchr eine strenge stilistische Tradition vorgeschrieben ist, so thut das unseren Zwecken doch keinen Eintrag, sobald wir uns an diese Kunstregeln gewöhnen. Der Künstler sucht zwischen ihnen und seinem naturalistischen Empfinden sowieso einen fortwälrenden Kompromiss zu schliessen. Die Tiere stellt er stets im Profil dar; wenn jedoch dadurch charakteristische Eigenschaften undeutlich werden, so hilft

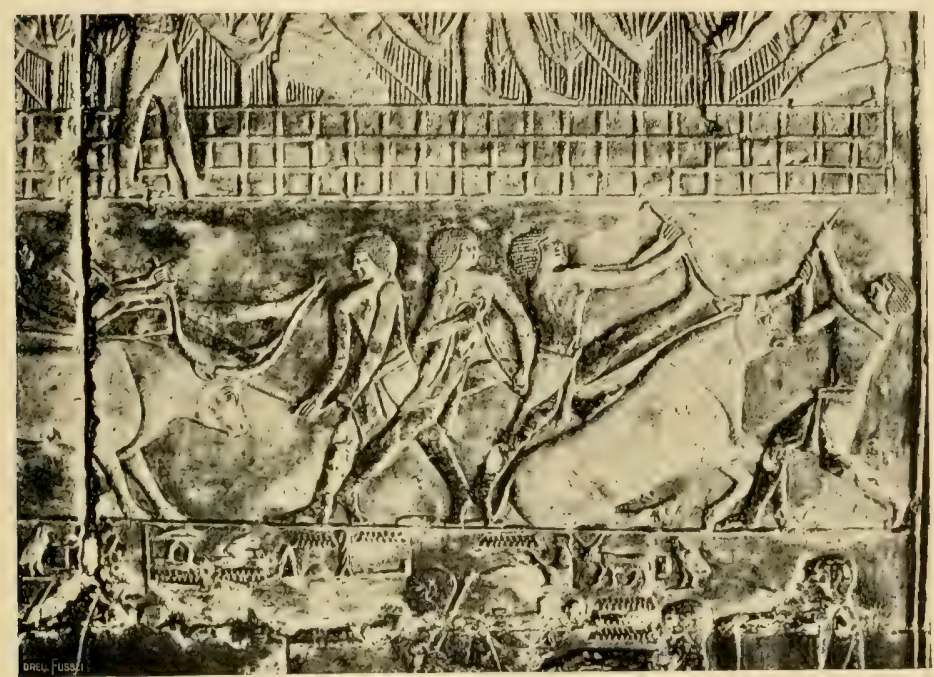

Altägyptisches I.anghornrind aus den Grabkammern von Sakkarah.

sich der Künstler einfach damit, dass er z. B. beim Rind den Kopf im Profil. sein Gehörn aber en face darstellt.

Werke wie die bekannte "Description de l'Egypte", die vorzüglichen "Denkmäler aus Aegypten und Aethiopien“ von Lepsizs, die Arbeiten von Prisses d'Avennes, Rosselini u. s. w. bieten bezüglich der Haustierfauna Altägyptens ein umfangreiches Material. Dazu kommen noch die neuesten Veröffentlichungen von Flinders Petrie und de Norgan über die vorhistorischen Funde in Oberägypten, die einzelne bemerkenswerte Anhaltspunkte über das Alter der zahmen Fauna Altägyptens gewähren.

Die alten Kulturgebiete in Südeuropa sind erheblich jünger als die asiatischen und nordafrikanischen. Doch tritt uns schon in vorhomerischer 
Zeit auf dem Boden Griechenlands und dem benachbarten Archipel eine eigenartige Kunstepoche entgegen, die man als mykenische bezeichnet. Wie eng der Name Schliemanns mit ihrer Entdeckung verknüpft ist, braucht kaum besonders betont zu werden. Man hat ihren Beginn etwa mit dem Anfang des neuen Reiches in Aegypten gleichzeitig betrachtet, doch scheint die sogenamnte Inselkultur erheblich älter zu sein, dabei sowolıl Westasien wie den mykenischen Kreis beeinflusst zu haben, sogar frühzeitig Wechselwirkung mit Altagypten aufzuweisen. Antike Funde in Cypern und auf Kreta lassen in Zukunft wichtige Aufschlüsse bezüglich des Uebertrittes zahmer Tiere nach Europa erwarten. Was aus der mykenischen Zeit vorliegt, ist schon jetzt wichtig genug. Ich erinnere nur an die Perle altgriechischerKunst, an die Goldbecher von Vaphio, deren Rinderdarstellungen eisen Tierplastiker allerersten Ranges verraten. Auch auf den Gemmen und Inselsteinen finden sich naturgetreue T'ierbilder von ausserordentlicher Feinheit.

Die spätere Kunst des klassischen Altertums in Griechenland und Rom giebt wiederum viele Anhalts-

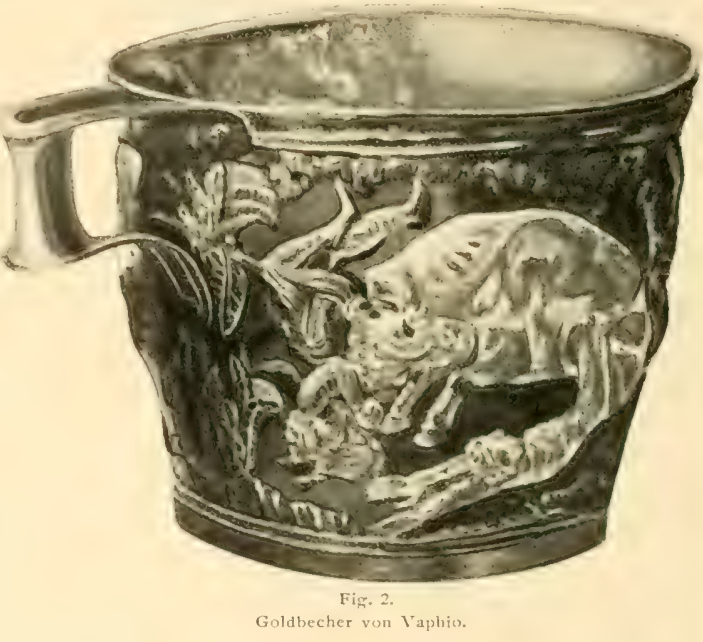

punkte über die Verbreitungswege zahmer Rassen in Europa. Zwar gewährt die plastische Darstellung der Ifllenen eine etwas magere Ausbeute in zoologischer Hinsicht, während die römische Kunst viel ergiebiger ist.

Dafür erwiesen sich die ältesten griechischen Münzen um so lohnender. Der primitive Handel war bekanntlich, wie dies ja heute noch bei manchen Välkern der Fall ist, ein Tauschverkehr, wobei das Vieh die Rolle des Geldes spielte. Griechenland und Süditalien besassen ja frühzeitig eine blühende Viehzucht. Als dam die ältesten Münzen in Aufnahme kamen. drückte man das ursprüngliche Verhältnis dadurch aus, dass man jene Münzen mit einer Prïgung vom Rind, Pferd, Schaf oder Hund u. s. w. versah. Die Prägung ist nicht selten von einer überraschenden Feinheit, die Zeichnung oft von einer Naturwahrheit, dass sie zoologisch 
verwertbar wird und weit besser orientiert als die genaueste litterarische Angabe.

Diese Tierstücke (pecuniae) sind namentlich von dem unermüdlichen Imhoof-Bhumer in seltener Vollständigkeit gesammelt und zum Teil in seinem umfangreichen Tafelwerk veröffentlicht worden. Auch archaeologische
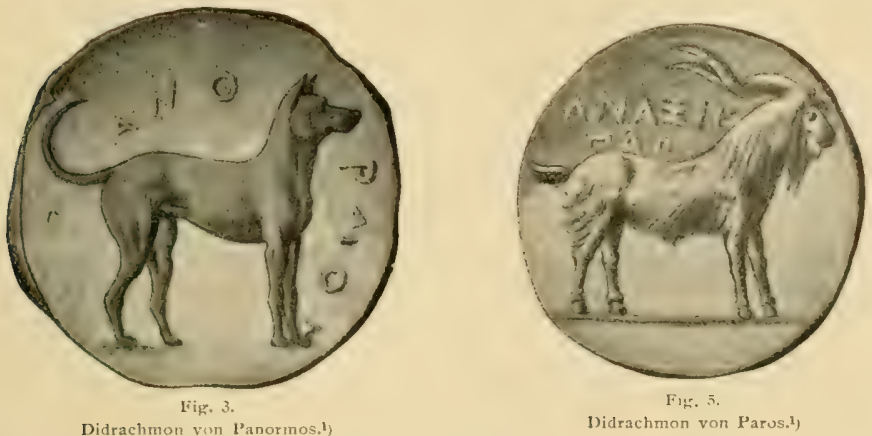

Didrachmon von Parus. $^{1}$ )

Fachschriften enthalten brauchbare Materalien. Wir können aus diesen Dokumenten den damaligen Rassenbestand rekonstruieren.

Die römischen Kunsterzeugnisse mit Tierdarstellungen gewinnen in den Fällen ein hervorragendes naturwissenschaftliches Interesse, wo dieselben als Erzeugnisse römischer Kolonien im Norden der Alpen auftreten. Sie beleuchten dann neben anderen zoologischen Reliquien die gewaltigen $\backslash$ eränderungen in der Haustierfauna Mitteleuropas, welche die römische Kultur zur Folge hatte. Die auf

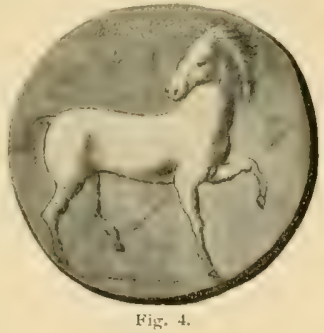

Altgriechische Münze aus Larissa. sorgfältig aufgehobenen Funde in Vindonissa. einer blühenden römischen Kolonie IIelvetiens. überbrücken in schönster Weise die Lïcke zwischen der PfahlbauzeitderSchweiz und der Gegenwart.

So wertvoll für die meine Veranlassung Haustiergeschichte die antike Kunst erscheint, so muss die Zoologie doch fortwährend Skepsis walten lassen. Dies gilt namentlich für solche Fälle, wo die Provenienz eines Fundes nicht sicher gestellt ist oder das Alter sich nicht genauer bestimmen lässt. Auch berücksichtigt man an besten jene Objekte nicht, die in ihren naturhistorischen Merkmalen zu unbestimmt gehalten sind.

1) Nach Imzoof-Blumer.

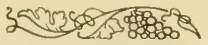




\section{DER VORG MNG DOER HAUSTIER- WERDUNG.}

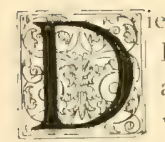

Meinumgen darüber. Was man in priziser wissenschafticher Fassung unter Haustieren zu verstehen hat, gehen heute noch auseinander. Es finden sich in der Umgrebung des Menschen viele fichohopfe. deren Charakter als athte Ilaustiere niemand bezweitelt. anderseits aber auch solche von so untergeordneter Vatur, dass sie vom Haustierbegriff ausgeschlossen werden müssen. Zu letzteren rechne ich alle Tiere, die nur gezähmt sind, wie z. B. der zahme Elefant.

Die Schwierigkeit einer scharfen Umschreibung des menschlichen Haustierbestandes rührt zum Teil daher, dass eine domestizierte Art nicht plötzlich, sondern erst nach und nach ihre Bestimmung annimmt.

Die neueste Definition, die Eduard $\left.H_{a} h n^{1}\right)$ in seiner einlässlichen geographischen Studie über den vorliegenden Gegenstand geliefert hat, lautet: "Haustiere sind Tiere, die der Mensch in seine l'flege übernommen hat, die „sich hier regelmässig fortptlanzen und so eine Reihe erworbener Eigen"tümlichkeiten auf ihre Nachkommen übertragen."

Ich kann nicht finclen, dass diese Definition sehr glücklich ausgefallen ist. Es ist geradezu autlallend, dass der genannte Autor in seinem mit vielem Fleiss bearbeiteten Werk zwar die wirtschaftliche Seite der Haustierwelt eingehend berücksichtigt, aber in seiner Begriffsbestimmung mit keinem Wort dieser wirtschaftlichen Pedeutung gedenkt. Diese gehört in erster Linie zur Signatur eines echten Haustieres und wo nicht eine ganz bestimmte und konstante Leistung gegenüber dem Menschen nachweisbar ist, kann man auch dann nicht ein Geschöpf in die Haustierliste aufnehmen, wenn es im übrigen der Zucht und Pflege des Menschen unterstellt ist. Daher sehe ich die Meerschweinchen und Kanarienvögel ebensowenig als Haustiere an, wie die systematisch gezüchteten Spielarten der zahmen Mäuse und Goldfische, trotzdem diese von manchen Autoren in die Liste aufgenommen werden. Wenn Mortillet ${ }^{2}$ ) sogar die Auster und die Weinbergschnecke unter den Haustieren aufführen will, so ist dies offenbar unzulässig.

1) Eduard Hahn. Die Haustiere und ihre Beziehungen zur Wirtschaft des Menschen. Eine geographische Studie. Leipzig. 1846.

$\left.{ }^{2}\right)$ G. de Mortillet. Origine de la chasse, de la pêche et de l'Agriculture. Paris. 1890. 
Die wirtschaftliche Bedeutung ist eine Vorbedingung für den Haustiercharakter, aber nicht die einzige und ausschlaggebende.

Es gebührt Darwin das V'erdienst, mit der nötigen wissenschaftlichen Schärfe darauf hingewiesen zu haben, dass im llausstand der Tiere die natürliche Zuchtwahl zurücktritt zu Gumsten der kï̈stlichen Zuchtwoahl. Der Tierzüchter nimmt gleichsam der Natur die Auslese aus der Hand und schaltet damit nach seinem Ermessen und nach seinen wirtschaftlichen Bedürfuissen. Es geschieht dies freilich nicht überall mit der gleichen Strenge und unsere Hauskatze ist beispielsweise der künstlichen Züchtung nur in beschränkter Weise unterworfen. Es gilt dies auch für diejenigen Gebiete, wo sich primitive Rinderrassen, Schafrassen u. s. w. erhalten haben.

Die Fähigkeit unbegrenzter Fortpflanzung und die P'llege durch den Menschen sind ebenfalls Vorbedingungen für die Ilaustierwerdung.

Will man endlich eine streng wissenschaftliche Definition des Haustierverhältnisses geben, so wird man zu untersuchen haben, ob es sich um eine in der Natur vereinzelt dastehende Erscheinung handelt oder ob nicht bei näherer Umschau in der Tierwelt gelegentlich amaloge Verhältnisse nachweisbar sind.

G. Cuvier hat das Haustierverhältuis als Sklaverei (esclavage) aufgefasst ${ }^{1}$ ) und noch heute vertreten manche Zoologen diese Anschaumg. Ich kam ihr nicht beistimmen, obschon sie namentlich in Laienkreisen weit verbreitet ist. Bei der Sklaverei handelt es sich stets um ein Verhältuis zwischen Individuen derselben Art oder doch zwischen Lebensformen, die im System nahe beisammen stehen. Nehmen wir menschliche Verhälnnisse, so sind es bei primitiveren Völkern entweder Kriegsgefangene, die man nicht töten will oder Schuldner, die ihre Verptlichtungen nicht einlösen können, die zu Sklaven gemacht werden; bisiveilen auch untergeordnete und schwächere Rassen, auf die Jagd gemacht wird. Dann fehlt gerade das Moment bei der Sklaverei, welches für den Haustiercharakter ausschlaggebend ist - die künstliche Züchtung. Sklaven gehen mit der Zeit in der menschlichen Familie auf oder müssen wieder frisch eingebracht werden eine systematische Züchtung und Umbildung von Sklaven hat auf die Dauer nirgends stattgefunden, einzelne Anläufe lokaler Natur, die vor Zeiten in den Südstaaten Amerikas vorgekommen sein sollen, können nur als zufällige menschliche Verirrungen aufgefasst werden.

Daher hält auch die Ethnologie Sklaverei und Viehzucht streng auseinander.") Aber auch in der Zoologie hat man mit gutem Grund an diesem Unterschied festgehalten. Bei den Ameisen beobachtet man an einer bekannten Art, Lasius flavus, dass sie die Blattläuse nicht nur ptlegt, sondern sich sogar förmlich mit der Aufzucht junger Blattläuse befasst und diese ebenso getreulich besorgt, wie die Aufzucht der eigenen Brut. Man hat

1) G. Cuvier. Recherches sur les ossements fossiles. Discours préliminaires.

2) Friedrich Ratzcl. Völkerkunde. Leipzig. 1894. 
daher eine solche Wechselbeziehung zwischen Ameise und Blattlaus als Viehzucht bezeichnet. Wenn dagegen beispielsweise Formica sanguinea auszieht, um den Kolonien der Formica fusca Kämpfe zu liefern, eine Anzahl Individuen dieser Art ins Nest schleppt und dieselben zwingt, Dienste zu verrichten, so sprechen die Entomologen in diesem Falle mit vollem Recht von Sklaverei der Ameisen und nicht von Viehzucht.

Ich fasse daher das Verhältnis der Haustiere zum Menschen nicht als Sklaverei, sondern als eine echte Symbiose auf d. h. als ein Konsortialverhältnis zweier Organismenformen, wie es in verschiedenen Abteilungen des Tierreichs in weiter Verbreitung nachgewiesen ist. Ich habe diesem Gedanken schon früher Ausdruck gegeben. ${ }^{1}$ )

In der That treffen alle Voraussetzungen und charakteristischen Züge der tierischen Symbiose auch für das Haustierverhältnis zu, wie sich im Einzelnen nachweisen lässt.

Symbionten stehen im System immer mehr oder weniger weit auseinander. Sie gehören verschiedenen Ordnungen (Paussus und Ameisen) oder Klassen (Krokodil und Charadrius aegyptiacus), selbst verschiedenen Tierkreisen an (Adamsia palliata und Eupagurus). Durchgeht man die Liste unserer Haustiere, so läst sich nicht ein einziges herausfinden, das dem Menschen im System näher steht.

Bei Symbionten sind es stets gemeinsame Interessen im Kampf ums Dasein, also wirtschaftliche Momente, welche die Symbiose einleiten. Die Unterstützung im Kampf ums Dasein ist eine wechselseitige, niemals eine einseitige. Das trifft auch für das Haustierverhältnis zu. Das Haustier leistet dem Menschen Dienste, empfängt anderseits von ihm Schutz, Nahrung und wenn nötig auch Obdach. Dass der Eintritt in den Hausstand gelegentlich geradezu Existenzfrage wurde, beweist das Rind. Der wilde Stammvater, der Ur (Bos primigenius), hat sich im freilebenden Zustande nicht zu behaupten vermocht; er erlosch, während seine zahmen Deszendenten sich sehr wohl befinden.

Die künstliche Züchtung, die der Mensch bei seinen Haustieren durchgreführt hat, kann nicht als Grund angeführt werden, das Haustierverhältnis von dem allgemeinen Symbiosenverhältnis abzutrennen.

Der Mensch hat damit seine Symbionten umgeformt und seinen Bedürfinssen angepasst : aber streng genommen verfuhren auch andere ( reschöpte beim Eingehen einer Symbiose thnlich, sie haben durch Auslese die geeignetsten Individuen erhalten.

Nehmen wir als Beispiel die Adamsia palliata, die in den Dienst eines Krebses (Eupagurus) tritt. Jedem Beobachter, der diese Tiergesellschaft im Leben eingehender beobachtet hat, wird die konstante und eigenartige Ausbreitung des Fusses dieser Seerose aufgefallen sein; aber die Art der

1) C. Keller. Die Tierwelt in der Landwirtschaft. Leipzig. 1893. 
Anheftung muss als die zweckmässigste erscheinen. Das Fussblatt kann ursprünglich diese Gestalt nicht besessen haben und die Auslese des Krebses hat eben diese Umformung erzielt.

Wenn wir endlich die bekannte, fast rührende Sorgfalt ins Auge fassen, die gewisse Krebse beim Umzug in eine neue Behausung entfalten, indem sie ihre Seerosen loslösen und auf die neubezogene Schneckenschale bringen, so erinnert das vollkommen an die Anhänglichkeit mancher Völker an ihre Haustiere.

Der Umstand, dass der Mensch eine relativ grosse Zahl von Haustieren seiner Wirtschaft einverleibt hat, spricht ebenfalls nicht gegen den Symbiosencharakter. Praktisch genommen liegen die Dinge insofern einfacher, als niemals gleichzeitign der ganze Bestand zur V'erwendung selangt. sondern die einzelnen Wirtschaftsgebiete sich mit wenigren Arten begnügen.

Nun kömnen wir auch bei niederen Tieren, die Neigung zur Symbiose haben, gelegentlich beobachten, dass sie ganz verschiedene Arten in ihren Haushalt aufnehmen.

Die gemeine Wollkrabbe des Mittelmeeres (I)romia vulgaris) nimmt für gewöhnlich einen orangeroten Korkschwamm (Suberites domuncula) in ihren Dienst, wählt aber auch nicht selten Sarcotragus spinulosus oder zusammengesetzte Ascidien aus.

Eine andere Krabbe (Maja) hat auf ihrem Rücken gleichzeitig Korkkorallen, Spongien und Hydroiden angesiedelt, welche dieses Tier maskieren müssen.

Die Haustierzucht wird demnach unter anderen Formen in der höheren und niederen Tierwelt häufig geübt. Ich schlage daher folgende I)etinition vor: Haustiere sind solche Tiere, die mit dem Menschen eine danernde Simbiose eingegangen haben, zom Menschen zu bestimmten wirtschaftichen Leistungen verwendet werden, sich in dieser Symbiose regelmässig fortpflanzen und dahei der kïnstlichen Züchtung vorübergehend oder dauernd untervorfen werden.

Da die wichtigsten Haustiere schon in vorhistorischer Zeit gewomnen wurden, sind wir bezüglich der allerersten Vorgänge bei der Haustierwerdung zunächst lediglich auf die Spekulation angewiesen. Mit einer bestimmten Absicht ist der Urmensch nicht zur Domestikation geschritten. M. Wilckens äussert zwar die Ansicht, dass der Mensch in der Tierwelt diejenigen Arten ausgewählt habe, die sich schon im Freileben ein grosses Anpassungsvermögen erworben hatten. ${ }^{1}$ ) So klug war der Urmensch sicher nicht. Die Erkenntnis, dass die Haustiere die alleranpassungsfähigsten Geschöpfe sind, konnte a priori nicht vorhanden sein, der Kulturmensch ist erst hinterher zu derselben gelangt. Ich stimme daher $F$. Ratzel vollkommen bei. wenn er bemerkt. ${ }^{2}$ ) dass der machtige (jeselligkeitstrieb beim

1) M. Wilckens. Naturgeschichte der Haustiere. Dresden. 1880. Pag. 21.

2) F. Ratzel. Völkerkunde. Leipzig. 1894. Pag. \$4. 
ersten folgenreichen Schritt zur Gewinnung von Haustieren mächtiger wirken mochte, als die Rücksicht auf den späteren Nutzen. Der primitive Mensch hat zunächst eine Anzahl Arten seiner Umgebung eingefangen und gezähmt, weil ihm dies Vergnügen und Unterhaltung gewährte. Wer mit Naturvölkern verkehrt hat, weiss, dass sie mit grosser Vorliebe in der Umgebung ihrer Wohnstätten eine Menge von zahmen Tieren halten, die wirtschaftlich völlig bedeutungslos sind. Von diesen erweisen sich einzelne als fortptlanzungsfähig. Hinterher kam die Erkenntnis, dass etliche davon wirtschaftlich verwendbar seien, diese wurden behalten, der übrige Teil ganz. oder teilweise entlassen. Die züchterische Auslese führte zur regelrechten Domestikation. Wir hätten damit als die einzelnen Etappen $\approx u$ bezeichnen: Wildzustand - Jagd und Gefangennahme - Zähmung - Domestikation. Hinterher hat der Zufall einen merkwürdigen Beleg für die Richtigkeit dieser Annahme gebracht. Wie ich später bei der Abstammung der Hausrinder genauer darlegen werde, hat uns die mykenische Kunst ein wichtiges Dokument geliefert, welches den ganzen Hergang der Haustierwerdung in einer sehr alten Kulturperiode überraschend naturgetreu darstellt.

Der oben geschilderte IVeg zum Haustier ist wohl der normale, aber nicht der einzige. Es lässt sich vielmehr nachweisen, dass unter Umständen auch religiöse Vorstellungen und Kultusmomente den Weg zum Haustier bahnten oder wenigstens eine Rassenbildung begünstigt haben.

Ein bemerkenswertes Beispiel ist die Hauskatze. Zuerst in Alägypten gezähmt, galt das geistig begabte 'Tier im ägyptischen Hause als guter Geist, als eine Art Vorsehung - die Katze wurde zunächst Gegenstand des Kultes, insbesondere war sie der Liebling der Frauen. Hinterher wurde sie im Haushalt degradiert und als Mäusefänger gehalten. Sie ist im Mittelalter nach Europa gekommen, aber in verzerter Form haben sich bei uns bis auf heute einzelne Reste der Kult-Stufe erhalten. Aehnlich verhält es sich mit dem Hahn, der auf seiner Wanderung nach dem Westen ebenfalls Kultbedeutung erlangte. I ie Heilighaltung des Rindes in Indien ist bekannt und hat dort zur Gewinnuns der schönen Tempelrasse geführt. Die Priester, von den Kultgaben des Volkes lebend und unter allen Breiten schlau auf ihren Vorteil bedacht, lesen unter den dargebrachten Rindern nicht die schlechtesten aus und die stattlichen Götterkühe der Tempel sind ein Produkt dieser priesterlichen selektion.

Prüft man das Material, aus welchem der Mensch seine Maustiere bezog und damit auf einer vorgeschrittenen Entwicklungsstufe sein Dasein von den Launen und Wechselfällen der Natur möglichst unabhängig gestaltete, so ergiebt sich sofort. dass die niedere Tierwelt ein höchst unbedeutendes Kontingent (Honigbiene, Seidenraupe) geliefert hat. Die meisten entstammen den höher stehenden Wirbeltieren, sind aber nach den einzelnen Ordnungen sehr ungleich verteilt. Von 13 Säugetierordnungen sind es nur drei, welche domestizierte Arten geliefert haben, nämlich die Huftiere, Raubtiere und 
Nager. Aus der Klasse der Vögel kommen nur zier Ordnungen in Betracht, nämlich die Hühnervögel, Tauben, Schwimmvögel und Strausse.

Wir können aus diesen Thatsachen entnehmen, dass gewisse Vorbedingungen vorhanden sein mussten, die nicht allein wirtschaftlicher sondern auch physiologischer Natur waren.

Es wird meist übersehen, dass die natürliche Intelligenz eine grosse Rolle spielte. Sie darf weder zu hoch, noch zu niedrig bemessen sein. Steht sie zu hoch, dann ist die Gefahr da, dass ein Haustier das Dienstverhältnis zu oft durchbricht. Es ist gewiss bemerkenswert, dass die dem Menschen im System nächstverwandten Affen niemals eine domestizierte Art zu liefern vermochten, trotzdem sie sich unschwer zähmen lassen. Ihre geistige Selbständigkeit ist eben zu gross. Die intelligente Katze steht schon an der oberen Grenze und dokumentiert ja nur zu leicht ihre Unab. hängigkeit, wenn diese eingeschränkt werden will.

Anderseits kanı der Mensch mit einem geistig beschränkten Geschöpf wiederum nichts anfangen, In Australien ist aus diesem Grunde kein einziges der zahlreichen Beuteltiere domestiziert worden, obschon deren Fleisch und Fell erwünscht sein musste; diese Tiere sind eben nicht erziehungsfähig. Bei den Eingeborenen von Madagaskar fand ich eine Menge von gezähmten Lemuren; die Geschöpfe sind in ihrem Wesen ungemein angenehm und zutraulich, aber geistig entsetzlich beschränkt und daher zu irgend welchen Dienstleistungen nicht verwendbar.

Der mittlere Grad von Intelligenz ist eine der Hauptursachen. warum gerade die Huftiere die brauchbarsten Arten geliefert haben.

Sodam ist eine ganz bestimmte Qualität der psychischen Eigenschaften erforderlich. Bereits Cuvier hat darauf hingewiesen, dass der Mensch sein tierisches Inventar denjenigen Arten entnahm, welche herdenweise lebten und Daruin erklärt im Schlusskapitel seines Werkes über „Das Variieren der Tiere und Pflanzen " diese 'Thatsache vollkommen richtig, wenn er bemerkt, dass nur ein soziales Tier unterjocht werden kam, weil es den Menschen als das Haupt der Herde annimmt. In unsere moderne psychologische Ausdrucksweise übersetzt, heisst das nichts anderes als dass ein soziales Tier im Freileben schon der suggestiven Einwirkung in hohem Grade zugänglich sein muss, wenn der Mensch mit seinen Suggestivmitteln bei ihm etwas erreichen will. Tierische Einsiedler, die durch KonträrSuggestion antworten, sind daher für den Ilausstand unbrauchbar.

Eine gewisse Formenbiegsamkeit der einzelnen Arten ist allerdings erforderlich, indessen nicht immer gleich stark ausgeprägt. Spezies, die sehr einseitig angepasst sind, konuten keine Berücksichtigung finden. Die Umgestaltung durch die Kultur erstreckt sich nicht allein auf die äussere Form, sondern auch auf die inneren Organe und selbst die Skelettteile, die man zu den am wenigsten wandelbaren Bildungen rechnet, haben so tiefeingreifende und konstant sich vererbende Eigentümlichkeiten erlangt, dass 
man auf osteologische Momente eine wissenschaftliche Rassenlehre begründen konnte.

Die Kultur-Rassen stehen hinsichtlich der Art ihrer Entstehung den natürlichen oder geographischen Rassen der übrigen Tierwelt gegenüber. Zwar werden in der zootechnischen Litteratur diese Unterschiede nicht immer auseinander gehalten und auch bei Haustieren neben Kultur-Rassen noch primitive Rassen und natïrliche Rassen unterschieden. Nach Nathusius z. B. sind die "natürlichen "Rassen im allgemeinen charakterisiert durch Einseitigkeit in den Leistungen oder wenn eine gewisse Harmonie vorhanden ist, durch relativ geringe Leistungsfähigkeit im ganzen. vie sind auf bestimmten geographischen Gebieten entstanden, bewahren aber ihre Eigentümlichkeit auch beim Versetzen in eine neue Heimat. Als Beispiel wird das orientalische Pferd, das graue Steppenrind und das spanische Merinoschaf angeführt.

Nun hat man aber Jahrhunderte lang an dem Schaf herumkünsteln müssen, bis es in Spanien zur Merinoform wurde und der Ausdruck ,natürliche Rasse" scheint mir eine Contraditio in adjecto, wenn er für ein Haustier angewendet wird. Jede Rasse im zahmen Zustande, ob sie sich stark oder nur wenig von der Stammform entfernt, ist direkt oder indirekt unter dem Einfluss des Menschen entstanden.

Ich würde es vorziehen, Formen wie das graue Steppenrind oder den Windhund Afrikas als primitize Russen zu bezeichnen, weil sie sich von der Stammform nur wenig entfernt haben. Im weitern würde ich als besondere Gruppen die alten Kultur-Rassen von den modernen KulturRassen auseinanderhalten. Erstere sind schon in vorgeschichtlicher Zeit gezüchtet worden, dann aber merkwürdig stabil geblieben, wie z. B. das Braunvieh der Alpen, das Rind Sardiniens, das romanische Schwein, das Bündnerschwein, das Bündnerschaf und das Fettschwanzschaf.

Die modernen fiultur-Rassen sind jünger, zum Teil erst in neuerer historischer Zeit entstanden, wie z. B, das Merinoschaf, das Shorthornrind, das englische V'ollblutpferd u. s. wv.

Von den V'eränderungen im Körper wird das Fortpflanzungssystem am allerwenigsten in Mitleidenschaft gezogen, Störungen in seinen Funktionen würde ja die Zucht beeinträchtigen. Immerhin sind auch da Fälle bekannt, wo Formenkreise von gemeinsamer Abstammung sich in ihren Endgliedern so weit entfernt haben, dass ihre Krenzung nicht mehr gelingt, wie das z. B. für die Zwergformen mancher Hunde der Fall ist.

Betrachten wir die räımliche Entstehung der einzelnen Haustiere, so sind die verschiedenen Erdräume in sehr ungleicher Weise daran beteiligt. Die Erklärung ist naheliegend. In erster Linie war das Vorhandensein eines zur Domestikation geeigneten Wildmaterials erforderlich und diese Voraussetzung traf nicht überall zu. Sodann kommt die Begabung der Menschenrasse für züchterische Kunst in Betracht und nach dieser Richtung sind die einzelnen Völker verschieden beanlagt. 
Am fruchtbarsten hat sich Asien erwiesen, so fruchtbar, dass man einst fast allen unseren Haustieren eine asiatische Urheimat zuschreiben wollte. Das war nun freilich über das Ziel hinausgeschossen.

Das südliche Asien lieferte ein zahmes Schwein, den Büffel, die Höckerrinder oder Zebu, das Haushuhn und den Pfau; das steppenreiche Hochasien das Kamel und den Grunzochsen, sowie den orientalischen Zweig der zahmen I'ferde, endlich eine stattliche Form des Haushundes: Nordasien das Renntier.

Das westliche Asien mit seinen für Viehzucht besonders begabten Völkerschaften ist die erste lleimat gewisser schafrassen. der Hausziegen. der edleren Form des Hausesels und wahrscheinlich auch der kleineren Spitzhunde und Haustauben.

Europa ist geographisch aufgefasst eigentlich nur ein Dependenz von Asien, hat aber doch eigenartige Iatustiere erzengt. Europäischen L rsprung besitzen unsere alten Landschweine, die nordischen schafe, das langkioptige. occidentale Pferd und vorab die grossen Formen der Rinder. Von Nagern wäre noch das Kaninchen hinzuzufügen.

Ein eigenartiges Verhältnis begegnet uns in Afrika. Sein 'Tiermaterial ist grossartig, insbesondere der Reichtum an Säugetieren hervorragend. Democh ist das Wichtigste von Asien her entlehnt, der ursprüngliche Erwerb war zwar etwas umfangreicher als man früher angenommen hatte, im Grunde genommen aber doch wirtschaftlich mehr untergeordneter Natur. Es spielen da offenbar ethnologische Gründe mit. Auf den unermesslichen Steppengebieten fanden vielfach Völkerverschiebungen statt und diese fortwhihrende Unruhe wirkte auf die Heranziehung afrikanischer Haustiere nachteilig. Afrika lieferte die kleinere Form des Hausesels; dieser hat jedoch über den hamosemitischen Kulturkreis hinaus nie eine sehr grosse Bedeutung erlangt. Die zahlreichen Antilopen hätten gewiss brauchbares Material enthalten, aber nur in dem stabilen Nilthal haben die Pharaonenleute während des alten Reiches einen Anlauf zur Antilopenzucht gemacht. später wieder aufgegeben. Schon während der älteren Dynastien, mehr noch während des neuen Reiches betrieb man die Geflügelzucht und die Nilgans (C'henalopex aegyptiacus) spielte als wirkliches Haustier eine hervorragende Rolle: ihre Zucht ist spurlos verloren gegangen.

Echt afrikanisch ist der Windhund, auch alte Schafrassen, die aber seit langer Zeit im Rückgang begriffen sind; die Hauskatze entstand im Nilthal. Fügen wir zum Perlhuhn noch den in neuester Zeit in den Hausstand übergetretenen Strauss hinzu, so ist der afrikanische Anteil erschöpft. Es sind also vorwiegend wirtschaftlich mehr sekundäre Arten.

Am unfruchtbarsten hat sich Austratien erwiesen. Es war eben kein geeignetes Material vorhanden. Das einzige Geschöpf, das etwa zu nennen wäre, ist die Krontaube, die auf Neuguinea von einzelnen Papuastämmen als Haustier gehalten wird und möglicherweise in der Zukunft für die 
Kolonisten einen brauchbaren Gegenstand für ausgedehnte Getlügelzucht abgeben kamn.

Amerika hat vor der Ankunft der Europaier nur wenige Haustiere besessen, nämlich autochthone Haushunde, die Schafkamele oder Lamas, das Truthuhn und die Kochenille. Diesem Mangel an Haustieren ist es zuzuschreiben, dass der präcolumbische Amerikaner nur lokal auf eine höhere Kulturstufe hinüberschreiten konnte, er blieb vorzugsweise Jäger. An Material für die Haustiergewinnung fehlte es nicht; der Bison hätte unschwer gezähmt werden kömnen; auch die Bisamschweine und Pekari sind leicht an die Umgebung des Menschen zu bannen und ihr Fleisch wird gegessen, allein der Indianer hat niemals eine hervorragende Begabung für züchterische Kunst besessen.

Das zeitliche Auftreten der Ilaustiere lässt uns ebenfalls einzelne wichtige Geschichtspunkte erkennen. Das lebende Inventar des Menschen ist nicht zu allen Zeiten dasselbe gewesen, sondern hat mehrfach gewechselt, atch sind die einzelnen Arten nicht gleichzeitig in den Hausstand eingetreten, worauf schon 1859 Isidore Geoffroy St. Hilaire eingehender hingewiesen hat. Er zählt auf der ganzen Erde 47 Haustier-Arten auf, wovon einzelne allerdings fraglicher Natur sind und zeigt, dass sie zum Teil erst in nenerer geschichtlicher /eit oder dam im historischen. Mltertum domestiziert wurden, während 14 Arten bereits in der prähistorischen Periode vorhanden sind. Letzteren werden zugerechnet der Hund, die Katze, das Pferd, der Esel, das Schwein, das Kamel, der Dromedar, die Ziege, das Schaf, das Rind, der Zebu, die Taube, das Huhn und die Seidenraupe. Der Haupterwerb wurde somit schon während der prähistorischen Zeit gemacht, was von der historischen 'Zeit an hinzukommt, ist mehr untergeordneter Natur. Diese Thatsache findet ihre Erklärung darin, dass eine mảssige Zahl von Arten ausreicht und durch allzu extensive Wirtschaft der Mensch seine Kräfte nur zersplittern würde.

In welcher Reihenfolge die prähistorischen Haustiere in den Dienst der Menschen eintraten, lässt sich mit Sicherheit nicht mehr ermitteln, da Funde aus den ältesten Kulturkreisen noch zu spärlich sind. Meist wird der Hund als das erste Haustier angesehen, aber auch das Rind muss in Asien sehr früh gehalten worden sein, da es bereits in einer stark umgeänderten Form in den allerältesten Pfahlbauten Mitteleuropas nachweisbar ist, einer Form, welche morphologisch mit asiatischen IIausrindern verknüpft erscheint.

In allen Kulturkreisen lässt sich eine Entwicklung von einfachen zu immer höher steigenden Stufen nachweisen, sei es, dass die anfänglichen Rassen umgebildet werden, sei es durch Wechsel des Haustierbestandes und Zufuhr neuer Rassen.

Auf dem Boden der prähistorischen Kultur in Mitteleuropa sehen wir heute vollkommen klar. Die ältere Steinzeit oder Höhlenzeit weist noch 
keine Ilaustiere auf, der Urbewohner trieb ckamals ausschliesslich Jagd. 'wischen der äteren und jüngeren Pahlbauperiode hat Rütime'yer erhebliche Unterschiede nachweisen kömen und Th. Shudor bestätigte dies später auf Grund seiner Untersuchungen der westschweizerischen Pfahlbauten, die eine ausserordentliche Fülle an Haustiermaterial geliefert haben, Er bemerkt, dass in den ältesten Stationen neben den I Iaustieren die Jagdtiere in ziemlich gleicher Menge vertreten sind. "I Hund, Schwein, Ziege, Schaf und Rind sind nur in einer je gleichförmigen Rasse vertreten. In der späteren Steinzeit finden wir, dass neben der Jagd auf die grossen Wiederkäuer des Waldes der Viehzucht eine ungemeine dufmerksamkeit zugewendet wird. Das wilde Rind wird gezähmt und mit der schon vorhandenen Rasse gekreuzt: aber auch auf die anderen Iatusticre erstreckt sich die umbilkende' 'Thaitigkeit der Züchtung. Der IImel wird nach lienierstens drei verschiedenen Richtungen umgehildet. Sichat und Ziege entwickeln sich \%u grösseren und krätigeren Forment Lind in der Bronzeperiode: wehendience L mbildungen noch weiter. Mit der Ankunft der Römer beginnt nenerdings eine IIebung der Viehzucht,

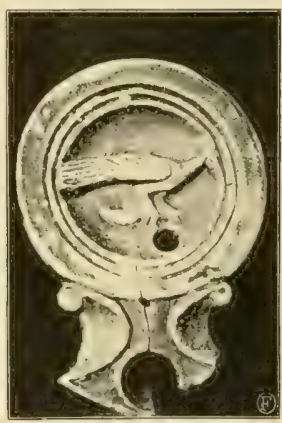

Fis... is.

Rönische Thonlanpe mit I'fau. Vintonissa. indem die vorhandenen Rilsen verbessert, aher atich neue formen in Viorden der. Mlpen eingeführt werden. Wie sich in Vindonissa nachweisen liess, haben römische Kolonisten eine grosse Ilunclerasse, sowic eine nene Ziegen- und R inderrasse mach Norden reehreitut. Auch der I'fau erscheint zum ersten Mal während der helvetischrömischen Zeit in Mitteleuropa.

Durch genaueres Studium des altägrptischen Kulturkreises bin ich zu ganz ihnlichen Ergebuissen gelangt.

Die Haustiere aus der vorpharaonischen Zeit (Rind, Esel, Schaf), von denen wir sehr brauchbare Darstellungen besitzen, sind noch ungemein primitiv und der wilden Stammart sehr nahestehend, das Sichaf z. B3. ähnelt seiner langen Halsmähne wegen noch dem. Mähnenschaf, ist aber später während des alten Reiches und mittleren Reiches schon in verschiedene Formen gespalten. I)as Rind ist $2 u$ der charakteristischen Langhorn-Rasse umgebildet. Das Schwein ist schon von der I. 1)ynastie an vorhanden: die Antilopenzucht, während der älteren Dynastien stark geübt, geht später verloren, dafür wandern zur \%eit des nemen Reiches asiatische Schafe ein und verdrängen die altangesessene Rasse. Kamel und Pferd sind im alten Reich nirgends nachweisbar, sie erscheinen im Nilthal relativ spät. Die anfänglich überwiegenden langhörnigen Rinder werden später in den I Iintergrund gedrängt und die kurzhörnigen Formen überwuchern: ob Umzüchtung oder fremder Import dies bewirkt hat, bleibt dahingestellt. Immerhin belehren 
uns Funde in Deir el Bahri, dass Kurzhornrinder aus dem südlichen Puntland eingeführt wurden.

Wenn der mesopotamische Kulturkreis erst vollkommener durchsucht ist, wird sich eine ähnliche Entwicklung nachweisen lassen. in neuerer geschichtlicher Zeit ist er freilich in Verfall geraten und die Haustierwelt durchaus anders, aber minderwertig geworden. Die edlen Zuchten altassyrischer Pferde gingen nach und nach an die Araber über; das Schwein wurde aus der Wirtschaft entlassen: an die Stelle des Rindes trat der Büffel, der möglicherweise in jener Region zuerst gezähmt wurde. Die rassenreinen, schönen Doggenhunde Altassyriens sind längst im Zweistromland erloschen und machten dem verachteten Pariahund Platz.

Schliesslich mag noch hervorgehoben werden, dass die Kunst der IIaustiergewinnung in den verschiedenen Kulturkreisen selbständig erworben wurde und ein ethnischer Zusammenhang anfüglich nicht nachweisbar ist. Wenn z. B. im Norden Asiens die Renntierzucht entstand oder im altamerikanischen Kulturkreis einige llaustiere auftraten, so geschah dieser Erwerb unabhängig von jedem äusseren Einfluss.

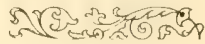




\section{DIE HAUSHUNDE.}

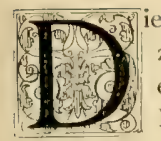

ie Reihe der schon in prähistorischer 7eit auftretenden domestizierten Arten dürfen wir wohl unbedenklich mit den Haushunden eröffnen. Sie bilden vermutlich den ältesten Erwerb, den der Mensch in der Tierwelt für seine häusliche Wirtschaft gemacht hat. In dieser Ilinsicht erscheinen zwei Thatsachen sehr beachtenswert: einmal erscheint der Hund als Besitztum gewisser Rassenelemente, die heute noch auf der allerprimitivsten wirtschaftlichen Stufe reiner Jägervölker verharren, wie z. B. die Natur-Weddas und die Buschmänner: sodann tauchen zahme Hunde bereits in weiter Verbreitung während der prähistorischen Periode der alten IVelt, aber auch in der präcolumbischen Zeit der neuen Welt auf.

Der Hund schliesst sich dem Menschen enger an als irgend ein anderes Haustier und wenn auch seine wirtschaftliche Bedeutung von anderen Arten übertroffen werden mag, so ist er doch ein kosmopolitisches Geschöpf im weitesten Sinne des Wortes greworden: in den Tropen findet er sich unter - den wechselndsten Lebensbedingungen, er folgt in der gemässigten Zone dem Menschen bis in die höchste (jebirussegion und vermag. wie clie neuenten Nordpolexpeditionen beweisen, als Zughund im Polargürtel bis zu Breiten vorzudringen, in denen selbst das Renntier versagt.

Dass die Rassengeschichte eines so alten Haustieres, bei welchem überdies Kreuzungen vieltach unvermeidlich blieben, ein ganz besonders schwieriges Problem darbietet, liegt auf der Hand.

\section{DIE PRAEHISTORISCHEN HUNDE-RASSEN}

\section{IN EUROPA. $\left.{ }^{1}\right)$}

Zahme Hunde scheinen bei den ältesten Ureinwohneru von Europa nicht vorhanden gewesen zu sein, denn bisher konnten ihre Spuren in den palaeolitischen Niederlassungen nicht nachgewiesen werden. Befragen wir zwei klassisch gewordene Fundstätten der nördlichen Schweiz, die sehr genau durchsucht sind, so lauten die Ergebnisse durchaus negatir. In Thayngen fand Rütimeyer etwa 200 Oberarmknochen des Schneehuhnes, aber Bissspuren von Hunden, die sich etwa an diese Küchenabfälle hätten machen kömnen, waren nicht zu bemerken. „Schon hierin möchte ein starker Beleg liegen, dass der Haushund damals fehlte", fügt der genannte Autor hinzı.

1) V'rgl. insbesondere die neueste zusammenfassende Arbeit von 7\%. Studer. Die prïhistorischen Hunde, Abh. d. Schweiz, palaeont. Gesellschaft. 1901. 
Die so minutiös clurchforschte Station Schweizersbild hat ebenfalls keine palaeolitische IIundereste geliefert. Erst mit Begim der Pfahlbaukultur, also in der jüngeren Steinzeit, taucht ein zahmer Hund auf. Dessen Schädel ist in der Regel gut erhalten, ein Beweis, dass er jedenfalls nicht der Nahrungszwecke wegen gehalten wurde, sondern wahrscheinlich zur Bewachung der menschlichen $\mathbf{W}$ ohnungen diente. Der anatomische Vergleich ergiebt, dass anfänglich eine einzige, merkwürdig beständige Rasse gehalten wurde, die Rütimeler als Canis familiaris palustris bezeichnet. Da in neuerer Zeit sich auch

deutsche Bienemumusen liim diese alten Rassen? cinbürgern.

kömnte matu diese Form am zutreifendsten als Torfspitzbezeichnen. da sie aurenscheinlich die - Insgangatorm minserer heutigen spitzhunde dirstellt.

Der märsig enrosse Torthund war leicht subaut, derschädel mitkur\%(r.maissign \%ugespitzter

sichnatuze. schön germudeter Schädelkapsel. schwach ent-

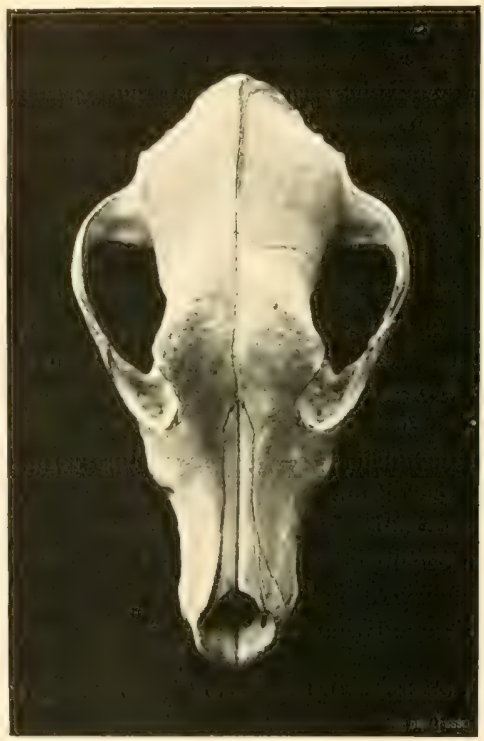

Irige. 7. fehidel des forthundes. Robenhausen.
wickeliemH Iinterhatuptshamm und rhwathenowenig nach aussen gerwibten fochhogent. I)ic+Baralkinge des sichidels betrug 1.30 bis 150 Millimeter.

Die genannte Rasse int bisher (1) verschiectenen Lekalititen

Eurrepas. selbst weit im Norden, atufuetunden worclen. Wie Th. Sunder-1) an sihacleln der westuchweizerinchen Plihhlatuten machweisen kisunte, wurden die anfänglich sehr konstanten

Torfspitze nach verschiedenen Richtungen umgezüchtet. So wurden in Pfahlbauten mit fortgeschrittener Kultur (Sutz, Lattringen, Lüscherz, Vinelz) neben der alten Rasse auch grössere Formen angetroffen, deren Schädel stärkere Muskelleisten und kräftigere Jochbogen besizen, also etwa unseren heutigen Hofspitzen nahestehen. Anderseits kamen auch kleine Spitzhunde vor, bei denen der Schädel mehr jugendiche Konturen annimmt oder wie aus Funden in Lattringen hervorgeht, der Typus des Pinschers gezüchtet wurde.

1) Th. Studer. Mitt. der naturf. Gesellschaft in Bern. 1883, und "Beitrïge zur ricschichte unserer IIunderassent. Naturw. Wochenschrift. 189\%. 
Damit im Einklang stehen die Befunde von Strobel, welcher in den Terramaren der Emilia neben dem gewöhnlichen 'l'orfhund noch eine kleinere Form (Canis Spalleti) vorfand. ${ }^{1}$ )

Eine grosse und von der vorigen abweichende Rasse aus der neolitischen Zeit entdeckte Amutschin ${ }^{2}$ ) in Ablagerungen am Ladoga-See neben dem gewöhnlichen Torfspitz. Er gab ihr den Namen Canis lnostranzewi. ihr Vorkommen wird von Studer auch für die Pfahlbau-Niederlassung Font am Neuenburgersee angegeben. Im Ilinblick auf die Seltenheit dieses Ilunde-Relikts, dessen nahe Beziehungen zum Wolfschädel betont wurde, zumal die Knochenleisten stark entwickelt sind und die Augenöfnung wie beim Wolf als schräg bezeichnet wird, kann man die Frage aufwerfen, ob es sich wirklich um eine zahme Rasse handle.

Unter dem Namen (anis Leineri hat fener Th. Studer ${ }^{3}$ ) eine grosse Rasse aus der neolitischen Station Bodmann am Ueberlingersee bekamnt gemacht. Die Eigentümlichkeit derselben besteht in dem relativ schwachen Gebiss und einem Profil. das an der Nasenwurzel nicht eingesenkt ist. Diese eigenartige Form, die gewisse Beziehungen zu den heutigen Ilirschhunden aufiveisen soll, ist nur in einem cinzigen Schädel bekannt geworden.

Eine weitere Rassenvermehung macht sich im mittleren und westlichen Europa mit Begim der Bronzekultur bemerkbar. Es erscheint der Bronzehund, den Foilteles 1872 in Olmütz entdeckte und unter dem Namen Canis matris optimae beschrieb. ${ }^{*}$ ) Seine Verbreitung erstreckt sich über ein grosses Areal. da er auch in Troppau, in Würzburg, am Neuenburgersee, in Morges am Genfersee, und in den L'fahlbaten des Starnbergersees (hier in 9 Exemplaren) nachgewiesen wurde. Der Bronzehund steht anatomisch dem heutigen Schäferhund am nächsten und bildet wohl den direkten Vorläufer desselben. Die Basilarlïnge des Schädels beträgt 170-189 Millimeter; das Schädelprofil ist flacher, die Hirnkapsel weniger gewölbt als beim Torfhund.

Nammann ${ }^{5}$ ) führt auf Grund der Funde am Starnbergersee aus, dass schon während der Pfahbauzeit der Bronzehund in zwei verschiedenen Formen gezüchtet wurde und hält es für wahrscheinlich, dass der Torfhund mehr zum Bewachen des Hauses, der grössere Bronzehund dagegen als Hüter der IJerden gehalten wurde. Diese Annahme erhält eine gewisse Stütze in der Thatsache, dass die Grossviehhaltung zur Zeit der Bronze-

1) Strobel. Le Razze dell'Cane nella Terramare dell'Emilia. 1880.

2) A uutschiu. Zwei Rassen des Hundes aus den Tormooren des Ladogasees-Moskau. 1882.

3) T\%. Studer. Zwei grosse Hunderassen aus der Steinzeit der I'fahlbauten. Mitt. der naturf. Gesellschaft in Bern. 1843.

1) L. II. Feitteles. Sitzungsber, der math,-phys. Klasse der kgl. bayer. Akad. der Wiss. zu München. 1872 .

5) Nanmann. Die P'fahlbauten in Starnbergersec. Archii für Anthrop. 1875. 
kultur etwas zurücktritt. während die Zucht des Kleinviehs einen entschiedenen Aufschwung nimmt.

Der Bronzezeit gehört noch eine Rasse an, die Woldrich im Jahre 1877 unter dem Namen Canis fam. intermedius beschrieb. $\left.{ }^{1}\right)$ Der bekannte Archaeologe Graf von IImmbrand entdeckte den ersten Schädel derselben in Weikersdorf (Niederösterreich), weitere Funde stammen aus Pulka und I'loscha in Böhmen. Wegren des typischen Vorkommens dieser RassenRelikte in Aschenlagern hat die erwähnte Form den Namen "Aschenhund" erhalten. Mit einer Basilarlänge von 164 Millimeter steht sein Schädel in der Mitte zwischen dem grossen Bronzehund und der kleineren PalustrisRasse, so dass es sich wahrscheinlich um ein Kreuzungsprodukt handelt. Als bemerkenswerte Eigentümlichkeit des Schädels wird von Woldrich die Kürze der Schnauze und die bedeutende Stimbreite hervorgehoben.

Der Aschenhund soll nach seinen osteologischen Merkmalen nahe Beziehungen zu den primitiven Formen unserer Jagdhunde aufweisen. $\mathrm{Ob}$ es sich da nicht um zufällige Konvergenzerscheinungen handelt? Wir müssen stets im Auge behalten, dass im altägyptischen Kulturkreis schon sehr früh hängeohrige Jagdhunde vom Charakter der Laufhunde vorhanden waren, deren südliche Abstammung sich leicht verfolgen lässt.

Als letzte prähistorische Rasse mag der in der Litteratur mehrfach aufgeführte grosse Ifund hier noch Erwähnung finden, den A. Vehring"2) als Canis familiaris decumanus beschrieb und ihn vom Wolf herleiten möchte. Es sind davon zwei Schädel im märkischen Museum vorhanden: sie wurden in der Nähe von Berlin in einer Kulturschicht aufgefunden; ein dritter Schädel stammt aus Eberswalde. Die Basilarlänge derselben wird zu 220 bis 230 Millimeter angegeben. Ich werde später die Gründe darlegen, die mich Zweifel in die Existenz so grosser prähistorischer Haushunde hegen lassen, auch Vehring ist, wie er mir schreibt, zweifelhaft geworden, ob seine Decumanus-Rasse der prähistorischen Zeit angehöre, da sich das Alter der Kulturschicht nicht sicher bestimmen liess.

Wir sehen also, dass frühzeitig, namentlich während der Bronzeperiode neben dem alten Torfhund neue Rassen auftauchen; im allgemeinen sind es jedoch nur drei, der Torfhund, der Bronzehund und der Aschenhund, für welche mit Sicherheit eine allgemeinere Verbreitung nachgewiesen ist. Sie reichen bis nach dem äussersten Westen des europäischen Kontinentes, wo die Funde in den "Terpen" Hollands eine besondere Beachtung verdienen. Diese schon in vorgeschichtlicher Zeit besiedelten Stellen lassen sich am ehesten den Terramaren Italiens an die Seite stellen, dürften aber den jüngeren Perioden angehören, da in den Terpen von Aalsund und

1) 7. N. Woldrich. Ueber einen neuen Haushund der Bronzezeit. Mitt. der anthrop. Gesellsch. in Wien. VII. I3d. $18 \% \pi$.

$\left.{ }^{2}\right)$ A. Nelining. Ueber eine grosse wolfsähnliche Hunde-Rasse der Vorzeit. Sitzungsber. der Gesellsch. naturf. Freunde. Berlin. 1884. 
Hallun neben der Palustris-Rasse auch Canis matris optimae und C. intermedius aufgefunden wurde. Diese Funde sind von $I I . K . \%$. Schoor beschrieben und abgebildet. ${ }^{1}$ )

Ich habe unlängst zwei Schädel aus den Terpen im Norden von Groningen untersucht, welche in einer Tiefe von drei Meter ausgegraben wurden und von denen der eine die grössere Palustrisform zeigt, der andere dagegen dem Formenkreis von C. intermedius zugerechnet werden muss. Ich gewinne an dem grösseren schädel neuerdings die Ueberzengung, dass es sich um ein Kreuzungsprodukt zwischen der Palustris-Rasse und einem grossen I Iund handelt. I)a wir kaum annehmen dürfen, dass in jener weit zurückliegenden Zeit schon bestimmte Zuchtprinzipien herrschend waren, so muss das Auftreten von Kreuzungsprodukten ganz natürlich erscheinen.

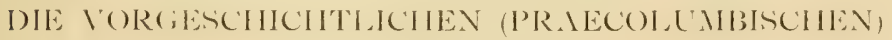 HUNDE AMERIKAS.}

Dic Kulturverhältnisse der neuen Welt lagen vor Ankunted der Europäer weit einfacher als in der alten Welt. - Dies gilt insbesondere für die I latustierzucht, die sich nur lokal und in geringem Umfang entwickelt hatte.

Am meisten verbreitet war der I Hund, der im Kulturkreis der Maya und Altmexikaner leider nicht genauer untersucht ist, um so besser aber in Nlt-Peru.

Nachdem schon Tschudi die Identität des alten Inkahundes der vorspanischen Gräber mit dem Hirtenhund der Indianer festgestellt hatte, sind in der Neuzeit durch A. Nehring - $\left.^{2}\right)$ die Inkahunde des Totenfeldes von Ancon eingehend untersucht worden.

Es erhellt daraus, dass die Altperuaner in der IIundezucht verhaltnismässig weit gekommen waren, wie sie auch die einzigen Völker des präcolumbischen Amerika waren, die darüber hinaus als Haussäugetiere noch das Lama und das Meerschweinchen gewonnen hatten.

Ihr Haushund war mittelgross und untersetzt gebaut, teils straffhaarig, teils eigentlich langhaarig. Unter den gut erhaltenen Gräberhunden treten verschiedene Farben-Nuancen auf (ockergelb, dunkelbraun, gelb und braungefleckt). Das Gebiss zeigt eine auffallende Neigung zum Variieren.

Nehring wies nach, dass vor Ankunft der Europäer bereits drei wohl unterscheidbare Rassen gehalten wurden, die sich hinsichtlich des Schädelbaues und der Form der Beinknochen charakterisieren lassen als:

1. eine Schäferhund-älnliche Rasse (Canis Ingae pecuarius Nehring) mit relativ schlankem Schädel und schlanken Beinen. Dieselbe durfte im äusserlichen Aussehen etwa den Collies ähnlich gewesen

1) H. h: F. Sckoor. De praehistorische honden der Terpen. Leeuwarden. 1887.

2) A. Vehring. Ueber altperuanische Haustiere. Compte Rendu đu congrès International des américanistes. Berlin. 1888. 
sein. Offenbar war dies die primitivste Rasse, die auch am meisten verbreitet war.

2. eine Duchshund-ähnliche Russe (C. Ingae vertagus Neluring) mit

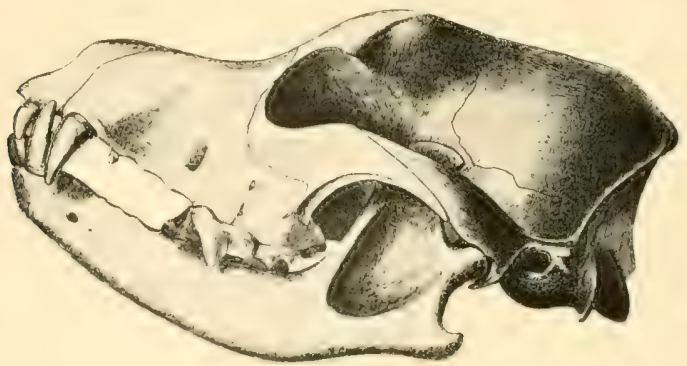

liig. 8 .

Canis Intrac pecuarius.'

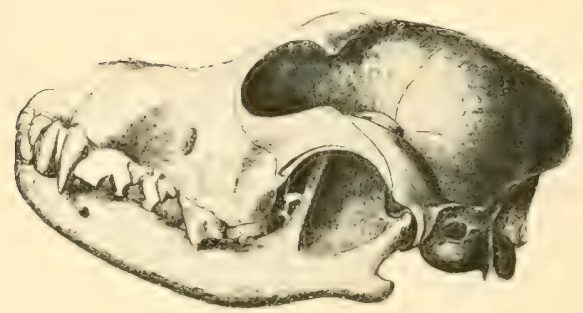

1. 12.1.

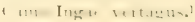

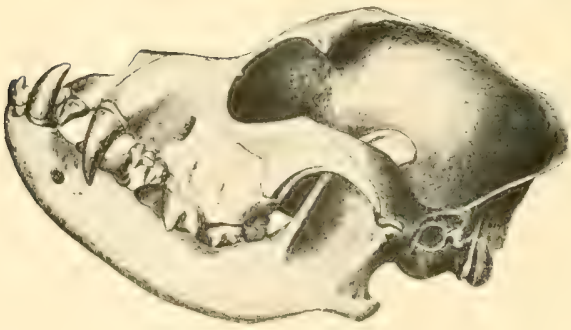

Fifar. ]

Canis Ingae molossoides?

kürzerem Schädel und kurzen, stark gekrümmten Beinen. Es braucht nicht besonders hervorgehoben zu werden, dass der Inka-I)achshund genetisch in keiner Bezielnung zu den I)achshunden der alten Welt

1) Nach A. Nehrins. 
steht, sondern sich granz unabhängig auf amerikanischem Boden entwickelte.

3. eine Bulldog-ähnliche Rasse (C. Ingae molossoides Nehring) mit kurzem, breitem Schädel, verkürzter Sichnauze, stark übergreifendem Unterkiefer und kurzen, plump gebauten Beinen. Auch hier liegt lediglich eine Konvergenzerscheinung zu der altweltlichen Bulldoggform vor.

Es bleibt späteren Untersuchungen vorbehalten, ob diese Rassen erst in Altperu entstanden oder aus dem Gebiet der Mayakultur oder der altmexikanischen Kultur eingeführt wurden.

I Iunde wurden den 'Toten ins Grab mitgegeben und ihnen dann gewöhnlich vorher die Ohren gestutzt.

\section{DIE HUNDE DES HISTORISCHEN ALTERTUMS.}

Von den alten Kulturkreisen liefert uns das Pharamenland, das alte Nilthal, weitaus das ergiebigste und zuverlässigste Material. Der Hund muss, wie wir aus den treftlich erhaltenen bildlichen Darstellungen der iltesten Dynastien entnehmen können, sich als Haustier einer grossen Beliebtheit erfreut haben, ja er bildete sogar lange 7eit hindurch den Gegenstand des Kultes. Mit Sicherheit lässt der Hund Altägyptens sich bis gegen 4000 Jahre v. Chr. zurückverfolgen und erscheint schon frühzeitig in verschiedenen Rassen.

Am häufigsten und geschätztesten war augenscheinlich der stattliche Windhund, dor an Grösse etwa dem heutigen russischen Barsoi gleich kam und seiner Schnelligkeit wegen besonders bei der Jagd auf Antilopen Verwendung fand.

Ein Blick auf das Werk von Lepsins belehrt uns, dass der typische Windhund Altägrptens schon während der IV. und V. Dynastie häufig abgebildet wird: wir kennen auch Darstellungen aus der XII. Dỹnastie.

Die leichtgebaute, hochbeinige Rasse besass Stehohren und eine stark vorgestreckte, feine Schnauze; sie wird meist ringelschwänzig dargestellt, einzelne Bilder lassen eine Stummelrute erkennen, woraus entnommen werden muss, dass schon bei den Alägyptern der Brauch bestand, den Hunden den schwanz zu stutzen.

Ich besitze eine genaue Kopie aus dem Grabe des Ti (V. I)ynastie). auf welcher der stehohrige Windhund eine buschige Rute erkennen lässt. Augenscheinlich war der altägyptische Windhund sonst kurzhaarig.

Auch andere Rassen wurden gehalten; hängeohrige Jagdhunde waren wohl neben Windhunden am häufigsten. Sie waren nicht selten getleckt, wie wir aus einer besonders schönen Abbildung in Theben aus der Zeit der XVIII. Drnastie ersehen kommen. Nanche ägyptische Jagdhunde erinnern sehr an unsere heutigen Laufhunde, während andere noch so windhundartig erscheinen, dass wir unbedingt eine Umzüchtung des $\mathbb{W}$ indspieles zur Jagdhundrasse annehmen müssen. 
Der Dachshund wurde ebenfalls gehalten; eine Abbildung aus Beni Hassan stellt ihn noch stehohrig dar.

Weniger häufig begegnet man dem Spitzhund, doch wird er schon auf einem Monument der $1 \mathrm{~V}$. Dynastie recht kenntlich dargestellt.

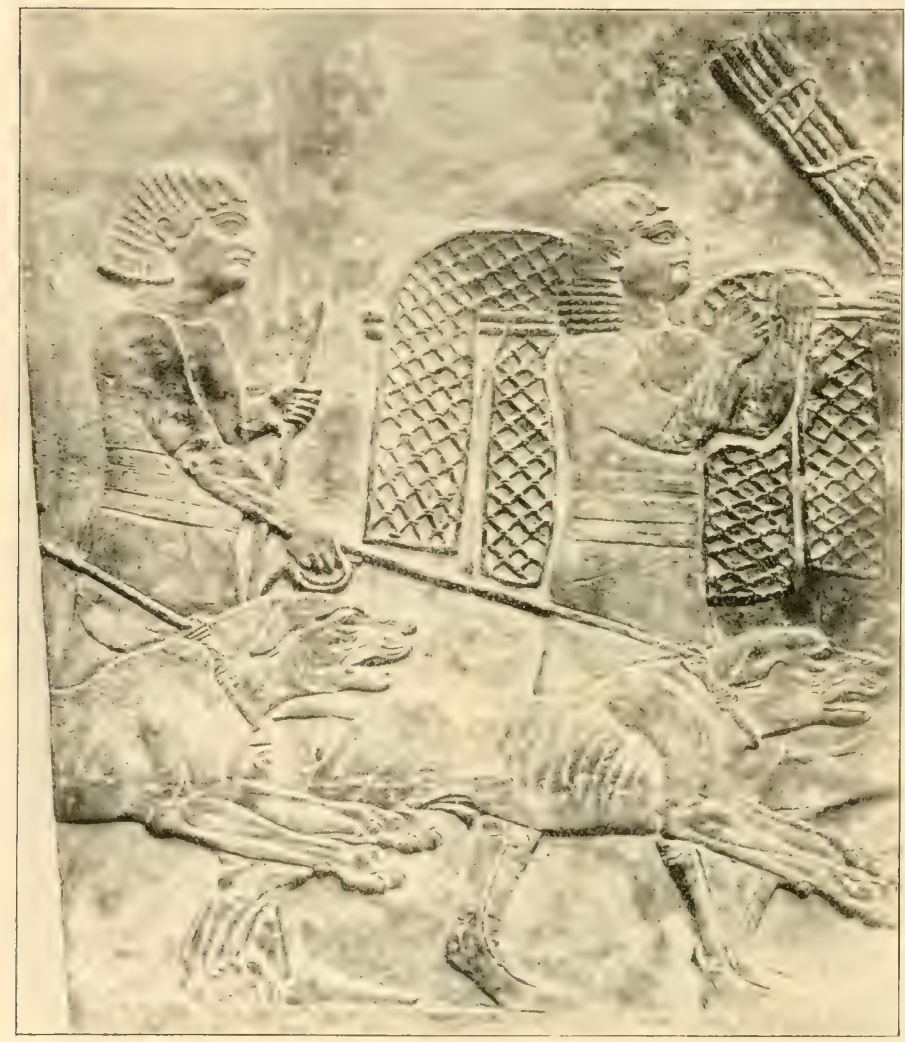

[iig. 11 .

Assyrische Jäger mit grossen Doggen. GhS v. Chr. (British Museum.)

Aufallend erscheint es, dass die altägyptischen Künstler IIunde aus der Doggenfamilie niemals abgebildet haben; diese Thatsache berechtigt zu dem Schluss, dass die Doggen den Pharaonenleuten nicht bekannt waren.

Eine Umschau in dem alten babylonisch-assyrischen Kulturkris lässt durchaus abweichende Verhältnisse erkennen; die Rassenzusammensetzung 
war offenbar einfacher. Die wichtigsten Dokumente reichen im Zweistromland 2500-3000 Jahre von der Gegenwart zurück. Von ächten Wind-

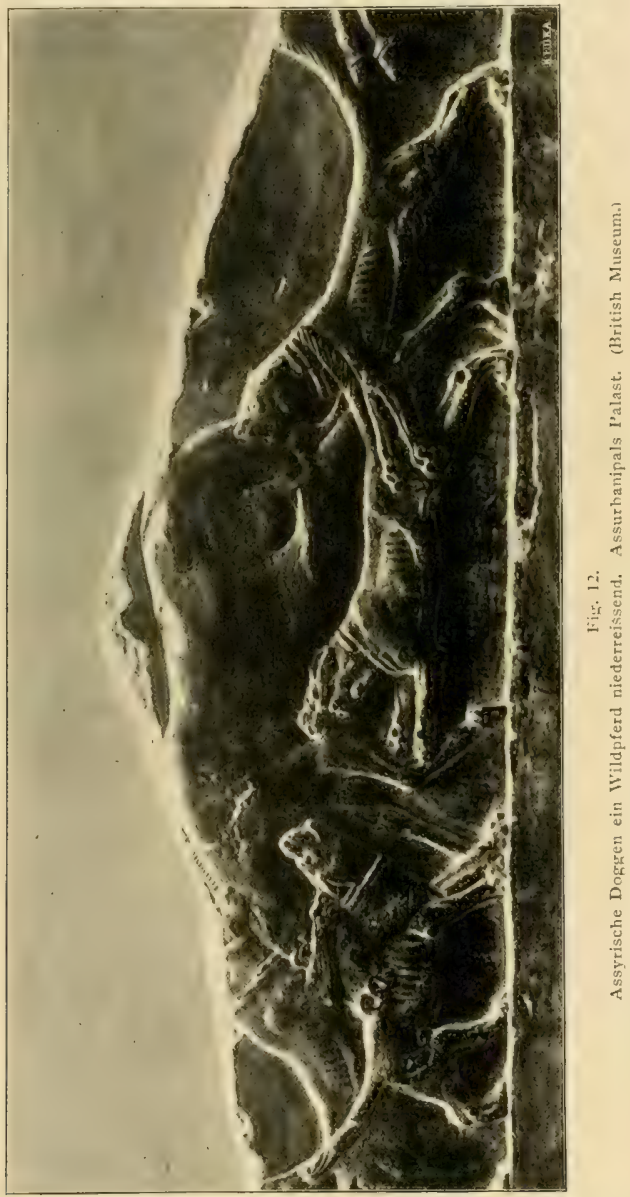

hunden oder hängeohrigen Laufhunden habe ich keinerlei Andeutungen auffinden können; der Lieblingshund der Babylonier und Assyrer war augenscheinlich eine mächtige Dogge von kraftigem Batu, an dem schweren Kopf sind die breiten Ilängeohren hoch angesetzt, die überschüssige Kopthaut 
crscheint in Falten gelegt. Eine ungemein charakteristische Darstellung der assyrischen Dogge findet sich auf einer Topfscherbe, die Colonel Razlinson aus Birs Nimrod mitgebracht hat und die sich gegenwätig im Besitz des British Museum befindet. $\left.{ }^{1}\right)$ Ebenso fanden sich vorzügliche Doggenbilder in Kujunschik als Basreliefs am Palast Assurbanipals, welche aus dem Jahr 668 v. Chr. stammen. Auf der einen Darstellung sehen wir den Auszug zur Jagd; ein Jïger schreitet mit den Jagdnetzen voran, hinter ihm folgt ein anderer. die jagdlustige Dogge an der Leine haltend. Ein anderes Basrelief führt uns eine Jagdszene vor, in welcher vier bissige Doggen ein Wildpferd niederreissen. es sind auffallend stumpfschnauzige IJunde mit langbehaarter Rute.

Schon Iforodot erwähnt, dass ein Satrap von Babylon die Einkünfte von vier Sitädten auf den Unterhalt solcher Hunde verwendete, was auf ihre grosse \%ahl schliessen litsst und Lalard fügt die Bemerkung himzu. dass sie von Indien eingeführtwurden. da bekanntlich heute noch an den Abhängen des llimalaya ind besonders in Tiluet grosse Doggen vorkommen.

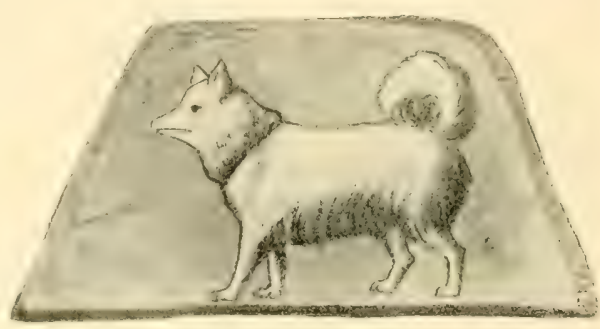

Liir. 13.

Aitriechischer spita. (Nach /I. Firamer.)

Eine zweite Inuderasse begegnet uns auf assyrischen Skulpturen bei Niniveh aus der Zeit von Sannacherib, von welchen Layad in seinem Atlas ${ }^{2}$ ) eine Abbildung geliefert hat. Diese Rasse steht der assyrischen Dogge an Grösse erheblich nach und scheint einen glatthaarigen Hund mit spitzer Schnauze darzustellen, der dem $W$ indhund nahe stelıt, der etwas schematisch gehaltenen Ausführung wegen aber mehr einem indischen Pariahund ähnlich ist.

In der klassischen Periode von Griechenland und lom wurde der Inndezucht sehr grosse Aufmerksamkeit geschenkt und neben der Reinzucht auch Kreuzungszucht betrieben. Man schente keine Opfer, um vom Auslande wertvolle Tiere einzuführen. In Griechenland genossen die epirotischen und lakonischen Hunde einen besonderen Ruf: die römischen Schriftsteller erwähnen Jagdhunde. I Iirtenhunde und IJothunde. Wir unterlassen es, die litterarischen Angaben der verschiedenen Autoren des Altertums hier im

1) Ein gut ausgeführtes 13ild gicbt 1 . II. Ialard in seinem "Discoveries in the Ruins of Niniveh and Babylon" auf pag. $52 \%$.

2) A. II. Luyard. A second series of the Momuments of Niniveh. London. 1853. Taf. 51. 
einzelnen aufzuführen, da sie uns über die Rassenverhältnisse doch nur sehr unvollkommen aufklären.

\%uverlässiger erscheinen die oft recht guten Rassenbilder auf altgriechischen Münzen, wobei die veröffentlichte Sammlung von Imhoof-Bhumer das ausgiebigste (Quellenmaterial liefert.

Der alte Spitzhund der Pfahlbauer tritt uns mit seinem charakteristischen Gepräge unverkembar entgegen, er wird mit aufrechter, starkbuschiger Rute abgebildet. Eigentliche Windhunde, denjenigen Aegyptens offenbar ganz nahe verwandt, erscheinen auf Münzen sizilianischer Städte: eine vorzügliche Darstellung findet sich auf einem Didrachmon von Panormos: die Ohren sind noch vollkommen aufrecht stehend.

Die Heimat des hochgeschätzten Molosserhundes (Canis molossus) dürfte Epirus gewesen sein, er ist nach seiner Einbürgerung in Europa dort zuerst gezüchtet worden, gelangte aber bald nach Italien. I)er wachsame, bissige Ilaushund, vor dem die Römer durch die Aufschrift .Cave canem " den Fremden zu warnen pllegten. war wohl ein Molosser. Columella hat davon die eingehendste Schilderung gegeben, aus welcher hervorgeht, dass es sich ım eine stark gebaute I ogge handelt, die dem T'ibethund am näclısten steht. Besonders beachtenswert ist es, dass er den mächtigen Kopf des Tieres hervorhebt (capite tam magno, ut corporis videatur pars maxima).

I3is vor kurzer Zeit war keine bildliche Darstellung des antiken Molosserhundes aus Griechenland oder Rom bekannt. Zwar ist die bekannte Statue des Tikias als Typus desselben angesprochen worden, indessen hat der verdiente Krnologe Max Sibr in seiner Monographie des Tibethundes Einwånde erhoben, die sicher berechtigt sind. ${ }^{1}$ ) Weder die Ohren noch clas gestreckte Profil am Kopf der Statue sprechen für den Molossercharakter: sodann sind die sehnigen Beine verhälnismässig schlank und nicht lang behaart, während Columella bei der Schilderung des Canis molossus ausdrücklich bemerkt: "Cruribus crassis et hirtis". Es unterliegt kaum einem 7weifel, dass die Statue des _Tikizs, von welcher Siber eine gute Abbildung gegeben hat, einen wolfartigen Hirtenhund (den Canis pecuarius der Römer) darstellt. Diese alte Rasse hat sich heute noch in Griechenland und in Albanien erhalten, ist auch in den Bergen Süditaliens heimisch, wo die Calabresen diesen Cane di pastore zum Bewachen ihrer Herden halten.

Erst kürzlich ist endlich in der römischen Kolonie Vindonissa auf mehreren Thonlämpchen ein vollständiges I Iundebild aufgefunden worden, das gut auf den antiken Molosser passt; das mehrfach wiederkehrende Bild stellt einen kräftig gebauten, hängeohrigen IJund dar, dessen Kopt im Profil stark gebrochen erscheint: der Körper erscheint langhaarig: die aufwärts gekrümmte, stark behaarte Rute erinnert stark an unsere Bernhardinerhunde. Die Originalbilder habe ich für die Sammlungen des schweizerischen Polytechnikums erworben.

1) Mux Siby. Der Tibethund. Winterthur. $189 \%$ 


\section{DAS VERHÄLTNIS DER ZAHMEN HUNDE-RASSEN ZU DEN HEUTIGEN WILDHUNDEN.}

Die vielumstrittene Frage der phyletischen Beziehungen unserer Haushunde hat im Laufe der Zeit manche Wandlungen durchgemacht. Ihre Beantwortung muss naturgemäss auf besondere Schwierigkeiten stossen, da es sich um das älteste Haustier handelt, dessen Domestikation zeitlich ausserordentlich weit zurückliegt, die Migrationswege sehr verschlungen sind und die unausbleiblichen Kreuzungen den phyletischen Ermittelungen grosse Hindernisse bereiten.

Im 18. Jahrhundert herrschte die Aufassung vor, dass alle zahmen Hunde monophyletischer Abkunft seien und Limé gab ihr dadurch bestimmteren Ausdruck, dass er sie unter dem Namen Canis familiaris zu einer besonderen zoologischen Spezies vereinigte. Es muss dies bei einem Anhänger der Konstanzlehre befremden, denn die Grössenverschiedenheiten dieses Haustieres sind ganz ausserordentliche. Isidore Geoffroy St. Hilairc hat später eine Liste der Längenmasse zusammengestellt und nachgewiesen, dass die grossen Gebirgshunde eine Länge von 1,33 Meter, die kleinsten Bologneserhunde nur eine solche von 0,22 Meter erreichen. Das Maximum beträgt also mehr als das Sechsfache des Ninimums. Nimmt man gar das Volumen, so übertreffen die grössten Rassen die kleinsten Hunde um das Zweihundertfache.

Auch Buffon ${ }^{1}$ ) hat an der Einheit der Hunde-Rassen festgehalten und deren Entstehung als das Produkt der Einwirkungen von Klima und Kultur erklärt; seiner Meinung nach bildet der Schäferhund die Stammrasse, für ihn ist dieser "le vrai chien de la nature".

Anderseits ist vielfach der Wolf als Stammvater des zahmen Hundes angesehen worden (Lupi cicures post multas generationes in Canes transeunt!). Güldenstädt $t^{2}$ ) ist meines Wissens der erste unter den Zoologen, welcher dieser Annahme entgegentrat (1776) und den Schakal als Stammform erklärte.

Cuvier, dem der Haushund mit seiner grossen Variabilität unbequem war, spricht sich nicht bestimmt über dessen Abstammung aus. Es hat heute keinen Zweck mehr, auf die zahireichen, aber recht ungenügend begründeten Hypothesen in der ersten Hälfte des 19. Jahrhunderts einzutreten; das Heranziehen der verschiedenartigsten wilden Arten als Stammväter drückte nur die allgemeine Ratlosigkeit und methodische Unzulänglichkeit aus, die Hundefrage richtig zu lösen.

Eine Wendung erfolgte durch Isidore Geoffroy St. Hilaire, ${ }^{3}$ ) der in

1) Buffon. Histoire naturelle. T. V. 1755.

2) Giildenstädt. Novi Conment. Acad. Sc. Imp. P'etropolit. p. a. 1\%55.

$\left.{ }^{3}\right)$ Isidore Groffroy St. Ifilare. Acclimation et domestication des animaux utiles. I'aris. 1861. 
einer für die damalige Zeit sehr lichtvollen Weise die Arteinheit des Canis familiaris bekämpfte und zudem hervorhob, dass die wilden Stammformen jetzt noch leben müssen; als solche betrachtete er neben den Schakalarten (Canis aureus und C. mesomelas) den abessinischen Wolf, freilich ohne genügenden osteologischen Beweis, sondern lediglich an der Hand von kulturhistorischen Thatsachen, Er steht also bereits entschieden auf dem Boden der polyphyletischen Richtung, die nun die allgemein herrschende wird und in jener Periode besonders nachdrücklich von $L$. Fitzinger betont wurcle. ${ }^{1}$ )

Dieser Autor steht zwar auf einem prinzipiell richtigen Boden, seine Ausführungen sind jedoch gänzlich verfehlt. Fitzinger nimmt nämlich nicht weniger als sieben Stammarten unseres Haushundes an (Canis domesticus. C. extrarius, C. vertagus, C. sagax, C. molossus, C. leporarius und C. caraibaeus); er betrachtet also beispielsweise unsere Spitze, Seidenhunde, Dachshunde. Bullenbeisser, Windhunde, als besondere Stämme, deren wilde Vorfahren aber nicht mehr leben, sondern in den domestizierten Formen völlig aufgegangen sind. Alle übrigen Hundeformen sind nach ihm nur Abänderungen, welche durch klimatische Einflüsse, durch geographische Isolierung, durch Kultur und namentlich auch durch Bastardierung entstanden sind. Er führt im einzelnen durch, was unvermischte Formen, einfache, doppelte und selbst dreifache Bastarde sind, verfällt aber dabei in eine morphologische Spielerei, der die nötige wissenschaftliche Unterlage fehlt.

Viel nüchterner hat Darwin in seinem bekannten Werk über das "Variieren der Tiere und Pflanzen im Zustand der Domestikation" die Frage aufgefasst und spätere Autoren, wie Feitteles, Woldrich und Th. Studer sind in ihren Beweisführungen ebenfalls strenger, in ihren Schlussfolgerungen vorsichtiger, indem sie namentlich auch die prähistorischen Thatsachen heranziehen.

Ist auch heute die Abstammungsfrage für jede einzelne Hundeform noch nicht gelöst, so sind wir, wie ich nachweisen werde, doch erheblich weiter gekommen.

Ich glaube, dass es methodisch am richtigsten ist, zunächst einzelne gut umschriebene Rassengruppen aufzustellen und für jede derselben die zugehörige wilde Stammart aufzusuchen. Solche gut zu charakterisierende Gruppen bilden beispielsweise die Spitzhunde, die Schäferhunde, die Pariahunde, die Windhunde und die grossen Ioggen.

Unter den wildlebenden Caniden, die sowohl über die alte wie neue Welt zerstreut sind, können wir von vorneherein eine grössere Zahl von der Stammvaterschaft des zahmen Hundes ausschliessen. Gar nicht in Frage kommen die Fuchsarten, schon wegen der vom Haushund völlig abweichenden Pupille und dem verschiedenen Schädelbau.

1) Leopold Fitzinger. Wissenschaftl-populate Naturgeschichte der Säugetiere. Wien. 1855-1861. Ferner: Der Hund und seine Rassen. Tübingen. 1876. 
Ebenso weinig sind der asiatische Canis primaevus und seine Verwandten an der Stammvaterschaft beteiligt, da alle diese Hunde nur 40 Zähne besitzen und daher auch als Gattung Cuon (Cyon) von den übrigen Caniden abgetrennt werden.

Es bleiben daher nur die Wölfe und Schakale übrig, da sie wie die domestizierten Hunde ein Gebiss mit 42 Zähnen und eine runde Pupillie besitzen. Bei den grösseren Arten wird die Anknüpfung bei den Wölfen, bei den kleineren bei den Schakalen zu suchen sein. Wir versuchen daher. die Entstehung der verschiedenen Rassengruppen klar zu stellen, wobei wir Bildungsherde in der alten wie in der neues Welt annehmen müssen.

\section{ABSTAMMUNG DER SPITZHUNDE.}

Diese Gruppe lässt sich zoologisch gut umschreiben und erscheint in Europa zu Beginn der neolitischen Zeit als sogenannte Palustris-Rasse. Alle Beobachter betonen, dass diese älteste Rasse Europas anfänglich merkwürdig konstant erscheint. Der sichädel erreicht nach Rütimejer eine Länge von 130-150 Millimeter, die Bezahnung ist relativ kräfig, die Nasenröhre auffallend eng. Einzelne Forscher haben auf Veränderungen hingewiesen, die der "Torfspitz" schon in den Pfahlbauten mit fortgeschrittener Kultur offenbar unter dem Einfluss der menschlichen Züchtungskunst erlitt. Jorab gebührt T\%. Studer das unbestreitbare V'erdienst, an der Iland eines reichen Materials ausreichend Licht in die Frage nach der Weiterentwicklung der Rasse gebracht zu haben. Ueber die Rassengliederung in der Pfahlbauzeit bemerkt der genannte Autor'): „Zunächst "wird in einer Richtung der Schädel grösser und kräftiger, die Jochbogen ..werden stärker und weiten sich aus. die Muskelleisten treten stärker her"vor, der I linterhauptshöcker wird höher und eine Scheitelleiste setzt sich „von da bis zu den Stirnbeinen fort. Diese Form steht aber nicht unver"mittelt gegenüber der Primitivform da, sondern Uebergangsglieder zwischen .beiden sind zahlreich vorhanden. Vergleichen wir aber die extreme Bildung „mit rezenten Rassen, so sehen wir, dass diese völlig mit unseren grossen .. Ilofspitzen, wie sie bald gelb, bald wolfsgrau oder auch weiss gefärbt in "den Bauernhöfen des bernischen Mittellandes gehalten werden, überein,stimmt mit einem Unterschied, der überhaupt bei prähistorischen Hunde„rassen gegenüber rezenten auffällt. Im allgemeinen ist nämlich bei prä..historischen Rassen die Nasenöfhumg niedriger als bei rezenten, und das "Nasenrohr enger, ebenso sind die Muskeln noch weniger kompliziert, das "Geruchsorgan ist also im Laufe der Zeit erst zu der Vollkommenheit, die "wir heute finden, ausgebildet worden."

.Neben dieser grösseren Rasse gingen aus dem Pfahlbautenspitz noch „zwei kleinere Rassen hervor. Beide Male geht mit dem kleinerwerden

1) T\%. Studer. Jeiträge zur (jeschichte unserer Ilunderassen. Naturw. Wochenschritt. 154-. 
"der Form die Erhaltung jugendlicher Charaktere am Schädel Hand in "Iland."

"In der einen Richtung sehen wir den I Iirnschädel sich erweitern, die „Knochenleisten verschwinden, die Stirngegend verbreitert sich, der Ge„sichtsteil setzt sich schärfer von den Hirnteilen ab und erleidet eine geringe "Verkürzung. Solche Formen treflen wir in der Station Lattringen. Noch "mehr fortgeschritten ist dieser Typus in einem Schädel von Bodmann: "der Hirnteil ist noch mehr erweitert, oben flach, während der Ilinterhaupts„höcker scharf vorspringt. Der verkürzte (jesichtsteil setzt sich noch ,schärfer vom Schädel ab, kurz der Schädel gewinnt den Typus unserer "heutigen kleinen Spitzhunde."

"Nach einer andern Richtung diflerenziert sich der Pfahlbauspitz dahin, "dass der Schädel mehr die jugendlichen Konturen annimmt, aber der "Gesichtsteil verkürzt sich weniger und setzt sich nicht so schroff von dem "Ilirnteile ab. Das Schädelgewölbe verlängert sich nach hinten und bewirkt. "dass der Hinterhauptshöcker, der schwach ist, sich erst weit unten ansetzt. "I)er Schädel nimmt, wie ein Exemplar aus der Station Lattringen zeigt. ,immer mehr den Typus des Pinscherschädels an. Die Züchtung kleinerer "Formen ist seit jener entlegenen Zeit immer weiter gegangen, und immer "mehr sehen wir, dass Zwergformen erzeugt werden, welche die Jugend„form des Schädels erhalten, und bei den extremen Formen des Zwerg"pinschers ist der Schädel gar auf dem Stadium des Embryos stehen ge„blieben. Der Ilirnschädel bildet eine clünne Knochenblase, an der sämt"liche Fontanellen otlen geblieben sind."

Soweit Studer, dessen Darlegungen sich wohl auf das umfangreichste Material stützen, das bisher zur Untersuchung gelangte.

Ueberblicken wir das aussereuropäische Gebiet, so fällt uns auf, dass spitzartige Hunde über gevaltige Erdräume verbreitet sind und zum Teil die Merkmale der alten Torfhunde heute noch fast unverändert forterhalten haben.

So fand Middendor $f$ in Sibirien bei den 'Tungusen einen kleinen, stehohrigen Spitzhund mit langen schlichten Haaren, in der Färbung vorn grau mit schwarz gemischt, auf der Unterseite weisslich. Der Schwanz wird in der Ruhe gestreckt oder nach unten gesenkt getragen. I)er Schädel besitzt ganz den Typus des Torfspitzes. I) gle glehe Rasse kommt auch bei den Samojeden und Tschutschken vor und zwar meist in weisslich-graner Färbung.

Südasien und der indische Archipel weisen neben dem halbwilden P'ariahund noch einen Haushund auf, dessen Schädel Studer an zuverlässigem Material untersucht hat.') Die Schädellänge der hieher gehörenden Battakhunde, die Mav Siher in Sumatra sammelte, schwankt zwischen 135-146

1) T\%. Studer. Der Hund der Battaks aul Sumatra. Schtveizer. Hunde-Stammbuch. Heft III. 1884. 
Millimeter, die Konfiguration des Schädels, wie auch des Gesamtskelettes liess einen dem Torfspitz ganz nahe stehenden Typus erkennen. Ganz ahnliche Hunde beobachtete Studer auf Neu-Irland im Bismarckarchipel und ich im Innern von Madagascar, wo der Malayenspitz möglicherweise von den Hova aus ihrer malayischen Urheimat eingeführt worden ist.

Nahe verwandt ist damit vermutlich der "T'schau" der Chinesen, für den Studer eine Schädellänge von 144-154 Millimeter angiebt. Ich finde an einem unlängst in meinen Besitz gelangten Tschauschädel aus Hongkong eine Basallänge von 154 Millimeter. Er besitzt im Gebiss und in der Beschaffenheit des Hirnschädels Spitzhundcharakter, die Muskelleisten sind kräftig, der Hirnschädel etwas in die Länge gezogen, der Schnauzenteil auffallend plump. Auffallend war mir an dem untersuchten Exemplar das an den Torfhund erinnernde enge Nasenrohr. Das betreffende Exemplar war dicht und vollkommen schwarz behart, die breiten Ohren aufrecht.

Der eigentümliche, kurz und dichtbehaarte, in den Beinen etwas niedrig gestellte Tschau der Chinesen gehört offenbar in den Palustris-Kreis hinein, ist aber, wie sich in einem Lande mit alter Kultur kaum anders erwarten lässt, durch lange Domestikation umgestaltet worden.

In Aegypten ist ein Spitz schon zur Pharaonenzeit abgebildet; $L$. $H$. Feitteles ${ }^{1}$ ) untersuchte einen altägyptischen Hundeschädel aus den Gräbern von Lykopolis mit schwach entwickeltem Ilinterhauptskamm und einer Basallänge von 141 Millimeter Länge; er betont seine nahe Verwandtschaft mit dem europäischen Torfhund. Inwieweit einzelne spitzartige Hunde Zentralafrikas und Südafrikas hieher gehören, bedarf zunächst noch einer besseren osteologischen Untersuchung.

Ueber ihre Verbreitung auf afrikanischem Boden hat MIa Siber ${ }^{2}$ ) in einer posthumen Monographie der Hunde Afrikas die bisherigen Angaben in erfreulicher $\mathrm{V}$ ollständigkeit zusammengefasst.

Wenn auch alles darauf hinweist, dass der alte, schon in der jüngeren Steinzeit vorhandene Torfhund, der sich im Norden Asiens fast unverändert bis heute forterhalten hat, die Stamm-Rasse der Spitzhunde darstellt und sich in seinen Abkömmlingen nach und nach fast über die ganze alte Welt verbreitete, so ist damit das Problem der Abstammung noch keineswegs völlig gelöst.

Der Torthund war ein zahmes Tier, das auf irgend eine Wildform zurückgeführt werden muss.

Es ist von "Woldrich ${ }^{3}$ ) versucht worden, einen diluvialen Wildhund Osteuropas (Canis Mikii), der Steppenfauna der postglazialen Zeit angehörig, als Stammform des Torfhundes nachzuweisen.

Es sind indessen zwei Momente, die mir gegen diese Annahme 7.1

t) I. II. Fcitteles. Die Stammväter unserer Hunde-Rassen. Wien. 187\%.

2) Max Siber. Die Hunde Afrikas. (Nach dessen Ableben herausgegeben) St, Gallen. 1844.

1) 7. . W. Woldrich. Mitt. der anthrop. Gesellschaft Wien. 1888. 
sprechen scheinen. Zunächst müssten die Reste diluvialer Wildhunde über weite Gebiete nachgewiesen sein, weun der Ueberschuss dieser Spezies an den Menschen als zahme Form abgegeben wurde; die bisherigen Funde sind nur spärlich. Sodam lässt sich der schwerwiegende Einwand erheben, dass der Haushund während der alteren Steinzeit durchaus fehlt und als auffallend beständige Rasse, ohne durch U ebergänge vermittelt zu werden. erst im Beginn der neolitischen Zeit erscheint.

Dies spricht dafür, dass der alte 'Torfhund weder auf mitteleuropäischem Boden, noch im Nordosten Europas zuerst gezähmt wurde, sondern aus einer anderen Region eingewandert ist. Da die Spitzhunde überall zu den kleineren Hunden gehören, die in primitiven Charakterformen über ein weites Areal zerstreut sind, so kann die Stammform ganz gut unter den heute noch lebenden kleineren Caniden zu suchen sein.

Schon im vorigen Jahrhundert hatte 1 . $\mathcal{F}$. Gïldenstädt ${ }^{1}$ ) auf Grund seiner eingehenden Studien in anatomischer und biologischer Hinsicht auf den Schakal (Canis aureus) als Stammvater hingewiesen. Er hatte seine Beobachtungen in den Kaukasusländern gemacht, wo der Schakal nach den kürzlich veröflentlichten Angaben von Radde ) jetzt noch häufig vorkonmt. Güldenstädt bemerkt ungemein zutreffend, dass sich der Schakal dem Menschen der Urzeit als Begleiter und Haustier förmlich aufgedrängt habe, da er wenig scheu ist und dem Menschen auf seinen Zügen gern folgt, um Abfälle zu erhaschen. Wer Schakale in der freien Natur beobachtet hat, wird deren Zudringlichkeit nur bestätigen können. Er geht darin allerdings zu weit, dass er alle zahmen Hunde auf den Schakal zurückführen will (ex qua omnes quae nunc existunt, Canis varietatis ortum duxerunt).

Kurz nachher gelangte Pallas zu ähnlichen Ansichten, glaubt jedoch, dass gewisse Rassen durch Kreuzung mit anderen wilden Caniden entstanden sind.

Isidore Geoffroy St. Hilaire betont, dass zwischen Schakal und den kleineren Hundeformen keine konstanten anatomischen Unterschiede vorhanden sind.

Allgemein wird bestätigt, dass junge Schakale dem Menschen sich sehr leicht anschliessen und ihm auf seinen Ruf folgen. Auch gewisse äussere Eigentümlichkeiten verraten beim Spitz eine grosse Aehnlichkeit mit dem Schakal. Wenn ein Spitz mit gesenkter Rute dem Menschen scheu ausweicht und dabei den Kopf vorsichtig umwendet, so ist dies Benehmen völlig schakalartig. In der Ostschweiz bin ich sehr oft Spitzhunden begegnet, deren Färbung völhig schakalähnlich ist. Das sind jedoch Aeusserlichkeiten, die noch nicht streng beweisend sind.

Man hat auf die verschiedene Trächtigkeitsdauer zwischen Hunden

1) Güldenstädt. Novi Commentarii Acad. Scient. Imp. Petropolit. Tom. XX pro anno 1775.

2) G. Radde. Die Sammlungen des kaukasischen Museums. Tiflis. 1899. 
und Schakalen hingewiesen, doch ist dieser Einwand von Darzin entkräftet worden, ${ }^{1}$ ) da er auf irrigen Angaben beruht. Die Trächtigkeitsdauer beträgt bei kleineren Hunderassen 60-63 Tage, beim Schakal 63 Tage; die Uebereinstimmung ist also so vollkommen als möglich. Mehrfach ist behauptet worden, der Schakal belle nicht. Zahlreiche Angaben beweisen aber das Gegenteil und Raddc, der wohl sehr zuverlässig ist und jahrelang im Kaukasus gelebt hat, sagt von den dortigen Schakalen: „In Borshom bestand ein Rudel Schakale die Höhen. Allabendlich hörte man von dorther ihr winselndes und bellendes Heulen."

In der neueren Zeit ist L. II. Feitteles') besonders lebhaft für die Abstammung des Torfhundes und der Spitzhunde von Canis aureus eingetreten, der ich mich auf ( jrund osteologischer Thatsachen vollkommen anschliessen muss.

Aus den zoologischen Sammlungen der Universität München erhielt ich durch die Freundlichkeit von Prof. Richard Hertaig eine Serie von Schakaischädeln verschiedener Provenienz (Algier, Griechenland, Kaukasus. Indien), die ich mit Torfhundschädeln vergleichen konnte.

Unter sich verglichen, zeigen die sichakalschädel nicht unerhebliche V'erschiedenheiten bezüglich der Ilöhe der Schädelleisten, der Wölbung des Ilinterschädels. der Stirnbreite und Sichnauzenbreite. So ist der indische Schakal spitzschnauziger als der kaukasische und griechische Schakal. Wir haben also mit einer gewissen Variationsgrenze zu rechnen. Dieselbe ist besonders hoch bei der Länge des harten Gaumens.

Indessen zeigt doch die Gesamtkonfiguration eine auffallende Uebereinstimmung mit dem Torfhund, wie denn auch beispielsweise der kaukasische Schakal in seinen Schädelmassen sich im Rahmen der von Rä̈imeyer angegebenen Palustris-Masse bewegt.

Ich finde nämlich:

Canis Canis fum. aureus palustris

(a.d. Kaukasus) (n. Rïlineyer)

1. Schädellänge vom Foramen magnum bis zu den Incisivalveolen IIIII

2. Vom Hinterhauptskamm bis zum hintern Ende Nasalia .

1.37

$1.30-150$

3. Vom Foramen magnum bis zum Hinterrand des harten Gaumens

4. Lïnge der Nasenbeine . . . . . . .

5. Jochbogenbreite . . . . . . . .

6. Grösste Breite am Alveolarrand des ()berkiefers

$\begin{array}{cc}64 & 57-64 \\ 51 & 47-54 \\ 91 & 92-97 \\ 55 & 51-59 \\ 116 & 110-120\end{array}$

7. Unterkieferlänge

Ho

\footnotetext{
2) C. Darwin. Das Varieren der T'iere und P'llanzen im Zustande der I omestikation. 1873.

$\Rightarrow$ L 11 . Foitteles, Die Stammïter unserer Hunde-Rassen. 18\%
} 
Wir ersehen aus diesen Zahlen, dass eigentlich nur die Jochbogenbreite :n der unteren Grenze. die Basis des Hinterschädels aber an der oberen Grenze bleibt, was augenscheinlich der gleichen mechanischen Ursache zu verdanken ist, denn der Einfluss der Domestikation hat den 'Torfhundschädel im Hirnteil gewölbter gemacht, die Verkürzung der Schädelbasis die Jochbogen um weniges weiter gemacht.

Das kräftige Gebiss des Schakals zeigt mit dem Torfspitz und unseren heutigen Spitzhunden die grösste Uebereinstimmung; ebenso finde ich das für den Torfhund so charakteristische enge Nasenrohr in gleicher Weise bei allen Schakalen.

Der Habitus des kaukasischen Schakalschädels scheint mir demjenigen des 'Torthundes am nächsten zu stehen, auch der algerische weist engere Beziehungen auf, etwas mehr scheint sich die indische form zu entfernen.

Wie nahe der Schakal des Kaukasus dem älteren Torfhund steht. beweist ein Vergleich mit einem sehr gut erhaltenen Torfhundschädel aus der I'fahlbaustation Robenhausen, der in der zürcherischen Sammlung vorhanden ist:

$\begin{array}{cc}\text { Canis } & \text { Canis fam. } \\ \text { aureus } & \text { palustris }\end{array}$

1. Basilarlänge des Schädels vom For, mágnum bis zu den sichneidezähnen.

(a. d. Kaukasus)(v.Robenhausen $)$

2. P’rofillänge . . . . . . . 158

140

$137 \quad 140$

3. Grösste Breite der Parietalregion . . . $50 \quad 50$

4. Jochbogenbreite . . . . . . . . . . 8 93

5. Schnauzenbreite vor den For, infraorbit. . 3132

6. Breite des Nasenrohres. . . . . . . . 18 is

7. Grösste Gaumenbreite . . . . . . . 4242

8. Gaumenlänge . . . . . . . . . . . . . . . . . . . . . .

9. Unterkieferlänge . . . . . . . . . . 116

10. Länge des untern Fleischzahnes . . . . 19

Die Messungen ergeben also die grösstmöglichste Uebereinstimmung, die ja zum Teil eine absolute ist. Der einzige nennenswerte Unterschied besteht bei dem Robenhauserschädel in einer stärkeren Entwicklung des Sinus frontalis, wodurch die Stirnregion gegenüber dem Schakal stärker aufgetrieben erscheint.

Ueber den Bildungsherd der altesten zahmen spitzhunde sind wir ledigrlich auf Vermutungen angewiesen. Da der Schakal als wilde Stammform bei seiner Fruchtharkeit und Zudringlichkeit durch die menschliche Kultur wohl kaum sehr stark zurückgedrängt wurde, so werden wir die erste Zälımung in dem heutigen Verbreitungsgebiet zu suchen haben. Dasselbe ist nun 
allerdings sehr ausgedehnt und erstreckt sich von Indien über Persien, die Kaukasusländer, Kleinasien, Arabien bis nach Nordafrika und Südosteuropa. Osteologische Gründe deuten darauf hin, dass der alte Torfhund zuerst in den östlichen Mittelmeerländern gezähmt wurde. Die enge Beziehung des Torfhundschädels zu der kaukasischen Form des Schakals macht es sehr wahrscheinlich. dass das westliche Asien das Stammland der altesten Spitzhundformen ist. Dasselbe liegt so auch ziemlich im Zentrum des V'erbreitungsgebietes der altweltlichen spitzhunde.

Für die Spitzhundgruppe ergiebt sich daher folgender Stammbaum:

Chinesischer Tschau Battakhund
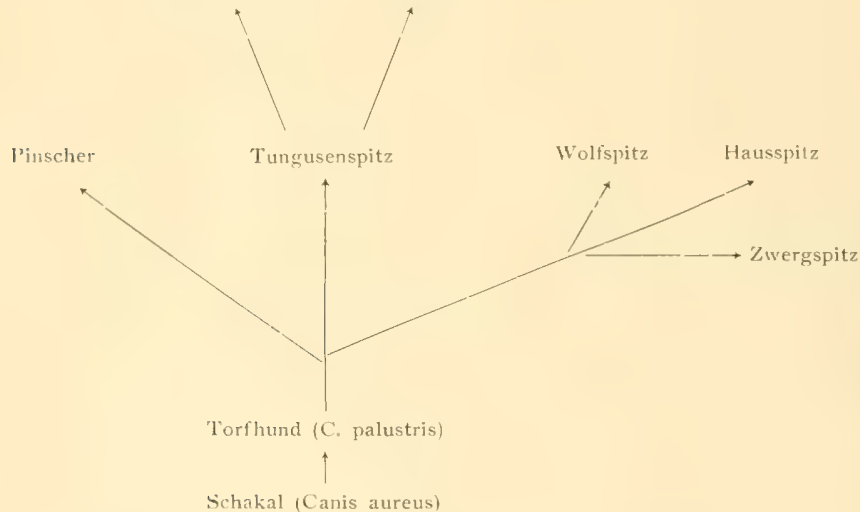

\section{DIE ABSTAMMUNG DER SCHÄFERHUNDE.}

Mit der wünschenswerten Sicherheit ist die Herkunft derselben zur Zeit noch nicht festgestellt. Schon Buffon hat den primitiven Charakter der Schäferhunde richtig hervorgehoben; er spricht sich besonders in dem gleichmässigen Körperbau, in der geringen Neigung zu variieren aus. Die Ohren sind noch aufrecht, an der Spitze leicht umgebogen; der stark behaarte Schwanz wird etwas eingezogen getragen.

Die Schäferhunde erscheinen in Europa etwas später als die Spitzhunde, d. h. erst mit der Bronzezeit, da die Hebung der Viehzucht einen Ilerdenhund zur Notwendigkeit machte. Diese Art der Verwendung ist ihm in der Folge geblieben.

Feitteles hat auf Grund des osteologischen Vergleiches nachgewiesen, dass der von ihm aufgefundene bronzezeitliche Canis matris optimae der direkte Vorläufer der heutigen Schäferhunde ist, eine Ansicht, die sich allgemein eingebürgert hat. 
Schwieriger gestaltet sich die Beantwortung der Frage, welche wilde Canidenart als Stammform des Bronzehundes angesehen werden muss.

Anfänglich neigte er dahin, den amerikanischen Prairiewolf (Canis latrans) als Stammquelle aufzufassen. Aeusserlich betrachtet, haben die nordischen Schlittenhunde, wie ich aus $N$ ansens Abbildungen ersehe, ebenso die Eskimohunde eine unverkembare Aehnlichkeit mit den Schäferhunden. aber auch mit dem Prairiewolf. und man könnte dadurch auf eine nordischamerikanische Urheimat des circumpolar verbreiteten Eskimohundes und Schäferhundes von Mitteleuropa geführt werden.

Feitteles bemerkt aber, dass er nachher von der amerikanischen Herkunft des Bronzehundes abgekommen sei; da sich zwischen diesem und Canis latrans trotz der allgemeinen Aehnlichkeit im Schädelbau Abweichungen in den Längenverhältuissen des Gaumens, im Verlauf der Oberkieferränder und in der Stellung der Backenzähne ergeben haben. I agegen fand er eine grosse Uebereinstimmung mit dem indischen Wolf (Canis pallipes), den er als Stammvater anspricht und vermutet, dass dessen 1)omestikation im alten Iran erfolgt sei.

Eine Wiederaufnahme der Untersuchungen ist wünschbar und es wäre vielleicht angezeigt, das Verhältnis der Bronzehunde und Schäferhunde zu den grösseren nordischen Hunden und den Prairiehunden aus verschiedenen Lokalitäten einer erneuten Prüfung zu unterziehen.

Unter den modernen Schäferhunden ist der auch auf dem Kontinent stark verbreitete Collie Schottlands wohl die am meisten verfeinerte Form.

Der Pudel scheint erst in historischer Zeit in Südeuropa durch Umzüchtung aus dem Schäferhund hervorgegangen zu sein, wobei der Gesichtsschädel eine Verkürzung erfahren hat. Fitzinger giebt an, dass kleinere Pudel den Römern bekannt waren, von den alten Deutschen aber noch nicht gehalten wurden und der grosse Pudel bei uns erst im 16. Jahrhundert durch Conrad Cressner nâher bekannt wurde.

\section{DIE ABSTAMMUNG DER PARIAHUNDE.}

Ueber den ganzen Tropengürtel der alten Welt zerstreut leben eigentümliche, unschöne Iunde, die vielfàch lokale Abweichungen erkennen lassen, in ihrem gesamten Typus jedoch an unsere Spitzhunde erinnern.

Nach dem Vorgang der Engländer nennt man sie Pariahunde, weil sie meistens verachtet werden, die Holländer in den indischen Kolonien gaben ihnen den Namen "Glattaker". Es sind verwahrloste, hässliche, schlecht domestizierte Hunde, die durch ihr nächtliches Geheul unangenehm sind, als herrenlose Geschöpfe einen scheuen Charakter besitzen und in der Nähe der menschlichen Wohnungen leben, von einzelnen Stämmen gelegentlich zur Jagd verwendet werden.

Nach Max Siber, ${ }^{1}$ ) der ihnen wohl am meisten Aufmerksamkeit ge-

1) Max Siber. Der Battakhund. Schweiz. Hundestammbuch. Heft II. 1886. 
schenkt hat, sind die indischen Pariahunde stehohrig. Das Gesicht verrät wenig Intelligenz, die Färbung ist vorwiegend unschön rotgelb. Sie sind nicht nur auf das indische Festland beschränkt, sondern kommen auch auf der I Ialbinsel Malakka in Siam vor. Auf Ceylon sind sie in den Besitz der primitiven Weddavölker übergegangen. Nach den Angaben von Paul und Fritz Sarasin ${ }^{1}$ ) unterscheidet sich der Weddahund, der als einziges Ilaustier bei der Jagd verwendet wird, in keiner Weise vom Paria des indischen Festlandes.

Die Rasse lebt auch auf Java und Sumatra, nach mündlichen Erkundigungen reicht sie sogar bis nach den Philippineninseln.

Der IHund von Neuguinea gehört nach den mir zugänglichen Abbildungen zu urteilen, ebenfalls in den Pariatypus hinein. Finsch nennt den Papuahund dingoartig mit spitzen Ohren und stark gekrümmtem Schweif. B. Hagen²) vergleicht ihn nach Grösse und Gestalt einem langgezogenen, kurzhaarigen P'inscher mit etwas längeren Ohren und einem mehr oder weniger geringelten Schwanz: die Farbe nennt er gelb. Ier Papuahund wird als Speise sehr geschätzt. Der gleiche Autor sagt von dem Ilund des Bismarcharchipels, dass er etwas vom Ijingo habe.

Es ist naheliegend, auch den bekannten I)ingo Australiens diesem Formenkreise anzugliedern, wofür Studer osteologische Gründe anführt.

Hinsichtlich der Abstammung der Pariafamilie muss darauf lingewiesen werden, dass vielorts von einer reinen Rasse kaum die Rede sein kamn. Aus den Reiseberichten geht hervor, dass dic Eingeborenen vielfach mit yrosser Begier fremde Hunde zu erwerben suchen und Kreuzungen bilden dann ganz natürliche Folgeerscheinungen. Die Pariahunde, wenn auch schlecht domestiziert, haben sich jedenfalls dem Menschen frühzeitig angeschlossen. Einige Winke über den Bildungsherd giebt vielleicht der seit langer Zeit verwilderte Dingo Australiens. Aus tiergeographischen Gründen müssen wir amnehmen, dass dieser Ilund in alter Zeit importiert wurde; er wanderte offenbar mit der australischen Menschenrasse ein. Es ist nun ziemlich sicher und durch die anthropologischen Untersuchungen von Paul und Fritz Sarasin neuerdings wieder evident dargethan worden, dass die Australier aus der dravidischen Bevölkerungsschicht in Indien hervorgegangen sind und von hier aus ihren Weg üher die indische Inselwelt nach Australien genommen haben. Als Jägervölker nahmen sie offenbar den Dingo mit. Es steht daher zu vermuten, dass altdravidische Völker Indiens den P'ariahund zuerst besessen haben. Die osteologischen Befunde stehen damit im Einklang.

Th. Studer, welcher den Paria aus Sumatra nach seiner Schädelbeschaffenheit zu untersuchen Gelegenheit hatte und die einzelnen Masse mitteilt, hebt als Eigentümlichkeiten den langen Hirnteil, die wohl entwickelte

1) Paul und Fritz Sarasin. Die Weddas von Ceylon. Wiesbaden. 1893.

2) B. Hagen. Unter den Papuas. Wiesbaden. 1899. 
Crista parietalis und die mässig breite Stirn hervor. Als Schädellänge wird 146 Millimeter und als Profillänge 165 Millimeter angegeben. Er findet eine nahe Verwandtschaft \%wischen dem Pariahund und dem indischen Schakal, von welchem rostrote Exemplare vorkommen. Auch der australische Ingo zeigt ihm nach der Schädelbeschaffenheit nahe V'erwandtschaft mit dem Paria, nur ist der Charakter etwas primitiver.

Aber nicht nur im Osten. sondern auch in Westasien und in Afrika begegnen uns herrenlose, schlecht domestizierte Pariahunde.

Die Strassenhunde Syriens und Konstantinopels, dann die agyptischen Strassenhunde sind zunżichst zu erwähnen. A if clem Isthmus von Suez konnte ich sie in Ismailja näher beobachten, sie sind etwas länger behaart als die indischen Paria, ebenfalls stehohrig und von rostgelber Färbung; die etwas buschige Rute wird hängend getragen. Ganz ähnliche Hunde kommen auch im Sudan vor; ich gebe hier eine Abbildung nach einer photographischen Aufnahme. Die Niamniam und die Bewohner von Uganda und Unyoro besitzen ảhnliche IIundeformen. Am roten Meer trifft man sie selten, im Innern der Somalilander habe ich sie nirgends angetroffen, dagegen kommen sie bei den Galla in der Umgebung von Harrar vor, wahrscheinlich durch die ägytische Ilerrschaft seiner / ceit dorthin verptlanzt. Pariahunde werden auch für Zanzibar und J)ar es Salam angegeben; die Hunde des Kongogebietes, die als stehohrig und von gelblicher oder gelblichweisser Farbe beschrieben werden, gehören offenbar in diesen Formenkreis hinein.

Diese westlichen, afrikanischen Pariahunde mit ihrem schäferhundartigen I Iabitus weichen offenbar vom indischen Paria erheblich ab: sie haben eben eine andere Stammquelle.

Schon Rob. Flartmann ${ }^{1}$ ) wies auf die Achulichkeit mit dem grossen Schakal des Nilthales (Canis anthus) hin: in bestimmter Weise wurde dieser als Stammvater der ägyptischen Strassenhunde von feitteles ${ }^{2}$ ) bezeichnet, was ich auf Grund eigener Untersuchungen für vollkommen richtig halte.

Die reinste Pariaform lässt sich am oberen Nil erwarten, da dort die Gelegenheit, sich mit fremden Rassen zu vermischen, nicht so häufig ist wie in Unterägypten. Ich bin nach vielen Bemühungen in den Besitz des Schädels einer Pariahündin gelangt, die aus dem ägyptischen Sudan (weisser Nil) stammt und lebend nach Zürich gelangte. Der Schädel weicht vom afrikanischen Canis aureus so erheblich ab, dass ich nähere verwandtschaftliche Beziehungen zu demselben ablehnen muss. I)er Scheitelkamm ist bei diesem weiblichen Exemplar auffallend kräfticg entwickelt, die Stirngegend breit und aufgetrieben, so dass die Profillinie ganz anders verläuft als beim Schädel des kleinen Schakals und von der Stin zur Schnauze stark abfällt. Der Schnamenteil ist nicht so fein wie beim Canis aureus.

1) R. Ilartmann. Die Haussäugetiere der Nilländer. Innalen der Landwirtschaft. IS64.

) L. II. Feitteles. Die Stammväter unserer Hunde-Rassen. 18; $;$. 
Dagegen erscheint die Uebereinstimmung mit dem von Gray abgebildeten Schädel von C. anthus, sowie mit dem nubischen Schakalwolf, mit dem ich den sudanesischen Paria-Schädel verglich, sehr gross. Letzterer kommt mit einer Basilarlänge von 160 Millimeter und einer Profillänge von 186 Millimeter, Dimensionen, die das Schakalschädelmass weit überschreiten, dem Canis anthus näher.

Auch physiologische Momente sprechen sehr für diese Abstammung. Die Strassenhunde, vom Menschen vernachlässigt, leben besonders während

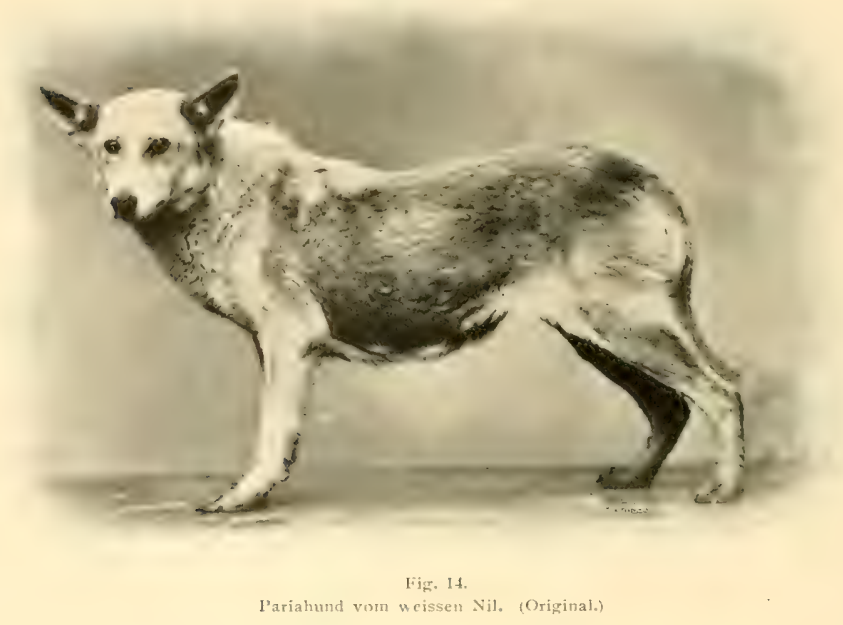

der Nacht in Rudeln beisammen; diese Gewohnheit wird auch für C. anthus angegeben.

Die Strassenhunde haben cine Vorliebe für Aas und finden dies selbst. wie sich an der Sudanhündin konstatieren liess, aus Kehrichthauten heraus. Die Liebhaberei für das findet sich auch beim Schakalwolf.

Letzterer hat als Wildhund die Gewohnheit, sich in der Erde Löcher zu graben; die in Zürich gehaltene sudanesische Pariahündin grub sich in wenigen Minuten unter der Thürschwelle einen Weg ins Freie. Nehmen wir dazu noch morphologische Uebereinstimmungen mit C. anthus, wie der kräftige Körperbau, die breite Stirn, die grossen und breiten Ohren, dann die bis zu den Fersen reichende, hängende Rute, so kann über die Abstammung kaum noch Zweitel herrschen. 


\section{DIE ABSTAMMUNC; IOER ITTNIOHLNIDE LNI) IIRER VERWANITEN.}

Nach der äusseren Erscheinung wie auch mit Bezug auf den anatomischen Bau bilden die ächten Windhunde eine ungemein scharf umschriebene Rassengruppe. Der magere Körper, in der Bauchgegend hoch aufgezogen, besitzt eine unverhältnismässig starke Entwicklung der Brustorgane; die Glieder erinnern wegen ihrer auffallenden Höhe und Zierlichkeit an die Antilope; der fein gebaute Kopf ist in eine lange Schnauze ausgezogen: der lange, meist kurz behaarte Schwanz wird anders getragen als bei den übrigen Hunden, entweder wird er nach Art einer Balancierstange gestreckt oder auch gesenkt oder gar eingezogen und heim altagyptischen Windhund wurde derselbe geringelt. Die dichte Behaarung ist in der Regel kurz und glatt, doch giebt es auch Windhunde mit langer, zuweilen struppiger Behaarung.

Es braucht ein nur halbwegs geschultes anatomisches Empfinden, im sofort heraus zu fühlen, dass der scharf, ja extrem ausgebildete zoologische Charakter der Windhundgruppe auf eine von allen anderen Haushunden abweichende Abstammung hindeutet. Ueber dieselbe herrschte noch bis in die jüngste Zeit eine auffallende Unklarheit. Ich habe kürzlich versucht, die Herkunft aufzuhellen und glaube, da im Grunde genommen die Sachlage viel einfacher ist, als man bisher annahm, dieses Abstammungsproblem endgültig gelöst $\mathrm{zu}$ haben.

Der psychische Charakter der Windhunde giebt uns einige Winke. Ihre ewige Unruhe und unstätes Wesen, ihr leichtes Orientierungsvermögen deutet auf die Steppe als ursprüngliches Wohngebiet. Damit steht auch der elegante, antilopenartige Bau des Körpers in voller Uebereinstimmung: Jie Emptindlichkeit ugegen Kälte, die sich bei manchen Windspielen heim Eintritt der kühlen Witterung durch ein häufiges Zittern des Körpers deutlich bemerkbar macht, deutet auf die warme, tropische Steppe als Stammland hin.

Das relative späte Erscheinen der Windhunde in Europa und Asien scheint diese beiden Erdteile von irgend welchem Anteil an der Erzeugung zahmer Windhunde auszuschliessen, so dass Afrika als deren älteste Heimat wahrscheinlich wird. In der That ist es von jeher aufgefallen, dass im Nilthal schon während der ältesten Dynastien stattliche Windhunde von den Pharaonenleuten ungemein häufig als Haustiere gehalten wurden und besonders bei der Jagd auf Antilopen Verwendung erfuhren.

Die altägyptischen Künstler haben uns vortreffliche Darstellungen dieser Tiere hinterlassen.

Es ist sehr bemerkenswert, dass schon Isidore Geoffroy St. Hilaire trotz seiner ausgesprochenen Neigung, alle unsere Haustiere aus Asien herzuleiten, vor dem Windhund Halt macht und ihn afrikanischen Lrsprungs erklärt. 
Er geht sogar noch einen Schritt weiter und vermutet, dass der von lï̈ppel cntdeckte Wildhund Abessiniens, der spitzschnauzige abessinische Wolf oder Canis simensis Rüppel, als Stammform angesehen werden könne und dass der altägyptische stehohrige Windhund eine Zwischenform zwischen jenem Wildhund und unseren europäischen Windspielen darstelle. ${ }^{1}$ )

Diese Iypothese wurde jedoch ungenügend begründet, vor allen I)ingen hat Isidore Geoffroy St. Hilaire den unerlässlichen anatomischen Nachweis nicht geliefert, er scheint namentlich genauere Schädelanalysen nicht ge-

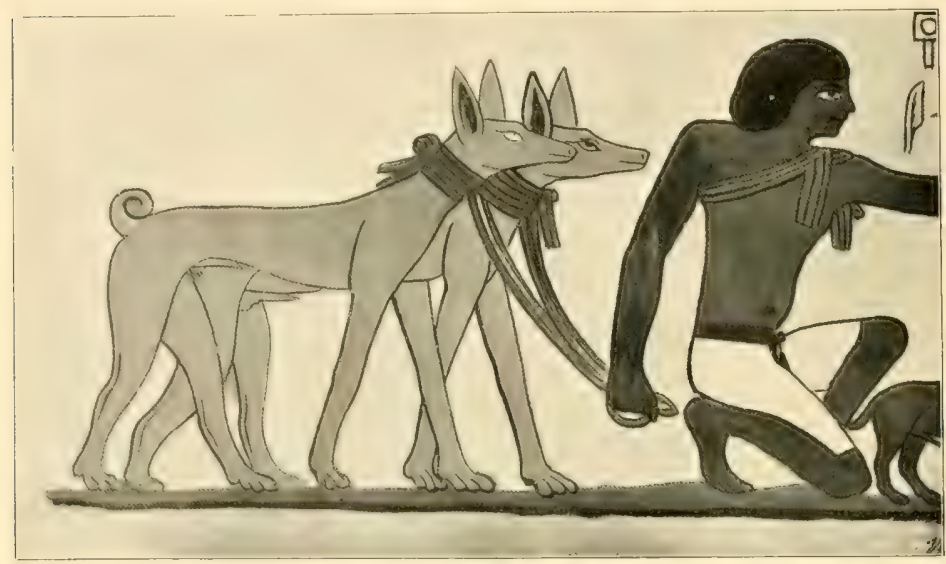

lig. 15 ,

Altügyptischer Windhund. Aus dem Ti-Grah. V. Dynastie. (Sakkarah.)

macht zu haben. Es ist dies wohl ein Grund, warum später Darwin diese Hypothese nur mit grosser Zurückhaltung in sein Werk aufnahm.")

Ausserhalb Frankreich ist sie spater entweder ganz verlassen oder geradezu bekämpft worden. Lcopold Filzinger stimmt wohl einer polyphyletischen Abstammung der I Iunderassen zu, nimmt auch eine besondere Stammform für die Windhunde an, stellt sich aber auf den Standpunkt, dass diese in toto domestiziert worden sei. als Wildform somit nicht mehr vorhanden ist. Ich habe schon früher das Unhaltbare einer solchen Theorie nachgewiesen.

Ein anderer österjeichischer Forscher, L. H. Fcitteles, dessen Autorität

1) Isidore Geoffroy St. Milaire. Acclimatation et domestication des animaux utiles. Paris. 1861. P'ag. 217 .

") Charles Darain. Das Variieren der Tiere und P'llanzen im Zustande der Domestikation. 13d. 1 . 
auf diesem Gebiete in weiten Kreisen anerkannt wurde, unterzog die Hypothese der Ableitung der Windhunde von Canis simensis einer erneuten Prüfung, ${ }^{1}$ ) wie es scheint an der Hand von Schädelanalysen. Er verwirtt sie in der allerbestimmtesten Weise, indem er zu dem Schluss gelangt, Canis simensis ,kann jedoch unbedingt nicht als beteitigt an dor Bildung. "zahmer Hunde betrachtet werden, da sein Schüdel gileich dem des Buansu "zon dem aller Haushund-Rassen ganz zerschicden ist. Uffentiar hatle "Geoffroy St. Hitaire nicht Gelegenheit gehabt, Schädel des Canis simensis "genauer zu untersuchen und mit solchen von Windhunden im cinzeluen "zu vergleichen".

Schliesslich gelangt feitteles zu dem Ergebnis, class der IVindhund zwar afrikanischen Ursprungs sei, aber von der zarteren Spielart des /)ib (Canis anthus) abstamme.

Später ist auch Th. Studer der Frage nach der Abstammung der Windhunde näher getreten.. ${ }^{2}$ ) Auch er betont eine südliche llerkunft. Auf Grund seiner Untersuchungen an Schädeln des Pariahundes finder er zunächst eine nahe Verwandschaft desselben mit dem indischen Schakal, anderseits aber verwandtschaftiche Inklänge an die heutigen Windhunde. "Der "Iauptunterschied zwischen Paria- und Windhundschädel beruht in Ge"sichtsteil, der schmäler und gestreckter beim Windhunde ist." Somit würde der indische Schakal die Stammform darstellen, aus welcher sich zunächst der Pariahund und aus diesem später der Windhund entwickelte. Die ursprüngliche Ileimat wäre daher Südindien, was Studer in folgenden Worten ausdrückt: „Im südlichen Asien, südlich den grossen Gebirgsmassen war , ein anderer Canide, vom Habitus der jetzigen indischen Pariahunde vom n.Menschen gezähmt worden. Derselbe, auf den Inseln und in den bewaldeten "Gebieten von Indien seinen ursprünglichen Charakter bewahrend, gestaltete "sich, in die Steppen und Wüsten Irabiens und Persiens verptlanzt, zu "einer schlanken, behenden Windhundform um, geeignet, das flüchtige Wild "der Steppe zu verfolgen."

Ich befinde mich auf Grund meiner Untersuchungen im Gegensatz zu Feitteles und Studer.

Wenn Feitteles die Windhunde vom afrikanischen Dib (Canis anthus) abzuleiten versucht, so kann man ihm gewichtige anatomische Gründe entgegenhalten.

Ich habe neben der Gray'schen Abbildung den Schädel von C. anthus der Nünchener Sammlung mit Windhundschädeln genau verglichen. Aber der aus Nubien stammende Dibschädel zeigt im Gegensatz zu diesen einen kräftigen Bau, eine breite Schnauze und eine so starke Auftreibung in der

1) I. II. Feitteles. Die Stammväter unserer Hunde-Rassen. Wien. 1877 .

2) Th. Studer. Der Hund der Battaks auf Sumatra. Sichweizerisches Hunde-Stammbuch. Heft 111. St. Gallen. 18sy. 
Stirnzone, dann ein so auffallend kräftiges Gebiss, dass von einer näheren Verwandtschaft gar keine Rede sein kann.

Gegenüber Th. Studer muss ich betonen, dass Pariahunde und reinrassige Windhunde offenbar ganz verschiedene Stammquellen haben. Bei letzteren ist eine so auffallende Streckung des Gesichtsschädels vorhanden, dass ich gar nicht einsehe, welche mechanische Ursachen den Pariaschädel in diese Form umwandeln konnten. Wir sehen im Gegenteil, dass die Domestikation bei Hunden sowie auch bei anderen Haustieren zur Verkürzung des Gesichtsschädels führt, die schliesslich in einer eigentlichen Mopsbildung endigt. Muss daher, ob wir vom Dib oder vom l'ariahund ausgehen wollen, eine Streckung des Schädels bis zur Windhundform als ganz unwalırscheinlich erklïrt werden, so bleibt nur noch der einzige Ausweg, diese Erscheinung durch Abstammungsverhăltnisse zu begründen. Dann bleibt allerdings nur eine wilde Canidenart übrig, deren Schädel extrem gestreckt ist und das ist Canis simensis, den man in der neueren Zeit allgemein als Stammquelle abgelehnt hat.

Ich glaubte daher, den Schädel des abessinischen Wolfes nochmals genauer untersuchen zu sollen und habe unlängst über das Ergebnis einen vorläufigen Bericht veröffentlicht. ${ }^{1}$ )

Ich finde zunächst, dass $L$. I/. Feittcles offenbar ein Irrtum unterlaufen ist. Aus seinen Angaben muss geschlossen werden, dass er Schädeluntersuchungen vorgenommen hat und bei Canis simensis ähnlich wie beim indischen Buansu ein vom Haushunde abweichendes Gebiss, d. h. nur to Zähne vorgefunden hat. Es ist mir nicht bekannt, woher er den Schädel des abessinischen Wolfes erhielt; nur so viel ist sicher, dass es kein SimensisSichädel war.

Sehe ich mich in der Litteratur um, so hat schon 1868 der englische Zoologe Gray den "Abyssinian Wolf" den ächten Wölfen mit 42 Zähnen angereiht, ${ }^{2}$ ) ihn aber der auffallend langen Schnauze wegen zu einer besonderen Gattung Simenia erhoben.

A. Breh $m^{3}$ ) stellt ihn ebenfalls zu den Wölfen im engeren Sinne, ebenso E. L. Tronessar ${ }^{4}$ ) in seinem Verzeichnis der lebenden und fossilen Säugetiere.

Um aus eigener Anschaumng urteilen zu können, wandte ich mich an das Museum in Stuttgart und erhielt durch die Freundlichkeit meines Kollegen Prof. Dr. Lampert den von /leuglin aus Abessinien mitgebrachten Schádel,

1) C. Keller. Ueber den Bildungsherd der südlichen Hunderassen. Globus. Band I.XXillt. Ni. $: 14010$.

2) 7. E. Giray. Notes on the skulls of the Species of Wogs, Wolves and Foxies in the Collection of the British Museum. I'roc. Zonl. Soc. London. 1868.

$\left.{ }^{3}\right)$ Brehms Tierleben. I3d. 11.

4) E. L. Trouessart. Catalogus Mammalium tam viventium quam fossilium. Nova Editio. Berolini. $184 \%$. 
der vorzüglich erhalten ist, nach 7 ürich zugesandt. Dass ich den ächten Canis simensis-Schädel vor mir hatte, ging ausserdem aus dem Vergleich mit dem 'Exemplar des britischen Museums hervor, von welchem Gray' eine gute Abbildung veröffentlicht hat.

Der Stuttgarter Schädel besitzt nun in der That nicht 40 , sondern 42 Zähne wie unsere Windhunde!

Schon äusserlich lässt sich eine auffallende Uebereinstimmung zwischen dem abessinischen Wolf oder Walgie und dem altägyptischen Windhund

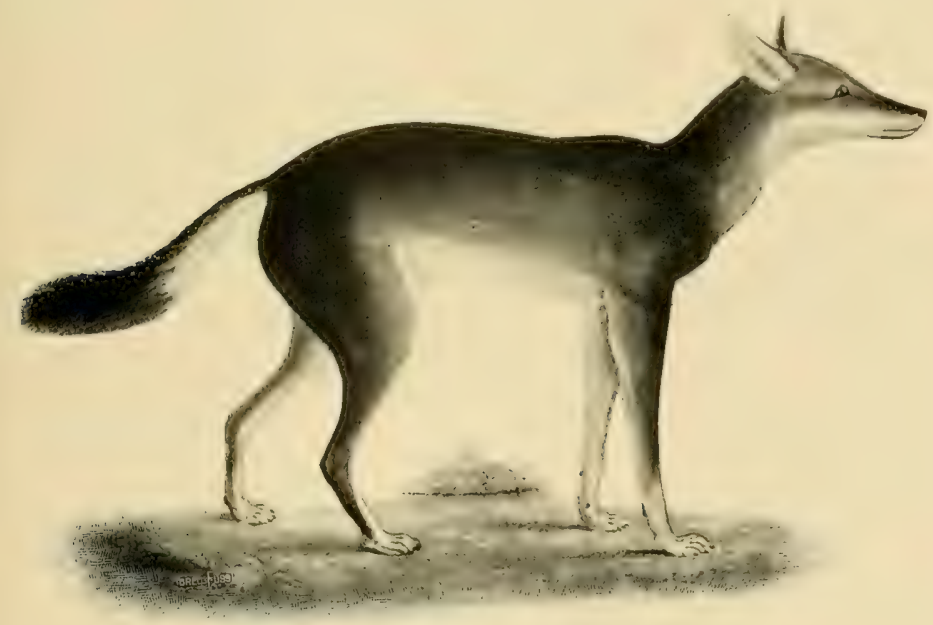

Fin. 16 .

Ahessinischer Wolf. (Canis simensis.) (Nach lïipel.)

erkennen. Nicht nur die Körperproportionen, sondern auch die Färbungen stimmen überein. Nach der Abbildung, die Kïppel gegeben hat, ist die Oberseite von Canis simensis rötlichgelb, die Unterseite weisslich; an Kopien, die ich aus ägrptischen Grabkammern habe anfertigen lassen, ist die Windhundfärbung dieselbe, sie wird anch auf der Unterseite weisslich, oben rotgelb abgebildet.

Man kann einwenden, dass der altägyptische Hund einen kurz behaarten Schwanz besass, während dieser beim abessinischen Walgie in der unteren Iälfte buschig ist. Ich besitze jedoch genaue Kopien aus dem Ti-Grab von Sakkarah ( $\mathrm{V}$. Dynastie), worin eine Begattungsszene von Windhunden dargestellt ist und bei beiden Hunden ist der Schwanz ebenfalls buschig. In Altägypten war also diese primitive form ebenfalls noch vorhanden. 


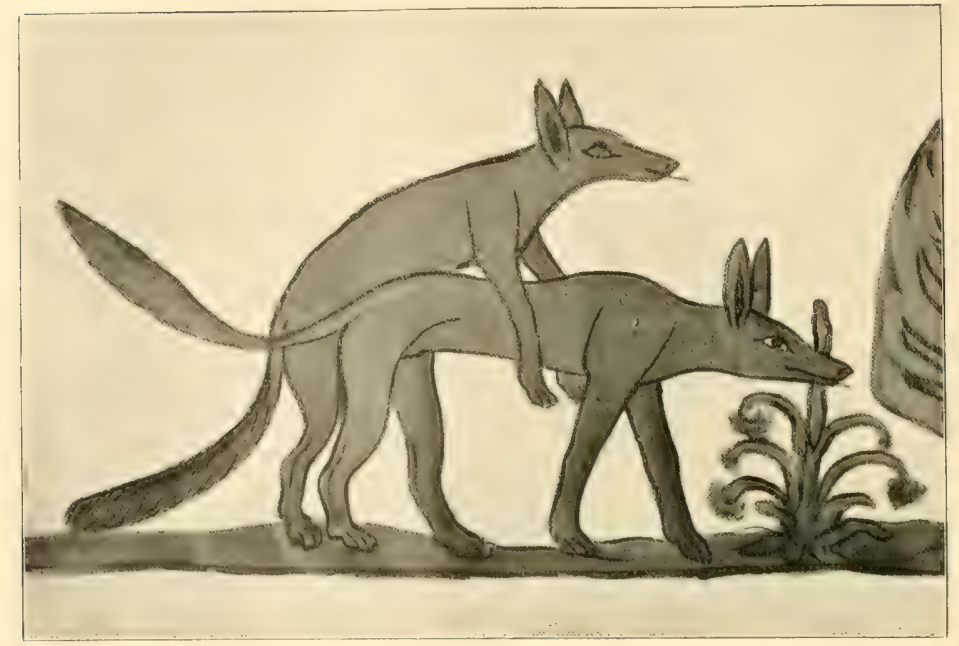

Firis. 17 .

Whägyptischer Winahund ron der Cams simensis-Form. Wandmaletei ats dem Ti-Grah. V. Dynastit. (Salkaralı.)

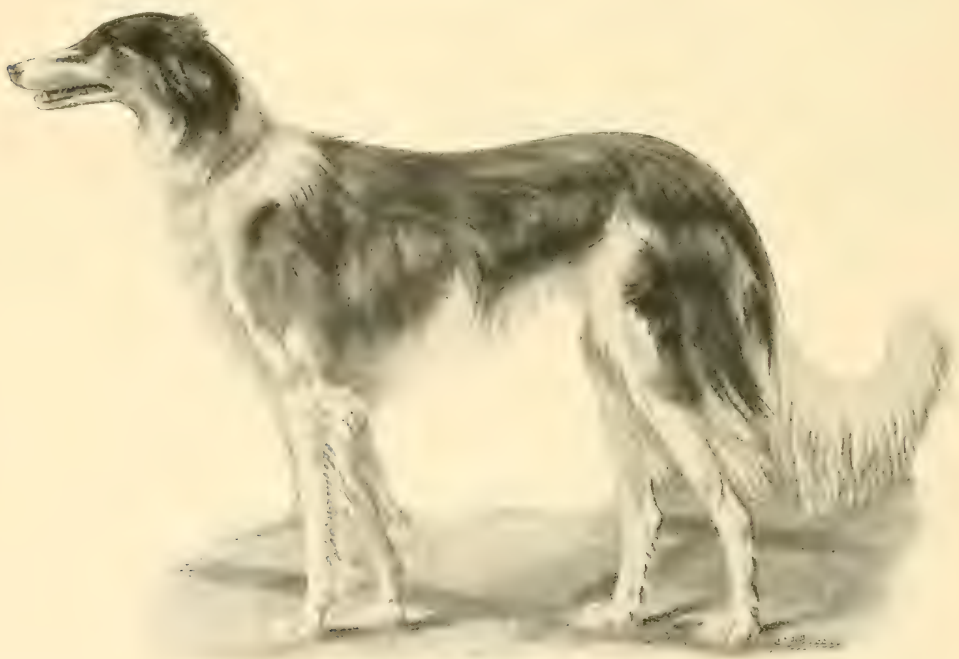

fijig. Ith.

Litusischer Wimdliunt uder Barzei. (Nach $/ 1$, spertingse) 
Da mir altägyptische Schädel fehlen, so verglich ich den zierlich gebauten Canis-Simensis-Schädel mit demjenigen des Barzoi oder russischen Windhundes, der einen sehr ausgesprochenen Charakter besitzt und der meiner Ansicht nach neben dem Beduinenwindhund dem altägyptischen Hund viel näher steht als unsere westeuropäischen Windhunde. Die russischen Kynologen sind über die Urabstammung ihres schönen Bärzoi (Barsoi) noch im Unklaren, Sergie Sergecuitsch Karcew neigt der Annahme zu, dass seine erste Ileimat der hohe Norden gewesen sei. Ich glaube und werde dies durch die Schädelmasse als sicher erweisen, dass er afrikanischer I Jerkunft ist. Er kann noch wie der ägyptische Windhund die Ohren vollkommen aufrecht stellen und stammt von ihm ab. Auf alten I Iandelsstrassen hat er frühzeitig den Weg von Aegypten nach dem Schwarzen Meere eingeschlagen und von hier aus sich weiter nach Norden verbreitet. Dass er langhaariger wurde und eine befahnte Rute erhielt, ist offenbar Folge des kälteren Klimas.

Durch die Güte von Professor Tichomiroff in Moskau erhielt ich den Schüdel eines kräftigen männlichen Barzoi, welcher unter dem Namen "Czerdetschnyi" von der kaiserlichen Gesellschaft mit einer Medaille ausgezeichnet wurde.

Ich stelle hier seine Schädehnasse und diejenigen von Canis simensis zusammen :

Absolute Masse:

1. Basilarlänge des Schädels (vom Foramen magnum bis zu den Incisivalveolen) .

2. Profillänge des schädels . . . . . .

3. Lange vom Foramen magnum bis zum Hinterrand des Gaumens . . . . .

4. Von der Crista occipitalis bis zur Wurzel der Nasalia.

5. Grösste Breite der Parietalregion . . .

6. Jochbogenbreite

7. Breite zwischen den Ohröffnungen . :

8. Kleinste Stimbreite zwischen den Orbitae

9. Grösste Stimbreite zwischen den Orbitae .

10. Breite des Foramen magnum

11. Länge der Nasalia (in der Mitte gemessen)

12. Schnauzenlänge bis zum For. infraorbitale

13. Schnauzenbreite hinter dem vord. Lückenzahn

14. Länge vom hint. Backenzahn bis zum Eckzahn

$\begin{array}{cc}\begin{array}{c}\text { Canis } \\ \text { simensis } \\ \mathrm{cm}\end{array} & \begin{array}{c}\text { Barzoi } \\ \text { Cierdetschny i" } \\ \mathrm{cm}\end{array} \\ 17 & 22 \\ 20,1 & 25,3 \\ 8.0 & 10.8\end{array}$

$10,1 \quad 13,6$

$5,7 \quad 4,9$

$9,6 \quad 10,3$

$5,0 \quad 6,3$

$3,3 \quad 4,2$

$4,8 \quad 5.7$

$2,0 \quad 2,2$

$7,2 \quad 8,8$

$6.3 \quad 8,0$

$2,5 \quad 3,3$

$7,7 \quad 9,2$

Wir sehen zunächst, dass der Schädel des Barzoi unter dem Eintluss der Domestikation grösser geworden ist und dass die Zunahme sich auf 
alle Schädelregionen erstreckt. Deutlicher tritt der Verwandtschaftsgrad hervor, wenn wir die relativen Masse zusammenstellen. Zu diesem Zweck wollen wir die Basilarlänge des Schädels gleich 100 ansetzen und darauf die übrigen Zahlen beziehen und sie in ganzen Prozenten ausdrücken. Wo Abweichungen vorkommen, die auf sexuelle Unterschiede zurückzuführen sind, habe ich in Klammer die Relativzahl beigesetzt, die ich an einer Barzoihündin meiner Sammlung (mit einer Schädel-Basilarlänge von $19 \mathrm{~cm}$ ) gemessen habe.

Relative Masse

1. Basilarlänge des Schädels

2. Protillänge des sichuidels

3. Länge vom Foramen magnum bis zum Hinterrand des Gaumens . . . . . . .

4. Von der Crista occipitalis bis zur Wurzel der Nasalia

5. Grösste Breite der Parietalregion. . . .

6. Jochbogenbreite

7. Breite zwischen den Ohröffunngen . .

8. Kleinste Stirnbreite zwischen den Orbitae

9. Grösste Stimbreite zwischen den Orbitae .

10. Breite des Foramen magnum . . . .

11. Länge der Nasalia . . . . . . .

12. Schnauzenlänge bis zum For. infraorbitale

13. Schnauzenbreite hint. dem vord. Lückenzahn

14. Länge vom hint. Backenzahn bis zum Eckzahn

$\begin{array}{cc}\text { Canis } & \text { Barzoi } \\ \text { simensis } & \text { Czerdetschnyi" } \\ 100 & 100 \\ 118 & 115 \\ & \\ 47 & 49 \\ 59 & 62 \\ 33 & 22(530 !) \\ 57 & 47(555 !) \\ 30 & 29 \\ 19 & 19 \\ 28 & 26 \\ 11 & 10 \\ 42 & 40 \\ 37 & 36 \\ 15 & 15 \\ 45 & 49\end{array}$

Daraus ergiebt sich eine Uebereinstimmung zwischen dem russischen Windhund und dem abessinischen Wolf, wie sie genauer wohl nicht erwartet werden kann, wie denn auch der Barzoi-Schädel auf den ersten Blick in seinem (jesanthilde an den Simensis-sichädel erinnert. Abweichungen zeigen sich zunächst in der Parietalregion. Beim Schädel des "Czerdetschnyi" ist ihre Wölbung gering und bleibt um volle $11 \%$ gegen den WalgieSchädel zurück. Dass diese Abünderung auch eine geringere Jochbogenbreite nach sich zieht, wird leicht verständlich, sie bleibt auch um $10 \%$ zurück. Dass es sich um individuelle oder sexuelle Abweichungen handelt, lehrt der Vergleich mit der Barzoihündin, ihr Schädel kommt in der Parietalregion der Wildform auf $3 \%$ und in der Jochbogenbreite auf $2 \%$ nahe.

Indirekt wird damit die Ableitung der Barzoihunde vom altägyptischen Windhund bestätigt.

Sollte die grosse Uebereinstimmung noch weitere anatomische Belege wünschen, so mag namentlich auf den Zahnbau aufmerksam gemacht werden. Die Eckzähne sind beim Barzoi wie bei Canis simensis relativ länger und 
schlanker als bei den übrigen I Iunde-Rassen : bei beiden sind die oberen Reisszähne schwach ausgebildet, dem bei dem viel kleineren Torthund ist deren absolute Grösse denen vom Barzoi und abessinischen Wolf gleich oder übertrifft sie sogar. Wie weit die anatomische Uebereinstimmung geht, zeigt am schlagendsten der vorletzte Backenzahn des ()berkiefers: seine vordere

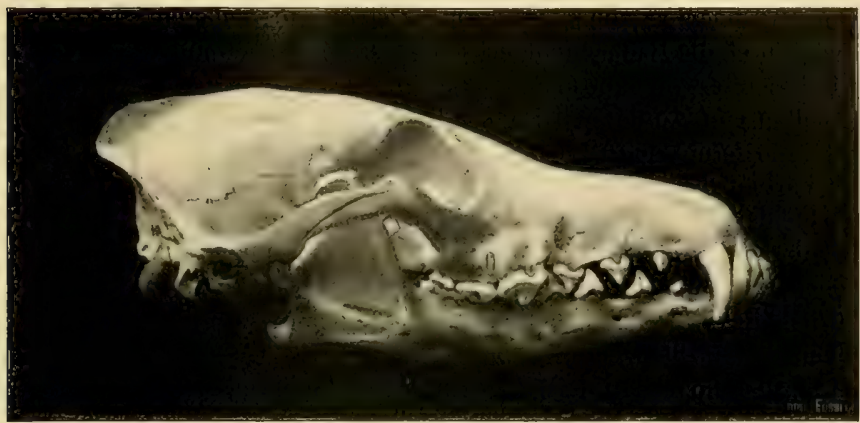

Fig. 19.

Schädel von Canis simensis, (Original im königl, Museum in Stuttgart.)

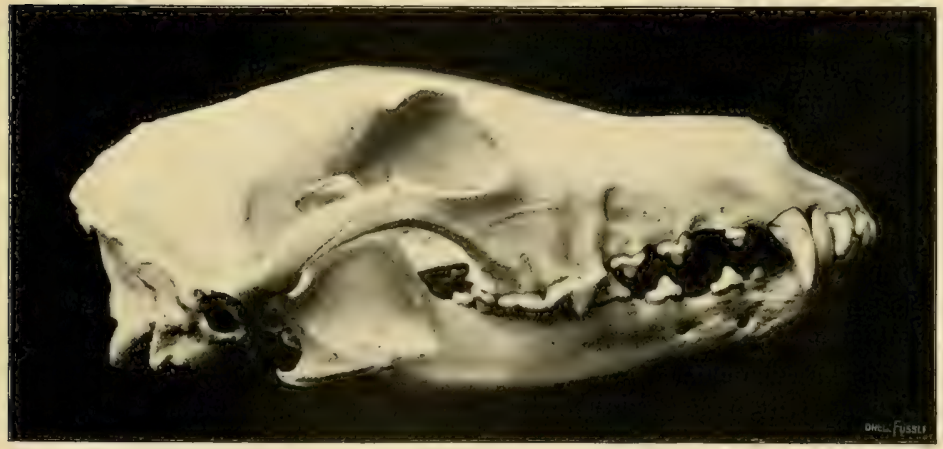

Fig. 21 .

Schädel des russischen Windhundes, Weihchen. (Landw, Sammlung Zürich.)

Wurzel liegt wegen der geringen I icke der Alveolenwand beim abessinischen Wolf frei zu Tage, dasselbe ist der Fall an den beiden weiblichen BarzoiSchädeln meiner Sammlung und am Schädel des männlichen Exemplares lässt der erwähnte Backenzahn sogar beide Wurzeln offen zu Tage treten. Letzterer hat wie der C. simensis eine stark entwickelte Hinterhaupts- und Scheitelleiste. beim weiblichen Barzoi sind sie erheblich schwächer. 
Nachdem die afrikanische Abstammung der' Windhunde auf Grund meiner Untersuchungen zweifellos festgestellt ist, lässt sich deren Ausbreitung ziemlich klar verfolgen. Die älteste Domestikation erfolgte wohl nicht im eigentlichen Aegypten, sondern in Aethiopien, beziehungsweise in den Ländern des oberen Nil, wo die Pharaonenleute frühzeitig ihren Bedarf an Tieren holten; der stehohrige Pharaonen-Windhund stammt aus jener Region, ist aber als zahme Rasse nicht etwa erloschen, sondern hat sich, wie wir durch die Beobachtungen von A. Brehm erfahren haben, am oberen Nil, insbesondere in Kordofan so gut wie unverändert bis zur Gegenwart forterhalten. In Kordofan ist auch die Wildform zur Beobachtung gelangt. Vor Jahren lernte ich diesen Hund in Kairo kennen, wo er nicht selten von Chartum her eingeführt wird. Merkwürdigerweise vermag er auf dem Hochland von Abessinien nie lang auszuhalten und die Exemplare, die wiederholt in den Besitz von Menelik, der persönlich zum grossen Aerger mancher Abessinier ein grosser Hundeliebhaber ist, gelangten, haben nie lange gelebt. Der Sudanhund ist augenscheinlich zu sehr an die feuchtwarmen Nilgegenden angepasst.

Der über ganz Nordafrika verbreitete Slughi oder Beduinenwindhund steht dem Pharaonen-Windhund ebenfalls ganz nahe, er hat in den edleren Zuchten meist auch noch dessen fahle Färbung.

Der Uebertritt nach Asien und Europa dürfte zu Beginn des neuen Reiches erfolgt sein, der persische Tasi und der russische Barzoi sind augenscheinlich die ältesten Typen. Nach Ostasien hin scheinen Windhunde seltener zu sein, doch werden sie nach mündlichen Mitteilungen von Ferars noch in Burma zur Iirschjagd benutzt.

In Westeuropa leben alte, etwas modifizierte Typen in England. Die Kelten waren grosse Liebhaber von Windhunden, deren Deszendenten wir offenbar in den struppigen, hochbeinigen, irischen Wolfshunden (Irish Woltlound) und in den schottischen Hirschhunden (Scotsch Deerhound) vor uns haben. Ein etwas verkommener Windhund ist der wenig bekannte, an abgelegenen Orten heimische ${ }_{n}$ Lurcher", der Lieblingshund der englischen Wilddiebe.

In der allerengsten genetischen Beziehung zu den ächten Windhunden stehen die Fagdhunde. Auch diese sind entschieden südlichen Ursprungs und tauchen zuerst im afrikanischen Gebiet auf. Die altägyptischen Wandmalereien lassen sozusagen Schritt für Schritt die Umwandlung der Windspiele in Jagdhunde erkennen.

Viele ägyptische Jagdhunde werden zwar hängeohrig abgebildet, besitzen im Uebrigen noch vollkommen windhundartigen Charakter, was uns ihren psychischen Charakter vollkommen erklärt. Unseren Laufhund finde ich recht kenutlich in den ( iribern von Sakkarah dargestellt. Prisse d'. Iénnes hat aus der Nekropole von Theben (18. Dynastie) das schöne Bild ,Rückkehr von der Jagd" veröffentlicht, auf dem ein gefleckter Jagdhund vorkommt. 
Ob die Umzüchtung zu Jagdhundformen ausschliesslich in Altägypten vor sich ging, ist eine Frage, die ich nicht bejahen möchte, denn Jagdhunde werden auch als Geschenk äthiopischer Völker dargestellt, sie waren daher über die gewaltigen Steppen ()stafrikas oflenbar frühzeitig weit verbreitet. Von Prof. E. Vaville erhielt ich ferner ein lübsches Hundebild aus Deir el bahri, das einen kräftigen, hängeohrigen Jagdhund mit nicht mehr ganz windhundartiger Schnauze darstellt. Der Hund stammt aus dem Puntland d. h. den lreutigen Somaliländern; er wurde neben Giraffen und anderen Tieren von der Expedition mitgebracht, weiche die Königin IIatsepsu nach den Weihrauchländern ausgesandt hatte. Er hat eine frappante. lehnlichkeit mit heutigen innerafrikanischen Hunden, die Colonel Denham vor Jahren nach Europa brachte. ${ }^{1}$ ) Demnach ist jene alte Jagdhundrasse in Afrika noch nicht erloschen.

Der Uebertritt der Jagdhunde von Nordafrika nach Südeuropa fand, was sich zur Zeit allerdings nicht mit der nötigen Genauigkeit feststellen lässt, sondern vielleicht erst durch die genauere Kenntnis der griechischen Insel-Kultur aufgeklärt wird, wohl gleichzeitig mit demjenigen der Windhunde statt, d. h. im Beginn des neuen Reiches, als Altägypten regere Beziehungen mit dem Auslande anknüpfte.

Th. Studer ${ }^{2}$ glaubt, dass der heutige Jagdhund aus Kreuzung des Ankömmlings mit den schon vorhandenen europäischen Haushunden hervorgegangen sei. Solche Kreußungen dürften allerdings häufig vorgetommen sein, ohne indessen den körperlichen und psychischen Charakter der afrikanischen Stammrasse allzuweit abzudrängen. Auch stimme ich ihm bei, wenn er unseren Laufhund als die älteste Form auffasst, aus welcher die modernen Vorstehhunde hervorgegangen sind.

Die Dachshunde weisen ebenfalls auf eine afrikanische Stammquelle. Sie sind bereits in Altägypten nachweisbar und werden (2300 v. Chr.) zunäclist stehohrig abgebildet. Die oft stark vorgezogene Schnauze mancher Dachshunde lässt sich wohl aul eine Windhundabstammung zurückführen. Ich möchte noch auf zwei Eigentümlichkeiten hinweisen. Mir ist mehrfach aufgefallen, dass einzelne Dachshunde in ihrem lebhaft-gutmütigen Blick an den Augenausdruck russischer Windhunde erinnern. Die Kynologen betonen, dass der eigenartige Blick der zahmen Hunde als Rassenmerkmal gut zu verwerten sei und sie haben darin wohl recht, denn der Blick ist ja schliesslich bedingt durch eigenartige anatomische Verhältnisse.

Sodamn möchte ich darauf hinweisen, dass bei unseren Dachshunden das I Iatarkleid sehr häufig rötlichgelbe sitellen, z. 13. über den Augen und

1) Ihre Abbildung ist in Bennetts "The Tower Menagerie, $1829^{4}$ enthalten. Das Original war mir nicht zugänglich, dagegen eine gute Reproduktion, die Max Siber in seinem Werk: "Die Hunde Afrikas, $189{ }^{4}$ gegeben hat.

$\left.{ }^{3}\right)$ Th. Studer. Beiträge zur Geschichte unserer Hunderassen, Naturwiss. Wochenschrift. Nr. 28. 1897 . 
an den Beinen aufweist, zuweilen ist die ganze Unterseite oder das ganze Fell rötlichgelb bis hellbramrot. Ich betrachte diese Färbung als ein Erbstück des altägyptischen W Windhundes.

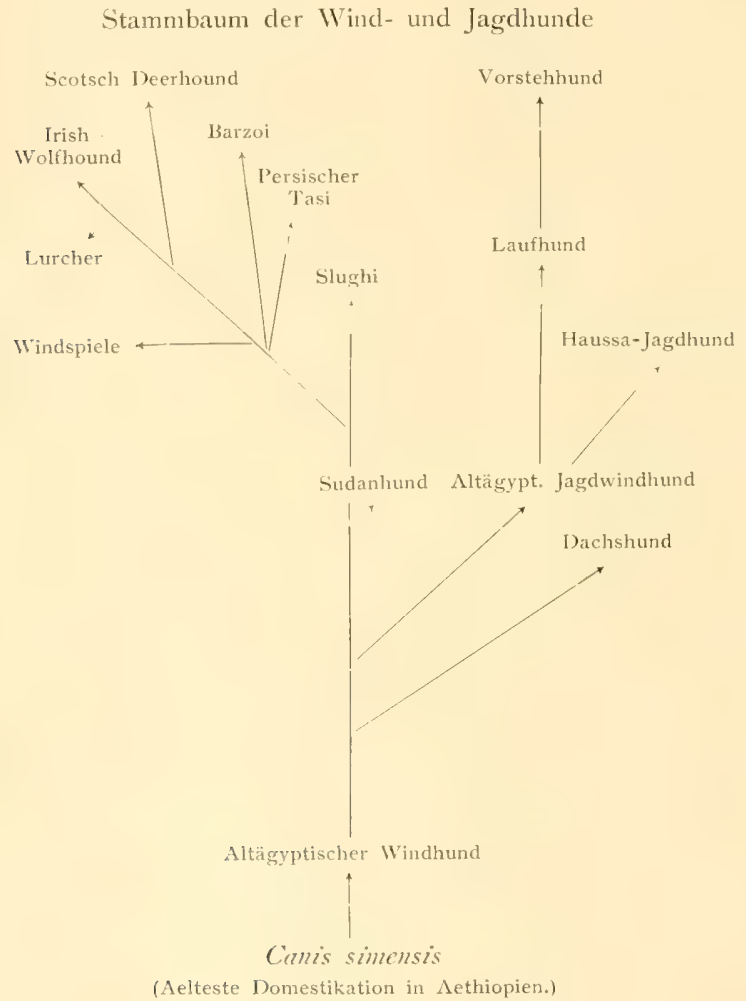

DIE ABSTAMMUNG DER DOGGEN-GRUPPE.

Die Familie der Doggen bildet das reine Gegenstück zur vorigen Gruppe der Windhunde, indem sie fast durchweg grosse, schwere, muskelkräftige Haushunde umfasst, deren psuchischer (hatrakter durch grosse Inhänglichkeit an den Besitzer einerseits, durch stark agressives Wesen dem Gegner gegenüber anderseits eine scharf ausgesprochene Nuance erhält.

Der schwergebaute, breite Kopf ist von eckigen Formen, die Schnauze 
ist auflallend dick und stumpf mit ausgesprochener Neigung zur Verkürzung bis zur extremen Mopsform. Die meist breiten und hängenden Ohren sind hoch angesetzt. Der gedrungene Körper ist fleischig, die Extremitäten starkknochig und stets gut bemuskelt.

Hierher gehören die alten Molosser, die Tibetdoggen, Bulldoggen, Mastiffs, Mäpse, die Neufundländerhunde und dits edelste Glied der ganzen Familie, der moderne Bernhardinerhund.

Irsprünglich scheinen alle Angehörigen der Doggenfamilie langhaarigg gewesen zu sein mit fast mähnenartigem Haarkleid am Vorderkörper und sehr dicht behaarter Rute, dagegren sind einzelne moderne Kulturformen kurzhaarig geworden.

Der scharf ausgesprochene zoologische Charakter der doggenartigen I laushunde lässt auf eine gemeinsame Ibstammung schliessen und die wilde Stammform muss in einem wolfsartigen Caniden gesucht werden. Unter den neueren Autoren, welche diese Frage auf dem Wege des anatomischen Vergleiches geprüft haben, ist zunächst 1. Nchring hervorzuheben. Er bezeichnet $^{1}$ ) den IVolf (Canis lupus) in sehr bestimmter Weise als Stammvater unserer grossen Hunde-Rassen, insbesondere auch des von ihm aufgefundenen Canis fam. decumanus. Dieser letztere unterscheidet sich vom wilden Wolf eigentlich nur durch die geringere Grösse des oberen Reisszahns und dem geringeren Abstand der Jochbogen. Diese Verminderung wäre eine Folge der Domestikation. Th. Studer scheint an eine ähnliche Stammquelle zu denken, indem er den prăhistorischen Canis Inostranzewi, dessen sichädel sehr viel Aehnlichkeit mit demjenigen des Wolfes besitzt, als Ausgangsform für unsere grossen, doggenartigen Hunde erklärt.

Ich gebe nun zu, dass der Doggenschädel anatomische Beziehungen zum Wolf aufweist, der indessen im Schädel sehr variabel erscheint. Ich kam jedoch kaum ammehmen, dass der prähistorische Bewohner Europas den Versuch gemacht hat, den schwer zähmbaren Wolf als Haustier zu gewinnen. Die prihistorischen Funde sind selten und nicht über jeden Zweifel erhaben. Das Alter der Kulturschicht, in welcher Canis fam. decumanus gefunden wurde, ist unsicher, wahrscheinlich frühgermanisch. Was den grossen Canis Inostranzewvi anbetrifft, so handelt es sich dabei vermutlich gar nicht um ein zahmes Tier, sondern um einen Wolf; wenigstens ist mir die Ingabe sehr aufgefallen, dass bei demselben die Augenöffnungen schräg gestellt sind. Das spricht für den Wolf. Ich werde in dieser Ansicht bestärkt durch einen grossen I Iundeschädel, den ich aus den westschweizerischen Pfahlbauten erhielt und den ich für einen jüngeren weiblichen Wolf halte.

Die Pfahlbauer dürften $a b$ und zu die zudringlichen Wölfe und deren Schädel als Trophäen erbeutet haben.

1) A. Neliring. Ueber eine grosse wolfsähnliche Hunde-Rasse der Vorzeit (Canis fam. decumanus) und über ihre Abstammung. Sitzungsber. d. Ges. naturf. Freunde. Berlin. 1884. 
Damit soll wie gesagt nicht bestritten werden, dass wir bei den WolfsFormen anzuknüpfen haben, die sich. in ihren Lokalformen oder Arten die Grenze ist schwer zu ziehen - auf dem palaearktischen Gebiet sehr bildsam erwiesen haben. I le Verbreitungsgeschichte der Molosserhunde, die wir heute ziemlich klar überblicken, fällt schwer in dic Wagschale und weist auf einen asiatischen Bildungsherd.

Vorläufig muss an der Thatsache festgehalten werden, dass ihre prähistorische Existenz fraglich ist und dass anf dem Boden Europas Molosserhunde erst in historischer Zeit aufreten. Den ältesten Schädel, dessen Doggencharakter sicher gestellt ist, erhielt ich aus der römisch-helvetischenNiederlassung Vindonissa. Es ist offenbar derantike Molosserhund. Die genaue Untersuchung des Fundstückes hat Hermann firämer in meinem Laboratorium vorgenommen und seine Ergebnisse in einer monographischen Arbeit über die I laustiere von Vindonissal veröffentlicht. ${ }^{\text {) }}$

Der Molosserhund der alten Griechen und Römer wird melurfach erwähnt und von Columella recht sut charakterisiert: amplissimi corporis, vasti latratus canorique, niger; capite tam magno, ut corporis videatur

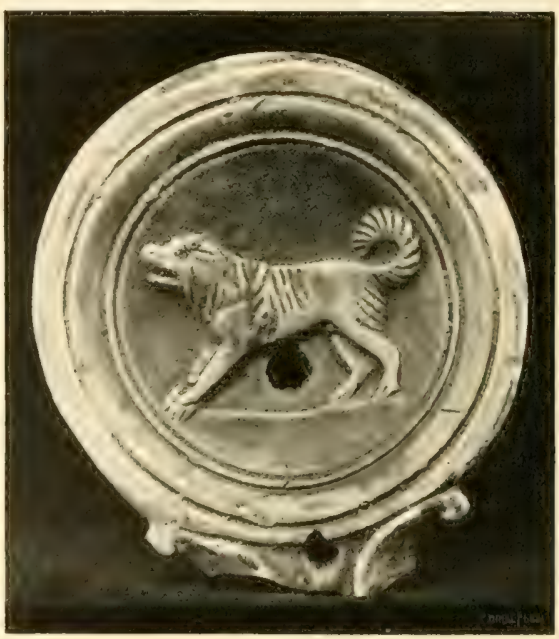

1.19. 21.

Thonlampe mit Molosserhund aus Vindonissa. (Landw. Sammlung Zürich.) pars maxima, deiectis et propendentibus auribus, nigris vel glaucis oculis, acri lumine radiantibus, amplo villosoqne pectore, latis armis, cruribus crassis et hirtis.

Die Beschreibung stimmt vortrefllich zu den inzwischen aufgefundenen Doggenbildern, die ich durch die Freundlichkeit des Archaeologen $U$. Hauser aus Vindonissa erhielt und clie an einen Neufundländerhund oder Bernhardinerhund erinnern.

Auf diesen Bildern ist die Behaarung am Vorderkörper und an den Schenkeln lang dargestellt, die Glieder muskelkräftig und die aufiärtsgekrümmte Rute lang behaart. Bemerkenswert und wiederum für den Doggen-

1) Kermann hrämer. Die Haustierfunde von Vindonissa. Revue suisse de zoologie. 1899. 
charakter sprechend ist der Umstand, dass an der Hinterpfote eine deutliche Wolfsklaue gezeichnet ist.

Der antike Molosser ist sicher nicht auf europäischem Boden gezähmt, sondern aus Asien importiert worden.

Torwes scheint der erste gewesen zu sein, der diese grossen Hunde nach Europa brachte; er führte sie auf seinem Kriegszuge gegen Griechenland mit sich, wie Herodot berichtet. Ob dieselben europäische Zuchten begründet haben, ist freilich nicht nachweisbar. Wahrscheinlich stammen die ältesten von grossen Doggen ab, die Alexander der Grosse auf seinem Zug nach Indien vou König Porus zum Geschenk erhielt. Diese gelangten

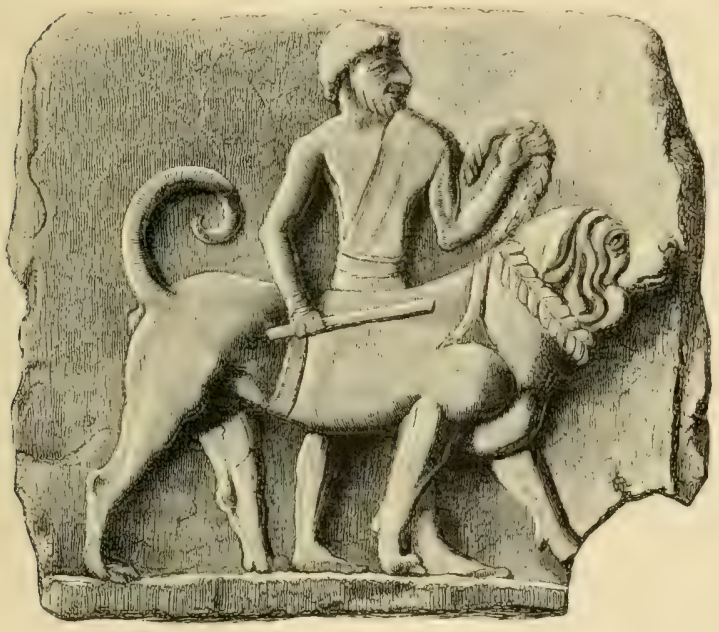

Hig. 22.
Altassyrische Dorge. (Nach Layard.) nach Macedonien und Epirus.

I) as Vorkommen von mächtigen Doggen in Assyrien während des ersten vorchristlichen Jahrtitusends ist sicher beglaubigt, da wir recht gute bildliche Darstellungen aus dem Zweistromland kennen. Auf der von Razelinson in Birs Nimrod gefundenen Topfscherbe, wie auf den Hundedarstellungen in dem Palast von Assur-

banipal (668 v. Chr.) ist der Doggencharakter unzweifelhaft sehr gut wiedergegeben: an den Bildern fällt mir auf, dass die Tiere kurzhaarig dargestellt sind, auch der Schwanz ist nicht buschig, sondern drehrund und relativ dünn gezeichnet. Es lässt sich, namentlich weil auf einem Jagdbild, das den Ueberfall auf ein Wildpferd darstellt. doch noch etwas Langharigkeit angedeutet ist, die Sache wohl so erklären, dass die ursprünglich zottig behaarten Hunde in dem warmen Mesopotamien ziemlich rasch die langen Ilaare verloren, wie dies heute noch in den heissen Ebenen Indiens mit den aus dem Ilmalajagrebict eingeführten Doggen geschieht. Es ist aus dem gleichen Grunde wohl nur ein starker künstlerischer Realismus, wenn auf einem Thorbogen in Sanchi Tope (Vorderindien) die aus dem dritten 
vorchristlichen Jahrhundert stammenden Doggenbilder ganz dünnschwänzige IHunde darstellen.

Die assyrischen Hunde sind - das eben genannte Bild giebt ja einen Fingerzeig - aus Indien bezogen worden; indessen ist die eigentliche Urheimat offenbar das Gebirgsland im östlichen Himalaja, speziell das Hochland von Tibet, dessen Zuchten schon im Altertum in Ostasien berühmt waren. Noch heute lebt die Tibetdogge in fast unveränderter Form in jener Region fort. Dieselbe ist nach $M a x$ Siber $\left.{ }^{1}\right)$ ein mächtiges Tier, an Grösse unsern Neufundlandern und Bernhardinern nicht nachstehend, ähnlich gebaut wie diese, nur ist die Schnauze etwas lang und nicht übermässig breit. Der schwere Kopf mit dem gebrochenen Profil zeigt einen düstern Ausdruck, wozu die faltige Gesichtshaut, die starken Lefzen und die blutunterlaufene Bindehaut des Auges beitragen mögen. Die Falte des unteren Lides ist eckig, die Ohren hängend, breit und hoch angesetzt, aber doch nicht übermässig gross. Der kurze Hals mit mähnenartiger Behaarung. Der schwere Körper ist nicht hochgestellt, die Wolfsklaue an den Hinterpfoten sowohl einfach als doppelt. Das Lichthaar ist schlicht, bisweilen sogar steif wie beim Spitz, zuweilen aber auch seidenartig, der Schwanz buschig behaart, dann mit langer Behaarung um den Hals und am Rücken, sowie auch an den Keulen (Hosen). Die Färbung ist einfach schwarz oder schwarzbraun: auch ein weisser Bruststern wird angegeben; haufig ist Sichwarz mit rotbraunen Flecken über den Augen.

Die 'Tibethunde sind in Europa heute noch wenig bekannt. Die ältesten Angaben über dieselben findet man in der chinesischen Litteratur (Chouking), denen zufolge $1121 \mathrm{v}$. Chr, ein Tibethund, der auf die Menschenjagd dressiert war, als Geschenk an den Kaiser von China abgeliefert wurde. Gegenwärtig bringen tibetanische Händler solche häufig nach dem chinesischen Reich.

Marco Polo fielen die Tibethunde aut, er sagt, dass sie die Grôsse eines Esels erreichen und zur Jagd auf wilde Ochsen (Yaks) verwendet werden.

Nähere Angaben erhielten wir jedoch erst im abgelaufenen Jahrhundert durch die Engländer, so durch Hodgson, Wallich und Hooker.

Da der genannte Hund nur vereinzelt über Tibet hinausgeht und $z$. B. in den Vorbergen des Himalajas nur spärlich angetroffen wird, so haben wir offenbar den Bildungsherd im tibetanischen Gebiet zu suchen. Die Domestikation ist augenscheinlich alt; da indessen nach den vorhandenen Angaben die Schnauze verhältnismässig lang und mässig breit erscheint, so steht die Tibetdogge der Stammform noch näher als die europäischen Verwandten.

Wenn ich mich hier positiver als es bisher geschah, über die zugehörige Wildform ausspreche, so bedaure ich allerdings, dass mir osteologisches

1) Max Siber. Der Tibethund. Winterthur. 1897. 
Material nicht zugänglich war. Jedoch hat kürzlich $T \%$. Studer die Abbildung eines Tibethundeschädels veroffentlicht.') Das Exemplar (ob reinblütig (:) stammt aus Nepal und ist im Besitz des British Nuseum. Im I Habitus steht er dem Molosserschädel aus Vindonissa nahe. Studer findet zwar Anklänge an den Dingo und möchte daher den Tibethund von einer südlichen Stammform ableiten, die bei der Domestikation Wolfblut aufgenommen hat. Im Ilinblick auf viele anderweitige Uebereinstimmungen zwischen

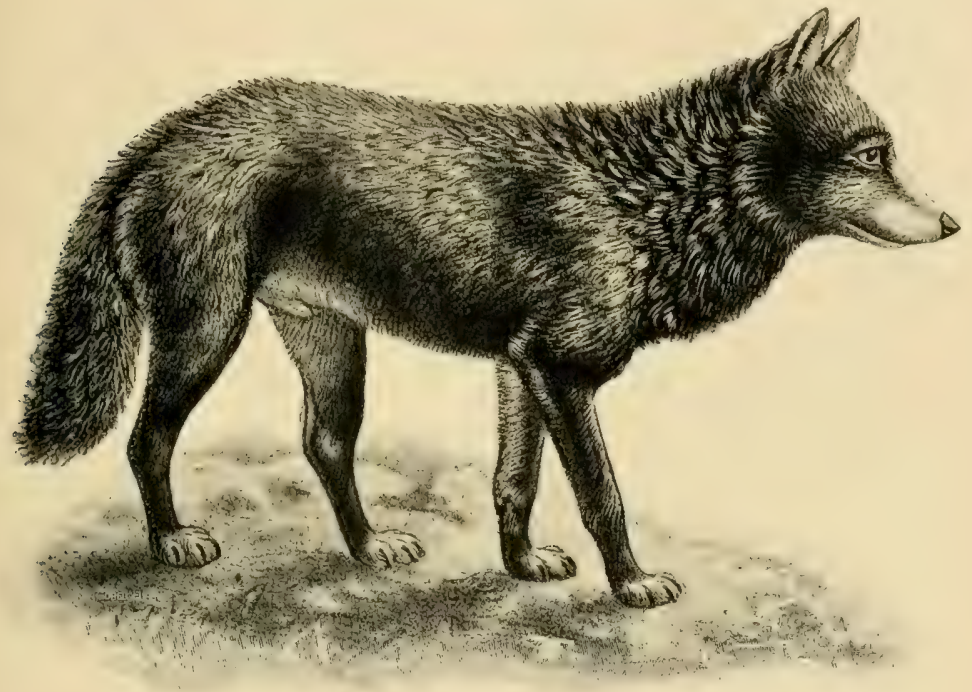

Fig. 23.

Tibetwolf (Canis niger). (Nach Sclater.)

Tibethunden und europaischen I)oggen erscheint jedoch eine Beziehung zum I ingo wenig sicher, zumal beim Nepalhund die Einwirkung von Pariablut denkbar ist.

Die Abstammung von einem asiatischen Wolf erscheint schon aus geographischen Gründen naheliegend. Man kömnte an eine in Hochasien lebende Lokalform von Canis Iupus denken. Diese Art ist bekanntlich sehr variabel, so dass $A$. Nehring selbst den indischen Canis pallipes als eine Lokalrasse unseres gemeinen Wolfes betrachtet.

Nun machte A. A. Kinloch im Jahr 1867 die höchst beachtenswerte

1) Th. Studer. Die prähistorischen Hunde in ihrer Beziehung zu den gegenwärtig lebenden Rassen. Abhandl, d. Schweiz. palaeont. Gesellschaft. Vol. XXVIII. 1901. 
- Ingabe, dass überall in Tibet wenigntens \%wei Wolfsarten vorkommen( . Wolves of at least two sorts are found all over Thibet"). Die eine ist grau und gehört in den Formenkreis des gemeinen Wolfes hinein. Die andere wurde im Londoner zoologischen Garten von P. L. Sclater lebend untersucht und als durchaus verschiedene Art erklärt, sie ist als Canis niger Sclater in die Wissenschaft eingeführt.") Die Höhe des Tieres wird zu zwei Fuss fünf Zoll (engl.) und die Länge zu drei Fuss vier Zoll (engl.) angegeben.

Die Färbung der beiden Geschlechter, sowie deren Nachkommen scheint sehr konstant zu sein, nämlich beinahe einfarbig schwarz mit weissem Brusttleck, weisser Schnauze und weissen ['foten.

Aus der beigegebenen, sehr guten Abbildung ist zu entnehmen, dass dieser Canis niger in den kräftig bemuskelten Beinen erheblich tiefer gestellt ist als unser Wolf; der Schwanz erscheint sehr buschig und die Behaarung an Hals und Brust affallend lang, fast zottig.

Diese Merkmale weisen alle auf die Abstammung der Tibetdogge von dem schwarzen Tibetwolf (Canis niger) hin, denn erstere besitzt ja auch neben dem schwarzen Haarkleid häufig weisse Pfoten und einen weissen Bruststern. Diese Abstammung wird unterstützt durch die Thatsache, dass die Doggen ursprünglich alle vorwiegend schwarz waren und es zum Teil jetzt noch sind. Nicht nur die 'Tibetdogge ist vorwiegend schwarz, sondern auch nach den vorliegenden litterarischen Quellen die altassyrische Dogge wie der antike Molosserhund der Römer; von den heutigen Formen ist bekanntlich der Nenfundländer vorwiegend schwarz, teils einfarbig, teils mit Abzeichen. I)ie späteren abweichenden Farbungen, die ja bei modernen Doggen vielfach zum Albinismus hinneigen, sind augenscheinlich sekundär erworben.

Die morphologischen Thatsachen wie die historisch nachweisbaren Verhältnisse der Verbreitung sind dieser Ableitung durchaus günstig.

Somit ist der Entwicklungsgang der IOoggengruppe im Wesentlichen folgender:

Der Bildungsherd, wo Doggen zum ersten Mal als zahme Tiere erscheinen, liegt in IIochasien, speziell in Tibet. Von hieraus drang das Haustier nach Nepal und nach Indien, vereinzelt auch nach China vor. Der babylonisch-assyrische Kulturkreis hat dasselbe frühzeitig übernommen. Auf afrikanischen Boden scheint whihrend der Pharanenzeit niemals ein Uebertritt stattgefunden zu haben, dagegen erscheinen die Doggen zu Alexanders Zeit auf dem griechischen Boden, um später an den römischen Kulturkreis abgegeben zu werden.

Römische Kolonisten brachten zu Beginn der jetzigen Zeitrechnung die Molosserhunde über die $\Lambda$ pen nach Helvetien und wohl auch nach

1) P. L. Sclater. On the Black Wolf of Thibet. Proceedings of the zoological Society of London. 1874. 
andern Ländern Mitteleuropas und Westeuropas. Mls einen der alten Rasse nahestehenden Hund betrachte ich den Neufundländer, an welchen die bildlichen I)arstellungen aus dem römischen V'indonissa in der Koptbildung auffallend stark anklingen, wozu noch die Uebereinstimmung in der Haarfarbe kommt. Dass die Neufundländer-Rasse auf einem geographisch weit abseits liegendem Gebiet erscheiut und später wieder nach Europa verptlanzt wird, ist nebensächlich.

Fitzinger ${ }^{-1}$ ) bemerkt, dass diese Rasse zur Zeit der ersten Niederlassung der Engländer in Neufundland im Jahre 1622 noch nicht vorhanden war und dass ihre Entstehung ohne Zweifel auf die dort später von Europäern

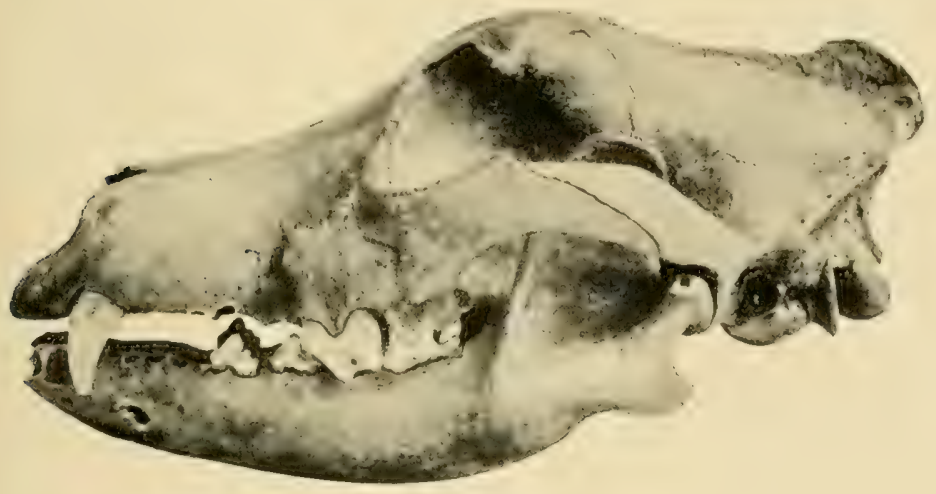

kig. 24 .

Schädel des Molosserhundes aus Vindonissa. (Nach /R. Krämer). (Original in d. Landw. Sammlung Zürich.)

zurückgelassenen I Junde zurückzuführen ist. Die geographische Isolierung erklärt die scharf ausgesprochene Eigenart des Neufundländerhundes.

Nach einer anderen Richtung entwickelte sich der antike Molosser zu dem edlen Bernhardinerhund, dessen Ableitung von prähistorischen Hunden Europas ich mit H. Krämer ablehnen muss. Schon früher habe ich diesen Standpunkt in schoss der hiesigen kynologischen Gesellschaft nachdrücklich vertreten.

Der Molosser als römischer Import ist, wie wir dies auch für andere Haustiere des Wallis nachweisen kömnen, an der altbegangenen Alpenstrasse, die nach dem Norden führte, hängen geblichen und in den Walliserbergen nach und nach zu dem heutigen edlen Gebirgshund umgezüchtet worden.

1) L. Fitzinger. Der Hund und seine Rassen. 18\%6. Pag. 170 . 
I) ie enge Bezichung drückt sich deutlich genng in den Massverhältnissen des Schädels aus, für welche $H$. Krämer folgende Längen bestimmt hat:

\begin{tabular}{|c|c|c|c|}
\hline $\begin{array}{r}\text { Nol } \\
\text { von Vi } \\
\text { (in } \mathrm{mm}\end{array}$ & $\begin{array}{l}\text { sser } \\
\text { adonissa } \\
\text { (in } \% \text { ) }\end{array}$ & $\begin{array}{c}\text { Bernha } \\
\text { (in } \mathrm{mm} \text { ) }\end{array}$ & ardiner \\
\hline 198 & $(100)$ & 230 & $(100)$ \\
\hline 120 & $(60,8)$ & 140 & $(60,6)$ \\
\hline 89 & $(44,9)$ & 105 & $(45, \bar{\jmath})$ \\
\hline 109 & $(5 \Sigma, 1)$ & 125 & $(54,3)$ \\
\hline 80 & $(40,4)$ & 86 & $(37,4)$ \\
\hline 100 & $(50,6)$ & 109 & $(47,4)$ \\
\hline 58 & $(29,2)$ & 68 & $(24,5)$ \\
\hline 120 & $(60,6)$ & 146 & $(6,3,4)$ \\
\hline 91 & $(39,5)$ & $7 T$ & $(38,8)$ \\
\hline 45 & $(22,7)$ & 53 & (2. \\
\hline
\end{tabular}

1. Vom For. mag. bis zu den Incisiven. 198 (100)

2. Von der Crista occip. bis zu der Nasalia

3. Vom For. magnum bis zum I Hinterrand des Gaumens .

4. Gaumenlänge . . . . . . . . .

5. Länge der Nasalia . . . . . . . .

6. Schnauzenlänge bis zu den Orbitae .

7. Stimbreite zwischen den Proc. orbit.

8. Jochbogenbreite . Grösste Breite zwischen den Backenzăhnen des Oberkiefers . . . . . . .

10. Schnauzenbreite zwischen den Alveolen der Eckzähne

Der Schädel des Bernhardiners ist. wie wir den absoluten Massen entnehmen können, gegenüber dem Molosser durchweg grösser geworden, was wir wohl der besseren Maltung und P'llege durch den Menschen erklären dürfen. Es sei übrigens bemerkt, dass die grossen Formen der Bernhardiner erst in der neueren Zeit gezüchtet worden sind.

Vergleichen wir die relativen Masse, die hier entscheidend sind, so springt die Uebereinstimmung sofort in die Augen. Der Gesamttypus des Schädels ist geblieben, nur in der Gesichtspartie ist bei der modernen Form etwelche V'erkürzung eingetreten.

Im Weiteren beweist die grosse Uebereinstimmung zwischen den grossen Hunden der grössten Gebirge Asiens und Europas, dass wir diese als wahre Homologien und nicht etwa als Analogien aufzufassen haben. Diese Homologien erklären sich aus der Verbreitungsgeschichte.

Als Seitenlinien haben wir die Bulldoggen und die Mopsformen anzusehen, bei welchen die Verkürzung des Gesichtsteiles noch weiter vorgeschritten erscheint. Es ergiebt sich also nebenstehender Stammbaum.

Im Anschluss an die Doggenfamilie mag noch zweier Formen Erwähnung gethan werden, die eine gewisse. Innaherung an den Doggencharakter zeigen.

Da ist zunächst die dänische Dogge und die ihr nahestehende deutsche Dogge. Beide sind schlanker gebaut als die ächten Doggen. in den Extremitäten erheblich höher gestellt und im Kopf weniger plump gebaut. Der Schnauzenteil ist spitzer. Allgemein wird von den Kynologen die Ansicht vertreten, dass die genannten Hunde ein Kreuzungsprodukt zwischen den grossen Windhunden und den ächten Doggen darstellen. Es ist dies vom anatomischen (jesichtspunkte aus jedentalls zutreffend, da diemorphologischen 
Merkmale die Mitte zwischen beiden halten. Manche deutsche Doggen sind lichtgelb behairt und etwas dunkel gestromt; hier ist die lichtgelbe Färbung jedenfalls auf den Einfluss des Windhundblutes zurückzuführen.

Sodann kennen wir in den Gebirgen der alten Welt noch grosse Hunde, deren Stellung etwas unsicher erscheint: dazu gehören die Pyrenäenhunde. die Schäferhunde der Sierra d'Estrella, die Abruzzenhunde, die starken Hirtenhunde in Griechenland und Albanien und die schweren Hunde des Kaukasus. Sie werden als Hirtenhunde benutzt, besitzen eine vorzügliche Witterung, bewachen aber mehr die I lerdentiere, ohne sie zusammen zu treiben.

Wir haben es augenscheinlich mit einer alten Form zu thun.

An dem Schädel eines Abruzzenhundes, den ich unlängst aus Süditalien erhielt, finde ich gegenüber dem W'olf so grosse Unterschiede, dass von einer näheren Verwandtschaft keine Rede sein kann, obschon manche Angaben die grossen Gebirgshunde als wolfsähnlich bezeichnen.

Anklänge an den Doggencharakter sind entschieden vorhanden, doch bleibt die ( rö̈sse weit hinter dem Bernhardiner und selbst hinter dem Moloswer von Vindonissa zurück. Gebiss und Beschaffenheit der Schnauze stehen anderseits dem Bronzehund (Canis matris optimae) auffallend nahe; die Crista sagittalis erscheint nur mässig stark entwickelt.

Dieser Mischcharakter deutet darauf hin, dass wir im Abruzzenhund und wohl auch in ähnlichen grossen (jebirgshunden einen Bastard zwischen dem Bronzehund und dem alten Molosser vor uns haben.

Stammbaum der Doggen

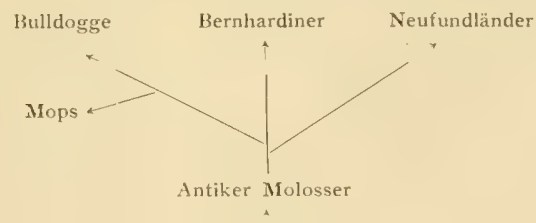

Altassyrische Dogge

Tibetdogge (C. molossus tibetanus)

Wilde Stammform: Canis niger (schwarzer Tibetwolf)

Urheimat der Doggen: Tibet.

\section{DIE AMERIK ANISCHEN HAUSHUNDE.}

Die Thatsache ist vollkommen sicher gestellt, dass die Eingeborenen Amerikas schon vor der Ankunft der Europäer zahme Hunde besassen. Alle Indianersprachen der Westküste von Südamerika hatten eigene Be- 
zeichnungen für den Hund und Garcilasco de la $V \operatorname{eg} a^{1}$ ) berichtet, dass in der ältesten Zeit die Huanca, bevor sie von Inka besiegt wurden, die Figur eines Ifundes anbeteten, ebenso assen sie Inudefleisch leidenschaftlich gerne.

$\dddot{J}$. F. von Tschudi"2) hat als Beweis für die Urexistenz des Hundes in Peru, in den alten, präcolumbischen Gräbern Hundemumien und -Skelette aufgefunden, die mumifizierten Hunde lagen meist quer vor den Füssen der sitzenden Kadaver. Auf seiner Reise nach Südamerika hat Tschudiden dortigen zahmen Hunden eingehende Iutmerkimbeit geschenkt, er erwähnt zunächst den nackten Caraibenhund (Canis caraibicus Less) mit haarlosem Körper und schiefergrauer Haut. Columbus fand denselben bei seiner Ankunft bereits auf den westindischen Inseln, Cortez in Mexico. Noch gegenwärtigg laufen diese halbverwilderten Hunde in den Dörfern umher, scheinen aber auf das Küstengebiet beschränkt zu sein. Im Gebirge tritt an die Stelle derselben der Inkahund (Canis Ingae Tschudi). Sein Kopf ist klein, scharf zugespitzt; die Ohren aufrecht, spitz und klein; der Schwanz stark behaart und gerollt; der rauhe Pelz von dunkelockergelber Farbe, am Bauch und auf der Innenseite der Beine etwas heller; die Haarspitzen sind schwarz. Mit dieser Art sind die Mumienhunde Perus ganz identisch. Tschudi traf im Gebirge neben europäischen Hunden diesen alten Inkahund noch häufig an bei den I Hirten und in den Indianerhütten. Sie dienten als Wachhunde und Hirtenhunde und werden als sehr bissig geschildert, ihre Abneigung gegen den Weissen war besonders auffällig. Gelegentlich wurden sie von den Eingebornen zur Hühnerjagd abgerichtet. Wie wir früher bemerkten, hat A. Nehring auf Grund der Gräberfunde nachweisen können, dass drei verschiedene Rassen des Inkahundes gehalten wurden.

Ueber die Iunde der Indianer Nordamerikas hat Darwin eine Reihe von Angaben gesammelt, aus denen hervorgeht, dass sie die grösste Aehnlichkeit mit den nordamerikanischen Wölfen (Lupus occidentalis) besitzen und nur geringe Anhänglichkeit an den Menschen zeigen. Die Eskimos verwenden Schlittenhunde, die häufig das schräge Auge der Wölfe besitzen.

Daneben kommt bei manchen Indianern ein Hund vor, der zu dem mehr fuchsartigen Prairiewolf (Canis latrans) in engster Beziehung steht.

Darwin betrachtet daher Canis lupus var. occidentalis und C. latrans als die wilden Stammformen des amerikanischen Kulturkreises und auch Nehring ist zu dem Ergebnis gelangt, dass die alten Inkahunde in allen Rassen nicht auf eine südamerikanische Canidenart zurückgeführt werden dürfen, sondern vom nordamerikanischen Wolf (Lupus occidentalis) abstammen.

1) Garcilasco. Comment, real. part. lib. VI.

2) F. F. von Tschudi. Untersuclungen über die Fauna Peruana. St. Gallen. 184t-18 16 .

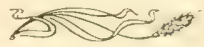




\section{DIE HAUSKATZE.}

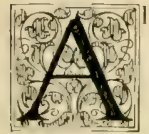

IIaustier nimmt dieses (jeschöpf eine eigenartige Sitellung ein, da es eine auffallend grosse Selbständigkeit bewahrt hat und dem Eintluss der künstlichen Züchtung so gut wie gar nicht unterliegt. I)er Eintritt dieses heute kosmopolitisch gewordenen Genossen des Menschen ins menschliche Haus erfolgte zu einer Periode, die jedenfalls für Europa noch prähistorisch war, aber der Bildungsherd liegt ausserhalb dieses Kontinents. Dies geht schon daraus hervor, dass prähistorische Reste der Ilauskatze nirgends nachweisbar sind, während der römischen Periode sind in den transalpinen Kolonien ebenfalls keine Spuren bemerkt worden, selbst bei den Ausgrabungen in Pompeji liessen sich keine solchen nachweisen.

Ueber die Abstammungsverhältnisse hat sich seit den Darlegungen von Ch. Darwin in unseren Anschauungen nur weniges geändert. Im grossen und ganzen stehen wir heute noch auf den von ihm vertretenen Standpunkt, so dass ich mich bezüglich der in Frage kommenden Wildarten kurz fassen kann.

Unsere europåische Wildkatze (Felis catus), die man in der ersten Uälfte des 19. Jahrhunderts noch ziemlich allgemein als Stammart unserer zahmen Form ansah, kommt nicht in Betracht. Abgesehen von der grossen Schwierigkeit der 7ähmung kommen erhebliche morphologische Unterschiede in Betracht. Schädelbau und Bezahnung ist bei der Hauskatze weit zierlicher als bei Felis catus, der Kopf mehr gestreckt. Der dicke, abgehackte Sichwanz unserer Wildkatze ist völlig verschieden von demjenigen der zahmen Arten, auch in der Wirbelzahl bestehen abweichende Verhältnisse.

Der Bildungsherd liegt in Afrika und augenscheinlich ist das Nilthal als Stammland der ältesten Hauskatzen zu bezeichnen. Herodot und Diodor berichten eingehend über die seltsame Stellung, welche dieselben im Pharaonenland als Kulttiere einnahmen und die von dem älteren Geoffroy St. Hilaire aufgefundenen Katzenmumien lieferten eine vollkommene Bestiitigung. Seither sind die altïgrptischen Kat\%enfriedhöfe ofters geplündert worden.

Der jüngere Geoffroy St. Hitaire ${ }^{\mathrm{l}}$ ) hat, auf die osteologischen Untersuchungen von Temminck und Blainzille' sich stïtzend, zunächst mit Natchdruck

1) Isidore Geoffroy St. Hilaire. Acclimatation et donestikation des animaux utiles. 1861. 
darauf hingewiesen, dass die ägyptischen Katzenmumien einerseits mit unserer Hauskatze, anderseits mit der von Rïppel in Nubien entdeckten Falbkatze die grösste Uebereinstimmung zeigen. Er betrachtet folgerichtig den Nordosten von Afrika als Stammland der zahmen Katzen und die Falbkatze (Felis maniculata) als Wildform, aus der letztere hervorgingen; immerhin hält er die Möglichkeit offen, dass noch eine ostasiatische Stammquelle daneben existierte.

Ch. Darvin ${ }^{1}$ ) hat den Gegenstand kritisch untersucht und eine Reihe von Beobachtungen zusammengestellt, aus denen hervorgeht, dass die Hauskatze sich nicht selten mit verschiedenen Wildkatzen verbastardiert, z. B. in Europa mit Felis catus, in Indien mit Felis chaus, in Agier mit Felis lybica, in Südafrika mit Felis caffra. Er lässt indessen die Frage offen, ob die Katzen von verschiedenen distincten Arten abstammen oder nur durch gelegentliche Kreuzungen modifiziert worden seien. Dass aber zum mindesten in einigen Fällen die Kreuzung hinreichend häufig eingetreten ist, um den Charakter der Rasse zu beeintlussen, hält Darwin für ausgemacht.

In der Neuzeit ist dem vorliegenden Abstammungsproblem besonders der italienische Zoologe G. Martarclli2 ${ }^{2}$ ) wieder näher getreten; er betont namentlich die Verschiedenheit in der Fleckenzeichnung bei unseren Hauskatzen und möchte diese phyletisch verwerten. Seine Auflassung markiert er in den Worten: "A me sembra, dopo quanto ho esposto, che non si possa attribuire ai gatti domestici una sola origine, cio solo quella africana comme fanno alcuni, o solo quella asiatica, come voglino altri . . . E Er ist sogar geneigt, einer von ihm näher beschriebenen südeuropäischen Wildkatze (Felis mediterranea) Anteil an der Erzeugung zahmer Rassen zuzuschreiben. Ich werde nachher auf diese interessante Frage zurückkommen.

Die polyphyletische Strömung, die neben verschiedenen Wildformen logischerweise auch verschiedene Bildungsherde zahmer Katzen annimmt. tritt bei Trouessart in seinem "Catalogus mammalium " am schärfsten hervor, indem er bei Felis domestica kurzweg bemerkt : "plurimi feri progenitores.

Im Hinblick auf die Verbreitungsgeschichte unseres Haustieres scheint mir eine unabhängige Entstehungsweise in verschiedenen Kulturgebieten nicht so unbedingt annehmbar und ich halte den vorsichtigen Standpunkt, den Darwin eingenommen hat, für richtiger.

Wir haben zunächst mit der wohl beglaubigten Thatsache zu rechnen, dass in Altägypten zu einer Periode, die in Europa noch nicht als geschichtliche bezeichnet werden kann, durch zufälige Verkettung verschiedener Umstände eine ausgiebige Zähmung der Katze erfolgte. Diese verweilt auffallend lang im Nilthal, denn der Uebertritt nach Europa erfolgt sehr spät, jedenfalls nicht wor Beginn der chrintlichen \% eitredhung. I agegen scheint die Verbreitung

1) Ch. Darwin. Variieren der Tiere und Pflanzen im Zustande der Domestikation. I. Bd. 1873.

2) (‥ Martorelli. Nota zoologica sopra i gatti selvatici e le loro affinità colle razze domestiche. Milano. 1896. 
nach Asien viel früher stattgefunden zu haben. Die sehr gut erhaltenen Mumien belehren uns über das Wildmaterial, das die Pharaonenleute bei der Zähmung benutzt haben. Die Hauptbezugsquelle war die Falbkatze (Felis maniculata Rüppel). Das Material war in der Nahe zu beschaffen. denn das Verbreitungsgebiet der genannten Wildkatze reicht von Palästina bis zum obern Nil und bis in die SomaliJänder. Die engeV erwandtschaft der ägyptischen Hauskatze mit der Falbkatze wird von verschiedenen Autoren betont. Ich erhielt aus I3ubastis und Beni Hassan mehrere Mumien. eine kleinere, die ich eröfnete, war sorgfültig in Leinwand eingebunden, Augen und Ohren aus Zeug künstlich nachgemacht. Die

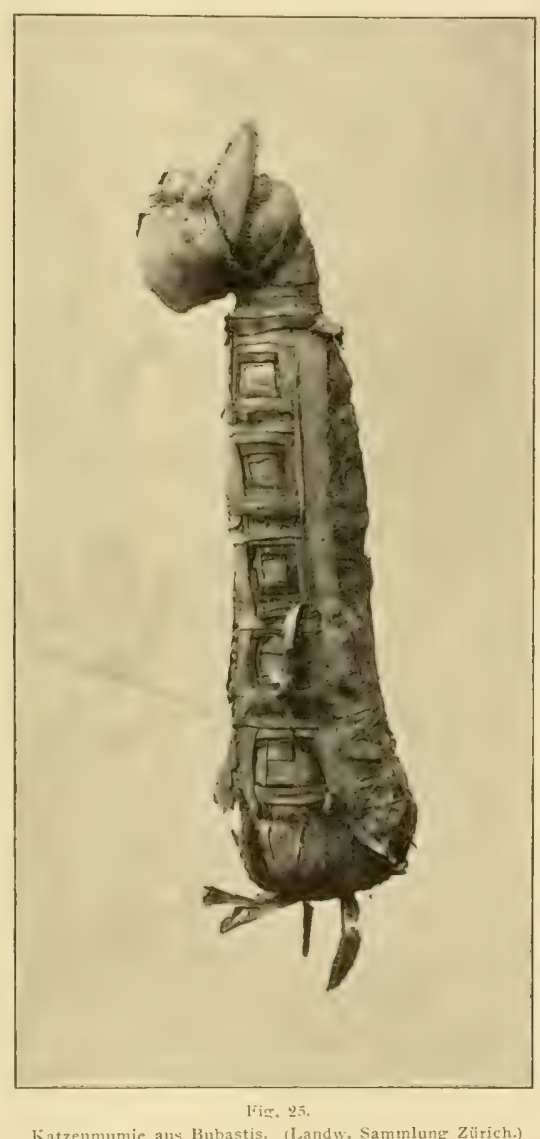

Katzenmumic aus Bubastis, (Landw, Sammlung Zürich.)
Behaarung, nur wenig abgeblasst, stimmte bei dieser Mumie in der deutlich erkennbarenZeichnung völlig mit Felis maniculata überein,auch die Grösse und das Gebiss stehen damit in Einklang, anderseits aber auch mit den falbkatzenähnlichen Hauskatzen, wie man sie jetzt noch in den Gegrenden des roten Meeres findet. Eine bedeutend grössereMumie, die ich aus Beni Hassan erhielt, gehört jedoch einer zweiten Art an, nämlich demSumpfluchs (Felis chaus). Letztere war es wohl, die in Altägypten als zahmes Tier den vornehmen Jäger begleitete und apportieren musste, wenn dieser in Sumpflande die Vogeljagd mit einem bumerangähnlichen Wurfgeschoss betrieb. ${ }^{1}$ ) 
Es ist nun anzunehmen, dass schon im Stammlande vielfach Kreuzungen beider Formen stattgefunden haben, wodurch manche Farbenabweichungen sich erklären lassen. Anderseits möchte ich der Zeichnung des Pelzes nur eine mässige phyletische Bedeutung zuerkennen, weil schon die wilde Falbkatze starken Variationen unterworfen ist. Es sind eine Reihe von Arten afrikanischer Wildkatzenarten unter den Namen Felis caffra, F: nigripes, F. caligata, F. lybica, F. pulchella, F. obscura beschrieben worden, deren Berechtigung der englische Zoologe Gray bestreitet und sie als blosse Varietäten dem Formenkreis der gewöhnlichen Falbkatze (Felis maniculata) zugewiesen hat. ${ }^{1}$ )

Von Wichtigkeit ist, dass die Falbkatze sich leicht zähmen lässt, wie schon Schrecinfurth bei den Niam-Niam in Innerafrika beobachten konnte. $\left.{ }^{2}\right)$ Ich kann dies nur bestätigen, indem mir in Nubien wiederholt gezähmte Exemplare angeboten wurden. Am mittleren Webi in den inneren Somaliländern konnte ich gezähmte Falbkatzen in den Dörfern antreffen, die ich vorher im Ogadeen nirgends vorfand. Sie dienen dazu, die Getreideschuppen gegen die schädlichen Nager zu schützen. Uebrigens richten die Somalifrauen auch ihre Knaben in origineller Weise zum Mäusefang ab und wie ich mich überzeugt habe, entwickeln diese ein grosses Geschick. Diese Thatsache liefert vielleicht die Erklärung für das lokale Fehlen der Hauskatze in manchen Gebieten Ostafrikas.

Ist somit der wesentliche Bestand der jetzt weit verbreiteten Hauskatzen afrikanischen Ursprumgs und dort aus Felis maniculata, zum Teil auch aus Felis chaus gewonnen, so muss jetzt noch die Frage geprüft werden, ob auch Südeuropa Anteil an der Bildung derselben hat, wie Martorelli behauptet und seine Felis mediterranea, eine Uebergangsform( $\bar{\zeta})$ von der Falbkatze zu unserer mitteleuropäischen Wildkatze, als eine der Stammformen auffasst.

Freilich betont dieser Autor die nahe V'erwandtschaft mit Felis maniculata, so dass sie nur als geographische Abart derselben aufzufassen ist.

Bisher ist diese südeuropäische Wildkatze nur in der toskanischen Maremma und auf der Insel Sardinien nachgewiesen worden, fehlt dagegen der Balkanhalbinsel und auch Süditalien. Lorenz zon Liburnau erhielt ein Exemplar, welches in den Bergen Sardiniens erlegt wurde und erklärt dasselbe für identisch mit der afrikanischen Kafferkatze (Felis caffra).

Um mir über dieses T'ier ein eigenes Urteil zu bilden, verschaflte ich mir aus Sardinien vier Bälge und ein Skelett. Es wurde mir berichtet, dass die Tiere zwischen Felsblöcken in wildem Zustande in der Umgebung von Cagliari gelebt haben. An Grösse steht diese Form erheblich hinter der Wildkatze unserer Alpen zurück. Das wäre an und für sich noch nicht

i) E. Gray. Notes on certain species of Cats in the Collection of the British Museum. Proc. Zool. Sioc. 1867 .

2) Nach mündlichen Mitteilungen in Brehm's Tierleben, Bd. 1. 
auffallend, da fast alle Säugetiere der Insel durch ihre bemerkenswerte Kleinheit sich auszeichnen.

Der Schwanz der wilden Sardenkatze ist niemals abgehackt, sondern lang und sehr licht behaart. Die Färbung der von mir untersuchten Stücke erinnert auffallend an die afrikanische Falbkatze. Bei dreien tritt die fahlgelbe Färbung auf der Bauchseite stark hervor und spielt an einzelnen Stellen ins rötliche. Bei allen ist die Nasengegend deutlich rostrot mit etwas dunkler Einfassung an den Seiten, der Fuss ist bis zur Ferse schwarz behaart, die Ohrspitzen tragen einen starken Haarpinsel, der bei Felis catus fehIt. Das urösste Exemplar misst von der Sichnauzenspitze bis zum sichwanzende 95 Centimeter, wovon 34 Centimeter auf den Schwanz entfallen; das kleinste Stück ist nur 80 Centimeter lang und etwas abweichend gefärbt, nämlich dunkelgrau mit weissen Haarspityen und undeutlichen Flecken: die tiefschwarzen Ohrpinsel sind bei diesem Stück auffallend und reichlich ein Centimeter lang. Der Schädel ist zierlich gebaut, von unserer Hauskatze nicht verschieden; das Gebiss schwach.

Mit dem Charakter eines ächten Wildtieres scheint mir trotz der unleugbaren Anklänge an Felis maniculata das lokale Vorkommen nicht recht vereinbar, da gerade die Feliden sehr bewegliche Raubtiere sind.

Um allfallige Bindeglieder zwischen der Sardenkatze und der Falbkatze Palästinas aıfzufinden, verglich ich damit die Wildkatze der Donauländer. Diese ist kleiner als Felis catus der Alpen und stimmt in der Grösse gut mit der Sardenkatze überein. Auch hat sie schwache Ohrpinsel, aber einen ganz anderen Schwanzbau, der sie sofort als Felis catus erkennen lässt.

Ich möchte nun ethnologische Gründe geltend machen, um den Nachweis zu führen, dass die von Martorclli beschriebene Felis mediterranea einfach eine verwilderte Hauskatze ist.

Dass die Altägypter eine falbgefärbte Hauskatze besassen, habe ich oben schon an dem Mumienbefund nachgewiesen; an dem Exemplar aus Bubastis sind die Hinterpfoten bis zur Ferse völlig schwarz wie bei der Sardenkatze. Brehm hat ähnliche Katzen in Abessinien beobachtet und ich finde bein durchblättern meiner Tagebücher Notizen aus Suakin, Maswatua und Aden, dass die dort beobachteten Hauskatzen merkwürdig falbkatzenartig aussehen, einen langen Kopf und einen langen, nur wenig dicht behaarten Schwanz besitzen. Besonders auffälig war die fahlgelbe, etwas ins rötliche spielende Pelzfarbe bei einer Katze in Massaua, die von den Dahlakinseln stammte.

Wir werden daher zu der Annahme gezwungen, dass die am roten Meer ansässigen Araber noch eine Rasse besitzen, die sich seit der Pharaonenzeit fast gar nicht verändert hat.

Nun ist ja hinlänglich bekannt, dass im Mittelalter die Araber die Herrschaft nicht nur über Aegypten, sondern auch auf der Insel Sardinien besessen haben; arabische Familien haben ihre primitive Katzenrasse als 
Haustiere dahin mitgebracht, beim Anstürmen der späteren Eroberer blieben damn diese sich selbst überlassen und verwilderten.

I) a die Pisaner schon im elften Jahrhundert nach Sardinien kamen und längere Zeit dort herrschten, können dieselben diese Rasse in ihrer Ileimat eingebürgert haben; jedenfalls ist es nicht zufällig, dass nur in der Toscana bisher die wilden Sardenkatzen angetroffen wurden.

Ich erblicke daher in der von Martorelli aufgestellten. Subspecies Felis mediterranea keineswegs eine südeuropäische Kolonie von Wildkatzen,

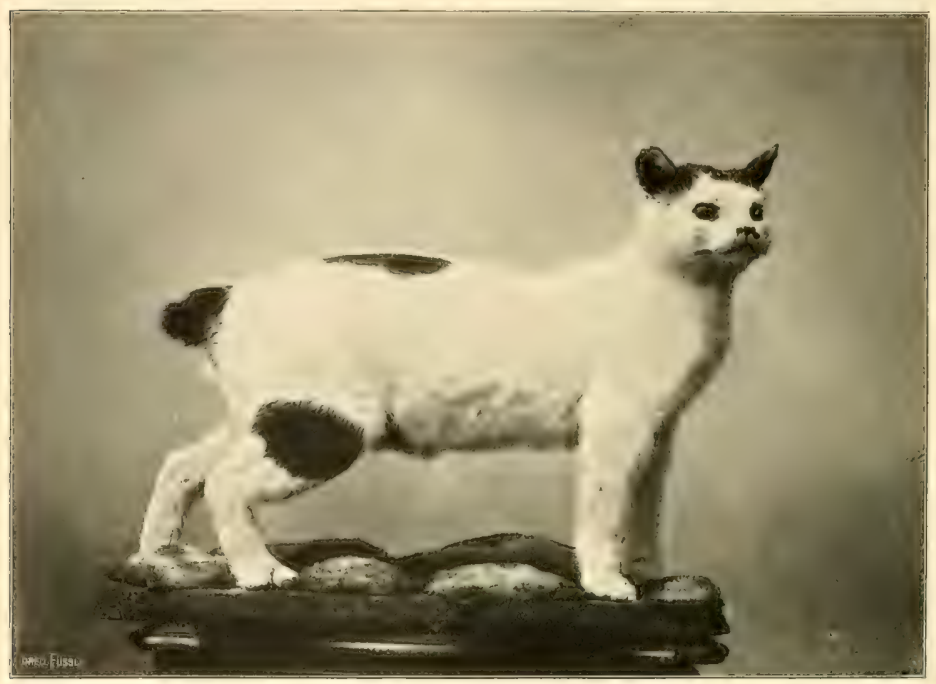

I.ig. 26

Stummelschwïnzige Katze aus Japan. (Landw. Sammlung Zürich.)

die dem Formenkreis von Felis maniculata angehört in dem Sinne, dass sie stets in Sardinien eingebürgert war. Sie hat daher auch keinen Einfluss auf die Bildung europäischer Hauskatzen ausgeübt. Meiner Ansicht nach ist diese Katze als zahmes Tier im Nittelalter durch die Araber importiert worden und später verwildert, teilweise auch nach Toscana verpflanzt worden.

Ich muss übrigens hinzufügen, dass der genannte italienische Zoologe ursprünglich auch dieser Meinung zuneigte und dieselbe erst später geandert hat. $\left.{ }^{1}\right)$

1) G. Martorelli. Osservazioni sui mammiferi educelli fatte in Sardegna. Pag. 8. Pistoja. 1884. 
Von Aegypten aus ist unser Haustier verhältnismässig wenig weit ins Innere des afrikanischen Kontinentes eingedrungen, im ( jebiet der äyuatorialen Seen ist sie selten, ebenso in den Somaliländern, da die gezähmte Felis maniculata an ihre Stelle tritt. Dass in Nordafrika und Südafrika Bastardierungen mit Wildkatzen vorkommen, ist leicht verständlich wegen der Blutsverwandtschaft.

Nach Asien gelangte sie offenbar frühzeitig und dürfte den Weg über Arabien genommen haben. Die grösste Verbreitung erlangte sie in Ostasien, wo sie bei den Chinesen und Japanesen sehr beliebt ist. In Asien ist der ursprünglichen Form wohl am meisten fremdes Blut beigemischt worden, wodurch neue Rassen entstanden. Es ist, bevor die asiatischen Formen nicht besser durchforscht sind, heute ein ziemlich müssiges Unternehmen, darüber mehr oder weniger gewagte Hypothesen aufzustellen. Bezüglich der Angorakatze ist Pallas möglicherweise im Recht, wenn er die Entstehung dieser Rasse auf eine Einwirkung von Felis manul zurückführt. Verschiedene Autoren leiten diese Rasse von Mittelasien her.

In China kommen hängeohrige Katzen vor. Am geschätztesten ist bei ostasiatischen Völkern die Siamkatze: als Luxustier steht sie ziemlich hoch im Preise und wird auch häufig in Japan gehalten. Sie wird mir als geistig sehr begabt und ungemein zutraulich geschildert, man schätzt an ihr das grosse Geschick im Rattenfang. Die blendendweissen, frischgeworfenen Jungen sehen aus wie weisse Mäuse, es sind in der That Albinos mit roten Augen. Später verfärben sie sich, der Pelz wird silbergrau mil schwärzlichem Gesicht; die Füsse, die Schwanz- und Ohrspitzen werden schwarz. Sind die Tiere ausgewachsen, so erscheinen die Augen vollkommen blau.

Beachtenswert erscheint, dass auf den insularen Gebieten Ostasiens, so in Japan, auf Sumatra, dann auch auf der Halbinsel Malakka die Hauskatze immer häufiger stummelschwänzig wird; andere Exemplare haben einen längeren Schwanz, der knotig angeschwollen, geknickt oder sonst wie verbildet ist. In einem sikelett der japanesischen Stummelschwanzkatze. die im Balg schwanzlos erschien, zähle ich nur wenige (7) Schwanzwirbel, die im übrigen normal sind.

Eine auffallende Parallele kennen wir in Europa seit langer Zeit, indem bekanntlich die Hauskatze der englischen Insel Man ebenfalls schwanzlos oder stummelschwänzig geworden ist.

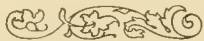




\section{PFERD UND ESEL.}

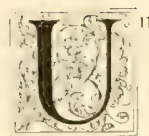

uter den Erwerbungen, welche der Mensch in der Tierwelt zu machen verstand, bilden die Hauspferde zwar nicht die allernützlichsten aber zweifellos die edelsten Glieder der zahmen Fauna, während dem Esel immer etwas Proletarierartiges anhaftet. Die aristokratische Stellung des zahmen Pferdes ist übrigens schon durch seine palaeontologische Geschichte bedingt, indem sein sozusagen lïckenloser Stammbaum von der Gegrenwart an bis in die früheste Eozaenzeit zurückverfolgt werden konnte.

Die Wiege des ganzen Geschlechtes liegt abseits von dem jetzigen Verbreitungsgebiet, in Nordamerika. Dort bergen die Tertiärschichten eine Fülle von Formen, deren ältere Entwicklungszustände tridactyle, tetradactyle und zuletzt pendadactyle Vorfahren aufweisen. Von seinem Ueberschuss hat Nordamerika offenbar wiederholt Material an die alte Welt abgegeben. Vermutlich geschah die Ueberwanderung der leichtbeweglichen, für das Leben auf dem Boden angepassten Tiere auf einer lange Zeit hindurch bestehenden Landbrücke. welche Nordamerika mit dem nördlichen Asien verband. In der ursprünglichen Heimat hat sich die Sippe bis zu der am Ende der Entwicklungsreihe stehenden Gattung Equus zu entwickehn vermocht und Ausläufer derselben bis nach Südamerika vorgeschoben; dann aber erlosch die ganze Pferdegruppe in Amerika in vorcolumbischer Zeit aus Gründen, die uns heute noch nicht völlig verständlich sind. Dagegen hat sich die altweltliche Kolonie unter Bildung von zahlreichen, bald edleren, bald weniger edlen Formen bis in die Gegenwart hinein im Wildzustande forterhalten - nicht ganz ungeschwächt, denn offenbar hat das Vordringen der menschlichen Kultur einzelne wilde. Irten schon erheblich zurückugedrängt.

Ein starker Bruchteil ist hier auch in den Hausstand übergetreten, was die Verbreitung derart begünstigte, dass die alte Welt von ihrem Pferdeüberschuss an die neue Welt, wo ursprünglich das Pferd niemals gezähmt wurde, abgeben konnte -. gleichsam als Gegenleistung für das frühere empfangene Wildmaterial.

Gehen wir den ältesten Spuren unseres Haustieres auf europäischem Boden nach, so begegnen wir ihnen schon in prähistorischer Zeit, aber verhältnismässig spät. Den Bewohnern der ältesten schweizerischen Pfahldörfer scheint das Pferd noch nicht bekannt gewesen zu sein, in späteren 
Ansiedelungen aus derselben Periode sind nach l'ä̈time'ver P'terdereste noch spärlich vorhanden, so dass die Vermutung naheliegt, es seien Beutestücke, welche mehr zufällig in den Bereich der P'fahlbauten gelangten. Auch Studer giebt an, dass Pferderelikte erst in den stationen der Bronzezeit hilufiger werden. Dabei muss die bemerkenswerte 'Thatsache hervorgehohen werden, dass der anatomische Bau der Reste auf ein orientalisches Pferd hinweist. Nach Frank ist dies auch für dasjenige anzunehmen, das in den Prahlbauten der Roseninsel im Starmbergersee aufgefunden wurde. Fin Pferdeschädel aus der römischen Kolonie Vindonissa, der sich in der zürcherischen sammlung befundet, weist ebenfalls auf eine orientalische (bstammung hin.

Alle Thatsachen sprechen dafür, dass nach Osten hin das massenhafte Auftreten des Hauspferdes sich sehr früh nachweisen lisst. Aut griechischem Boden spielte es schon eine Rolle zur Heroenzeit, Gefässbemalungen aus dem vorhistorischen Tiryns weisen Ross und Wagen auf, beides wohl aus dem phönizischen Kulturkreis übernommen. Thracien war schon zur homerischen Zeit rosseberühmt, in Macedonien wurden Züchtungen begründet aus der reichen Beute von Stuten, welche den Skythen abgenommen wurde. Thessalien betrieb eine starke P'ferdezucht und antike Münzen aus Larissa lassen neben einem leichtgebauten zierlichen Schlag auch einen schweren Typus erkennen.

Den Juden und Arabern fehlte ursprünglich das Pferd. Erst zu Salomos Zeit kam die Rossezucht stark in Aufschwung und die Araber leiten bekanntlich ihre edlen Pferde der Abstammung nach von den Gestüten Salomos ab. Ich werde weiter unten zeigen, dass diese weit verbreitete Annahme unwahrscheinlich ist. Auf afrikanischem Boden erscheint das Pferd verhältnismässig spät. Die Aegyptologen haben längst darauf hingewiesen, dass während der ältesten Dynastien und auch noch während des mittleren Reiches das P'ferd niemals abgebildet wird; es hat somit wirklich gefehlt. Erst mit der 18. Dynastie (etwa 1500 v. Chr.) begegnen wir demselben auf den ägyptischen Denkmälern. A. Ermann bemerkt, dass seine Einführung in die dunkle Epoche zwischen dem mittleren und dem neuen Reich fällt. Von welchem vorderasiatischen Volke die legypter das Pferd übernommen haben. lässt sich zur Zeit nicht mit Sicherheit feststellen; dass es von den in jener Periode mächtigen Hyksos eingeführt wurde, steht keineswegs fest. Im neuen Reich gewann es rasch an Ausdehnung. Die Tiere werden als braun dargestellt, einmal jedoch auch Schimmel abgebildet, der Körper ist leicht gebaut mit konkavem Profil und trockenem Gesicht des orientalischen Typus; sie wurden vor den Kriegswagen gespannt, aber auch zum Reiten benutzt. Iuf einem thebanischen Gräberbild erscheint auch bereits das Kreuzungsprodukt mit dem früher schon im Hausstande gehaltenen Esel als Maulesel.

Von allen alten Kulturkreisen steht offenbar das mesopotamische Gebiet 
in Mittelpunkt der Pferdezucht. Kein Haustier wird in der altassyrischen Kunst so häufig dargestellt wie das Pferd, das bald als Reittier dient, vor dem Kriegswagen in der Schlacht verwendet oder bei der hohen Jagd mitgeführt wird. Wie weit dasselbe zeitlich bei den Babyloniern zurückreicht, müssen künftige Funde im Zweistromland erst noch aufklären. In Assyrien, wo die Blüte der Kunst ganz unvermittelt und ohne Jugendstadium auftritt, haben wir bereits edle und hochgezüchtete Rassen, als deren Abkömmlinge wir die heutigen reinblütigen Araberpferde ansehen dürfen. Die südlichen Semiten haben aus jener Region das P'ferd übernommen und weiter verbreitet.

Frühzeitig scheint dasselbe nach Jndien vorgedrungen zu sein, indem es schon in den Vedas erwähnt wird.

Alle die genannten historischen Thatsachen weisen auf eine asiatische Stammquelle der alltesten Hauspferde hin. In Mittelasien oder doch in einer davon nicht allzuweit entfernten Region hat man einen Ilauptbildungsherd zu suchen, wobei wir nicht notwendig gerade Mesopotamien als solchen anzusehen haben, da auch mongolische Stimme frühzeitig in den Besitz des Pferdes gelangt sind. Es soll damit auch keineswegs einer monophyletischen Abstammung das Wort geredet werden, da offenbar auch noch andere Regionen an der Erzeugung domestizierter Pferde beteiligt sind.

Ein Ueberblick ïber die heutigen Rassenbestände lässt im einzelnen weitgehende Unterschiede erkennen, die sich sowohl auf die Grösse wie auf den anatomischen Bau erstrecken. Wwischen dem schweren deutschen Karrenpferd und dem zwergartigen Pony der insularen Gebiete Europas und Asiens ist ein weiter Abstand, im Bau des Schädels und der Glied. massen besteht eine grosse Kluft zwischen dem zierlichen Pferd Arabiens und dem schwerfälligen germanischen Gaul.

Der französische Zootechniker Sanson hat nicht weniger als acht Rassentypen unterschieden, ${ }^{1}$ ) die teils kurzköpfig oder brachycephal (Equus caballus asiaticus, E. c. africanus, E. c. hibernicus, E. c. britannicus) sind. teils langköpfige oder dolichocephale Pferde aufweisen (Equus caballus germanicus, E. c. frisius, E. c. belgicus und E. c. sequanius).

Weit zutreffender erscheint die Einteilung von $L$. Frank, welcher 1875 seine Untersuchungen veröffentlichte ${ }^{2}$ ) und nur zwei Hauptrassen - die orientalische Hauptrasse und die occidentale Hauptrasse - annimmt. Ich stimme ihr bei, weil sie phylogenetisch gut begründet werden kann.

Der orientalisclie oder arabische Typus ist dadurch charakterisiert, dass der Gehirnschidel sehr stark entwickelt ist, während der Gesichtsschadel zurücktritt, wodurch die Backzahnreihen verhältnismässig kurz werden und das Profil konkav erscheint, auch mehr gerade, niemals aber geramst ist.

1) Sanson. Traité de Zootechnie. 1874.

") L. Frank. Ein Beitrag zur Rassekunde unserer Pferde. Landwirtschaftliche Jahrbücher. Berlin. 18;5. 
Das muskelarme Gesicht wird als trocken bezeichnet. Die Knochen besitzen bei geringer Massigkeit eine dichte Beschaffenheit, so datsi die Gliedmatssen grosse Festigkeit mit einem zierlichen Bau verbinden. Die Lendenwirbel sind kurz, zusammengedrängt. I lierher gehören das arabische, persische, griechische, russische und ungarische Pferd, sowie das P'ahlbaupferd und die ostasiatischen Ponies.

Der occidentale oder norische Typus zeigt umgekehrt eine starke Entwicklung des Gesichtsschädels, während der Hirnschädel zurücktritt. Der Kopf ist also lang und schwer, häufig geramst d. h. mit konvexer Profillinie. Die Backzahnreihe ist mehr in die Länge gezogen und die Schmelzfaltung der Marken komplizierter als beim orientalischen P'ferd. Im Skelett fällt das Massige des Knochenbaues auf. Als Vertreter dieser Hauptrasse sind das schwere germanische P'ferd, das tlandrische und das alte Normannenpferd, das Luxemburgerpferd anzusehen.

Nach Frank ist der dem Esel näher stehende orientalische Typus der ältere, der occidentale der jüngere; der erstere ist in seiner Reinheit auf weiten Gebieten erhalten geblieben, withrend der letztere durch Aufnahme von orientalischem Blut vielfach verwischt erscheint.

Die beiden genannten Typen sind ihrer Abstammung nach zweifellos verschieden.

Für die orientalischen P'ferde muss ein asiatischer Ursprung angenommen werden, da sie nachweisbar in Afrika relativ spät erscheinen und im mittleren Europa erst zur Bronzezeit sich häufiger einzubürgern begannen.

Asien besitzt Wildmaterial, an das sich anknüpfen lässt. Die einzelnen Arten desselben werden von den Autoren zum Teil zu hoch in der Zahl bemessen, dat oflenbar geosraphische Varietiten als grute speries ausgegchen wurden. Man wird die asiatischen Wildformen auf drei Spezies reduzieren dürfen. Unter diesen ist der mehr westliche Onager (Equus onager) als Stammform von Hauspferden ausgeschlossen, da er nach seinem Körperbau den Eseln zugerechnet werden muss.

Der in den Steppen des südöstlichen Russland lebende "Tarpan", ein herrenloses Pferd mit anscheinendem Wildcharakter kann als Stammart ebenfalls nicht in Betracht kommen. Wir besitzen von Gmelin, Schatilozu und Radde nähere Angaben über den Tarpan; er wird von kleiner Statur geschildert, der Kopf ist ziemlich dick, die Färbung meist mäusegrau mit dunklem Rückenstreif. $\mathscr{F}$. Tscherski hat uns 1893 zuerst eine genaue anatomische Inalyse des Schädels geliefert. $\left.{ }^{1}\right)$ atus welcher hervorgeht, dass der Tarpan der orientalischen P’ierdegruppe zugerechnet werden muss, jedoch eigentümliche Verhältnisse anfireist, die eine Annaherung an das germanische Pferd dokumentieren. Der Schnauzenteil des Kopfskelettes ist auffallend kurz, der Hirnteil schmal, in seiner grössten Breite steht er jedenfalls unter

1) F. Tscherski. Wissenschaftliche Resultate der Neusibirischen Expedition. Mémoires de r'Academie de St. Petersbourg. 1893. 
dem Mittel der östlichen Gruppe. Mit dem postpliocaenen sibirischen Pferd steht der Tarpantypus in keiner engeren Beziehung und so dürften die russischen Naturforscher Recht behaiten, wenn sie diesem angeblichen Wildpterd gegrenüber sich skeptisch verhalten und den Tarpan einfach als verwildertes Hauspierd ansehen.

Beim Kulan (Equus hemionus), den Brehm einst für den Stammvater des Hauspferdes erklären wollte, ist die Stirn zwar breit, aber der Schnauzenteil

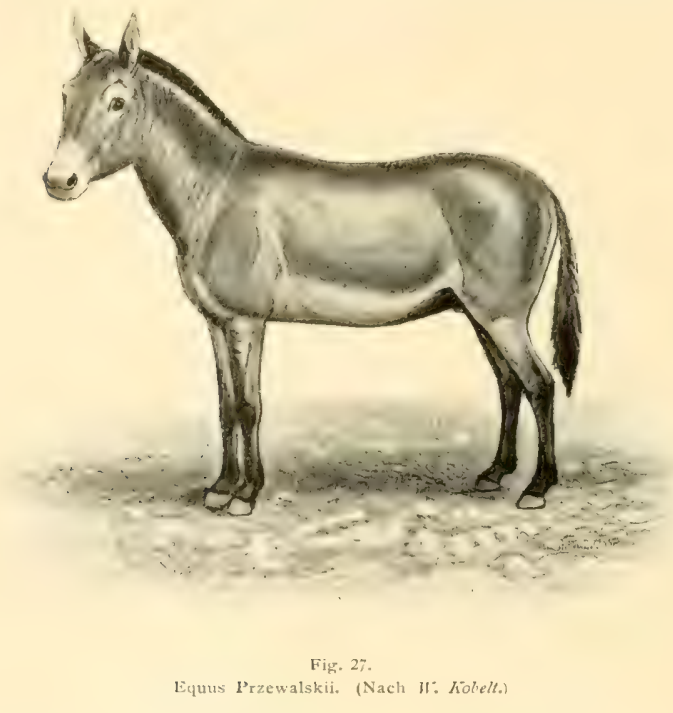

so extrem lang, dass der Facialindex selbst denjenigen der abendländischen Pferde erheblich übertrifft. Dieser Typus entfernt sich daher vom orientalischen Pferd viel zu sehr, als dass an eine verwandtschaftliche Beziehung, wie sie die Domestikation verlangt, gedacht werden kanm. Dazu kommt noch der weitere Umstand, dass der Kulan sich nicht leicht zähmen lässt und wenn er auch jung aufgezogen anfänglich sich dem Menschen anzuschliessen scheint, doch bald wieder in den wilden Charakter seiner Art zurückschliugt. Vun besonderer Wichtigkeit wurde dagegen teine Entdeckung. die der russische Reisende Przewalski 1879 in Innerasien machte. Während seines Aufenthaltes im Saisanschen Posten erhielt er das Fell und den Schädel eines wilden Pferdes, das die Kirgisen in der Sandwüste Kanabo erlegt hatten. Das Exemplar gelangte in den Besitz des Museum der kaiserlichen Akademie der Wissenschaften in Petersburg und wurde von 
Poljakow unter dem Namen Equus Przewalskii als neue Art beschrieben. Hier handelt es sich nicht wie beim Tarpan um ein verwildertes Hauspferd, sondern um eine ächte Wildform, die seither von Büchner in der I) sungarei wieder angetroffen wurde. Er hat 1899 zehn Fohlen eingebracht und in Südrussland akklimatisiert. ${ }^{1}$ )

Das Przezualski'sche Pferd lebt in Herden von 5-15 Stück unter Anführung eines alten Hengstes, seine Statur ist klein, die Ohren kurz, die Maihne aufrecht stehend. Der Schweif ist nur in der unteren Ialfte mit langen Haaren bewachsen. Die vorherrschende Färbung wird als weissgrau angegeben, die Beine werden vom Knie an bis zu den Hufen hinunter dunkel. Tscherski, welcher eine grenaue (Tntersuchung des (Originalichaidels vornahm, hat betont, dass man es hier mit einem den echten Pferden zugehörigen Tier zu thun hat. Der Hirnteil erreicht eine Breite, die über dem Mittel der Vertreter orientalischer Pferde steht, die Stirnknochen erscheinen flach; die Nasenbeine verschmälern sich langsam nach vorn, also nicht plötzlich wie beim Esel. Der Schädel steht seinem ganzen Bau nach demjenigen des russischen Pferdes am nächsten.

Seither hat Tichomiroff durch erneuerte Untersuchungen die Ueberzeugung gewonnen, dass genanntes Wildpferd thatsächlich dem Hauspferd sehr nahe steht, aber zweifellos als Wildart, nicht als verwildertes Haustier, angesehen werden muss.

Wir haben somit in Equus Przewalskii, dessen Reste heute noch leben, früher aber wohl weit über Innerasien verbreitet waren, die Stammquelle der orientalischen P'ferde zu erblicken.

Ich kann diesem auf anatomischem Wege erlangten Resultat noch eine wichtige Restätigung durch die Kunstgeschichte hinzufügen. Auf einer Marmorplatte, welche in Kujundschik im Palast des Assurbanipal (668 v. Chr.) gefunden wurde, wird eine Jagd auf Wildpferde als Basrelief dargestellt. Ier assyrische Künstler hat hier eine Tierszene wiedergegeben. die an Naturtreue und Sorgfalt in der Ausführung den besten Leistungen der antiken Tierplastik an die Seite gestellt werden darf. Zwei kräftige Männer haben mit einem Lasso ein junges Pferd eingefangen, während zwei andere davongaloppieren. Dass es sich um ein Wildpferd handelt, beweist die aufrecht stehende Mähne. Dieses Pferd wird nun von den Archaeologen beharrlich als Wildesel Westasiens oder Onager bezeichnet, weil der Schwanz nur im unteren Teil lang behaart ist. Neuerdings noch hat G. de Nortillel diese Ansicht vorgebracht.") Eine genauere zoologische Analyse wird uns die Unhaltbarkeit derselben sofort darthun. Der Bau des Tieres verrät die Zierlichkeit des orientalischen Pferdes. Die meisterhaft modellierten Köpfe der drei l'ferde haben durchaus nichts Eselähnliches.

1) Zitiert nach $\boldsymbol{U}$. Kobelt. Die Verbreitung der Tierwelt. 1901.

$\left.{ }^{2}\right)$ G. de Mortillet. Origine de la chasse, de la péche et de l'Agriculture. Paris, 1840. Pag. 199. 
sondern bringen mit ihrem konkaven I'rofil, dem trockenen Gesicht, den vorgewölbten Angen und kurzen Ohren den Charakter des edeln arabischen P'erdes in prägnanter Weise zum Ausdruck. Der Schwanz ist kein Eselschwanz, dafür spricht schon seine Kürze; beim Onager ist nur das untere Drittel lang behaart, hier aber schon von der Mitte an. Nun bemerkt mir ein guter Pferdekenner, dass diese an Grunde kurze Behaarung ein Merkmal des edeln arabischen Blutes sei und bekanntlich findet es sich auch bei P'ferden Sardiniens, wie Maltzan berichtet." )

Dieser angebliche altassyrische Onager ist also in Wirklichkeit ein

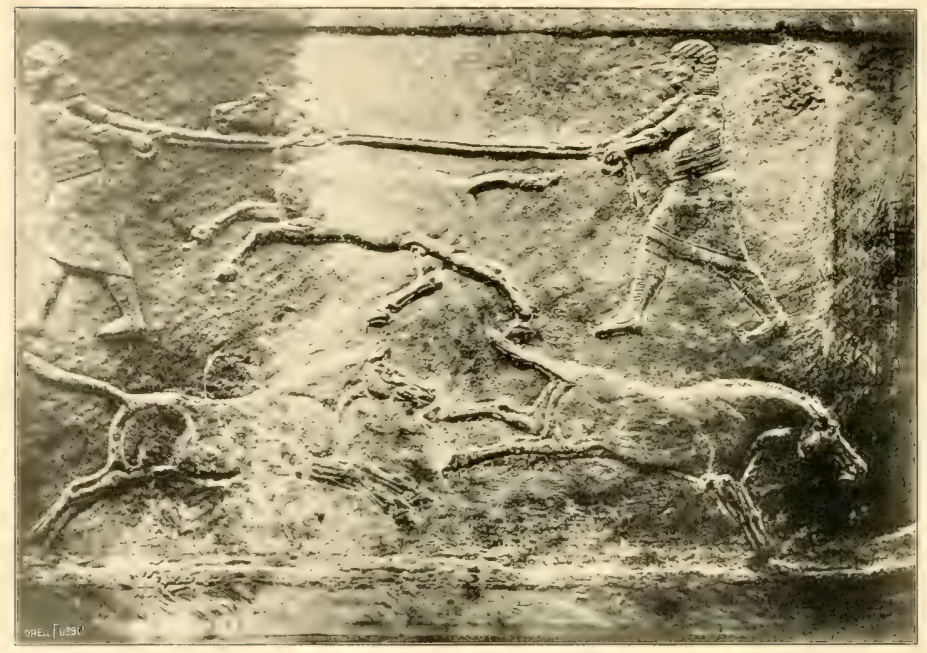

Fig. 28.

Assyrische i)arstellung der Jagd auf Wildpferde, Palast des Assurbanipal in Kujundschik. GG8 v. Chr. (Briti<h Museum.)

Equus Przewalskii, vielleicht eine trockengesichtige Varietït desselben. Tiergeographisch ist es jedenfalls von Interesse, dass diese heute auf die Isungarei zurückgedrängte Art im ersten vorchristlichen Jahrtausend auch in Mesopotamien heimisch war.

Ich glaube, dass das vorliegende Kunstwerk auch Aufschluss über die Entstehung des edeln arabischen Pferdes giebt, das ja in der Kopfbildung mit den assyrischen Figuren übereinstimmt. Der mesopotamische Kulturkreis mag vou Norden her das zalme I'ferd übernommen haben; aber von Zeit zu Zeit dürfte eine Blutauffrischung mit einheimischem Wildmaterial statt-

1) Afaltzan. Keise auf Sardinien. 1869. 
gefunden haben. I3eachtenswerter scheint, dass das eingefangene junge Pferd ein IJengst ist. Daraus entstand wohl ein feuriger Stamm, der später von den Arabern noch veredelt wurde. Durchmustert man die altassyrischen P'ferdebilder, so begegnet uns meistens ein sehr langschweifiges Pferd, daneben eine andere Rasse mit kurzem Schweif und nackter Rübe. ${ }^{1}$ ). Die orientalische Rassengruppe des Hauspferdes ist, wie bei dem hohen Alter der Domestikation sich erwarten lïsst, in der Gegenwart räumlich weit ausgebreitet.

Immerasien und IIochasien sind die individuenreichsten Gebiete. Die mongolischen Schligge der Kiahü̈cken und Kirgisen, in ganzen klein, aber sehr beweglich und ausdauernd, haben sich in neuerer Zeit bis zum WValdgebiet Nordsibiriens verbreitet: im Osten sind sie nach China, Birma und Siam vorgedrungen, längst auch in Indien heimisch. In den feuchten Niederungen Südasiens vermag das P'ferd sich nicht leicht zu behaupten. Auf den Inselgebieten z. B. in Java erscheint es in einer ponyartigen Form.

In Japan wird gegenwärtig die ursprüngliche Rassezusammensetzung stark verwischt, in dem in jüngster Zeit europätische Pfercle, namentlich Normänner-Schläge und ungarische Pferde in grösserer Zahl eingeführt wurden. Auf der Hauptinsel überwiegt immer noch der schwarze oder braune, ziemlich grosse Nambuschlag, im Süden der Insel fehlt das l'ferd. Auf den kleineren Inseln trifft man ponyartige T'iere von $1 \frac{1}{3}$ Meter Höhe an. Das dunkelbraune P'ferd der Insel Jesso ist nach den mir zugegangenen Mitteilungen ein Abkömmling des mandschurischen Schlages; im Winter wird es nach den Bergen verbracht, wo es seine Nahrung unter dem Schnee hervorscharren muss.

Westasien, die Kaukasusländer, Russland; Griechenland, Bulgarien, Siebenbürgen und Ungarn weisen überall orientalische P'ferde auf, die dem innerasiatischen Schlag nahe stehen. Afrika hat seinen Pferdebestand Asien entlehnt. Die Einwanderung zu Beginn des zweiten vorchristlichen Jahrtausends ins Nilthal wurde früher schon hervorgehoben. Gegenwärtig besitzt Aegypten einen nicht gerade sorgfältig gehalten, etwas verdorbenen arabischen Schlag. Die I3erberschläge Nordafrikas haben sich in Südspanien eingebürgert und sind von da nach Mexiko gelangt.

Ostafrika besitzt einen grossen Reichtum an zahmen P'ferden edler Rasse. Die Somalistämme und Gallavölker haben für das Haustier keinen eigenen Namen, sie nemnen es "faras" wie die Araber, was für die Abstammung bezeichnend ist. Das Somalipferd ist etwas grösser als der Araber, im übrigen durch den feinen Bau des Gesichtes und der Glieder ihm nahe verwandt. Schweif und Mähne sind lang, die Brust enorm entwickelt. Nach Süden reicht das orientalische Pferd bis in die Hochländer von Transvaal. Die ostafrikanischen Inseln Réunion und Mauritius haben

1) Vrgl. Layard. The monuments of Niniveh. 
früher meistes abessrnische Pferde eingeführt. Madagaskar besitzt keine I'ferde, da das fenchtwarme Klima dem an die steppe gewöhnten Geschöpf nicht zusagt.

Gehen wir der I Jerkunft der abendländischen Iauptrasse nach, so liegen jetzt bestimmte Thatsachen vor, welche auf einen europäischen Bildungsherd schliessen lassen. An Wildmaterial hat es ja auch hier nicht gefehlt. In der Diluvialzeit besass Europa zwei Wildpferde, nämlich Equus caballus foss. und Equus hemionus (Halbesel oder Dschiggetai). Letztere Art war selten, reichte aber bis in die Nähe der Alpen, indem ihre Spuren in den prähistorischen Niederlatsungen des schweizerischen Kantons Schafthausen nachgewiesen werden konnten. Nehring erwähnt das Vorkommen in Nordund Mitteldeutschland. Der Halbesel hat sich längst nach dem inneren Asien zurückgezogen. Weit verbreiteter war Equus caballus im Wildzustande. Die massenhaften P'ferdereste der prähistorischen Station Solutré lassen vermuten, dass der Urbewohner Europas zum Zweck des Nahrungserwerbes Wildpferde gejagt hat. Nehring $g^{-1}$ ) fand bei Westeregeln in der Nabe von Magdeburg. P'ferdeknochen mit steppentieren vergesellschaftet, in den Lössablagerungen bei Remagen am Rhein kam das Skelett einer zehnjährigen Stute mit Resten von Bison und Moschusochs zum Vorschein; als weitere Fundstellen sind Thiede bei Wolfenbüttel und die Lindenthaler Höhle bei Gera zu nennen. Dieses Diluvialpferd war ein schweres, mittelgrosses P’ferd, das dem occidentalen Typus des germanischen Hauspferdes so nahe steht, dass wir es als den ummittelbaren Vorläufer des letzteren ansehen müssen. Dafür spricht neben dem Schädelbau auch die starke Faltelung des Schmelzbleches an den Halbmonden der oberen Backenzälnue. Die Extremitäten sind sehr kräftig gebaut.

Auch in Schweden sind Spuren eines Wildpferdes bemerkt worden, indem im November 1900 F. A. Sjörgren bei Ingelstad einen P'ferdeschädel aus der jüngeren Steinzeit auffand, ${ }^{2}$ ) in welchem noch eine Feuersteinwaffe, ein abgebrochenes Dolchblatt steckte. Das Alter des Pferdes dürfte auf zwei Jahre anzuschlagen sein und da man ein so junges P'ferd, wäre es zahm gewesen, gewiss nicht geschlachtet hatte, so lässt dies auf eine Wildform schliessen. Wahrschemlich reichte die Art bis nach Sibirien, da \%. Tscherski an den diluvialen Resten Nordasiens Abweichungen von dem orientalischen Typus festgestellt hat. ${ }^{3}$ )

Die Wildpferde Europas haben noch weit in die historische Zeit hineingereicht. Selbst wemn wir den Angaben von Plinius und Strabo keinen

1) A. Veliving. Fossile Pferde aus deutschen Diluvial-Ablagerungen und ihre Beziehungen zu den lebenden P'ferden. Landw. Jahrbücher. 1884.

2) Zeitschrift "Globus" vom 20. Juni 1901.

3) F. Tscherski. Resultate der Neusibirischen Expedition. 
grossen Wert beimessen wollten, so haben wir doch eine spätere und bestimmtere Angabe für das ostschweizerische Gebiet, indem von Eklichard IV, Magister scholarum im Kloster St. Gallen das wilde Pferd in seinen Speisesegnungen aufgefülnrt wird (Sit feralis equi caro dulcis in hac cruce Christi. ${ }^{1}$ ) Sein Fleisch kam also auf die Klostertafel der frommen Mönche. Nach Erasmus Stella kamen noch im Anfang des 16. Jahrhunderts wilde Pferde in Preussen vor und Hclisaens Rösslin erwähnt das Wildpferd aus dem Wasgauischen Gebirge im Jahr 1593. Der Bewohner Europas hatte somit in seinem Wildstande genügendes Pferdematerial, um auf seinem Boden ein Haustier daraus zu erziehen. Es ist denkbar, dass das Andringen der älteren orientalischen Hauspierde den äusseren Anstoss dazu gab.

Im Sinne von Nchring haben wir daher die schweren Schläge Mitteleuropas als direkte Abkömmlinge des kräftig gebauten diluvialen Wildpferdes, das noch in die historische \%eit hineinreicht, zu betrachten, während die östlichen, meist kleinen Pferde asiatischer Abstammung sind und aus dem heute noch in Hochasien lebenden Equus Przewalskii hervorgingen.

Die abendländischen Pferde sind in der Gegenwart reinblütig nur auf einem beschränkten Areal anzutreften, vielfach ist orientalisches Blut eingeflossen. Ausgesprochen occidentalen Charakter besitzen die norischen Pferde in Salzburg, Tirol und Steiermark, den stärksten Schlag bildet das Pinzgauer Pferd; im weiteren werden hieher gerechnet das alte NormannerPferd, das flamländische Pferd, der Percheron-Schlag und das mächtige, englische Karrenpferd (igricultural Horse).

Weit früher als das Pferd dürfte der weniger edle Vetter, der Esel, in den Hausstand eingetreten sein, wobei er zunächst eng mit dem hamosemitischen Kulturkreis verknüpft ist und über das Gebiet der Semiten und Hamiten hinaus eigentlich niemals die richtige Würdigung erfahren hat. Wohl hat er sich auch stark in Südeuropa eingebürgert, sank aber hier zur Karrikatur herab. Die ältesten Spuren zahmer Esel, die uns bisher bekannt geworden sind, lassen sich auf afrikanischem Boden nachweisen und reichen dort in die urägyptische Zeit zurück. Jedenfalls war der Esel vor der I. Dynastie im Nilthal Haustier geworden, da er schon in der Negadahzeit aut einer schicterplatte abgebildet wirch und \%war in fexellschat von zahmen Schafen und Rindern. Es ist die gewöhnliche Form des Hausesels mit schwarzem Schulterkreuz, das auf allen Figuren deutlich erkembar ist. Während des alten Pharaonenreiches dehnte sich die Zucht des Esels stark aus, sagt uns doch der Bericht eines Oberschreibers an seinen Herrn, dass dieser nicht weniger als 5023 Stück Vieh sein eigen nemnen darf, darunter

1) Ferdinand heller. Benedictiones ad mensas Ekkehardi. Mitteilungen der Antiquarischen Gesellschaft in Zürich. 11I. Bd. 1847. 
760 Esel. ${ }^{1}$ ) In den ältesten Dynastien wird das Tier häufig dargestellt; es wurde als Lasttier sowie zum Dreschen auf der Tenne verwendet, dagegen als Reittier nicht in der Weise, dass der Aegypter sich auf seinen Rücken setzte, sondern so, dass ein Reitsessel zwischen zwei Eseln befestigt wurde, um darin die über Land reisende P'erson aufzunehmen. In neuen Reich trat mit der Einführung des P'ferdes die Bedeutung des Esels zurück.

Die Juden kannten den Esel seit Abrahams Zeiten und hatten ihn wohl von den Aegyptern übernommen. In Südeuropa erscheint er schon frühzeitig, da er schon von Aristoteles erwïhnt wird und zu seiner Zeit stark verbreitet war.

Mit Bezug auf die Abstammung der einzelnen, in Grösse, Färbung und Behaarung vielfach abweichenden Schläge bemerkt Darwin: "Man kam nicht zweifeln, dass unsere domestizierten Tiere von einer einzigen Art, nämlich dem Asinus taeniopus abstammen".") Ich glaube indessen, dass wir auch hier eine diphyletische Abstammung anzunehmen haben.

Für die kleineren Schläge ist die Herkunft vom ostafrikanischen Steppenesel (Asinus taeniopus) zweifellos, dafür spricht nicht allein das bei vielen zahmen T'ieren deutliche Schulterkreuz und die Bänderung an den Beinen, sondern auch die Kopfform und die übrigen körperlichen Proportionen. Im allgemeinen ist der Hausesel gegenüber der Wildform etwas kleiner im Wuchs, doch habe ich im Innern der Somaliländer Karawanenesel gesehen. die ihr an Grösse fast gleich kommen. Auch die Bänderung an den Beinen ist oft scharf ausgeprägt; bei einem Esel in der Ungebung von Massaua zählte ich sieben Beinstreifen.

Der ostafrikanische Steppenesel, ein Uebergangsglied zwischen den afrikanischen Tigerpferden und den asiatischen Wildpferden, ist heute noch von Obernubien bis zum Kap Guardatui verbreitet. Nach mündlichen Mitteihungen von $G$. Schweinfurth kommt er sogar auf der Insel Sokotora vor, doch ist er dort möglicherweise nur verwildert. In Nubien habe ich von den Eingebornen von seinem Vorkommen gehört, in den Somaliländern sah ich mehrfach Trupps von sieben bis acht Stück, so schon in der Nähe von Bulhar, dam im Gebiet der Aulihan: die Tiere sind aber sehr scheu und werden nach den Aussagen der Eingebornen dort niemals eingefangen und gezähmt.

Die IIauptmasse der zahmen Esel, die ich unter dem Namen der Taeniopusschläge zusammenfässen möchte und zu denen auch der südeuropäische Esel gehört, ist jedenfalls afrikanischen Ursprungs. Da der Hausesel in Oberägypten schon vor der I. Dvnastie nachweisbar ist, haben wir dort oder jedenfalls in der Nähe den ältesten Bildungsherd zu suchen. Weil der Neger von jeher den Esel abgelehnt hat, so waren es offenbar hamitische Volksstämme, wahrscheinlich die Vorfahren der heutigen Galla, welche die Zähmung des afrikanischen Steppenesels zuerst an die Hand genommen haben.

1) A. Erman. Aegypten und ägyptisches Leben im Altertum. I'ag. 586.

2) Ch. Darwin, Variieren der Tiere und Pllanzen im Zustande der Domestikation. Bd. I. 
Daneben existiert jedoch noch ein wostasiatischer Bildungsherd. In der Litteratur finde ich vielfach eine schöngebaute, weisse Eselrasse erwähnt, die mir mit den übrigen wenig gemeinsam zu haben scheint. Ich beobachtete dieselbe zum ersten Mal in Kairo. Es ist ein anmutiges, grosses Tier, das einem kleineren Araber in der Höle nahekommt; die Haare sind kurz, dicht anliegend und von weisser oder isabellgelber Färbung, der eselartige Kopf wird stolz getragen. Von dem störrischen Wesen, das allen

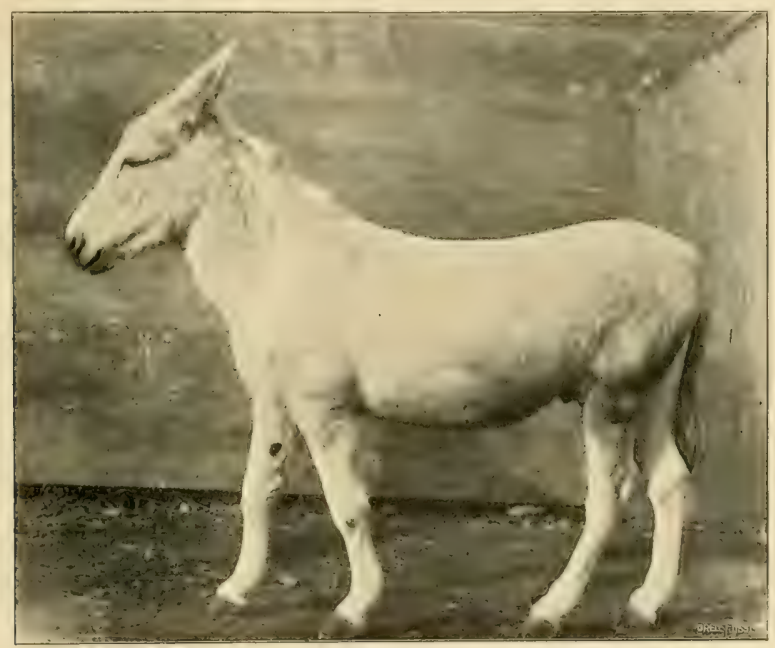

Fin, 20,

Aegyptischer Ilausesel der Onaurer-Răsse. (Originalaufnalume).

übrigen Eseln gemeinsam ist, besitzt diese Rasse nichts, sie ist im Gegenteil sehr lenksam und wird von den vornehmen 1)amen in Kairo als Zelter benutzt. Nach mündlicher Mitteilung von Fohn Sundberg; welcher als Konsul in Mesopotamien einige Jahre zugebracht hat, kommt diese schöne Rasse auch in Bagdad neben dem gewöhnlichen Lastesel häufig auf den Markt und wird dort mit 25 Pfund (etwa 700 Franken) per Stück bezahlt. Die besten Zuchten stammen aus Nedje in Zentralarabien. Es war mir nicht möglich, Schädelmaterial zu erlangen, allein der psychische Charakter, der Körperbau im allgemeinen und die Färbung lassen für mich keinen Zweifel übrig, dass diese edlen Esel vom westasiatischen Wildesel (Equus onager) abstammen und daher eine eigene Rasse bilden, die ich als OnagerRasse bezeichnen möchte.

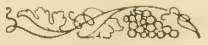




\section{DIE HAUSSCHWEINE.}

Obschon zahme Schweine sehr früh in der Umgebung des Menschen erscheinen, haben sie unter dem Einfluss der Domestikation im ganzen doch weniger Umgestaltungen erlitten als andere Haustiere.

Wie H. von Tathusius an der I Iand treftlicher Studien über die altweltlichen Rassen gezeigt hat, lassen sich, soweit es sich um ungekreuzte Tiere handelt. zwei Formenreihen unterscheiden, die im ausseren IIabitus wie in osteologischen Merkmalen sehr beständige Eigentümlichkeiten aufweisen. Im Schädel sind es namentlich die Thränenbeine und der Verlauf der Backenzahnreihen. welche einerseits die Sus europaeus-Reihe, zu der die gegenwärtig immer mehr zurücktretenden Landschweine Mitteleuropas gehören, anderseits die Sus indicus-Reihe Ostasiens durch charakteristische Unterschiede auszeichnen. Die Sus indicus-Formen sind übrigens nicht auf Süd- und Ost-Asien beschrïnkt, sondern auch über Oceanien und einen grossen Teil von Afrika verbreitet, sie greifen sogar aut die romanischen Gebiete von Südeuropa hinüber.

Wir werden nachweisen, dass die erwähnten beiden Formemeihen auf verschiedene Stammquellen zurückführbar sind.

\section{DAS AUFTRETEN DER SCHWEINE IN DER}

\section{PRAEHISTORISCHEX ZEIT ('NI) IX IOEN AELTESTEN}

\section{KULTURPERIODEN.}

Wir kennen Reste zahmer Schweine seit langer Zeit aus den schweizerischen Pfahlbatuten; sie reprilsenticren eine Rasse, die vom mitteleuropäischen Landschwein und dem hei uns heimischen Wildschwein nicht unerheblich abweicht. L. Rütimcier hat daraus eine besondere Art, das Torfschwein (Sus palustris) gemacht; er bemerkt in seiner "Fauna der Pfahlbauten", dass in den altesten Pfahldorfern das Schwein als Haustier fehlte, erst in den späteren Perioden des Steinalters Haustier wurde und dann in immer steigender Menge erscheint. Er glaubte anfänglich, dass neben dem gewöhnlichen Wildschwein in Europa noch eine zweite wilde Art lebte, die zuerst gezähmt wurde, die Torfrasse lieferte und als wilde Form schon vor der historischen Zeit erlosch. Ihm war die Thatsache noch nicht bekannt. dass heute noch ein Torfschweinähnliches wildes Schwein. über das ich 
später noch einige Bemerkungen machen werde, im mediterranen lnselgebiet vorkommt. Der Widerspruch von $\left.\boldsymbol{V}_{\text {athusius }}{ }^{1}\right)$ veranlasste Rütimejer später, von der ursprünglichen Annahme abzugehen, da ihm die nahen Beziehungen der 'Torfschweine zu den asiatischen Hausschweinen. nicht mehr entgehen konnten.

Etwas später erscheint in den schweizerischen Pfahlbauten ein grösseres Hausschwein, das offenbar ein Abłömmling des gewöhnlichen Wildschweines

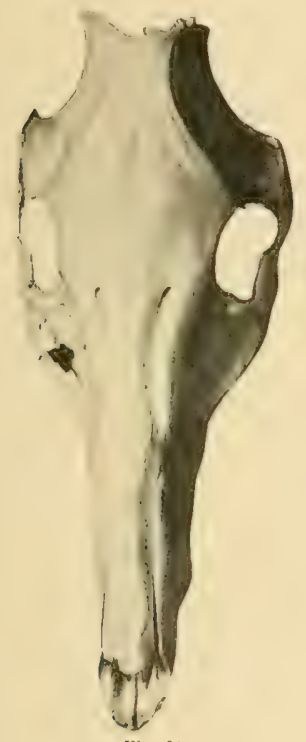

Schidel des Torfschweines von Lattringen. (Nach F: Otto.)

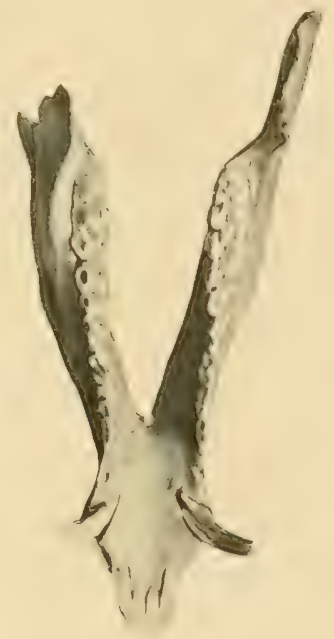

Fig. 31 .

Unterkiefer des Torfschweines aus der Pfalllhante von Schaffis.

(Nach F. Otto.)

(Sus scrofa) ist und seinen kleineren Vorgänger allmählig zurückdrängt.

Immerhin ist noch während der helvetisch-römischen Zeit das Torfschwein in der Schweiz stark verbreitet; von den in Vindonissa aufgefundenen Resten gehören ihm 28 Knochenrelikte an, während das europäische Landschwein nur durch 10 Stücke vertreten war.

In den norddeutschen Pfahlbauten und in den prähistorischen Resten aus Dänemark ist das Hausschwein ebenfalls aufgefunden worden. Während aber in den schweizerischen Pfahlbauten zwei Rassen vorkamen, scheint die echte Palustrisform im Norden zu fehlen, wenigstens hebt A. Neluing

1) Hermann żou Nathusins. Vorstudien für Geschichte und Zucht der Haustiere zunächst am Schweineschädel. 1864 . 
als beachtenswert hervor. dass die von ihm untersuchten Schweinereste alle einem etwas kleinen Abkömmling des europäischen Wildschweines angehören (Sus scrofa nanus). ${ }^{1}$ )

Auf asiatischem Boden muss das Auftreten von Hausschweinen sehr früh stattgefunden haben, da ja das prähistorische Torfschwein Europas enge verwandtschaftliche Beziehungen zu den zahmen Schweinen des ostasiatischen Kulturkreises aufweist. In China kommen letztere nach der Ansicht der kompetentesten Sinologen schon seit Jahrtausenden vor, sie spielen noch in der Gegenwart eine wichtige Rolle im wirtschaftlichen Leben des äussersten Osten. Die weite V'erbreitung der Sus indicus-Rassen

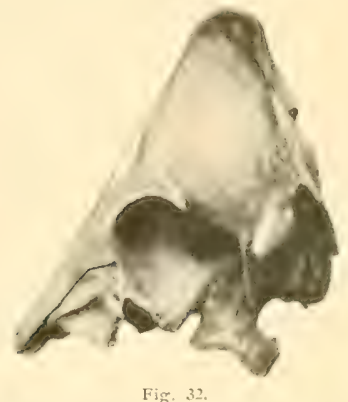

Hinterschädel des Torfschweines aus Aer römischen Niederlassung Vindonissa. (Nach H. Krïner.)

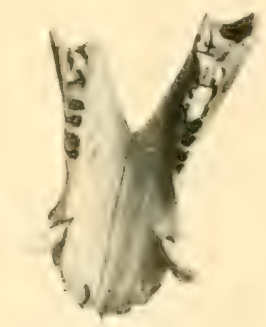

liig. 33 ,

Unterkiefer des Torfschweines aus Vindenissa.

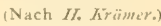

spricht wiederum für ein hohes Alter. /ukünftige prähistorische Nachforschungen im östlichen Asien versprechen genauere Aufschlüsse.

Die Zwischengebiete, welche zum Wohngebiet des alten Torfschweines Mitteleuropas führen, lassen die Wege erkennen, welche bei der Migration benutzt wurden. Im mesopotamischen Kulturkreis erscheint eine sehr getreue Darstellung des Schweines in Kujundschik, also aus der assyrischen Zeit. Das Bild lässt uns ein Mutterschwein mit Ferkeln erkennen. Layard glaubt, dass es sich um ein wildes Tier (wild sow) handle, ${ }^{2}$ ) was keineswegs sicher ist; mir scheint vielmehr die Zeichnung für ein zahmes Schwein der Sus indicus-Rasse zu sprechen, da der feine Kopf verhältnismässig kurz erscheint.

Dass in Aegypten zur Pharaonenzeit Hausschweine in grosser Zahl gehalten wurden, erfahren wir durch Horodot, der auf seinen Reisen in Aegypten sah, wie im Delta Schweine zum Einstampfen der Saat verwendet wurden. Im allgemeinen verachtete man jedoch diese Geschöpfe und wer sich mit ihrer Aufzucht befasste, durfte den Tempel nicht betreten.

1) G. Vehring. Verhandlungen der Berliner anthrop. Gesellschaft. 1888.

$\left.{ }^{2}\right)$ A. 11. Layard. Discoveries in Niniveh and Babylon. 185.3. Pag. 109. 
Bildliche Darstellungen des altägyptischen Iausschweines finden sich in Theben aus der Zeit des neuen Reiches, doch ist die mehrfach ausgesprochene Meinung, das Schwein sei erst seit der 18. Dynastie im Nilthal eingeführt worden, kaum zutreffend. 1. Erman ${ }^{1}$ ) bemerkt, dass die Künstler der älteren Zeit das Schwein nie dargestellt haben. Das beweist natürlich noch keinesweges sein völliges Fehlen, da die religiöse Scheu die Künstler der älteren klassischen Zeit wahrscheinlich davon abhielt, das verachtete Tier abzubilden.

Ich finde jedoch aus der allerältesten Zeit, nämlich aus der ersten Dynastie eine recht gute Umrisszeichnung des Schweines, das offenbar gemästet war und wie die indischen Schweine Stehohren besitzt. Das Bild ist in Oberägypten gefunden und von Flinders Petric ${ }^{2}$ ) veröffentlicht worden.

Das Vorkommen von angeblich wilden Schweinen in Sennaar und Kordofan mit nahen Beziehungen zu den asiatischen Schweinen erscheint damit in neuer Beleuchtung; es sind offenbar verwilderte Schweine aus der Pharaonenzeit.

In Griechenland und besonders im alten Rom stand das Schwein im Ansehen höher als im Orient. I)ie Feinschmecker Roms schätzten sein Fleisch und die Suarii, die besonders von Sardinien aus den römischen Markt versorgten, erlangten zur Kaiserzeit besondere Rechte. Bildliche Darstellungen sind nicht sclten. I) is prächtige Bascelief des Forum Romanum führt uns eine kurzköpfige, sehr mastfähige Rasse mit gerundeten Formen vor, deren Beziehungen zum indischen I Iausschwein nahegelegt wird, zumal das asiatische Blut noch heute im Hausschwein der römischen Campagna unverkennbar ist. In Herculanum wurde die gleiche Rasse zur Zeit des Untergangs gehalten; eine in Portici gefundene Bronze-Statuette bringt deren Merkmale sehr charakteristisch zum Ausdruck.

\section{DIE HEUTIGEN IVILDSCHWEINE UND IHRE GEOGRAPHISCHE VERBREITUNG.}

Bei dem Versuch, die Stammquelle unserer Hausschweine zu ermitteln, ist eine kritische Betrachtung der bisher beschriebenen Wildschwein-Arten unerlässlich. Eine übereifrige Speziesmacherei hat die Nomenklatur ins Ungebührliche ausgedehnt und damit nur Verwirrung angerichtet.

Da die Suiden-Gruppe geologisch aufgefasst ein hohes Alter besitzt, so darf es nicht überraschen, dass mit Ausnahme von Australien alle übrigen Erdteile Wildschweine besitzen, welche mehreren Gattungen angehören.

Die amerikanischen Wildschweine entfernen sich ihrer dreihufigen Hinterfüsse wegen von der Stammgruppe am meisten, auch im Gebiss lässt sich eine starke Reduktion erkennen, da die Zahl der oberen Schneidezähne

i) A. Erman. Aegypten und ägyptisches Leben im Altertum. 1885.

2) Flinders Petric. The Royal Tombs. 1901. 
nur vier beträgt und in jedem Kiefer nur sechs statt der ursprünglichen sieben Backenzähne vorhanden sind. Die amerikanischen Nabelschweine (Dicotyles) besitzen somit nur 38 Zähne nach der Formel J $\frac{2}{3} \mathrm{C}_{1}^{1} \mathrm{M}_{\frac{6}{6}}$.

Das tropische Gebiet Afrikas beherbergt zwei eigentümliche Gattungen. Die Warzenschweine, ausgezeichnet durch eine grosse Wangenwarze, bilden die eine Gattung Phacochoerus. Die oberen Schneidezáhne fallen bei ihnen meist früh aus, die Hauer sind gewvaltig entwickelt und in jedem Kiefer sechs Backenzähne vorhanden. Die afrikanischen Flussschweine (Potamochoerus), die bis nach Madagaskar hinüberreichen, zeigen entweder sechs Backenzähne in jedem Kiefer oder die $7 \mathrm{ahl}$ sinkt im Unterkiefer auf fünf herunter. Die Hirscheber (Babirussa) repräsentieren eine eigentümliche Sichweineform, welche auf Celebes und einige nördliche Molukkeninseln beschränkt zu sein scheint, also dem Gebiet des malayischen Archipels angehört. Das Stammgebiss ist bei dieser ( indem die Zahl der Backenzähne in jedem Kiefer auf fünf herabsinkt und oben nur vier Schneidezthue vorkommen.

Nur die letzte Gattung Sus, deren Vertreter in Europa, Asien und Afrika wild leben, vermochte die ursprüngliche Zahl von 44 Zähnen zu erhalten und weist daher die Zahnformel $J_{\frac{3}{3}} \mathrm{C}_{1}^{1}-\mathrm{M}_{\frac{i}{7}}$ auf. Sic umfasst die zahlreichsten Arten, unter denen man allerdings zu sichten genötigt is. Es sind folgende:

1. Sus scrofa. Das europäische Wildschwein. Das Verbreitungsgebiet erstreckt sich über den $\mid V^{\top}$ esten der alten Welt, nämlich über ganz Europa, Nordasien bis ins Amurland, Westasien und ganz Nordafrika. Im Osten wird es von Tibet und dem Himalaja an durch andere Formen abgelöst.

2. Sus cristatus. Indisches Schwein. Es lebt wild in Vorder- und Hinterindien.

3. Sus andamanthsis. Andamanenschwein. Als insulare Form auf die Andamanen in bengalischen Neere beschränkt.

4. Sus lencomystax: Weissbartschwein. In China und Japan heimisch.

5. Sus taizanis. Auf der Insel Formosa.

6. Sus moupinensis. Westliches China.

7. Sus salvianus. Zwergartiges Schwein aus dem Himalaja-Gebiet.

8. Sus rittatus, Bindenschwein. Diese durch eine weisse. vom Unterkiefer gegen den Hals verlaufende Binde charakterisierte Art lebt auf Java und Sumatra.

9. Sus papucnsis. Papuaschwein. Auf Neuguinea.

10. Sus niger. Schwarzschwein. Ebenfalls auf Neuguinea.

11. Sus timoricnsis. Timorschwein. Auf der Jnsel Timor.

12. Sus harbatus. Bartschwein. Auf Borneo.

1.i. Sus longirostris. Langrüsselschwein. Auf Borneo und vielleicht auch auf Java. 
14. Sus verrucosus. Warzenschwein. Auf Java.

15. Sus celebensis. Celebesschwein. Auf Celebes und einzelnen Molukkeninseln.

16. Sus phitippinensis, Philippinenschwein. Auf Luzon und Mindanao.

17. Sus sennantionsis, Sennaarschwein. Im Sudan, in Sennaar und Kordofan.

Wie man aus dieser Liste ersieht, weist der Westen der alten Welt nur eine einzige Art auf, während Ostasien, Südasien nebst dem indoaustralischen Archipel eine ungebührlich hohe Zahl der bisher beschriebenen Arten beherbergt. Die vielen insularen Spezies müssen von vornherein den V'erdacht erwecken, dass es sich vielfach nur um Lokalformen handeln kann.

Seitdem die asiatischen Suiden anatomisch etwas besser durchgearbeitet sind, muss in der That die Zahl der Arten erheblich eingeschränkt werden.

Schon Nathusius fand sich veranlasst. die Zersplitterung der asiatischen Spezies zu rügen. Später haben L. Rälimever ${ }^{1}$ ) und $G$. Rollestone ${ }^{2}$ ) gleichzeitig und unabhängig an der. Hand von Schädelanalysen die Notwendigkeit dargethan, eine Reihe von Spezies zusammenzuziehen.

Zunächst repräsentieren die festländischen Vildschweine im östlichen und südlichen Asien, dann auch auf der dem Kontinent zunächst angelagerten Inselwelt einen einheitlichen Typus, den man jetzt ziemlich allgemein unter dem Speziesnamen Sus vittatus zusammenfasst. Diese Bezeichnung ist wohl die zutreffendste, da den meisten Formen eine von der Wange oder den Kiefern nach dem Halse verlaufende weisse Binde zukommt. Rütimejer betrachtet diese Kieferbinde als ein Leberbleibsel der "Livree", welche bekanntlich den Frischlingen eigentümlich ist, aber beim europäischen IVildschwein später ganz verloren geht. Dieses kann daher als moderner Typus aufgefasst werden, während die östliche Sus vittatus-Reihe der primitivere ist. Auf Grund von sehr sorgfältigen Untersuchungen des Suidengebisses ist $H . G$. Stehtin ${ }^{3}$ ) ebenfalls zu dem Resultat gelangt, dass die Bindenschweine einen mehr ,altmodigen" Charakter besitzen und ihre jüngste Erscheinungsform in dem zwergartigen Sus salvianus (Porcula salviana) vorliegt.

Der Sus vittatus-Typus, in Japan und Formosa in Lokalformen ebenfalls heimisch, reicht im Archipel östlich nur bis Java und wird darüber hinaus von den Verrucosus-Schweinen abgelöst. Bei allen Vertreterı der Vittatus-Gruppe erscheint der Schädel im Vergleich zum europäischen Wildschwein relativ kürzer, höher und breiter: das Thränenbein ist viel kürzer als bei Sus scrofa und nähert sich der quadratischen Form. Diese Merk-

1) L. Rütimever. Einige weitere Beiträge über das zahme Schwein und das Hausrind. Verhandl. d. nat. Ges. in Basel. 1878.

2) G. Rollestone. On the Domestic Pig. Transactions of the Linnean Society of London. 2 Series, Zoology. Vol. 1.

3) H. G. Stehlim. Ueber die Geschichte des Suidengebisses. Abhandlung d. schweiz. palaeontolog. Gesellschaft. 1899. 
male sind S. cristatus, leucomystax, taivanus, andamanensis, moupinensis gemeinsam, so dass wir in ihnen keine selbständigen Spezies erkennen können, sondern lediglich lokale Formen von Sus vittatus.

Anders liegt die Sache bei der Verrucosus-Gruppe. Hier erscheint der Schädel auffallend gestreckt, die Beschaffenheit des Gebisses entfernt sich sowohl von derjenigen des europäischen Wildschweines wie des asiatischen Bindenschweines. Die näheren Belege für den abweichenden Zahnbau hat H. G. Stehlin zusammengestellt. Von äusseren Kennzeichen sind die Gesichtswarzen hervorzuheben. Diese Gruppe ist von Java an im östlichen Teil des indo-australischen Archipels heimisch: die drei bis vier haltbaren Arten (Sus verrucosus, barbatus, longirostris, celebensis) bewohnen neben Java auch Borneo, die Philippinen, Celebes und die Molukken.

Nähert man sich dem australischen Teil der grossen Inselwelt, so begegnet man wilden Schweinen, welche wiederum in den Sus vittatus-Kreis hinein gehören. Von der Insel Timor wird Sus timoriensis als besondere Art erwähnt, auf Neuguinea sollen sogar zwei Wildschweine heimisch sein, indem neben dem Papuaschwein (Sus papuensis) von Finsch noch das Schwarzschwein (Sus niger) als neue Art beschrieben wurde.

Es ist sehr bezeichnend für den Scharfblick von Vathusius, dass er schon vor bald to Jahren sich den Wildschweinen von Neuguinea gegenüber sehr skeptisch verhielt und in demselben ein verwildertes Iausschwein vermutete. Spätere Autoren, $L$. Kä̈timever ausgenommen, wollten die Frage noch offen lassen und erst in der jüngsten Zeit tritt II. G. Stehlin wieder mit aller Entschiedenheit für die Auffassung von Ththusius und Rülimever ein, dass das Papuaschwein verwildert sei. ${ }^{1}$ ) Ich stimme aus ethnologischen und tiergeographischen Gründen vollkommen bei. Alle neueren Reisenden berichten übereinstimmend, dass im Papuagebiet die I Iausschweine eine so freie Lebensweise führen, dass es geradezu wunderbar wäre. wenn einzelne Tiere nicht verwildern würden. Ilerrscht doch in manchen papuanischen Dörfern noch der Brauch, die zahınen Schweine zu blenden, damit sie nicht weglaufen.

Dass Sus papuensis, $\mathrm{S}$. niger und $\mathrm{S}$. timoriensis als völlig unberechtigte Arten aus der Liste der Wildschweine zu streichen sind, geht auch aus tiergeographischen Gründen hervor. Das Vorkommen von Huftieren in der australischen Region, der ursprünglich alle placentalen Säugetiere fehlen, muss von vorneherein verdächtig erscheinen. Es müsste die Wanderung auf Landbrücken erfolgt sein, die noch in nenerer geologischer Zeit vorhanden waren. Es gab nun in der That solche Brücken, wie Paul und Fritz Sarasin nachgewiesen luaben., ${ }^{2}$ ) Der indo-australische Archipel ist nicht, wie man bisher mit Salomon Müller und Wallace allgemein annahm,

1) H. G. Stehlin. Loc, cit.

*) Paul und Fritz Sarasin. Ueber die geologische Geschichte der Insel Celebes auf Grund der Tierverbreitung. 1901. 
das Trümmerfeld eines alten Kontinentes, sondern eine verhältnismässig junge Bildung. Noch zur Eocalenzeit bestand dort ein weites, offenes Meer, aus welchem sich während der Miocaenzeit einzelne insulare Gebiete emporzuheben begannen. Aber erst während der jungtertiären Zeit, d. h. in der Pliocaenzeit war die Hebung soweit fortgeschritten, dass von Asien her ausgedehnte Landbrücken nach den einzelnen Inselgebieten führten; sie wurden dan zu Beginn der diluvialen Periode wieder unterbrochen.

Auf diesen jungtertiären Landbrücken wanderten aber von Asien her die Sus vittatus-Wildschweine nur bis Java, darüber hinaus kamen sie nicht, während dagegen die Verrucosus-Schweine, die nie gezähmt wurden, noch einen weitern Vorstoss machten und nach Borneo, Celebes, den Philippinen und den nördlichen Molukken vordrangen. Gäbe es auf Neuguinea echte Wildschweine, so könnten sie nur der Verrucosusgruppe angehören. Da sie aber dem Vittatus-Kreis aus anatomischen Gründen zugewiesen wurden, so sind die Schweine Neuguineas erst durch den Menschen als zahme Gieschöpfe eingeführt worden und später teilweise in den wilden Zustand zurückgekehrt.

dehnlich liegen die Verhältnisse beim Sennarschwein (Sus sennariensis). Diese angebliche, von Fitzinger aufgestellte Wildschweinart steht nach den vorliegenden anatomischen Untersuchungen im Schädelbau der Sus vittatusGruppe ganz nahe. Es ist nun schwer verständlich, warum diese Wildkolonie so isoliert im Innern Ostafrikas auftauchen sollte, während ja dic Bindenschweine in Vorderindien ihre westliche Grenze erreichen. L. Rätimejer hat daher bezweifelt, dass hier eine echte Wildform vorliege ${ }^{1}$ ) und ich kann sie nur für verwilderte Schweine ansehen, denn nachweisbar gelangte die asiatische Rasse des Hausschweines in prähistorischer Zeit nach Europa und nach Afrika, wo wir schon aus der I. Dynastie den Nachweis seiner Gegenwart im Nilthal erhalten haben. Abgesehen davon, dass später der eindringende Islam das Hausschwein zurückdrängen musste, konnte während der langen Zeit, die seit der I. Dynastie vertloss, unter den primitiven Wirtschaftsverhältnissen Oberägyptens recht oft eine Rückkehr des zahmen Schweines zum Wildleben erfolgen.

Das gleiche Phaenomen hat sich ja, wiederum zum Teil unterstützt durch islamitische Einflisse, auf einem viel näher liegenden Gebiet abgespielt, nämlich auf der Insel Sardinien.

Ueber die auf dieser Insel lebenden wilden Schweine habe ich vor einiger Zeit versucht, etwas mehr Klarheit zu verbreiten. ${ }^{2}$ ) Die Angaben einzelner Autoren lauteten widersprechend, indem Forsyth Wajor das Wildschwein Sardiniens als nahe verwandt mit Sus vittatus erklärte, während A. Nehring umgekehrt behauptet, ${ }^{3}$ ) dass in demselben eine kleine Insel-

1) Rütimey'er. Einige weitere Beiträge über das zahme Schw ein etc, 1878. Sep.-Abdr. Pag. 27.

2) C. Keller. Verwilderte Haustiere in Sardinien. Globus. 1899.

$\left.{ }^{3}\right)$ A. Vehring. Zoologische Einleitung in Rohde's Schweinezucht. 4. Autl. 
rasse des europäischen Wildschweines (Sus scrofa) vorliege. Eigentlich haben beide Autoren bis zu einem gewissen Grade Recht. Da mir eine sehr zuverlässige Quelle in Sardinien zu Gebote stand, verschaffte ich mir Schädelmaterial und erhielt dabei die bestimmte Aufklärung, dass in Sardinien zwei verschiedene Wildschweine vorkommen. I) drei eingesandten Schädel, nunmehr der zürcherischen Sammlung einverleibt, bestätigten dies.

Der grösste Schädel mit allen Kennzeichen der Wildform gehört einem ausgewachsenen Keiler von Sus scrofa an. Die Profillänge beträgt 37 Centimeter und die Grösse kann also nicht viel gegen einen Keiler aus dem schweizerischen Jura zurückstehen, bei dem ich die Profillänge zu 40 Centimeter bestimmt habe. Das lange und schmale Thränenbein lässt über die Artzugehörigkeit keine Zweifel aufkommen.

Die beiden andern Schädel sind kleiner. bei dem mämnlichen Schädel mit zierlichen Hauern misst die Profillänge 28 Centimeter, bein weiblichen nur 27 Centimeter. Die Abnutzung der Zähne lässt auf völlig ausgewachsene Tiere schliessen. Die schiefe Stellung der Iinterhauptsschuppe und die relativ kräftigen Muskelleisten scheinen zwar für ein echtes Wildschwein Europas zu sprechen, aber die nahezu quadratischen Thränenbeine und die dicke Schmelzlage der Backenzähne erinnem an die asiatischen Schweine. Die beiden Schädel gewähren trotz ihrer Kleinheit vollkommen das Bild von Sus vittatus. Wenn diese kleinen Sardenschweine auch nach ihrer Lebensweise als Wildschweine aufgefasst wurden, so ist doch die Gegenwart einer so weit nach Westen vorgeschobenen Kolonie des Bindenschweines nicht anzunehmen, zumal Zwischenstationen fehlen. Da dort wie in ganz Südeuropa die romanischen Schweine als Haustier gehalten werden und diese Rasse vorwiegend asiatisches Blut enthält, so handelt es sich beim kleineren Wildschwein wohl nur um ein verwildertes Tier. Es sind im Laufe der Geschichte so viele Stürme über die Bevölkerung hinweggegangen und namentlich auch arabische Einflüsse thätig grewesen, dass ein V'erwildern des Hausschweines ganz natürlich erscheint.

Ein ähnlicher Vorgang scheint sich an der nordafrikanischen Küste in Tunis abgespielt zu haben, indem nach den (intersuchungen von $F$. Otto der Schädel des tunesischen Wildschweines (in Wirklichkeit nur verwildert) den (harakter von Sus vittatus besitzt. $\left.{ }^{1}\right)$

\section{DIE ABSTAMMUNGSVERHAELTNISSE DER HAUSSCHIVEINE.}

Die Beziehungen der zahmen Schweine-Rassen zu den Wildformen sind gegenwärtig in befriegender Weise aufgeklärt. Zieht man diejenigen Organe, welche sich durch grosse Beständigkeit auszeichnen, also vorab

1) Fricdrich Otto. Osteologische Studien zur Geschichte des Torfschweines. Revue suisse de Zoologie. 1901. 
den Schädel und die Bezahmung zu Rate, so muss die Stammform bei der Gattung Sus gesucht werden. Alle anderen Gattungen kommen nicht in Betracht und es liegen zur Zeit keinerlei Anhaltspunkte vor, dass dieselben auch nur lokal Blut auf zahme Schweine vererbt haben.

Die Gattung Sus ist auf die alte Welt beschränkt, was einen deutlichen Hinweis auf das Gebiet der ältesten Domestikation abgiebt. Vergleicht man ihre einzehnen wilden Vertreter mit den domestizierten Formen, so ergeben sich bezüglich des schaidelbatues gew isse I bureichungen, die zunachst mit stammesgeschichtlichen Fragen nichts zu thun haben, sondern aus rein mechanischen Gründen erklärbar sind.

Dahin gehört die bei allen IJausschweinen vorkommende Verschwächlichung der Eckzähne, die Abnahme der Dicke der Lamina vitrea an den flachen Schädelknochen sowie die weniger rauhe Beschaffenheit der Obertläche. Aber auch die Gesamtgestalt des Schädels hat Umbildungen erfalren. Die fächerförmige Schuppe des Hinterhauptbeines ist nicht mehr wie beim Wildschwein nach hinten gerichtet, sondern steigt mehr oder weniger senkrecht empor oder ist in extremen Zuchtresultaten nach vorn geneigt, so dass der höchste Punkt des Hinterhauptskammes vor das Hinterhauptsloch zu liegen kommt. Damit richten sich auch Stirn- und Scheitelgegend nach oben, wodurch die Gegend zwischen Stirn und Nase eine Einknickung erfährt. Beim Wildschwein ist das Profil stets gerade, weil beim Wühlen im Boden Rüssel und Hauer angestemmt werden und die kräftige Nackenmuskulates am Ilinterhaupt eimen starken Zug ausübt. Bei dem in den Stall gebamnten Tiere hört mit dem Wühlen auch der Zug am Hinterkopf auf, die Verlagerung der nicht mehr in Mitleidenschatt gezogenen Knochen bedingt eine Annäherung an die V'erhältnisse des jugendlichen Schädels. Nur da, wo dem zalhmen Schwein die Freiheit der Bewegung gestattet wird, wie z. B. auf den ostasiatischen Inseln, ist das Profil nur wenig geknickt. Auch die Torfschweine der Pfahldörfer weisen ein ziemlich gerades Profil auf, woraus wir schliessen müssen, dass deren prähistorische Bewohner ihre Tiere ziemlich frei herumlaufen liessen.

Iandelt es sich bei diesen Veränderungen um Erscheinungen allgemeiner Nitur, so lassen sich innerhalb des Formenkreises zahmer Schweine reiner Rasse zwei scharf getrennte Reihen unterscheiden, die beständige osteologische Unterschiede aufweisen. H. von Lathusins hat 1864 in seinen "Vorstudien" zuerst in überzeugender IVeise den Nachweis geleistet, dass diese Unterschiede einen phyletischen Hintergrund haben, da der Gegensatz unvermittelt erscheint.

Bei den asiatischen Schweinen (Sus indicus-Reihe) ist der Schädel verhälnismässig kurz, breit und hoch; die Thränenbeine sind kurz und hoch, nähern sich also der quadratischen Form; der kuöcherne Gaumen erscheint nach vorn verbreitert, so dass die vorderen Backenzâhne stark auseinander gedrängt werden, die Zahmreihen also divergierend sind. 
Bei den europä ischen Hausschweinen oder Landschweinen (Sus europaeusReihe) bleibt der Schädel im V'ergleich mit asiatischen Hausschweinen niedrig, schmal und langgestreckt; das Thränenbein ist lang und niedrig, also mehr rechteckig, der knöcherne Gaumen nach von nicht verbreitert. so dass die Backenzahnreihen anmăhernd parallel sind.

Dass im Laute der Zeit vielfach Kreuzungsprodukte entstanden, braucht kaum hervorgehoben zu werden. Schon aus der prähistorischen Zeit sind Spuren derselben bekannt geworden. Bei phylogenetischen Erörterungen bleiben solche Mittelformen zunächst ausgeschlossen.

\section{ABSTAMMUNG DER SUS EUROPAEUS-REIHE.}

Genetisch genommen, ist das curopäische Hausschucin, das sogenannte Landschacin jüngeren Datums als das asiatische Hausschwein, dennoch stellen wir es hier voraus, weil sein Bildungsherd uns rüumlich am nächsten liegt. I)ie primitiveren Schläge sind kurzohrig, daneben kommen auch grossohrige vor; ihr Borstenkleid ist schlicht; der hochbeinige Körper seitlich etwas zusammengedrückt; besonders charakteristisch erscheint der scharfgrätige Rücken (Karplenrücken).

Gegenwärtig sind die einst im mittleren und nördlichen Europa vorherrschenden Landschweine auf der ganzen Linie im Rückgang begriffen, in der Schweiz beispielsweise nur noch in wenigen Zuchten rein erhalten, häufiger dagegen in süddeutschland.

H. von lathusius hat auf Grund vergleichend-osteologischer Untersuchungen nachgewiesen, dass alle Sus europaeus-Schläge von unserm gemeinen Wildschwein (Sus scrofa) abstammen, das in ganz Europa, Nordafrika und Westasien heimisch ist. Der Schädelbau im ganzen genommen, die Form der Thränenbeine, der Verlauf der Backenzahnreihen zeigen eine so vollkommene Uebereinstimmung, dass jeder Zweifel ausgeschlossen erscheint. Der Kopf des wildschweinähnlichen Hausschweines ist zwar gegenüber der Wildform breiter und höher geworden, die Stellung der Hinterhauptschuppe so, dass der Occipitalkamm vor das Hinterhauptsloch gelagert wird, was aber lediglich eine Wirkung der Domestikation ist.

Einen ganz direkten Beweis für die Abstammung der alten Landschweine von unserem europáischen Wildschrein darf man in gewissen Rückschlagserscheinungen der Ferkel erblicken. Bekanntlich besitzen die Frischlinge unseres Wildschweins eine Livree $\mathrm{d}$. h. sie sind längs gestreift; sie geht freilich nach einigen Monaten verloren. Es ist bisher nicht beobachtet worden, dass Ferkel asiatischer Hausschweine gelegentlich gestreift sind, dagegen zeigen die Ferkel reinrassiger Landschweine zuweilen in den ersten Monaten eine mehr oder minder dentliche Livree. Die Sache ist bestritten worden und Sanson, der unser Wildschwein gar nicht als Stammform irgend 
welcher zahmen Schweineformen anerkennen will, $\left.{ }^{1}\right)$ in seiner Beweisführung jedoch sehr anfechtbar ist, behauptet, dass die Streifung neugeborner Schweine in Frankreich nie zu seiner Kenntnis gelangt sei. Dagegen giebt Nehring an, ${ }^{2}$ ) dass in Norddeutschland und Russland früher, als die Landrassen noch verbreiteter waren, neugeborne Ferkel häufig gestreift erschienen. Dies wird mir von einem erfahrenen norddeutschen Beobachter bestätigt und ich konnte unlängst sogar an einem Kreuzungsprodukt die Richtigkeit der Thatsache feststellen. In der Nähe von Zürich erhielt ein Züchter einen

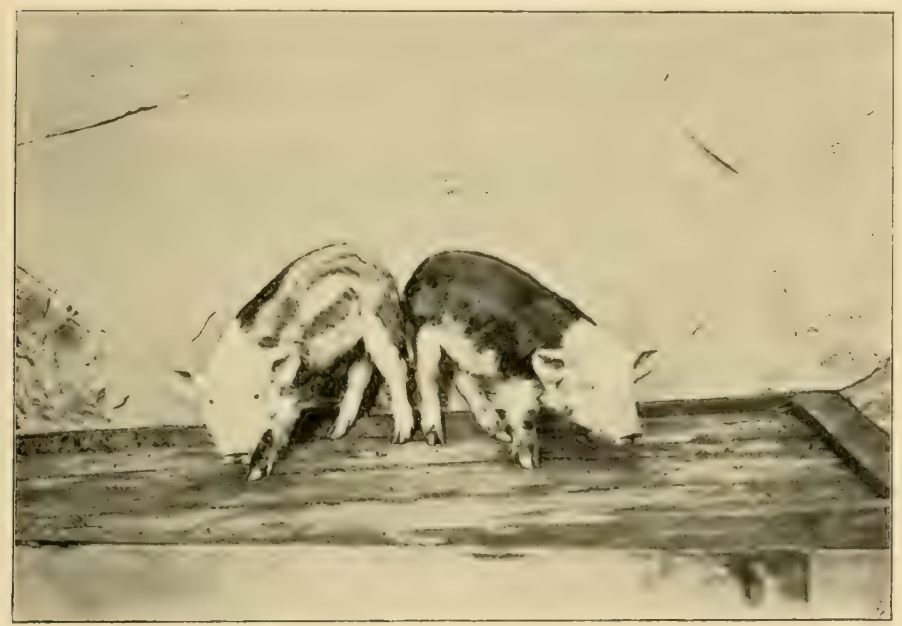

Figr. 34

Gestreifte Ferkel des Ilansschweines aus einer Zucht bei Zïrch.

Wurf Ferkel von einem Landschwein, das mit einem Yorkshire-Eber gekreuzt wurde und darunter befanden sich zwei Exemplare mit deutlicher Livree. Eines davon ist für die zürcherische landwirtschaftliche Sammlung erworben worden.

Der Anstoss zur Zähmung des Wildschweines erfolgte offenbar in der jüngeren Steinzeit im mittleren und nördlichen Europa, als die Viehzucht ihren ersten Aufschwung nahm. In den schweizerischen Pfahlbauten begegnet man anfänglich nur dem eingewanderten Torfschwein, in der jüngeren Steinzeit erscheint dann das gezähmte Wildschwein nach den unlängst

1) Sanson. Sur la prétendue transformation du sanglier au cochon comestique. Compt. Rend. de l'Acad. d. Scienc. 1866.

$\left.{ }^{2}\right)$ A. Fehring. Deutsche landw. Presse. Dez, 1889. 
veröffentlichten Untersuchungen von Friedrich Otto ${ }^{x}$ am Bielersee in den Stationen-Lattringen, Lüscherz und Sutz in immer steigender Menge. Die Gewinnung des neuen Haustieres war wohl nicht allzuschwer, da die wilden Ferkel sich unschwer zähmen lassen. Ihr Erwerb war auch dadurch erleichtert, dass sie überall zahlreich vorkamen. Von der Häufigkeit der Wildschweine kann man sich eine ungefähre Vorstellung machen, wenn man erfährt, dass noch im 18. Jahrhundert in Württemberg auf einer einzigen Jagd 2600 Sauen eingefangen wurden und die sächsischen Kurfürsten von 1611-1680 über 50,000 Stück Schwarzwild erlegten,

In Norddeutschland und Dänemark scheint ursprünglich das Torfschwein gefehlt zu haben und nur das europäische Blut gehalten worden zu sein. Die prähistorischen Knochenreste weisen auf eine sehr kleine Rasse hin.

\section{DIE ABSTAMMUNG DER SUS INDICUS-REIHE.}

Die räumliche Ausdehnung asiatischer Hausschweine ist eine sehr grosse, indem sie nicht nur die grossen Erdräume Asiens, besonders im Süden und Osten, erfüllen, sondern in Oceanien und Afrika heimisch sind, sich auch seit alter Zeit in Südeuropa eingebürgert haben und gegenwärtig das alte Landschwein aus seinem bisherigen Wohnsitz verdrängen. Offenbar sind die hieher gehörenclen Rassen alter als unsere wildschweinähnlichen Landschweine, daher auch durch künstliche Züchtung stärker umgebildet. In der äusseren Erscheinung lassen sich charakteristische Züge herausfinden. Der Rumpf ist verhältnismässig tief gestellt, die Rippen stark gewölbt, so dass der Querdurchmesser der Brust dem senkrechten Durchmesser gleichkommt. Der Rücken erscheint schön gerundet, die Kreuzgegend breit. Der Kopf ist ausgezeichnet durch eine hohe Stirn und kurzen Rüssel, welcher bei extremen Kulturformen sich aufstülpt und an der Basis eingeknickt wird. Die Ohren sind kurz und aufrecht stehend. man kenut aber auch grossohrige und hängeohrige Schläge.

Der Schädelbau zeigt so konstante Abweichungen vom europäischen Wildschwein und dessen zahmen Abkömmlingen, dass an engere Verwandtschaft nicht zu denken ist. Valhusins wies in seinen "Vorstudien " darauf hin, dass die nach vorn verbreiterte Gaumenplatte, die bei einzelnen KulturRassen sogar konvex nach unten gebogen ist, ferner der Zahnbau und die nach vorn divergierenden Backenzahnreihen, namentlich auch die kurze, quadratische Form des Thränenbeins das asiatische Bindenschwein (Sus vittatus) als Stammquelle vermuten lassen. L. Rütimever hat später diese Annahme durclı neue Belege gestützt. Nimmt man hinzu, dass bei der so häufig eingetretenen Verwilderung asiatischer Schweine der Schädel wieder vollkommen zur Form von Sus vittatus zurückkehren kann (wie ich z. B.

4) Fricdrich Otto. Osteologische Studien zur Geschichte des Torfschweines. Revue Suisse de zoologie. 1901. 
dies an verwilderten Schweinen Sardiniens nachgewiesen habe), so erscheint die Abstammung vom asiatischen Binclenschwein (im weiteren Simne) völlig gesichert und daher auch von den meisten Autoren angenommen.

Veben tiergeographischen Thatsachen sind es auch ethmologische. Nomente, die den ältesten Bildungsherd dieses zahmen Tieres im Südosten Asiens

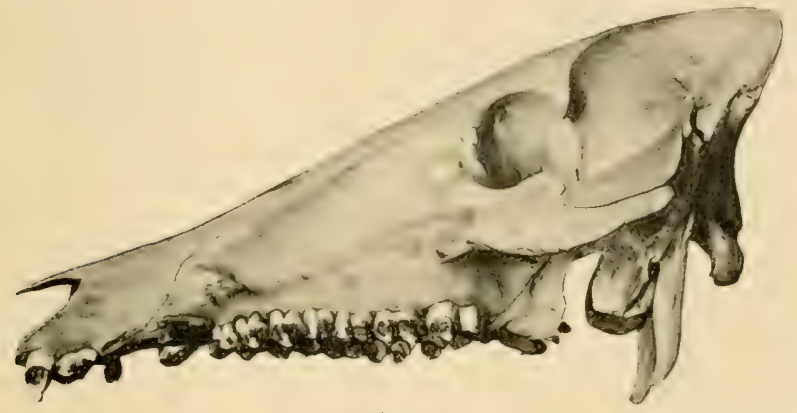

Fig. 35 .

Schädel von Sus vittatus aus Sumatra. (Nach $F$. Otto.)

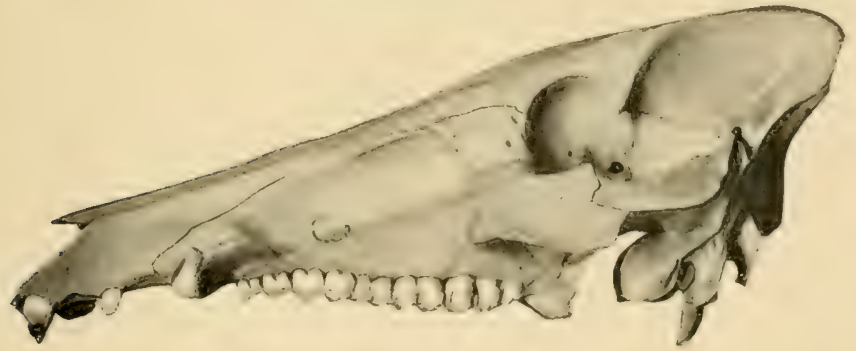

Fig. 36.

Schidel des Hausschweines von Sumatra. (Nach $F$. Otto.)

vermuten lassen. Mehr kömnen wir mit Sicherheit nicht aussagen, bevor die Urgeschichte Ostasiens nähere Autklärungen bringt.

In jenen (jebieten scheinen gegenwärtig zahlreiche Achläge vorzukommen. Die originellste Form bildet das sogenannte japanische Maskenschwein, für welches Gray ganz unnötigerweise den Namen Sus pliciceps geschaffen hat. Ausgezeichnet durch dicke Gesichtsfalten und sehr lange hängende Ohren, ${ }^{1}$ ) ist dieses sonderbare Kulturprodukt 1861 in Europa eingeführt worden und bürgerte sich in den zoologischen Gärten ein. Angeblich stammt

1) Eine gute Abbildung des Kopfes giebt Darwin in seinem bekannten Werk über das Variieren der Tiere und Pflanzen.* 
es aus Japan, doch möchte ich meine Zweifel an der Richtigkeit der Angaben des Importeurs (des Tierhändlers Jamrach) aussprechen. Die Schweinezucht hat wohl in Siam und China, nicht aber in Japan eine hohe Stufe erreicht. Meines Wissens werden zur Zeit einzig und allein in der Provinz Kangoschima chinesische Schweine gehalten. Herr fanson, der als Zootechniker im Dienste der japanesischen Regierung Jahre hindurch sich grosse Erfahrungen sammeln konnte, versicherte mir, dass er in Japan niemals etwas von Maskenschweinen gehört habe. Nach den Untersuchungen von Nathuszus(1) ist Sus pliciceps hinsichtlich der Schädelbeschaflenheit eine dem kurzohrigen chinesischen Hausschwein sehr nahestehende Form.

Asiatisches Blut enthalten neben den hochgezüchteten englischen Kulturrassen die Hausschweine Südeuropas. Das sogenannte krause Schwein im südïstlichen Europa zeigt nach _tuthusius im schädel eine Verbreiterung des Gaumens zwischen den Praemolaren und sehr kurze Thränenbeine, ist also dem indischen Schwein ähnlich. Dasselbe gilt für das romanische Schwein, welches in ganz Italien, Spanien und Portugal gehalten wird, das aber im Laufe der Zeit vielfach Blut von Sus europaeus aufgenommen haben dürfte. Sein Wohngebiet erstreckt sich auch über einzelne Gebirgskantone der Schweiz.

Das alte Bündnerschwein vermochte sich wohl am reinsten zu erhalten, auch um das Gotthardmassiv herum, im Tessin und oberen Wallis wiegt das indische Blut vor; in den südlichen 'Thälern des Wallis wird ein schwarzes oder fuchsrotes Schwein gehalten, das sich nach der Kopfform zu schliessen als Kreuzungsprodukt herausstellt und unverkennbare Einvirkungen des schon zur Pfahlbauzeit in der Westschweiz häufigen Landschweines erkennen lässt.

Von prähistorischen Rassen verdient das Torfschwein der schweizerischen Pfahlbauten noch besonders erwähnt zu werden, da sich über dessen Stammeszugehörigkeit früher lebhafte Kontroversen erhoben haben.

L. Rütimeyer, ${ }^{2}$ ) welcher es als Sus palustris bezeichnet, erblickt in demselben eine Form, die den asiatischen Hausschweinen und ihrer Stammform Sus vittatus entschieden näher stehen als dem europäischen Sus scrofaTypus, wogegen Nehring ${ }^{3}$ ) anfänglich, offenbar beeinflusst durch die Funde in nördlichen Gebieten Deutschlands, im Torfschwein einen durch primitive Domestizieruug verkümmerten Abkömmling des gemeinen europäischen Wildschweines erkennen wollte. Das ist nun sicher nicht der Fall, das asiatische Blut ist im Torfschwein der schweizerischen Pfahlbauten ganz unverkennbar und es dürfte den direkten Vorläufer der romanischen Schweine bilden. Neuerdings nähert sich jedoch Lehring dem Rütimeyer'schen

1) Ilermann ion Vathusius. Vorstudien. Berlin. 1864. Pag. 155.

2) L. Rütimeyer. Weitere Beiträge über das zahme Schwein etc. Basel. 1878.

3) A. Vehring. Verhandlungen der Berliner anthropologischen Gesellschaft. 1888. 
Standpunkte sehr wesentlich, in dem er die asiatische Beimischung im Torfschwein zugiebt, aber eine Kreuzung mit dem europäischen Sus scrofa annimmt. Solche Zwischenformen mögen vorkommen, auch unsere hiesigen Sammlungen besitzen einen aus Robenhausen stammenden Torfschweinschädel, der etwas Sus scrofa-Blut beigemischt enthält, anderseits kamen aber in der späteren helvetisch-römischen Periode in Vindonissa Relikte zum Vorschein, die dem 'Torfschwein angehören und den Sus indicus-'Typus auffallend rein erhalten haben.

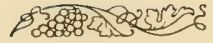




\section{DIE HAUSRINDER.}

(bos taurus und bos indicus.)

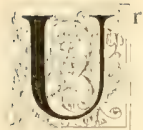

sprünglich auf die alte Welt beschränkt, ist der Stamm zahmer Rinder heute vollkommen kosmopolitisch geworden, in der neuen Welt sogar mehrfach wieder verwildert. Er umfasst Formenkreise, die im einzelnen unter sich starke Abweichungen zeigen, aber zunächst in zwei phylogenetisch gut begründeten Reihen untergebracht werden können. Den europäischen Rinderbestand und seine ausgewanderten Abkömmlinge fasst man in herkömmlicher Weise unter der Bezeichnung Bos taurus zusammen. während die südasiatischen und afrikanischen Höckerrinder als Zebu-Gruppe oder Bos indicus vereinigt werden.

Das äusserlich vom indischen Rinde etwas abweichende Höckerrind Afrikas als Bos africanus abzutrennen, wie dies vielfach geschehen ist, erscheint völlig ungerechtfertigt, da die geographische Isolierung und lange Domestikation die Abweichungen erklären, letztere aber hinsichtlich des anatomischen Baues nicht gross genug sind, um eine Trennung zu befürworten. Die Siedelungsgeschichte \frikas weist zudem mit aller Deutlichkeit darauf hin. dass der Rinderbestand nicht autochthon sein kann. sondern frühzeitig aus Asien entlehnt wurde.

Aeltere Autoren, wic Cuvier und Vagner, fassten sämtliche Rinder in eine einzige Art zusammen, wihlend $L$. Rätimeyer an der spezifischen Verschiedenheit von Bos taurus und Bos indicus festhält. ${ }^{1}$ ) Wenn auch die Kreuzung leicht gelingt und die Bastarde fruchtbar sind, an der Grenze beider sogar häufig vorkommen, wie z. B. in Buchara, so wird man dennnoch aus phylogenetischen Gründen dieser 'l'rennung beistimmen müssen, allerdings mit dem Vorbehalt, dass man nur die primigenen Rinder Europas als Bos taurus bezeichnen darf, dagegen die brachyceren Bestande davon ausschliesst.

Die Zahl der Rassen und Schläge ist sehr gross. Unter den in Europa vorkommenden Rindern hat liütime era $^{2}$ ) drei gut charakterisierte Rassen unterschieden : die Primigenius-Rasse, die Frontosus-Rasse und die BrachycerosRasse. Später hat 11. Wilckens ${ }^{3}$ ) noch die Kurzkopfrasse (Brachycephalus-

1) L. Rätimeyer. Versuch einer natürlichen Geschichte des Rindes. Neue Denkschriften der allgemeinen Schweiz. Ges, f. d. gesanten Naturwissenschaften. 1867.

") L. Rütimeyer. Fauna der I'fahlbauten. 1862.

3) M. Wilckens. Die Rinder-Liassen Mitteleuropas. 18;6. 
Rasse) hinzufügt und in jüngster Zeit wies E. O. Arenander ${ }^{1}$ ) auf die hornlosen Rinder Nordeuropas hin, die er in seiner Akeratos-Rasse zusammengefasst hat. Es mag hier eine kurze Charakteristik dieser fünf europäischen Rinder-Rassen folgen.

1. Primigenius-Rasse (Bos taurus primigenius Rütimeyer). Grosse, starkknochige Rinder mit starkem Gehörn, das oft leierförmig erscheint. Der Schädel zeigt auffallend geradlinige Umrisse, sein Giesichtstei] gestreckt. Die Stirn ist flach, die Zwischenhornlinie gerade, die Augenhöhlen (orbitae) schief nach vorn gerichtet. Die kräftigen Hornzapfen entspringen ohne stielartige Verlängerung des Stirnbeines in der hintersten Ecke der Stirntliche. wenden sich etwas nach hinten und aussen, um dann mehr senkrecht emporzusteigen. Die Hinterhauptstläche steht senkrecht zur Stirnfläche, die Nasenbeine lang und stark gewölbt. Diese Rasse gehört den europäischen Niederungen an und ist hauptsächlich in Holland, Norddeutschland und in den Steppen des südöstlichen Europa heimisch (Steppenrind).

2. Frontosus-Rasse (Bos taurus frontosus Ni/s). Ebenfalls schwer gebaut. Die Stirnfläche unfangreich (Grosstirn-Rind), länger als breit, im hinteren Teil dachig und mit deutlichem Stirnwulst, im übrigen T'eil gewölbt; die Hornzapfen gestielt. die Hornscheiden lang und etwas abgeplattet, nach auswärts und abwärts gerichtet, die Spitzen aber wieder aufrecht; der Nasenspiegel tleischfarben. I)iese Rasse, scheckig mit scharf begrenzten Flecken zeigt eine lokale V'erbreitung, sie findet sich im südlichen Schweden und in der Westschweiz (Fleckvieh).

3. Brachyceros-Rasse (Bos brachyceros Rütimeyer). V'erhältnismässig kleine, zart gebaute Rinder mit schmalem, schlankem Schädel. Die ungestielten Hornzapfen entspringen etwas vor der hinteren Stirngrenze, erscheinen kurz und stark aufwärts gekrümmt, das Gehörn kurz, die Stirn uneben, verhältnismässig lang (über $50 \%$ der Schädellänge), aber nichts destoweniger breit, hinten mit steil abfallender IInterhauptswulst; die Augenhöhlen gross, über die Stirntläche hervortretend; Hinterhaupt mit der Stirn einen spitzen Winkel bildend. Der Unterkiefer ist verhältnismässig schwach mit senkrecht aufsteigendem Ast, die Schnauze fein gebaut mit dunkelm Flotzmaul, die Backenzähne mit starkem Schmelzblech von einfachem Verlauf. Diese Rasse ist in den Alpen stark verbreitet, aber auch in Südeuropa und im nordöstlichen Europa, sowie in England vorhanden.

4. Brachycephalus-Rasse (Bos brachycephalus Wilckens). Der Kopf dieser Rinder-Rasse zeichnet sich durch eine auffallende Kürze aus (Kurzkopfrind) und ist zwischen den Augen sehr breit: die Stirn vor den Hörnern stark eingezogen; die unebene, wellige Stirntläche zwischen

1) E. O. Arcnander. Studien über das ungehörnte Rindvieh im nördlichen Europa Berichte des landw. Inst. d. Univ. Halle. 1898. 
den Augen eingesenkt. Die Hornzapfen fallen seitlich etwas ab, drehen sich dann nach oben und aussen. Das Gehörn ist stark. weiss mit schwarzer Spitze, bei einzelnen Formen sogar von sehr bedeutender Grösse. Kleine Formen sind im gebirgigen Teil Mitteleuropas zerstreut, sehr grosse Rinder dieser Rasse kommen in Spanien und Portugal vor.

5. Akeratos-Rasse (Bos akeratos Arcnander). Eine kleine, zartgebaute Rasse, deren Hauptmerkmal in der völligen Hornlosigkeit besteht. Die Form des Schädels ist lang und schlank; die Stirn uneben, hinten sich in einen Genickhöcker von wechselnder Höhe erhebend; Augenhöhlen stark vortretend. Diese eigentümliche Rinderform ist über das nördliche Europa verbreitet.

Ueberblickt man den augenscheinlich sehr alten Rinderbestand Südasiens, Ostasiens und Afrikas, so fällt uns seine ungemeine Formenbiegsamkeit auf, so dass sich ein einheitliches Bild schwer geben lässt. Der Kopf ist bei sehr vielen afrikanischen und asiatischen Hausrindern etwas geramst, der Schädel pferdeähnlich. Doch giebt es auch breitköpfige Rinder; die Schnauze erscheint fast durchweg sehr fein gebaut und kurz, die Ohren häufig stark hängend. Grösse und Richtung der Hörner zeigen starke Abweichungen; der Höcker ist bei einzelnen Schlägen mächtig entwickelt, bei anderen klein, vielfach gänzlich fehlend; die Körpergrösse zeigt gewaltige Schwankungen, neben grossen Tieren kommen eigentliche Zwergformen vor, hinsichtlich der Haarfärbung kann hervorgehoben werden, dass milchweisse Rinder stark verbreitet sind, gefleckte Tiere sind ebenfalls häufig, aber die Ränder der Flecken sind nicht scharf, sondern verwaschen, getigerte Individuen treten gern auf. Wenn Blyth bemerkt, dass die indischen Zebu den Schatten selten aufsuchen, so darf dies nicht als eine allgemeine Eigentümlichkeit angesehen werden, da ich beim afrikanischen Zebu sehr oft das Gegenteil beobachtet habe.

Vorläufig dürfte es genügen, beim Zebu (Bos indicus) vier Formen zu unterscheiden, über deren Verbreitung später berichtet wird. Wir finden eine völlig hornlose Rasse, eine riesenhörnige oder Langhorn-Rasse, ein mittelhörniges Buckelrind und eine kurzhörnige, buckellose Rasse, letztere sowohl im äussersten Osten wie im Westen und dem europäischen Kurzhornrind angenähert.

\section{PRAEHISTORISCHE RINDER.}

\section{DAS RIND DER AELTESTEN KULTURKREISE.}

Bisher konnte ein zahmes Rind für die ältere Steinzeit nirgends mit Sicherheit nachgewiesen werden. Die ersten Spuren tauchen erst in der neolitischen Zeit Europas auf. In den ältesten Pfahlbauten (z. B. Schaffis am Bielersee) begegnet man a:Ischliesslich der zartgebauten, kleinen Brachy- 
ceros-Rasse, der sogenannten Torfkuh. Ihre weite V'erbreitung über Europa während der Urzeit lässt uns vermuten, dass die älteste Besiedelung mit Hausrindern von Südeuropa aus bis weit nach Norden und Westen durch die Torfrasse erfolgte, die in ihren anatomischen Merkmalen von Anfang an scharf ausgeprägt erscheint. Etwas später erscheint eine grössere Rasse, das Primigeniusrind, das in der Folge in den Niederungen die ausschliessliche Herrschaft erlangte. Während anfänglich beide Rassen unvermischt neben einander vorkamen, treten in der Folge Kreuzungsprodukte auf. In den westschweizerischen Pfahldörfern erreichte die Rinderzucht in der Bronzezeit ihren Höhepunkt, die Schläge werden vielgestaltiger und es tritt dort auch ein hornloses Rind auf, das wahrscheinlich aus einem stärkeren Torfrind hervorging. Dagegen lässt sich am Ende der Bronzeperiode ein starker Zerfall der Viehzucht nachweisen. ${ }^{1}$ ) Nicht nur hat die Zahl der Rinder ahgenommen, sondern das vorhandene Material verschlechtert sich zusehends, die Tiere werden vielfach zwergartig, die Knochen zeigen eine krankhafte Beschaffenheit und im Schädel tritt eine Hinneigung zur Mopsbildung auf.

Die Frontosus-Rasse war während der pähistorischen Periode auf den Norden Europas beschränkt, wo sie von Vilsson $^{2}$ ) in Skandinavien und England aufgefunden, irrtümlicher Weise aber einer wilden Rinderart zugerechnet wurde.

In den schweizerischen P'fahlbauresten sind bisher mit Sicherheit keine sicheren Andeutungen dieser Rasse nachgewiesen, obschon in der Gegenwart dieselbe im Fleckvieh der Schweiz stark vertreten erscheint. Ja noch im Beginn der historischen Zeit, d. h. in der helvetisch-römischen Periode ist das Frontosus-Rind nirgends vorhanden.

Halten wir Umschau in den alten Kulturkreisen, so gevährt zunächst Altägyfen ausserordentlich zahlreiche Einhlicke in den damals vorhandenen Rinderbestand. Unser Haustier war schon im Nilthal eingebürgert zu einer Zeit, da Europa kaum die ältesten P'ahlbauten kannte, denn schon zur alten Negadahzeit, also vor der eigentlichen Pharaonenzeit wird es recht kenntlich auf schieferigen Steinplatten abgebildet. ${ }^{3}$ )

Während der Pharaonenzeit werden Hausrinder ungemein häufig dargestellt, sei es in Basreliefs oder auf Wandmalereien. Die Bilder aus den alten Dynastien zeichnen sich ganz besonders durch Sorgfalt in der Ausführung aus. Auch osteologisches Material ist aus jener Zeit auf uns gekommen und in verschiedenen Museen Europas aufbewahrt. Schon Gicoffroy St. Hilaire brachte aus Aegypten Rindermumienschädel nach Paris, wo sie von Cuvier untersucht wurden. Ins Jahr 1851 fallt die be-

1) A. Dazid. Keiträge zur Kenntnis der Abstammung des Hausrindes, gegründet auf die Untersuchungen der Knochenfragmente aus den Pfahlbauten des Bielersees. 1897.

$\left.{ }^{2}\right)$ Nilsson. K. Vetensk. Akad. Oefrersigt. 1847. (Zitiert nach Rütimeyer.)

$\left.{ }^{3}\right)$ De Morgan. Recherches sur les Origines de l'Egypte. 1897 . 
rühmte Entdeckung Nariette's; derselbe förderte zahlreiche Mumiensärge in dem Serapeum von Memphis zu Tage, zum Teil enthielten sie noch die wohlerhaltenen Leichen des heiligen Apis (Hapi). Ich gebe hier die Abbildung eines solchen Apisschädels, der im ägyptischen Museum in Gizeh bei Kairo (früher in Bulak) aufbewahrt wird.

Das altägyptische Hausrind gehörte, wie das heutige Rind Afrikas durchweg der Zebugruppe an, wenn auch der Fettbuckel sehr häufig fehlte. Der Apisschädel lässt als charakteristisches Merkmal eine nach der Seite

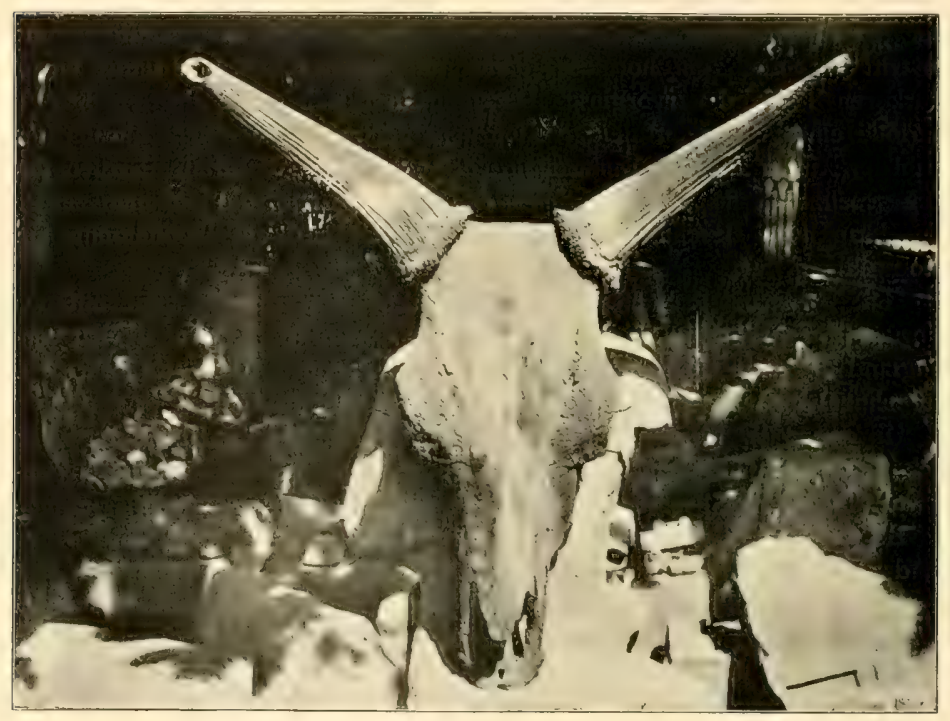

Fis. 3i;.

Schädel des Apis. Nach einer Aufnahme von F. Sarasin. (Museum in Gizeh).

stark abfallende Stirn, wenig vortretende Augenhöhlen und einen relativ feingebauten Gesichtsteil erkennen. Auch an alten Bildern fällt die feine, kurze Schnauze auf, die den heutigen afrikanischen Rindern eigentümlich ist.

Die Pharaonenleute züchteten verschiedene Rassen, für welche sie besondere Benemnungen (neg, eua, hredeba) hatten. ${ }^{1}$ ) Im alten Reich überwog die schöngebaute, meist buckellose Langhornrasse, aus der meistens der heilige Apis entnommen wurde (vergl. obige Figur). Gegenwärtig fehlt sie dem Nilthal. Das ungewöhnlich lange Gehörn war lyraförmig oder mehr halbmondförmig oder auch gerade nach aussen und oben gerichtet,

1) Ad. Erman。 Aegypten und ägyptisches Leben. 1885. Pag. 580 u. ff. 
die Haarfarbe milchweiss, schwarzbunt oder rotbunt. Für den als Kultusobjekt verehrten Apis wird von den alten Autoren als Farbe Schwarz mit weissen Abzeichen angegeben; beachtenswert ist, dass wir diese Färbung jetzt noch haufig beim I uxerschlag und namentlich bei den Eringerschliggen des südlichen Wallis antreffen.

Neben Langhornrindern wurde schon im alten Reich eine hornlose Rasse gehalten. Dass sie nicht gerade selten war, geht aus der Angabe hervor, dass auf dem Gute des Cha'fra'onch neben S35 Langhörnern 220
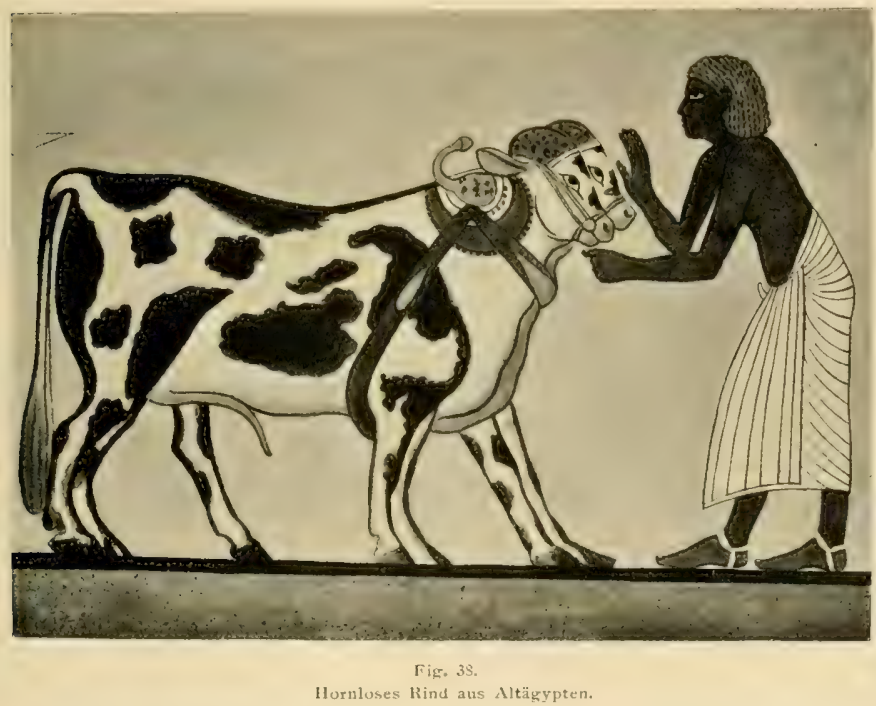

hornlose Rinder vorhanden waren. ${ }^{1}$ ) Darstellungen von Höckerrindern kennen wir ebenfalls. Im neuen Reich scheint ein kurzhörniges, meist buckelloses Rind in den Vordergrund zu treten, wenigstens ptlegen es die Künstler fast immer abzubilden. Wogegen die eigentliche Langhornrasse zurücktritt: im heutigen legrpten ist sie hekanntlich ausgestorben. Iut einem in Wasserfarben ausgeführten Wandgemailde in Thehen, aus der 18. Dy nastie stammend. bemerkt man eine leopardähnliche Fleckenzeichnung an einzelnen Rindern, was bekanntlich eine Eigentümlichkeit des Zebu ist.

Untersuchen wir die Dokumente aus dem mesopotamischen Kulturkreis, so begegnet uns auf bildlichen Darstellungen das Rind sehr häufig, wobei allerdings bei den alleriltesten Figuren die Entscheidung nicht leicht ist.

1) Ad. Erman. Loc. cit. 
ob es sich um eine wilde oder zahme Form handelt, weshalb in der Deutung eine gewisse Vorsicht geboten ist. Bemerkenswert erscheint ein sehr alter chaldäischer Cylinder, ${ }^{1}$ ) anf welchem das Rind bereits vor den Ptlug gespannt erscheint; die mangelhafte Ausführung lässt keine sicheren Schlüsse auf die Rassengehörigkeit zu, doch darf man aus der geringen Grösse des hochgestellten Körpers vermuten, dass es sich nicht um eine Primigeniusform, sondern um ein kleines indisches Hausrind handelt. Primigene Rassen sind mit Sicherheit zur Zeit im alten Mesopotamien nicht nachzuweisen und

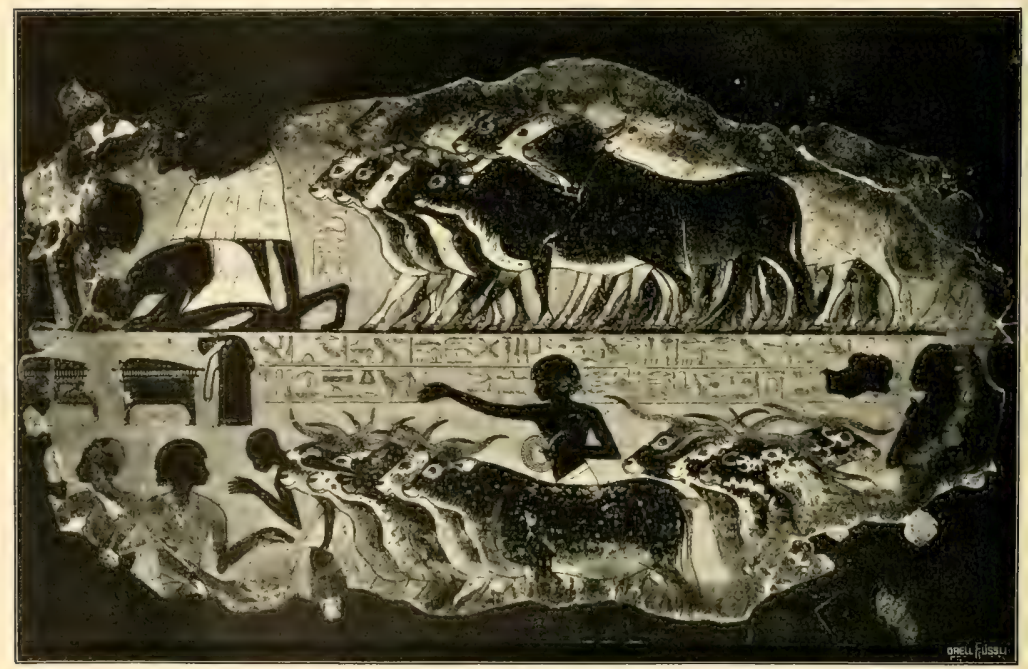

F1, 2.34.

lainder des neuen Feiches. Nach einem Wandgemälde von Theben. 18. Dynastie. (British Museum.)

auch heute findet man in jener Region nur indisches Blut. Aus der assyrischen Zeit kemnen wir bessere und häufigere Darstellungen.

Auf einem (Quarzcylinder, dessen Reproduktion Layard giebt ${ }^{2}$ ), ist ein typisches, langhörniges Zeburind, eine säugende Kuh, als Skulptur erkennbar, der Fettbuckel ist umfangreich, die Wanne stark, der Schwanz sehr lang wie beim indischen Zebu. Unter dem Beutevieh auf den Skulpturen der Königspaläste begegnen wir Rindern häufig, sie werden stets mit gewölbtem Rücken oder mit eigentlichem Fettbuckel dargestellt. ${ }^{3}$ )

\footnotetext{
1) Abgebildet von F. U. Dürst in: L'Anthropologie. 1900. Pag. 155.

'A. H. Layard. Discoveries etc. 1853. Pag. 604.

1) A. H. Layard. The monuments of Niniveh.
} 
In Indien sind Rinderskulpturen vorhanden, die ein hohes Alter besitzen sollen und die typische Form des Zebu mit Fettbuckel zum Ausdruck bringen. Beispielsweise sei das Bild der heiligen Kuh „Nandi“ erwähnt, zu welchem die Indier während der Hungersnot und Pest massenhaft wallfahrteten.

Durch die archaeologische Forschung sind wir über die Rassenzusammensetzung im altgriechischen Fullurkreis etwas besser aufgeklärt worden ats

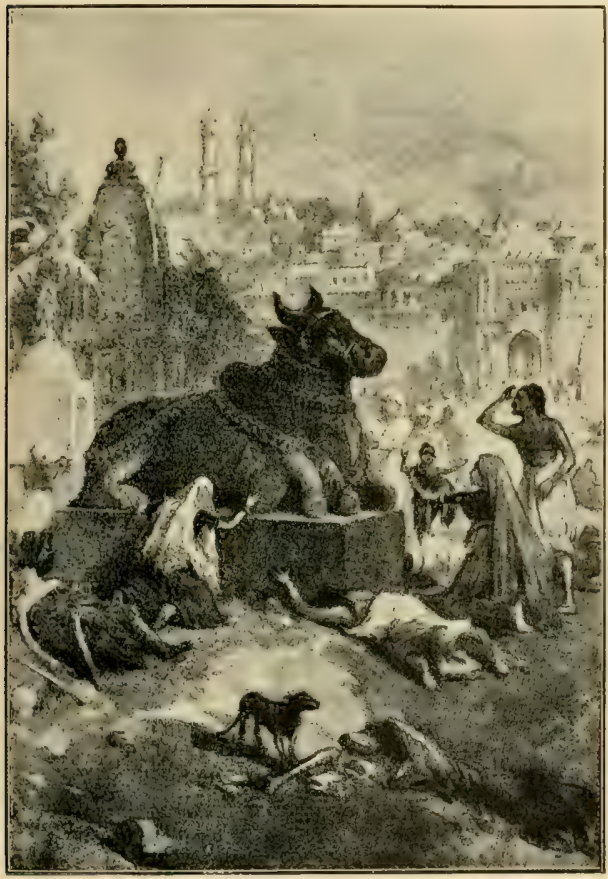

Fiz. 40 .

Die heilige $\mathrm{Kuh}$,Nandi" in Indien. (Nach $\mathrm{W}^{*}$. Simfson.) dies früher der Fall war. Sicher ist, dass die Bewohner desselben die Rinderzucht $\mathrm{zu}$ hoher Blüte gebracht haben, neben der kurzhörnigen Brachyceros-Rasse taucht hier mit aller Deutlichkeit das Primigenius-Rind als weitverbreitetes Iaustier auf. Erstere finden wir aufaltgriechischenMünzen mehrfach abgebildet, primigene Rinder erscheinen bereits zur mykenischen Zeit, für deren zahmen Charakter der eine Goldbecher von Vaphio mit seinen vollendeten Reliefbildern deutliches Zeugnis ab. gelegt. ${ }^{1}$ )

Der von Schliemamn aufgefundene Rinderkopf mit leierförmigem Gehörn lässt sich vielleicht auch auf die genannte Rasse zurückführen. Dieselbe reichte auch auf Vorderasien hinüber, denn unter dem Tierknochenmaterial, das Schliemann in Hissarlik zu Tage förderte und das sich in Berlin befindet, konnten unzweifelhafte Reste von Primigeniusrindern nachgewiesen werden. ${ }^{2}$ ) Später erscheint Epirus das Zentrum der Zucht dieser Rasse geworden zu sein.

Eigentliche Buckelrinder (\%ebu) kameu auf griechischem Boden ebenfalls

1 C. Feller. Figuren des ausgestorbenen Ur aus vorhomerischer Zeit. Globus. Bd. 72 und nochmals die Goldbecher yon Vaphio. Bd. 74.

2) 7. U. Dïrst. Die Rinder von Babylonien, Assyrien und Aegypten. 1899. 
vor. Alexander der Grosse sandte nach dem Bericht von Arrian eine Heerde von 2-3000 Stück aus Indien nach Macedonien, auf Cypern gab es Rinder mit grossem Höcker und verrenkten Hörnern, nach dem Zeugnis von Plinius besass Syrien höckertragende Zebu, die sich nach Phrygien und Carien verbreiteten.

Auf dem Boden Italiens entwickelte sich die Rinderzucht frühzeitig, offenbar beeinflusst durch Altgriechenland. Das grosse Primigenius-Rind gelangte von Epirus nach Lucanien (Boves Lucani) und II. Krämer bemerkt wohl zutreffend. dass auf diesen Import die Grösse der heutigen Rinder Süditaliens und Siciliens zurückzıführen sei. ${ }^{1}$ )

Daneben ist die Brachyceros-Rasse weit verbreitet. Auf dem Denkmal der Haterier in Rom findet sich ein Schädel des Rindes in Reliefdarstellung, der ana-

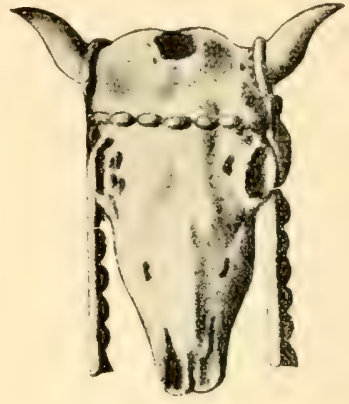

Fig. 41.

Reliefdarstellung des Schädels eines Brachycerus-Rindes auf dem Denkmal der Haterier in Rom.

(Nach II. firäunc't? tomisch tadellos alle Merkmale des brachyceren Typus nachgebildet hat. Zum ersten Mal taucht auf dem antiken Boden Italiens eine Rasse

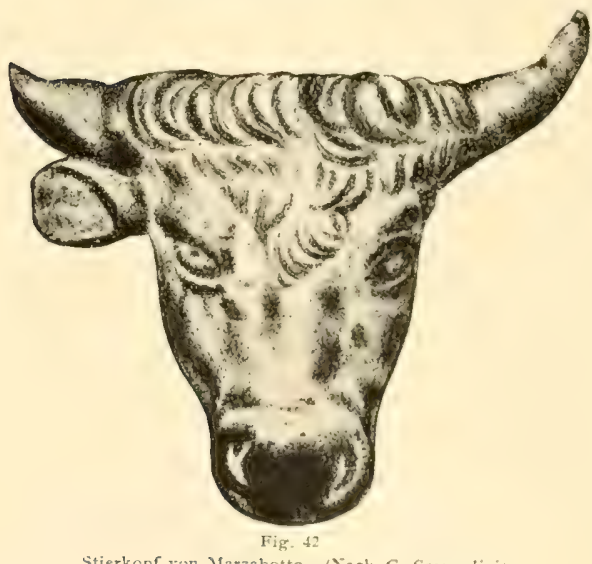

Stierkopf vun Marzabotto. (Nach G. Gozardini.) auf, die vermutlich als Kulturprodukt der gehobenen Rindviehzucht ihre Entstehung verdankt -- nämlich die Brachycephalus-Rasse (Kurzkoptrind). Das Gesicht ist verkürzt, die Stirn breit, das Gehörn derb gebaut: die Zierlichkeit des Brachycerosrindes fehlt dem Kopf durchaus. In Marzabotto bei Bologna kam ein in Bronze gegossener Stierkopf zum Vorschein, ${ }^{2}$ ) an dem die Merkmale der Rasse bereits erkennbar sind, ein anderer Bronzekopf der Kurzkopfrasse stammt aus Octodurus, dem heutigen Martigny im Kanton Wallis, also aus der

1) H. Krämer. Die Haustierfunde in Vindonissa. 1899.

2) Criozanui Gozzardimi, Di un antica necropoli a Marzabotto. Bologna 1865. Tav. 16. 
helvetisch-römischen Zeit der Schweiz; das Original wird im historischen Museum in Sitten aufbewahrt. Römische Kolonisten scheinen diese Rasse stark nach dem Norden der Alpen verbreitet $\mathrm{zu}$ laben, wenigstens kamen bei den Ausgrabungen in $\checkmark$ indonissa ihre Reste zahlreich zum Vorschein. Aus den zum Teil noch gut erhaltenen Unterkieferstücken zu ur-

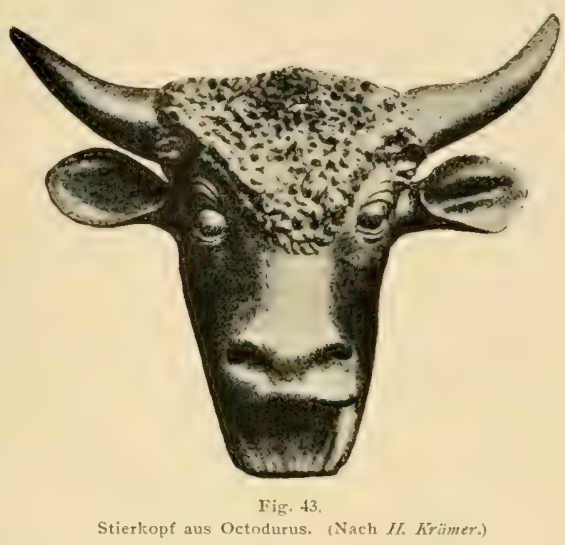
teilen, besass damals diese Rinderform eine stattliche Grösse. Im Laufe der Zeit hat sich jedoch der Wohnsitz derselben verschoben, denn heute findet man nur noch einzelne Reste derKurzkopfrinder in den Alpen, hier allerdings in zwergartiger Form. Ein starker Bestand vermochte sich auf der iberischen Halbinsel als grossgehörnte, schwere Tiere zu erhalten.

\section{DIE WILDRINDER UND IHRE VERBREITUNG.}

Um ein Urteil über die phyletischen Verhältnisse unserer Hausrinder zu gewinnen, muss zunächst Umschau gehalten werden über die heute noch lebenden oder wenigstens in historischer /eit noch vorhandenen Wildrinder der alten Welt.

Die Reihe der Bovina im weiteren Sinne wird am naturgemässesten mit den Bütleln (Bubalina) eröffnet, da letztere den natürlichen Uebergang zur Antilopengruppe herstellen. Von ihnen aus lässt sich anatomisch und palaeontologisch die Entwicklung bis zu den extremsten Rinderformen sehr klar verfolgen. Insbesondere ist es die Schädelmetamorphose, die noch alle Zwischenstufen erhalten hat.

Der Büffelschädel erinnert besonders in seiner hinteren Partie stark an den Antilopenschädel, er ist im Hinterhaupt abgerundet, der Occipitalknochen und die Scheitelbeine sind noch so wenig zurückgedrängt, dass sie hinter dem Hornansatz von oben sichtbar sind. Die Wisente (Bisontina) gehen, um einen zutreffenden Ausdruck Rütimeyer's zu gebrauchen, auf der Strasse der den Rindern zukommenden Schädelmetamorphose einen guten Schritt weiter als die Büffel, aber sie bleiben auf halbem Wege zu den hö̈hststehenden Rindern (den Taurina) stehen. Die breiten, gewälbten Stirnbeine haben an Ausdelnung gewonnen, die sicleitelregion wird stärker 
zurückgedrängt, aber noch ist die Hinterhauptsschuppe von oben deutlich sichtbar, der Hinterkopf immer noch gerundet, wenigstens nicht scharf abgeknickt.

Die jetzt lebenden Arten der genannten Untergruppen kömen übergangen werden, da sie sicher keinen Anteil an der Erzeugung von Bos taurus oder Bos indicus haben.

Es bleiben somit nur noch die Endglieder, die Rinder im engsten Sinne, unter denen man die mehr östlichen Bibovina als primitivere Gruppe von den westlichen Taurina abgetrennt hat. Der Bildungsherd beider ist offenbar in Südasien zu suchen, wotür sowohl palaeontologische als tiergeographische Gründe sprechen. Die westlichen Taurina sind heute im Wildzustande als erloschen zu bezeichnen, während die Bibovina in Asien noch mehrere lebende Vertreter aufweisen. Ein fossiler Ausläufer greift auch nach Südeuropa hinüber (Bos etruscus), dieser kann aber wegen der noch stark über den Hornansatz hinausragenden Hinterhauptspartie des Schädels in keiner Weise als Stammform der Iausrinder in Frage kommen, trotzdem seinerzeit $\boldsymbol{M}$. Wilckens diese Möglichkeit andeutete.

Bei den Rindern im engeren Sinne erreicht die Schädelumwandiung eine extreme Stufe, über welche nicht mehr hinausgegangen werden kann. Die Stimbeine sind hier derart ausgedehnt, dass die ganze Oberseite der Hirnkapsel von ihnen eingenommen wird; dadurch wird die Parietalzone in die Schläfengrube hinabgedrängt und die Iinterhauptsschuppe senkrecht aufgerichtet; sie stösst in einer Kante mit dem Stirnabschnitt zusammen, wodurch das Profil im Hinterhaupt scharf abgeknickt erscheint. Nach dem Prinzip der Rekapitulation wiederholt der jugendliche Rinderschädel während seiner Entwicklung die oben erwähnten Metamorphosen.

Von asiatischen Wildrindern bewohnt die originellste Form, der Grunzochse oder Yak (Bos grunniens) als eigentliches Gebirgstier die Hochtlächen von Tibet und die angrenzenden Gebirgszüge; er ist übrigens auch in den Hausstand übergetreten und findet in der Mongolei sowie in den Transbaikalländern vielfach V $\mathrm{e}$ erwendung.

Aeusserlich erinnert das sonderbare Geschöpf einigermassen an den Bison; die lange Behaarung, der gewölbte Rücken und die breite, gerundete Stirn sprechen für eine Verwandtschaft, doch handelt es sich nur um eine oberflächliche Analogie, der anatomische Bau des Schädels ist abweichend. Dieser ist ausgezeichnet durch eine kurze und breite Stimzone, während der Gesichtsteil lang und schmal ist; die Augenhöhlen ragen stark hervor: das drehrunde, schlanke Gehörn wechselt an Grösse, bei zahmen Tieren kann es sogar gänzlich fehlen.

Zwei andere Wildrinder bewolnen das Festland von Indien, nämlich der Gayal (Bos frontalis) und der Gaur (Bos gaurus). Die Frage ist mehrfach diskutiert worden, ob beide spezifisch zu trennen seien oder nicht. Der Gayal dehnt sein Wohngebiet vom Brahmaputra bis nach Indochina 
aus und gehört wohl zu den imposantesten Rinderı, da er eine Länge von $3 \frac{1}{2}$. Meter erreichen kann. Die flache Stirn ist ungemein breit, das Gehörn namentlich beim Stier dick, kegelförmig, nach aussen und oben gerichtet, aber verhältnismässig kurz; die Wanne schwach, der Rücken stark gewölbt. Seit langer Zeit wird der Gayal als Haustier gehaiten und dürfte lokal sein. Blut mit dem indischen Buckelrind vermischt haben.

Der Gaur (Bos gaurus) ist eine ähnliche stattliche Erscheinung und lebt in Vorder- und Hinterindien bis zur Halbinsel von Malakka. Der kurze und breite Kopf zeigt einen dreieckigen Umriss, indem er von der spitzen Schnauze an rasch an Breite zunimmt. Das starke Gehörn beginnt mit breitem Ansatz und wendet sich in starker Krümmung erst nach aussen und dann nach oben. Im Schädel tritt als hervorstechender Charakterzug der mächtige Stirnwulst entgegen, der sich über dem Hinterhaupt wie eine Wand erhebt. Vor diesem Wall erscheint die Stirnfläche stark vertieft. was Hodgson veranlasste, dieser Art den Namen Bos cavifrons zu geben. Die sexuellen Unterschiede im Schädelbau sind viel geringer als bei den übrigen Wildrindern Südasiens.

Als weitere, am meisten nach Süden vorgeschobene Art ist der dem Gebiet der Malayen zugehörige Banteng (Bos sondaicus) zu nennen. Dieses schönste aller Wildrinder scheint infolge der mit den wirksamen modernen Feuerwatfen betriebenen Jagd im Rückgang begriflen zu sein. Am häufigsten findet man den Banteng gegenwärtig noch auf Java, doch ist er nach meinen lnformationen dort stark zurückgedrängt worden und gegenwärtig nur noch in den wenig bevölkerten Preanger Regentschaften und in Bantam vorhanden. Er soll auch auf der Insel Bali wild vorkommen, ebenso auf Borneo und der Halbinsel Malakka. In der Litteratur wird angegeben, dass er als gezälımtes Tier in Bali gehalten werde, nach einer mündlichen Mitteilung vou $F$. Sarasin ist er auch in Celebes eingeführt.

Die Haarfarbe ist dunkelgraubraun oder rötlichbraun mit breitem, weissem Spiegel an den Hinterbacken; der etwas erhöhte Widerrist stellt einen langgezogenen Buckel dar, der jedoch nicht stark hervortritt, die Wanne stark entwickelt.

In der Bildung des Kopfes und des Gehörns zeigen sich bei diesem Rind starke sexuelle Unterschiede. Bei der Bantengkuh ist der Kopf gestreckt mit feiner Schnauze, hinten verhäitnismässig schmal, das Profil etwas geramst, das mässig starke Gehörn nach hinten gerichtet und mit den Spitzen nach innen gebogen. Der Stier erscheint im Hinterkopf erheblich breiter: das Gehörn, wie bei der Kuh auf deutlichen Hornstielen aufsitzend, wendet sich erst abwärts und auswärts, biegt dann in starkem Bogen nach oben; durch seine stärkere Entwicklung nähert es sich dem Gehörn des Gaur. Auf die anatomischen Einzelheiten soll in einem späteren Abschnitt eingetreten werden.

Als letztes Wildrind, das bei der phylogenetischen Ableitung unserer 
Hausrinder sehr wesentlich in Betracht kommt, muss der Ur (Bos primigenius Boj.) hier angereiht werden.

Als gewaltiger Ausläufer der Taurina hat man sein einstiges Wohngebiet wemn nicht ausschliesslich, so doch vorwiegend in Europa zu suchen. Für unsere Fauna ist diese Art seit Jahrhunderten verloren gegangen und die Erinnerung an dieselbe bereits so verwischt, dass man sie einst ganz ungerechtfertigter Weise zu negieren versuchte und mit einem anderen

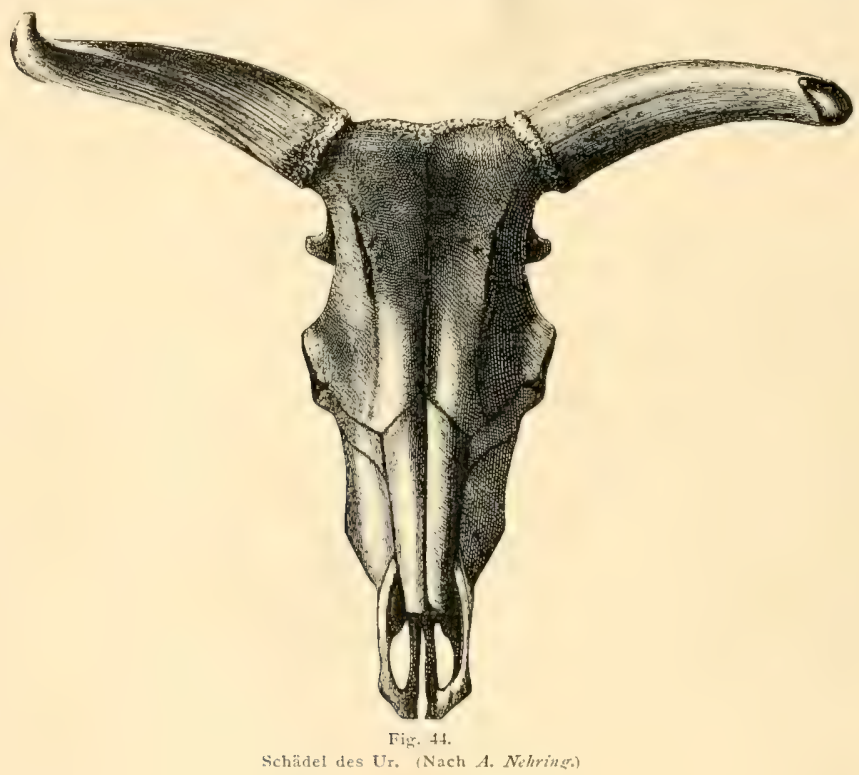

Wildrind Europas, dem noch in spärlichen Resten lebenden Wisent (Bison) zusammenwarf. Es gebührt $G$. Cuvier das Verdienst, in diese Frage zuerst die nötige Klarheit gebracht zu haben, ${ }^{1}$ ) in dem er nicht allein die osteologischen Merkmale vom Wisent und Ur klar auseinander hielt, sondern bereits auch auf litterarische Zeugnisse hinwies, welche die historische Existenz des letzteren darthun.

In der Erdgeschichte erscheint unser Ur erst in der pleistocaenen (diluvialen) Periode und sein Schädelbau dokumentiert ihn als das Endglied in der Entwicklungsreihe der Bovina. Der Schädel zeigt auffallend gerad. linige Umrisse. Die Stimbeine sind flach und stossen in rechtem Winkel

1) G. Cwzier. Recherches sur les ossements fossiles. Tom. IV. 
mit der Hinterhauptsfläche zusammen, der Hinterrand ist ziemlich gerade, in der Mitte etwas ausgeschweift, der Gesichtsschädel zeigt eine verhältnismässig starke Entwicklung. Charakteristisch erscheint die schiefe, nach vorn gerichtete Stellung der Augenhöhlen und der schief aufsteigende Ast des Unterkiefers. Das mächtige Gehörn besass im ganzen Leierform, erst sich nach aussen wendend. damn nach oben und vorn sich über der Stirn erhebend, die Spitzen zuletzt aufwäts gerichtet. Uebrigens sind auch Variationen im Verlauf der Hornstiele bekannt geworden. Die Grösse des Tieres war nicht überall dieselbe, neben Formen, welche über unsere grössten Hausrinder hinausgehen, gab es kleinere Exemplare.

Die geographische Verbreitung des wilden Bos primigenius lässt sich auf Grund zahlreicher Funde ziemlich genau umschreiben. In Europa kennen wir Fundstellen seiner Reste von Scandinavien bis nach Italien hinunter und von England bis nach Russland. Am dichtesten hat er wohl das nordöstliche Europa bevölkert, wo er auch am längsten ausgehalten hat. In den diluvialen Ablagerungen und Torfmooren des nördlichen Deutschland sind vielfach Schädel, zum Teil vollständige Skelette aufgefunden worden. Im Osten reichte der Ur weit über Europa hinaus. Schon Brandl hat sein Vorkommen im Altaigebiet signalisiert, $\left.{ }^{\prime}\right)$ Tscherski wies 1875 dasselbe auch für Ostsibirien (Irkutsk) nach, ${ }^{2}$ ) ja noch aut dem Boden Chinas erschien einst der Ur, Abbé Davidª hat in diluvialen Löss einen Schädel bei Suan-hoa-fu in Norden von Peking aufgefunden. Es handelt sich aber wohl nur um versprengte Exemplare und Tscherski, der die pleistocaene Fauna Nordasiens wohl am genauesten untersucht hat, macht darauf aufmerksam, dass unzweifelhafte Primigeniusreste in Sibirien spärlich angetroffen werden, ganz im Gegensatz zu den häufigen Bisonresten; er erblickt daher im nordasiatischen $\mathrm{Ur}$ nur einen verháltnismässig seltenen Einwanderer.

Weiter südlich sind Spuren in Vorderasien aufgetaucht. Wir kennen durch Tristram einen Zahnfund vom Libanon, deutliche Anhaltspunkte weisen auf Mesopotamien als einstiger Wohnort hin. Zwar dürfte dort das Tier kanm in die heissen Niederungen hinabgestiegen sein, aber be: wohnte doch das kühlere Bergland von Nordbabylonien. Für die assyrischen Könige bildete es Gegenstand der hohen Jagd und die bekannte Skulptur, welche auf dem N. W. Palast in Nimrud (884 v. Chr.) Assurnassirpal darstellt, wie er dem gewaltigen Wild das Messer ins Genick stösst, lässt uns mit aller Deutlichkeit den wilden Ur erkennen. Der Künstler hat nicht nur das starke Gehörn gut dargestellt, sondern in sehr naturalistischer Weise den schief aufsteigenden Unterkieferast. Zur assyrischen Zeit hiess der Ur "Rimu“, was identisch mit dem biblischen "reem" ist.")

1) Brandt. Zoogeographische und P'alaeontologische Beiträge. 1867.

2) Tscherski. Wissensch. Result. d. neusib. Exped. Mémoires de l'Acad. St. Petersbourg. 1842.

3) 7scherski. Loc cit. Pag. 5̋0.

4) F. U. Dürst. Die Rinder von Babylonien, Assyrien und Aegypten, 1849. Pag. 10. 
Das mediterrane Gebiet weist Spuren des Ur nicht nur auf der europäischen und asiatischen Seite auf, sondern auch in Nordafrika, wo pleistocaene Reste in Algier durch Thomas und Pomel beschrieben worden sind. ${ }^{1}$ )

Die vielumstrittene Frage, ob der Ur ausschliesslich der Vorzeit angehörte oder noch in die historische Zeit hineingereicht hat, ist heute vollkommen abgeklät und zwar zu Gunsten der letzteren Meinung, da sich über den Rückgang und das endgültige Ableben genatere Daten gewinnen liessen. Auf die weitschichtige Litteratur über diesen Gegenstand oäher

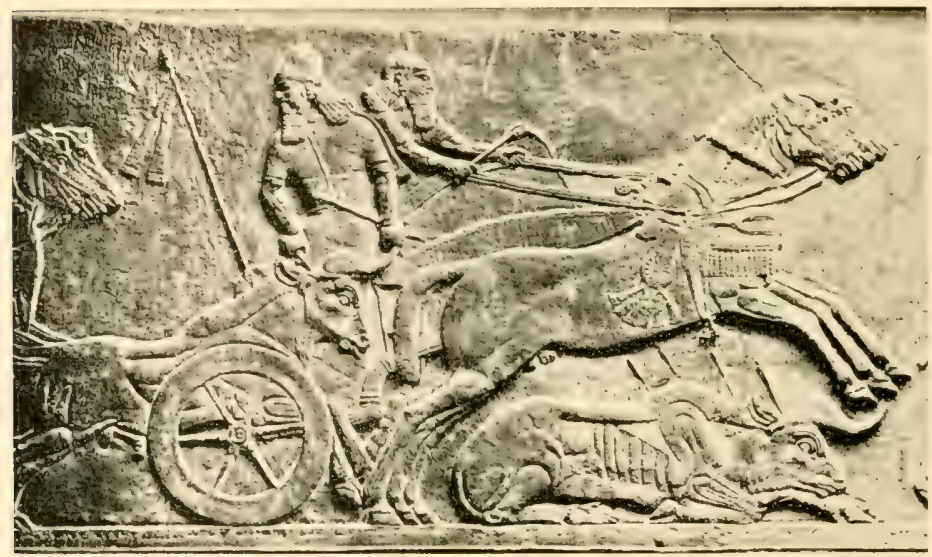

Fig. 4.5.

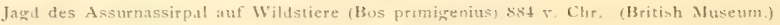

einzutreten, ist hier nicht beabsichtigt. Der Nachweis der historischen Existenz dieses Wildrindes ist vom Standpunkt der Geschichte des Hausrindes aus betrachtet von fundamentaler Bedeutung.

Von litterarischen Zeugnissen bezieht sich die bekannte und oft zitierte Stelle bei Caesar²) zweifellos auf den Ur. Ums Jahr 1000 wurde der Urus noch in der Umgebung des Klosters St. Gallen gejagt und an der Klostertafel verspeist, wie wir den "Benedictiones ad mensas Ekkehardi“ entnehmen können. ${ }^{3}$ ) In Brombers wurde ferner ein Urstier-Schädel aufgefunden, der atus dem 12. oder 13. Jahrhundert stammt: ${ }^{*}$ ) er zeigt auf der Stirn drei

2) Vergl. E. L. Trouessart. Catalogus mamnalium tam viventium quam fossilium, 1V. 1 s4s.

2) In sy.lva Hercynia nascuntur qui appellantur Uri. Hi sunt magnitudine paulo inira elephantos, specie et colore et figura Tauri. (Carestr de bello gallico.)

") Ferdinand Killer. Benedictiones ad mensas Ekkehardi monachi Sangallensis. Mitteilungen der antiquar. Ges, in Zürich. 1847.

i) Alfred Milhing. Ueber Herberstain und Hirsfogel. 189\%. I'ag. 84. 
Lanzenstiche, ein Beweis, dass er um jene Zeit noch gejagt wurde. Hauptzeuge ist der österreichische Gesandte Freiherr von Herberstain, der im 16. Jahrhundert in hervorragender Stellung diplomatische Reisen nach dem ehemaligen Königreich Polen unternahm und um 1550 einen toten Ur als Geschenk erhielt. Er hat das in Masowien lebende Tier in seinem Werk $^{-1}$ ) nicht nur erwähnt, sondern auch abgebildet. Conrad (Gessner ${ }^{2}$ ) erhielt überdies von einem seiner Schüler, Schneeberger und von Foham Bonar zuverlässige Nachrichten über den in Polen lebenden Urochsen, der dort "Thur" genannt wurde.

In neuerer Zeit hat August Mrzesniowski die polnischen Quellen ein-

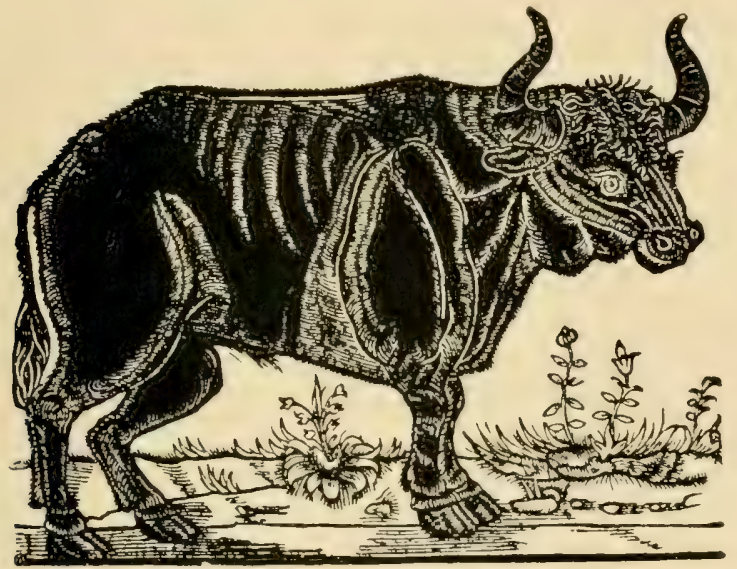

Fig. th.

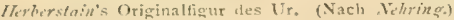

gehend benutzt und nachgewiesen, ${ }^{3}$ ) dass schon im 13. Jahrhundert die Jagd auf den Thur der Polen ausschliessliches Vorrecht der Herzoge von Masowien war, im 16. Jahrhundert der Ur bereits selten zu werden anfing und nur noch in den Forsten von Jaktorowka in Masowien (etwa 55 Kilometer westlich von Warschau) vorkam. Hier wurde er zuletzt förmlich gehegt und über die vorhandenen Exemplare Buch geführt. 1564 zählte man nur noch 30 Stück: 1599 im ganzen 24 Stück. 1602 ging der Bestand auf vier Thure zurück. die letzte Urkuh starb 1627.

1) Heherstain. Rerum moscociticarum commentarii. 1556. (Editio secunda.)

2) C. Gessner. Icones animalium. 1560.

3) Aug. Hrzesniouski, Studien zur Geschichte des polnischen Thur. Zeitschrift für wissenschaftliche Zoologie. 1878. 
Die äussere Erscheinung dieses gewaltigen Wildrindes Europas ist uns nicht ganz verloren gegangen, sondern im Bilde aufbewahrt. Herberstain, der letzte Zeuge, der den Ur noch gesehen, liess eine Abbildung herstellen, welche auf einer "Tabula" 1552 oder 1553 erschienen sein muss, in weiteren Kreisen aber zuerst durch Conrad Gessner 1553 bekannt wurde. Letzterer erhielt das Urbild Herberstain's durch den Wiener Arzt Wolfgang La ius.

Wilckens ${ }^{1}$ ) hat mit Unrecht die Aechtheit der Figur angezweifelt, 1. Nehring hat jedoch dieselbe in überzeugender Weise nachgewiesen. ${ }^{2}$ )

Daneben existiert noch das sogenannte "Augsburger Urstierbild", das auf Holz gemalt eine Darstellung des Thur giebt. Es soll aus dem 16. Jahrhundert stammen, gelangte in den Besitz von Hamillon Smith, der eine Kopie davon in Griffiths "Animal Kingdom" 1827 veröffentlichte und ist im Original seither verschollen. Ich kann mich des Eindruckes nicht erwehren, dass dieses starkkropfige Rind ein zahmes Steppenrind darstellt.

Wir kennen zum Glück weit bessere und ältere Bilder. Schon die oben erwähnte assyrische Jagdszene aus der Zeit Assurnassirpals kann den Anspruch auf Naturtreue und gute Ausführung erheben. Ich habe indessen den Nachweis geleistet, dass die viel äleren, aus der mykenischen Zeit (1500-1200 v. Chr.) Griechenlands stammenden Rinderfiguren auf den Goldbechern von Vaphio Darstellungen des Bos primigenius aufweisen. ${ }^{3}$ ) Es sind dies weitaus die besten Urbilder, die wir besitzen. Die auf dem einen Becher erkennbare Jagdszene ist vom Künstler zweifellos dem Leben abgelauscht worden, die Naturtreue vollkommen überzeugend. Wir erhalten dadurch auch einen Belees dafür, dass den Bewohnern des griechischmykenischen Zeitalters das Tier wohl bekannt war.

\section{DIE BISHERIGEN ANSICHTEN UEBER DIE ABSTAMMUNG DER HAUSRINDER.}

I)ie Stammesverhälnisse des zahmen Rindes haben in I aut der Zeit eine sehr verschiedene Beurteilung crfahren, selten waren die Kontroversen über irgend einen Gegenstand grösser als hier und noch hente gehen die Meinungen weit auseinander. Ich will versuchen, kritisch auf die Ansichten derjenigen Autoren einzugehen, die auf anatomischem Wege eine Lösung des I'roblems versucht haben.

Mehrere derselben nehmen einen monophyletischen Standpunkt ein, indem sie eine einzige Stammquelle für alle Hausrinder der Erde aufsuchen.

Ilier ist zunächst ( $\dot{x}$. Cuzier zu nennen, der zum ersten Mal mit einer

1) 1\%. Wikkens. Landwirtschaftliche Jahrbücher. 1885.

2) A. Vehring. Die Iierberstan'schen Abbildungen des Ur und des Bison. Landwirtschaftliche Jahrbücher. 1896.

3) C. Keller. Figuren des ausgestorbenen Ur (Bos primigenius) aus vorhomerischer Zeit. Globus. Bd. LXXII. 
wirklich wissenschaftlichen Methode operiertc. Zunächst sucht er den einheitlichen Charakter aller Formen anatomisch nachzuweisen: Ces caractères assignés à l'espéce du boeuf ne sont pas ceux d'une ou deux variétés, ils se sont trouvés constans, non seulement dans tous nos boeufs et vaches ordinaires, mais encore dans toutes les variétés étrangères que nous avons examinées. ${ }^{1}$ )

Als deren europäische Stammquelle (original de notre boeuf) bezeichnet er den ausgestorbenen $\mathrm{Ur}$ (Bos primigenius). Er bemerkt ausserdem, was in der Folge bestätigt wurde, dass die schottischen Parkrinder am unmittelbarsten an diese Wildform anknüpfen, die Iausrinder sich aber schon etwas weiter entfernt haben.

Die Cuvier'sche Ansicht hat noch in der Neuzeit entgegen abweichenden Ergebnissen in A. Vehring einen entschiedenen Verfechter gefunden. Es entging diesem Autor nicht, dass der wilde Bos primigenius starken individuellen Schwankungen, namentlich auch hinsichtlich der Grösse unterliegen kann. Er hält daher die kleineren Rinder, namentlich auch die prähistorischen Torfrinder für einfache Kümmerformen ${ }^{2}$ ) des Primigenius, entstanden durch schlechte Haltung und ungünstige Lebensbedingungen, wie er auch das Torfschwein als Kümmerform erklärte. Dieser Theorie lassen sich aber mehrere Einwảnde entgegenhalten:

1. Im Sinne von Nchring müsste man in den altesten Fundstätten aus der prähistorischen Zeit grosshörnige Primigeniusrinder antreffen, die Uebergänge zu den Kümmerformen ebenfalls nachweisen können. In Wirklichkeit ist aber das grosshörnige Rind jünger als das T'orfrind, das über ganz Europa zerstreut von Anfang an als scharf ausgesprochene Rasse auftritt und erst später mit grösseren Rindern gekreuzt wird.

2. Eine experimentelle Prüfung am Wildrind, inwieweit es durch ungünstige Lebensbedingungen Yeränderungen erleidet, ist schon einfach deswegen ausgeschlossen, weil dieses Wildrind erloschen ist.

3. In Sibirien erfährt vielorts das Hausrind die denkbar schlechteste Pflege und lebt unter kümmerlichen Verhältnissen. Ich verschaffte mir Bildermaterial von solchen Rindern, sie sehen in der That sehr verwahrlost aus - aber die typischen Merkmale eines grosshörnigen Primigeniusrindes sind geblieben.

4. Die kleinen, kurzhörnigen Rinder auf den englischen Kanalinselı Jersey, Alderney und Guernsey sind berühmt wegen ihrer Milchergiebigkeit; sie sind Abkömmlinge des alten Torfrindes und mit dem Braunvieh der Alpen nahe verwandt. Wie ich der englischen zootechnischen Litteratur entuehme, werden diese Kanalrinder von den ersten Lebensmonaten an mit grosser Sorgfalt gepflegt und gut

1) G. Cuitier. Recherches sur les ossements fossiles. Tom. IV. 1823. P'ag. 109.

2) A. Veluring. Verhandlungen der Berliner anthropologischen Gesellschait. April 1888. 
ernährt - aber sie bleiben trotzdem klein und kurzhörnig; niemals tritt die Neigung hervor, primigenen Charakter anzunehmen.

Es bleibt somit unerwiesen, dass alle unsere Rassen vom Bos primigenius ableitbar sind.

In neuester Zeit hat, um diesen Schwierigkeiten gerecht zu werden, die monophyletische Abstammung durch E. O. Arenander ${ }^{-1}$ ) eine andere, sehr eigentümliche Ausgestaltung erfahren. Dieser skandinavische Forscher untersuchte das früher nur ungenügend bekannte Gebirgsvieh Nordschwedens und Norwegens. Dieses ist wegen seiner Hornlosigkeit bemerkenswert. Die genamnte Eigenschaft findet sich auch bei andern nordeuropäischen Rindern. Arenander erblickt in der hornlosen Rasse einen uralten, selbständigen Trpus. dessen phylogenetische stellung aher offenhar unichtig heurteilt wird.

Die weisse Farbung der Tiere scheint ihm eine Naturfarbe zu sein; er hält unser Rind nicht als Einwanderer aus Asien, sondern auf europäischem Boden entstanden: die wilde europäische Stammform war hornlos (Bos akeratos). Hinsichtlich des genetischen Zusammenhanges der einzelnen Rassentypen Europas bemerkt er: „Der älteste ist Bos akeratos. Aus ihm ist Bos brachyceros durch "spontane Variation" entstanden und aus diesem haben sich Bos frontosus und Bos primigenius entwickelt. Dieser letztere ist also der Schlusspunkt, und nicht der Ausgangspunkt, wie man bis jetzt gewöhnlich angenommen hat."

Der jetzige Akeratustypus hat sich seiner Auffassung nach nur an der P'eripherie des V'erbreitungsgebietes als ursprüngliche Form erhalten, den Bildungsherd der Wildform sucht er in Südeuropa.

Manche Einzelgedanken der eingehenden und fleissigen Arbeit Arenanders sind brauchbar, der allgemeine Ideengang und das Schlussergebnis jedoch sicher verfehlt.

Zunächst erscheint es im Hinblick auf die palaeontologische Entwicklung der Rinder, die wir doch ziemlich genau kennen, sehr gewagt, eine hornlose Stammform aufzustellen. wälrend doch die Mehrzahl der zahmen Rinder gehörnt ist.

Das Gehörn hat sich von den antilopenartigen Stammformen her durch die ganze neuere Tertiärzeit hindurch als Waffe erhalten und beim diluvialen Ur bereits mächtig entwickelt, eine rückläufige Entwicklung ist also nicht vorhanden.

Eine wilde Akeratosform hätte man bisher sicher an den jungen, oberflächlichen Schichten Europas antreffen müssen, falls eine solche wirklich existierte; ihre Zähmung wäre erst im Beginn der neolithischen Zeit erfolgt. Die Ausrede, dass unsere palaeontologischen Kenntnisse unvollkommen seien, ist nicht stichhaltig.

Uebrigens widerspricht sich Arenander, wenn er die weisse Farbe der

3) E. O. Arenander. Studien über das ungehörnte Rindvieh im nördlichen Europa. Berichte des landwirtschaftlichen Instituts der Universität Halle. 13. Heft. 1898. 
nordischen Akeratosrinder als Naturfarbe, resp. Erbstück der an nordische Verhältnisse angepassten Stammform erklärt und dann ihren Bildungsherd nach Südeuropa verlegt. Im Widerspruch mit seiner Theorie steht auch die 'Thatsache, dass in den ältesten P'ahlbauten das kleine Torfrind gehörnt ist und erst in jüngeren Niederlassungen gelegentlich als ungehörnte Form auftritt.

Endlich heisst es denn doch die anatomischen Beziehungen gänzlich verkennen, die zwischen dem diluvialen Ur, der noch in die historische Zeit hineinreicht und den grossen Niederungs- und Steppenrindern bestehen, wenn man diese als Schlussglied einer Reihe bezeichnet, deren Anfangspunkt hornlos war. Anatomen wie Cuvier und liätimejer haben jene Beziehungen ja eingehend nachgewiesen.

Dieser letzte Einwurf kann auch gegenüber M. Nilckens erhoben werden.') der zuletzt den Bos primigenius als Stammquelle von Hausrindern gänzlich abwies: n-Aber nirgends ist der Beweis geliefert worden, dass der "wilde Ur gezähmt wurde und die Stammform der heutigen Rinder ge.worden ist. Es ist auch in höchstem Grade unwahrscheinlich, dass der ,Mensch in vorgeschichtlicher Zeit - denn nur damals könnte die Zähmung "des Urochsen geschehen sein, da aus geschichtlicher Zeit keinerlei Nach"richt darüber vorliegt - ein so unbändiges Tier gezähmt habe." Er findet schliesslich, dass wir über die Abstammung und Zähmung des Rindes ebensowenig positive Kenntnisse haben wie von den meisten übrigen Haustierarten.

Im Laufe der Zeit haben übrigens die Anschauungen von Wilckens über diese Frage manche Wandlungen durchgemacht. Anfänglich neigte er Rütineyer zu, die von ihm neu aufgestellte Brachyceplaalus-Rasse schien ihm erst Beziehungen zur Wisentgruppe zu haben, später glaubte er an Bos etruscus anknüpfen zu können.

Den hier dargelegten Annahmen steht die diphyletische Abstammung der Hausrinder gegenüber; sie wird von mehreren Autoren vertreten und dürfte sich in der Folge als allein richtige allgemein einbürgern.

Um die Mitte des 19. Jahrhunderts trat zunächst Isidore Geoffroy St. Hilaire der durch Cuvier begründeten Ansicht von der europäischen Herkunft der Rinder entschieden gegenüber und befürwortet eine orientalische, beziehungsweise asiatische Abstammung. ${ }^{2}$ ) Seine Beweisführung ist jedoch nicht zwingend, weil sie sich vorwiegend auf kulturgeschichtliche und sprachwissenschaftliche Gründe stützt. Er hält unser europäisches Rind und den Zebu streng auseinander und weist zunächst an der Hand altagyptischer Bildereien nach, dass im Vilthal schon frühzeitig beide Formen

1) Martin Hilckicns. Grundzüge der Naturgeschichte der Haustiere. Dresden. 1880. Pag. 153.

$\left.{ }^{2}\right)$ Isidore Geoffroy St. Ifilatre. Acclimatation et domestication des animaux utiles. 1861. Pag. 200 und If. 
neben einander gelebt haben(?). Da aber die Wildrinder im engeren Sinne hente nur noch in Asien lebend angetroffen werden, so sind die Stammformen dort zu suchen. die ältesten Zentren der Domestikation seien nach Asien zu verlegen. Isidore Geoffroy St. Hilaire spricht sich indessen weder über die Region der Domestikation, noch über das in Frage kommende Wildmaterial näher aus, scheint auch nie die erforderlichen vergleichendosteologischen Untersuchungen vorgenommen zu haben; er betont nur die ungenügende Kenntnis asiatischer Wildrinder.

Ungefähr zu gleicher Zeit hat Ludwigr Rülimeyer in ganz anderer Weise und auf Grund eines sehr glücklich ausgewählten Materials die Abstammung der europäischen Rinder-Rassen klar zu legen begonnen. ${ }^{1}$ ) Er unterscheidet im Viehstapel unseres Kontinentes zwei genetisch durchaus verschiedene Elemente. Nur eines derselben - und hierin schliesst er sich wieder enger an Cuzier an - entstand auf europaiischem Boden, wo der Ur (Bos primigenius) als Stammquelle diente. Dazu gehören vorab die grossen Niederungsrinder Norddeutschlands und die Marschrinder Hollands, sowie die podolischen und romanischen Rinder. Sie bilden zusammen die zahme Primigenius-Rasse, weil ihre Schädelbeschaffenheit mit dem wilden Ur am meisten gemeinsame Züge aufweist. Fine ihr nahestehende Trochoceros-Rasse hat er spitter wieder fallen lassen. Die Frontosus-Rasse ist in letzter Instanz auch auf die genamite Quelle zurückführbar, muss aber als ein Kulturprodukt angesehen werden, das aus der Umbildung zahmer Primigeniusrinder gewonnen wurde. Im Schädel dieser Form treten jugendliche Charaktere wieder auf. Dieser Ilerleitung entspricht das verhältnismässig späte Erscheinen des Frontosusrindes.

Daneben existiert ein zweiter Stamm, dessen Elemente sehr früh über Europa zerstreut sind - der Brachyceros-Stamm, gebildet von kleinen, kurzhörnigen Rindern. Ihr Prototyp ist das alte Torfrind, von dem unser modernes Braunvieh herzuleiten ist. Diese Rinder entfernen sich anatomisch durch eine Reihe von konstanten Merkmalen vom P'rimigenius-Vieh derart, dass eine andere Stammquelle aufgesucht werden muss. Eine durch Kultur erzeugte Form bildet das nahe verwandte Kurzkopf-Rind (BrachycephalusRasse), das aus dem brachyceren Rind durch beginnende Mopsbildung hervorging. Die hornlosen Formen betrachtet er in Uebereinstimmung mit den übrigen Forschern als Abkömmlinge gehörnter Tiere und weist in dieser Beziehung speziell auf das Angus- und Galloway-Rind Englands hin, das früher gehörnt war.

Hinsichtlich der wilden Stammform der Brachyceros-Gruppe beobachtet Rütimeyer bei der ihm eigenen Umsicht eine gewisse Zurückhaltung. Nur das eine ist für ihn sicher, dass Bos primigenius nicht in Frage kommen kann und gleichzeitig die Hoffnung, einen Stammvater in Europa zu finden,

1) L. Rütimeyer. Fauna der Pfahlbauten, 1562 und Versuch einer natürlichen Geschichte des Rindes, Schweiz. Denkschriften, $186 \%$ 
aufgegeben werden muss. Die Urheimat ist also ausserhalb Europa zu suchen. Er deutet an, dass unser südlicher Nachbarkontinent Afrika zunächst Aufschlüsse verspreche. indem an Nordrand desselhen die kleinen algerischen Rinder den Brachyceros-Charakter sehr treu erhalten haben und deswegen dem alten Torfrind sehr nahe stehen. Indessen herrschte zu seiner Zeit noch eine grosse Unkenntnis der afrikanischen Rassen. Noch im Jahre 1888 muss sich Rütimeyer „ausser Stand erklären, eine wilde Stammform für das Torfrind namhaft zu machen." $\left.{ }^{1}\right)$ Er spricht lediglich die Vermutung aus, dass man vielleicht noch weiter rückwärts suchen müsse, so dass in letzter Instanz eine Stammquelle eher in dem rinderreichen Asien gefunden werden dürfte als in dem so ärmlich ausgestatteten Nordeuropa.

Ich habe seither den Rätimeyer'schen Standpunkt, der mir weitaus der natürlichste zu sein schien, in der Weise verfolgt, $\left.{ }^{*}\right)$ dass ich zunächst genauere Erhebungen über die afrikanischen Rinderschläge an Ort und Stelle vornahm und im Laufe der Jahre sind mir dieselben in Nord- und Ostafrika bis nach Madagaskar aus eigener Anschaung bekannt geworden. In osteologischem Material konnte ich die Umwandlungen nachweisen, die an dem so äusserst variabeln Zeburind in den einzelnen Schlägen Ostafrikas auftreten. Diese Umformungen führen nach Norden zu einer Annäherung an den europäischen Brachyceros.

Es hiesse wohl alle Thatsachen der Völkergeschichte verkennen, wollte man nicht zugehen, dass von Nordafrika her sehr früh und anhaltend Kultureinwirkungen auf - iüdeuropa erfolgt sind. Die archateologischen Entcleckungen der neuesten Zeit liefern fortwährend Beweise, dass diese Einwirkungen schon sehr alt siud. Dass sie auch den Uebertritt gewisser Haustier-Rassen von Nordafrika nach Südeuropa im Gefolge hatten, ist zweifellos; das Mittelmeer bildete keine trennende Schranke. In einem späteren Abschnitt soll auf die afrikanischen Rassen und ihre Beziehung zu asiatischen Rindern näher eingetreten werden.

Dass anderseits auch auf europäischem Boden zahme Rinder aus dem Ur (Bos primigenius) herangezogen wurden, dafür kounte ich einen neuen und klaren Nachweis auf Grund archaeologischer 'Thatsachen erbringen. ${ }^{3}$ ) Eine von mir vorgenommene Analyse der aus mykenischer Zeit stammenden Goldbecher von Vaphio ergab die unzweidentige P'rimigeniusnatur der auf ihnen vorhandenen Rinderfiguren; der ganze Vorgang der IIaustierwerdung des Ur ist in künstlerisch vollendeter Weise dargestellt.

Einen diphyletischen Standpunkt vertritt in der Neuzeit auch Leopold

1) L. Rütimever. Verhandlungen der Berliner anthrop. Gesellschaft. Dez. 1888.

2) C. Koller. Das afrikanische Zeburind und seine Beziehungen zum europäischen Brachyceros-Rind. Vierteljahrsschrift der naturf. Ges. Zürich. 1896. Ferner:

C. Killer. Les éléments africains parmi les animaux domestiques de'l'Europe. Archives des Scienc. phys, et nat. Genève. 1898.

$\left.{ }^{3}\right)$ C. Keller. Figuren des ausgestorbenen Ur aus vorhomerischer Zeit. Globus. Bd. LXXII. 
Adametz, aber er weicht insofern von Rütimeyer und mir ab, als er auch für den Brachycerosstamm eine europäische Herkunft befürwortet und sogar die zugehörige Wildform aufgetunden zu haben glaubt. ${ }^{1}$ )

Adametz stützt sich bei seinen so weittragenden Folgerungen auf einen einzigen Schädelfund, der auf einem Gute in Krzeszowice (Westgalizien) in einer Tiefe von 12 Fuss gemacht wurde und angeblich aus einer diluvialen Bodenschicht stammt. Das Stück ist unvollständig erhalten, indem die Gesichtspartie fehlt und die Hornzapfen in der Nähe der Basis abgebrochen sind. Auf diesen einzigen Fund eine Wildform der Brachycerosrinder begründen zu wollen, erregt gewisse Bedenken. Ein diluviales Wildrind, das schon in prähistorischer Zeit von seinem Individuenüberschuss an den Menschen abtreten könnte, um ihm zahme Formen zu liefern, müsste jedenfalls zahlreiche Reste hinterlassen haben, wie wir dies ja beim Bos primigenius erfahren haben. Das wilde Brachyceros-Rind ist aber bisher mit Sicherheit an andern Punkten nirgends zum Vorschein gekommen, wo man es etwa zu finden glaubte, hat es sich immer als zahmes Tier herausgestellt.

Ich gebe zu, dass der von Adametz beschriebene Schädel einen eigentümlichen Charakter besitzt und der genannte Autor war nahe daran, die richtige Spur zu erkennen, in dem er in semer Arbeit gelegentlich das kurzköpfige Rind des Duxerschlages damit vergleicht.

Seitdem mir aus Vindonissa inzwischen die wichtige Thatsache bekannt geworden ist, dass schon in römischer Zeit Kurzkopfrinder nördlich der Alpen auftauchten, so halte ich jenes eigentümliche westgalizische Schädelfragment herstammend von einem zahmen Rind und zwar von einem Brachycephalusrind aus frühhistorischer Zeit. Es ist dabei geviss beachtenswert, dass nicht allzufern von der Fundstätte, sozusagen nur wenige Längengrade davon heute noch lebende Kurzkopfrinder vorhanden sind, nämlich im nordivestlichen Böhmen (Egerland).

\section{DER UR (BOS PRIMIGENIUS) ALS STAMMQUELLE EUROPAEISCHER HAUSRINDER.}

Im europäischen Viehstapel treten uns, wie früher schon bemerkt wurde, auf verschiedenen Wohngebieten Schläge und Rassen entgegen, welche sich durch bedeutende Körpergrösse, kräftige Entwicklung des Knochensystems und meist starke Entwicklung des Gehörns auszeichnen. Sie finden sich zunächst als Niederungs- und Marsch-Rinder der Ostsee und Nordsee entlang bis nach Holland, dann wieder in den Steppengebieten von Südosteuropa und in Italien.

Die allgemeinen Umrisse des Kopfes, die starke Entwicklung des Gesichtsabschnittes, besonders auch die Richtung des Gehörns, das sich meist

1) L. Adametz. Studien über Bos (brachyceros) europaeus, die wilde Stammform der Brachyceros-Rassen des Hausrindes. Journal für Landwirtschaft. Berlin. 1898. 
rasch über die Stirn erhebt und nach vorn wendet. lassen unverkennbare Aehnlichkeit mit dem wilden Ur erkennen. Dass es sich hier nicht um eine blosse Analogie, sondern um wirkliche Blutsverwandtschaft handelt, dafür legen die anatomischen Einzelheiten 7eugnis ab. Beim wilden Ur wie bei Bos taurus beträgt die Zahl der Rückenwirbel und der entsprechenden Rippenpaare 13; die geraden Umrisse des Schädels, die tlache Stirn, die ziemlich gerade \% wischenhonlinie, die schief nach vorn gerichteten Augenhöhlen, die starke Entwicklung der Nasenbeine und der Gesichtsknochen überhaupt, der schief aulsteigende Ast des Unterkiefers und die relativ kurze Backenzahureihe - das alles sind Eigentümlichkeiten des norddeutschen Niederungsrindes und des holländischen Marschrindes, die wir ja schon von Bos primigenius hervorhoben. I lese $U_{r}$-Rasse oder Primigenius-Rasse entfernt sich nur wenig von dem wilden Original, unter dem Einfluss der Domestikation ist die Grösse etwas vermindert und weil der Mensch den Schutz übernommen, die natürliche Waffe. das Gehörn schwächer greworden. Der Ur, als freilebendes 'l'ier erloschen, lebt also in diesen zahmen Nachkommen nur wenig verïndert fort.

Als primitivste form mit dem höchsten Betrag von Wildmerkmalen gilt das halbwilde Rind der schottischen Parks (Chillinghamrind). Primigene Rinder sind ausser in den norddeutschen Niederungen und holländischen Marschen auch in Frankreich vorhanden, wo nach 1dametz das Bergrind der Auvergne diesem Typus angehört. Dagegen haben die stattlichen, grosshörnigen Rinder spaniens und l’ortugals damit nichts zu thuı. Stark verbreitet (als Steppenrind) ist die primigene Rasse im Südosten Europas ınd im Süden (Italien): es erscheint über die Donauländer, die Balkanhalbinsel und über die südrussischen Steppen zerstreut; im Osten greift die Rasse über Europa hinaus nach Kleinasien und Zentralasien, hier das Gebiet des Bos indicus erreichend.

Auch Sibirien hat bis weit nach Osten hin primigenes Vieh, das zum Teil allerdings unter elenden Verhältnissen lebt.

Ist es zur Zeit so gut wie unbestritten, dass der Ur sein Blut aut diese grosse Rasse vererbt hat, so entsteht die weitere Frage, ob sich über die Zeit und den Ort der ältesten I)omestikation des Ur genaueres aussagen lässt.

Die Thatsache. dass diese Wildform im wesentlichen doch eine Charakterform der europäischen Fauna bildete und auf asiatischem Boden, soweit unsere heutigen Kenntnisse reichen, nur spärlich vorkam, weist darauf hin, dass die erste Zähmung in Europa stattgefunden hat. Diese erfolgte naturgemäss in einer Region, die am frühesten nachhaltigen Kultureinflüssen ausgesetzt war, also im Südosten unseres Erdteiles. Zum Glück griebt uns hier die Archaeologie, beziehungsweise die antike Kunst einen unzweideutigen Aufschluss.

Auf den mehrfach genannten myenischen Goldbechern ist ja, wie ich nachgewiesen habe, der ganze Vorgang der Primigeniusdomestikation dargestellt. 


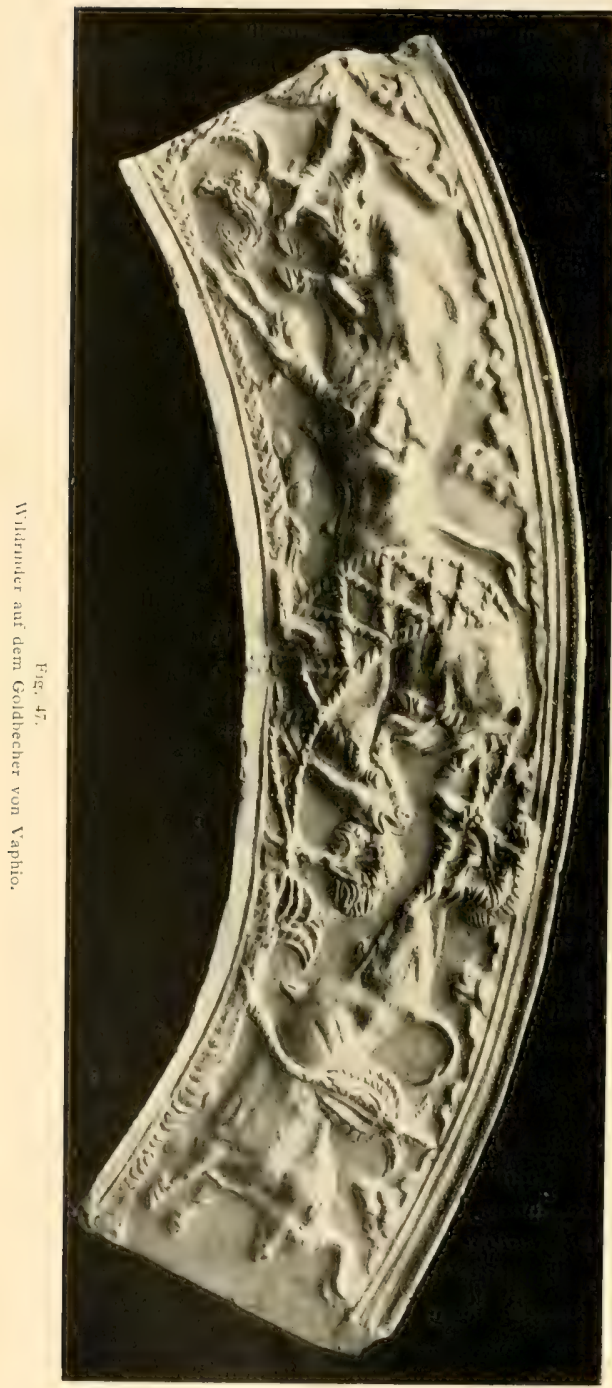


Die beiden Becher, von dem griechischen Archaeologen Tsunda 1888

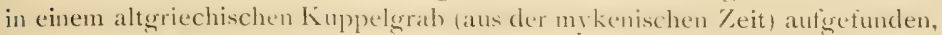
gehören offenbar zusammen und sind aus der Werkstätte eines uns unbekannten antiken Künstlers hervorgegangen. Auf dem einen Becher erkennen wir als fein ausgeführtes Basrelief eine Jagdszene mit drei Wildochsen; Jäger sind bestrebt, diese einem starken Jagdnetz zuzutreiben; ein Tier verwickelt sich in demselben; zusammengeknäuelt und schnaubend versucht es umsonst, sich aus dem Garn zu befreien. Ein zweiter Wildstier setzt mit gewaltigem Satze üler seinen gefangenen (jenossen hinweg, während der dritte Kehrt macht, einen Jäger zu Boden rennt, einen anderen an sein rechtes Horn spiesst und emporwirft.

Auf dem zweiten Becher erscheint ein Wildochse gefangen und fügt sich unwillig, dann folgen zwei Tiere, welche sich gemütlich zu unterhalten scheinen, zuletzt ein grasender Stier in ruhiger Haltung, infolge der reichen Nahrung eine merkliche Körperfülle verratend.

Der Gedanke des Künstlers ist vollkommen durchsichtig. Tsunda meinte zwar bei seiner Veröffentlichung in der griechischen Zeitschrift "Ephemeris", es handle sich um einen Fang aus einer I Herde zahmer Tiere, doch hat der französische Kunsthistoriker G. Perrol ${ }^{1}$ ) diese Deutung angezweifelt. Ich habe dann auf Grund einer genauen zoologischen Analyse den Nachweis geliefert, dass diese Zweifel berechtigt waren und es sich um Jagd, Gefangennahme und Zahmung des wilden Bos primigenius handelt. Bei den wilden Rindern auf dem ersten Becher erkennen wir das mächtige Gehörn des Ur mit seinen typischen Verlauf $d$. h. leierartig und nach vorn und oben gerichtet. Bei den zahmen Rindern des zweiten Bechers ist das Gehörn wesentlich kürzer und dünner dargestellt - eine Folge der Domestikation. Die feine Beobachtungsgabe des griechischen Künstlers tritt uns hier besonders entgegen.

Derselbe hat also alle Phasen der Haustierwerdung im Bilde festgehalten und muss nach dem Leben beobachtet haben. Lin heutiger Künstler könnte unmöglich auf eine derartige Idee kommen.

Dass die ganze Szene auf griechischem Boden spielt, dafür spricht namentlich das charakteristische hellenische Profil der Jäger.

Ich bin daher der Ansicht, dass die erste Zähmung und Domestikation des Ur in Südosteuropa von den ältesten griechischen Volkselementen an die Hand genommen wurde und zwar in vorhomerischer Zeit. Der mykenische Künstler hat diese Domestikation noch im Gange gesehen. Damit ist jedoch nicht gesagt, dass nicht schon früher zahme Primigeniusrinder da waren. Ein solcher Vorgang ist nicht auf einen bestimmten /eitpunkt anzusetzen, sondern nahm vielleicht Jahrhunderte in Anspruch. I)ie I Iaustierwerdung des Ur dürfen wir also etwa in den Beginn des zweiten vorchristlichen Jahrtausends verlegen.

1) G. Perrot. Les vases d'or de Vatio. Bulletin de correspondance hellénique. 1891. 


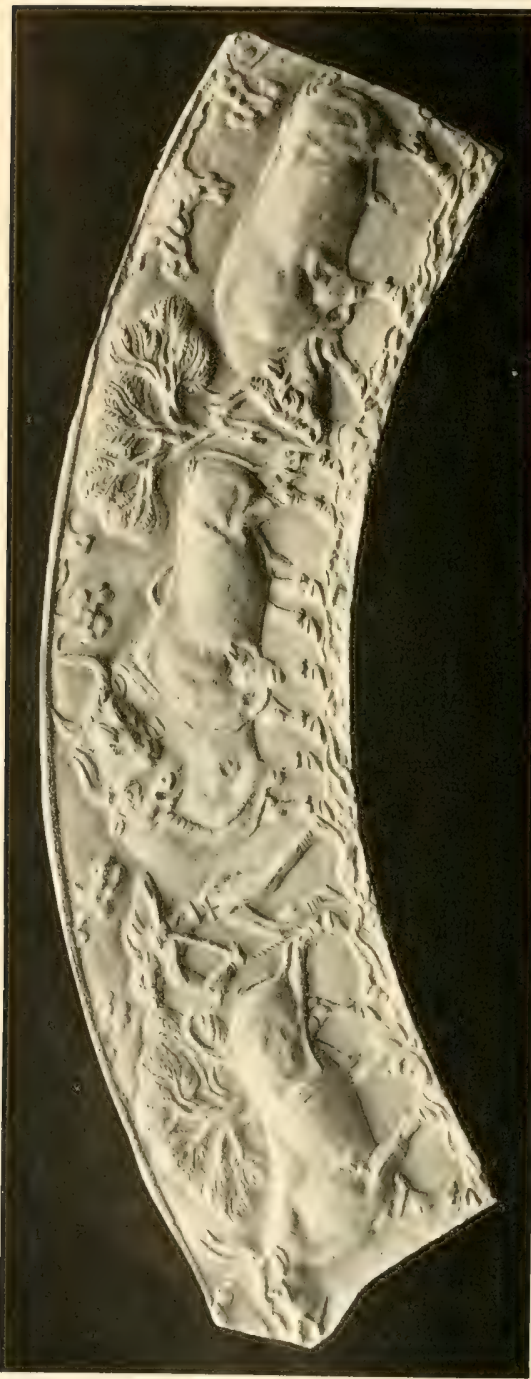

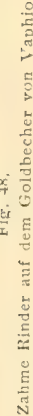


Wir können uns denken, dass der neue Erwerb anf alten Verkehrswegen des Ostens vom Schwarzen Meer aus nach den Niederungen der Ostsee gelangte. Möglicherweise haben die prähistorischen Bewohner der jüngeren Pfahlbauten ihr zahmes Primigeniusrind nicht aus autochthonem Material herangezogen, sondern aus dem Südosten von Europa erhalten, wobei man die Donaustrasse als natürlichsten Verbreitungsweg annehmen dürfte. Ist dem so, dann würde nebenbei auch einiges Licht auf das Niter der P'ahlbauten geworfen.

Als ein mehr indirekter Abkömmling des Ur muss das Frontosus-Rind betrachtet werden. Es ist ebenfalls eine grosse Form und seinen Rassemerkmalen bereits früher geschildert worden. Das Gehörn ist gegenüber der vorigen Rasse bedeutend kleiner, der Schädel stärker modifiziert worden, indem er im Hinterhaupt höher, im Stirnteil länger erscheint.

Rütimeyer betrachtet die Frontosus-Rasse als ein Kulturprodukt, das aus der älteren Primigenius-Rasse durch Umzüchtung hervorging. Dafür sprechen allerdings historische und tiergeographische Gründe. Diese Rasse erscheint verhältnismässig spät und erlangte nur eine sehr lokale Verbreitung. Der Bildungsherd ist im nördlichen Europa zu suchen, wo Frontosusreste schon aus prähistorischer Zeit nachgewiesen wurden.

In England ist die eigentümliche und weit verbreitete Langhorn-Rasse diesem Formenkreis zuzuweisen: lebende Reste sollen sich in Südschweden in dem Vieh der Insel Gotland erhalten haben; die stärkste Entwicklung erlangt das Frontosus-Rind jedoch in der Westschweiz, reicht aber auch in der nördlichen Schweiz bis zum Bodensee. Der hochgezüchtete simmenthalerschlag ist rotscheckig, während der Freiburgerschlag, der übrigens stark im Rückgang begriffen ist, schwarztleckig erscheint. Das schweizerische Fleckvieh ist sicher nicht auf dem heutigen Wohngebiet autochthon entstanden, sondern offenbar von Norden her eingewandert. In den westschweizerischen Pfahlbauten fehlen sichere Spuren gänzlich, ebenso lauten, wie $H$. Kränzer nachwies, die Befunde für die helvetisch-römische Zeit durchaus negativ ${ }^{1}$ ) seither ist mir aus (indonissa noch ein sehr reiches Material an Rinderknochen zugekommen, aber Frontosusreste finden sich nicht darunter. Die Thatsache ist jedenfalls schwerwiegend, dem die Römer, die in Vindonissa eine starke Besatzung zu unterhalten liatten, würden ohne Zweifel vorgezogen haben, die Fleckvieh-Rinder aus der westlichen Schweiz z. holen, falls solche vorhanden gewesen wăren, statt die schweren Kurzkopfrinder aus dem Süden über die Alpenpässe in Helvetien einzuführen. Das Fleckvieh wanderte hier offenbar viel später ein und ist wohl mit den Burgundionen nach der Westschweiz gekommen.

Ueber das Verhältnis der Freiburger Schwarzllecken zum rotbunten Simmenthalerschlag müssen noch eingehendere anatomische Untersuchungen

1) II. Krämer. Die Haustiertunde ron Vindonissa. 1899. 
angestellt werden. Sie gehören zwar nach den osteologischen Merkmalen zur Frontosusrasse, dagegen ist das Gehörn steiler aufgerichtet und nach meiner Beobachtung häufig primigeniusähnlich. Daher die Behauptung, dass das Freiburger V ieh Einwirkungen von niederländischem Vieh erhalten habe. Andere vermuten eine Mischung mit Braunvieh. Leider war es mir bei dem starken Rückgang dieses Schlages bisher nicht möglich, ausreichende Schädelserien zu beschaffen, wie denn überhaupt die Erwerbung von Haustiermaterial auf kaum glaubliche Schwierigkeiten stösst.

\section{DER BANTENG (BOS SONDAICUS) ALS STAMM- QUELLE DER ASIATISCHEN UND AFRIKANISCHEN ZEBU-RINDER.}

Die ungeheuren Erdräume des südlichen Asiens und ganz Afrika beherbergen im Zebu (Bos indicus) ein augenscheinlich ungemein altes und vielseitig verwendbares Hausrind, von dem bereits lï̈tmeyer in seiner

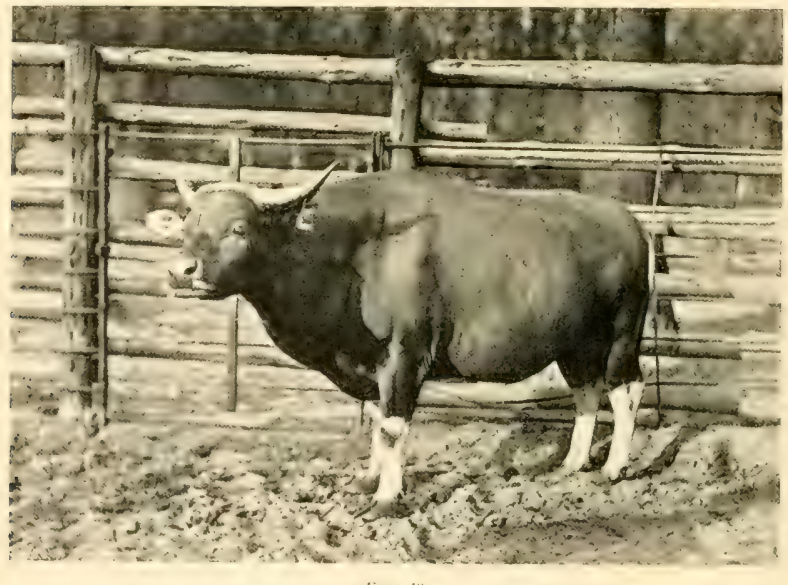

$$
\text { Fin. 4y. }
$$

Banteng (Bus sondaicus). (Zoolog. Garten Berlin.)

"Fauna der P'fahlbauten" sehr zutreffend bemerkt. dass es nach seiner eigentümlichen Ausprägung unbedingt den Anspruch erheben könne, von der allgemeinen Stammform des Bos primigenius abgelöst zu werden. In (ler That ist das allgemeine ( jepritge des Zebu trotz der grossen Formenbiegsamkeit und trotz gelegentlicher, durch Domestikation hervorgerufenen Analogien so grundverschieden rom Ur, dass jede engere Stammesbeziehungr 
ausgeschlossen erscheint. Auch tiergeographische Gründe reden hier sehr deutlich: Der Zebu erscheint am frühesten auf Gebieten, in denen der Ur niemals heimisch war. Man hat somit bei den südasiatischen Wildrindern anzuknüpfen. Cuvier dachte einst an den Yak (Bos grunniens) als Stammquelle, ist aber wieder davon abgekommen. $L$. Rütimejer liess die Frage der Abstammung in seinen früheren und späteren Publikationen offen, da er nicht wagte auf (jrund des noch zu spärlichen Materials und mit Hinweis auf die damals fast unbekannten afrikanischen Zebu-Rassen ein bestimmtes Urteil abzugeben. Er weist gelegentlich auf Beziehungen des Zebu zum Yak, dam aber auch auf gemeinsame Züge mit dem Banteng hin. Aus seinen anatomischen Befunden geht indessen so viel hervor, dass man bei den Bibovina anzuknüpfen hat, deren Vertreter heute ja ausschliesslich in Asien leben.

Wenn man von ganz lokalen Einwirkungen absieht, so muss der lák als Stammvater des Zebu durchaus abgelehnt werden. Ganz abgesehen von der grundverschiedenen äusseren Erscheinung sind die anatomischen Unterschiede zu gross. Die kurze, breite Stirn des Yak steht im Gegensatz zur Stirn des Kebu, die sich nach hinten gern verjüngt; der Yak besitzt 14 Rippenpaare, der Zebu deren nur 13. Auch die physiologischen Momente sind nicht geeignet, diese Ableitung zu unterstützen, da der Yak doch wesentlich Gebirgstier ist, sich dem heissen Tieflande aber nicht anpasst.

Gegen einen Zusammenhang mit dem indischen Gayal (Bos frontalis) spricht die gewaltige Ausdehnung der Stirnfläche des letzteren, die abweichende Gestalt und Richtung des Gehörns; ausserdem besitzt der Gayal 14 Rippenpaare.

Der Gaur (Bos gaurus) steht zwar dem Zebu schon näher und weist, wie der letztere, 13 Rippenpaare auf, dagegen hat der Gaurschädel eine durchaus entgegengesetzte Entwicklungsrichtung eingeschlagen. Während sich der Zebuschädel nach hinten oft verschmälert und einen pferdeartigen Habitus gewinnen kann, so wird er bei dem genannten Wildrind ungemein breit und im Stirnteil aufallend konkav: hinter dieser Konkavität erhebt sich ein mächtiger Stirnwulst, der beim Stier einer schiefen Wand vergleichbar ist, beim weiblichen Tier etwas niedriger, aber immer noch ansehnlich hoch ist. Also muss auch der Gaur aus anatomischen Gründen als Stammvater des Zebu abgelehnt werden.

Es bleibt daher das Verhältnis zum letzten Wildrind Südasiens, zum Banteng (Bos sondaicus) zu untersuchen. Auf die Andeutungen von Rätimeyer hin habe ich, weil eben kein anderes Wildrind in Betracht kommen konnte, in meinen früheren V'eröffentlichungen wiederholt den Sundapochsen mit dem Zebu in Verbindung zu bringen gesucht.

Inzwischen habe ich nach längeren Bemühungen zuverlässiges V'ergleichsmaterial erhalten. Es ist mir nicht völlig klar, inwieweit bei dem, was man in Ostasien als Banteng ausgiebt, Kreuzungsprodukte unterlaufen. 
Ein alter Bantengstier, dessen Schädel ich aus Indien erhielt, zeigt mir beispielsweise einen merkwürdigen Mischcharakter von Bos sondaicus und IBos gaurus. Ich legte daher Wert darauf, Vergleichsmaterial aus einem

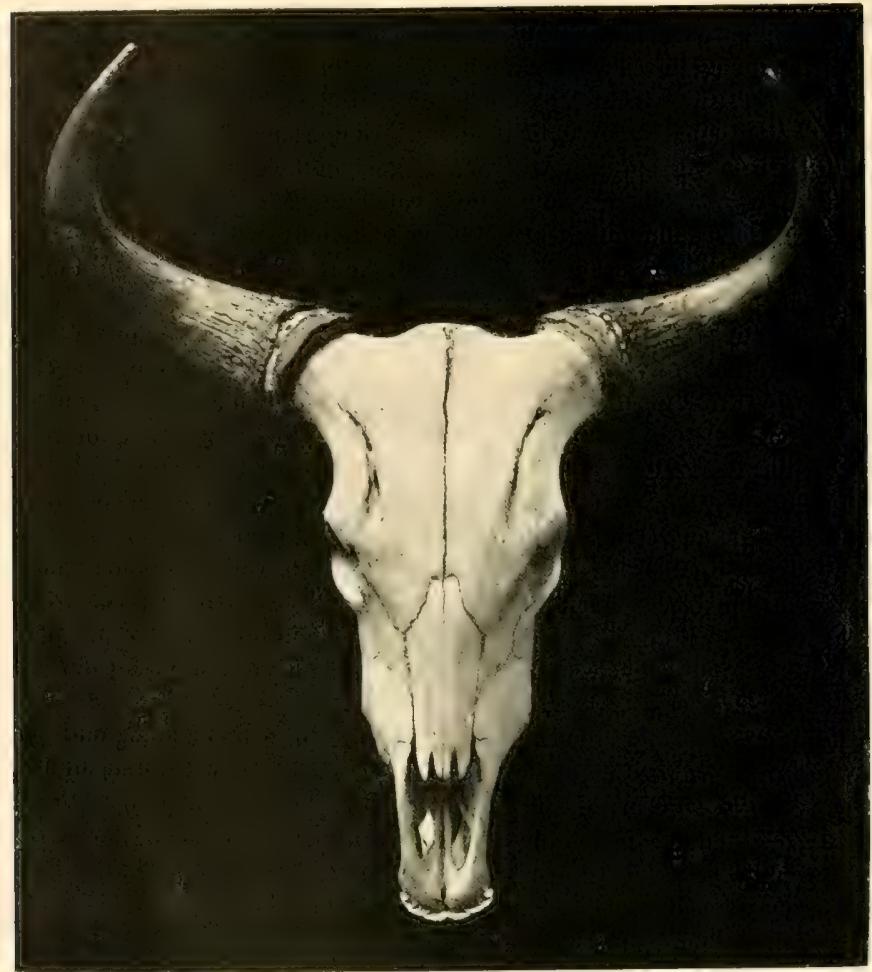

I in in il

Schilidel des Bantenr-Stieres (Bus sumbicus) aus Javit. Oririnal, (Landw. Sammlung Zürich.)

Gebiet zu erlangen, wo der Banteng sicher noch in seiner ganzen Ursprünglichkeit vorhanden ist, nämlich aus den wenig bevölkerten PreangerRegentschaften in Java. ${ }^{1}$ )

1) Durch die freundliche Verwendung von Herm Konsul Inomaner in Batavia bei der holländischen Kolonialbehörde erhielt ich vom malavischen Regenten in Tandjoer, Herrn Radîn Adifati Aria Prawira di liedja zwei prächtige, vollkommen erhaltene Bantengschädel (Stier und Kuh) zum Geschenk. Die Stïcke befinden sich in der Sammlung des eidgenössischen l'olytecluikwus. 
Die ausserordentliche Variationsfähigkeit von Bos sondaicus ist bekannt und sein Schädel zeigt nach Alter und Geschlecht Abweichungen von einer mittleren Norm, wie sie bei keinem anderen Rinde angetroffen werden. Männliche und weibliche Schädel sind so stark verschieden, dass man zwei generisch getrennte Formen annehmen müsste, würde man nicht die Zusammengehörigkeit verbürgt wissen.

Der mir vorliegende weibliche Schädel gehört einem jüngeren 'Tier an, dessen definitives Gebiss mässig stark abgenutzt ist. I)ie Gesamtform

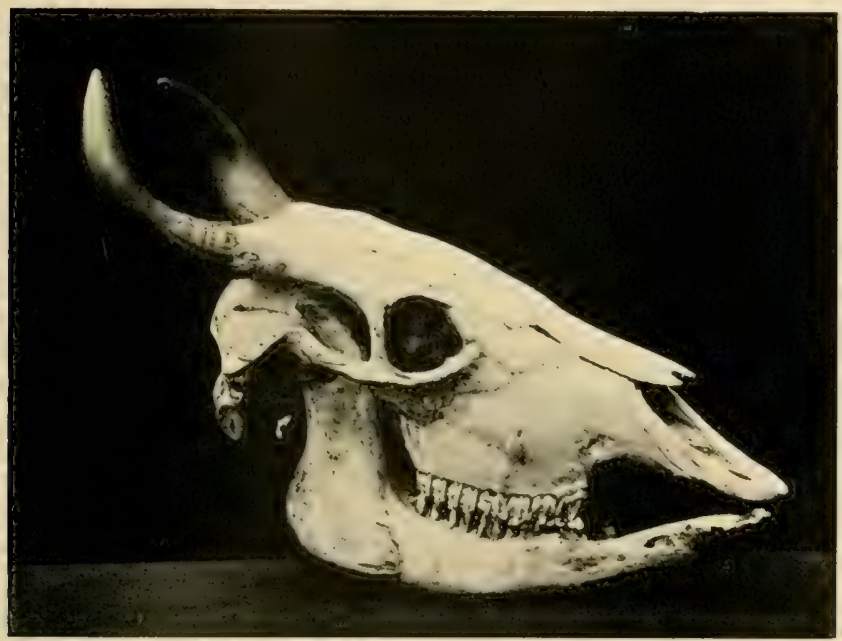

Fig. 51 .

Schädel der Banteng-Kuh (Bus sundaicus) aus Java. Original. (Landw. Sammlung Zïrich).

ist lang und schmal, in I Interkopt etwas verengt; der Occipitalhöcker schwach, vor diesem verläuft eine Rinne in der Mittellinie der Stirn. Eine ganz schwache Vertiefung liegt vor demselben, sonst aber ist die Stirnfläche zwischen den Augen gewölbt, nach den Seiten sowohl wie nach hinten abfallend, so dass das Protil deutlich geramst erscheint. Die Augenhöhlen treten sozusagen gar nicht aus der Stirnfläche heraus. Die Supraorbitalrinnen sind tief, nach vorn konvergierend, die Schläfengruben sehr breit und flach, ihre obere Kante abgerundet, dagegen da, wo sie auf die Hinterhauptsfläche übergreifen, nach oben durch eine kräftige, scharfe Kante begrenzt.

Die Jochbogen schwach entwickelt; der obere Rand des Thränenbeins fast gerade, nur wenig ausgebuchtet, am Zusammenstoss mit dem Stirnbein und Nasenbein eine deutliche Lïcke offenlassend. 
Das drehrunde Gehörn von mässiger Stärke wendet sich in halbmondfömigen Bogen nach hinten, verläuft in der Flucht der Stirn, erst gegen die Spitze hin erhebt es sich über dieselbe, die Spitzen sind nach innen gewendet. Die Hornzapfen entspringen auf deutlichen cylindrischen Hornstielen.

In Gesichtsteil sind die Maxillarhöcker nicht besonders stark vortretend. der Nasenast des Zwischenkiefers erreicht die Nasenbeine nicht, sonderm endigt etwa ein Centimeter unterhalb derselben.

Die Stellung der säulenförmigen Backenzähne ist schief, die letzteren weisen einfache Marken und ein derbes Schmelzblech auf. Im Unterkiefer steigt hinten der Ast scnkrechl aufwärts, die Schneidezähne sind schwach.

Der männliche Schädel zeigt ein wesentlich anderes Gepräge, wenı auch viele der oben erwähnten Merkmale wiederkehren. Vor allen Iingen verbreitert sich die Stirntläche nach hinten stark, fällt zwar seitlich ebenfalls ab, doch treten die Augenhöhlen weit stärker heraus als beim weiblichen Schädel. Die Hinterhauptsschuppe greift etwas auf die hintere Stirn1lïche hinüber. Letztere ist in zwei mächtige kurze Säulen ausgezogen, auf denen die kräftigen Stimzapfen entspringen, die Beschaffenheit der letzteren machen den Eindruck von wurmstichigem Holz, Längsrinnen fehlen. Das an der Basis etwas abgeplattete, erst gegen die Spitze hin drehrund werdende Gehörn wendet sich erst abwärts und auswärts und zuletzt aufwärts, die Spitze ist nach hinten und innen gerichtet.

Die Schläfengruben sind im Grunde ebenfalls weit, aber aussen durch die starken Hornsticle etwas verengt, die obere Kante ist wiederum deutlich abgerundet. Hinten greifen sie sehr weit in die Occipitaltläche hinein, so dass letztere im unteren Teil fast dreieckig erscheint. Der Occipitalhöcker ist niedrig mit rauher Oberfläche.

Die Beschaffenheit des Thränenbeines, die Kürze des Nasenastes der Internaxilla. der Ban des Unterhiefers stimmt mit den Verhältnissen des weiblichen Schädels vollkommen überein.

Vergleicht man an der Hand obiger Befunde die Verhältnisse im Schädelbau beim Zebu, so muss von vorneherein darauf hingewiesen werden, dass hier so weite Variationsgrenzen vorhanden sind, wie bei keinem anderen Ilaustier.

Schon in der iusseren Erscheinung spricht sich dies aus: stellt man asiatische und afrikanische \%ebu zusammen, so ergeben sich Entwicklungsreihen, deren Endglieder sich von der Ausgangsform bis fast zur Unkenntlichkeit entfernen. Veben formen von gewaltiger Körpergrösse kommen eigentliche Zwerge vor, der Fetthöcker erscheint bald mächtig entwickelt, bald ist er nur schwach oder vollständig fehlend. Die Kopform ist bald schmal, bald breiter.

Das Gehörn, im einen Fall drehrund, im andern abgeflacht, ist mittelgross bis kurz, daneben erlangt es besonders bei afrikanischen Zeburindern 
zuweilen eine kolossale Grösse, sodann sind gewisse Formen schlapphörnig und schliesslich vollkommen hornlos. Der Verlauf des Giehörns ist wiederum den stärksten Schwankungen unterworfen.

Der Zebu erweist sich als das formenbiegsamste aller unserer Ilaustiere und seine ausserordentliche Variationsfähigkeit. die beiden P'rimigeniusabkömmlingen sehr viel eingeschränkter erscheint, dürfte wohl nicht erst im llausstande im ganzen Umfange erworben worden sein, sondern wurde als Erbstïck von der wilden Stammart herübergenommen.

Schon diese Thatsache weist aut den Banteng hin, dessen Variationsfähigkeit von keinem anderen Wildrind erreicht wird. Der Sundaochse besitzt wie der Zebu 13 Rippenpare, bei beiden zeigen die

Rückenwirbel in

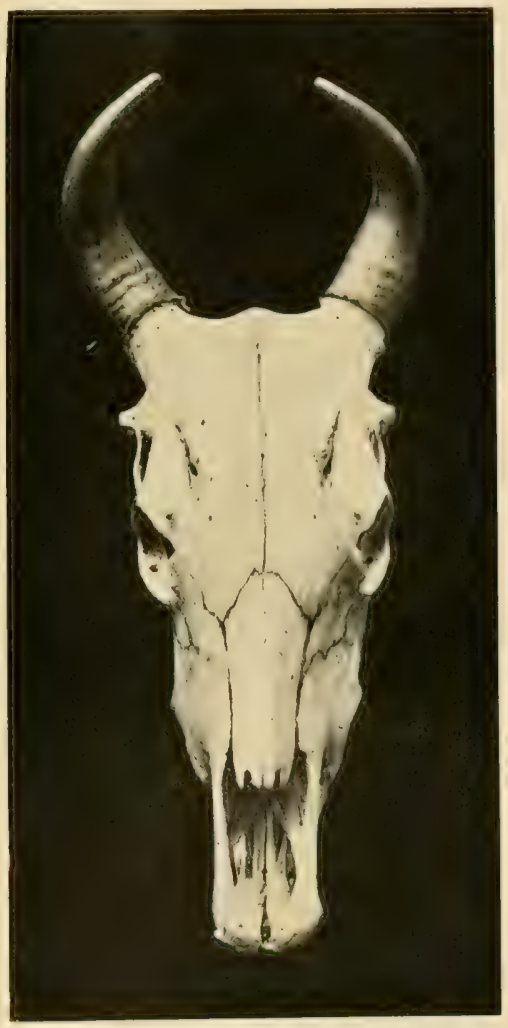

17is 52 .

Schädel der Banteng-Xuh von thell. Original doppelteNervenöffuungen.

I)abei sind anatomische UebereinstimmungenimSchädelbau in ïher. raschender Zahl vorhanden. I'm diese nachzuweisen, wird man sich in erster Linie an die asiatischen \%eburinder wenden, weil sie der vermuteten Stammquelle näherliegen als die afrikanischen

Formen.

Ich wähle als Paradigma den bengalischen Zebu, der in den zürcherischen Sammlungen durch einen wohlerhaltenen und rassenreinen

Schädel vertreten ist. Derselbe erscheint der Mehrzahl in den äusseren Umrissen auffallend pferdeähnlich und weil einer grossen Rasse angehörend, gehen seine Dimensionen merklich über den Banteng hinaus. Die Basilarlänge des Schädels beträgt an diesem Stück 45 C'entimeter, die Profillänge 42 Centimeter, gegenüber 43,5 Centimeter und 49 Centimeter beim Bantengstier unserer Sammlung.

Die lange, schmale Kopfform beim bengalischen Zebu, sowie das 
allgemeine Gepräge des Schädels zeigt eine aufallende Uebereinstimmung mit dem weiblichen Banteng, die Stirn ist nach allen Seiten stark abfallend, nach hinten verschmalert. Die Wölbung derstirntläche zwischen den Iugente ist so stark, dass dic. Siџprarhitalrimese verstreicht: dadurchwird das P'rofil stark ecramst. I)ie . Ingemholiten treten fast gatr nicht aus dem Sitirnummiss heraus: der I lint(erhatuptshäcker seder schwach, von ihm aus verliiuft in der Stirmmitte, die ville latngsrimne besityt. eise scharte. niedriger ariste nach vorn. I be sichliafengrulenen erscheinen weit und wenige tiet wie beim Ban. tenc, ebenso ist der obere Rand gegen

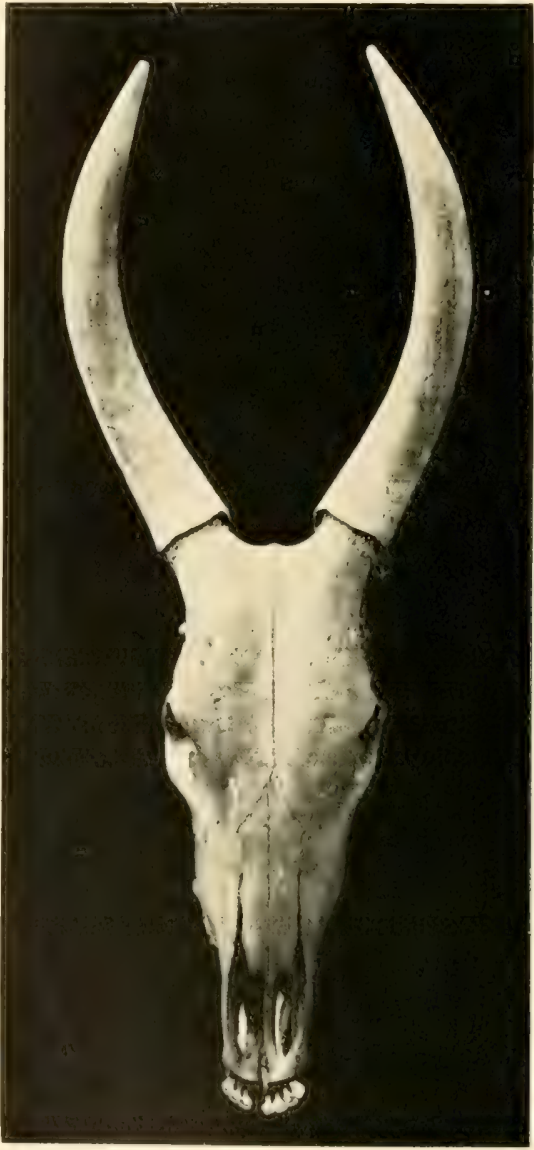

Lig: 33 .

Schidel ses hemgalischen Hausrindes von ohen. Original abgerundet, die Kante gegendasHinter hauptdagegen scharf vortretend: die I Iomzapfen sitzen aut Kräftigen, säแlenfirmigen sticlen, in welche die Stirnfliche hinten ausgezogeren erscheint. I)ie Maxillarhücker sind maissig stiark, die Jochbogen alufiallend schwach. I)as ( $\mathrm{ie}$ hörn ist stärker als bei der Bantengkilh, im ührienson yan\% ähnlichem Ver lauf d. h. nach hinten serichtot.indertlucht der sitirn ver. lautend und mit denspitzen cinwärts gekrümmt.

Die Stellung der Backkenzälne ist schief, die Marken einfach, das Schmelzblech kräftig, der Unterkieferast senkrecht aufsteigend. der Nasenast des Zwischenkiefers kurz d. h. nicht bis zu den Nasenbeinen heranreichend. 
Ist also das Gesamtbild demjenigen des weiblichen Banteng ungemein ähnlich, durch die Domestikation nur wenig modifiziert, so findet sich doch ein anatomisches Merkmal beim Bengalenzebu, das eigenartig ist, nämlich ein mächtiger Frontalwulst, der als abgerundete Leiste sich erheblich über die Hinterhauptstläche hinausschicbt, also primigeniusähnlich ist. Dieser Wulst fehlt dem Banteng in beiden Geschlechtern, der Bau des Occiput weicht ab, was offenbar Rälimejer verhindert hat, vorläufig einen sicheren Zusammenhang anzunehmen.

I lier hat num der afrikanische /ebu Aufklärung geboten. Ich habe in den Somalilandern eine Schädelserie gresammelt, also auf einem Gebiet, das

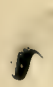

Hig. $\bar{s} t$.

Schiddel des zentralafrikanischen Wacussi-1kindes. Auliahme von $\%$. Dürst

(Museum fiti Naturkunde in Berlin.)

bis in die jüngste \%eit von der Welt abgeschlossen war und offenbar eine primitive Zeburasse beherbergt. I) as Somalirind vermittelt num in schönster Weise die Extreme in der Bildung des Ilinterkopfes, wie sie die Bantengkuh und das Bengalenrind aufweisen.

Gerade im Iinterhaupt variieren meine Exemplare ungemein, bald schneidet die Schläfengrube wenig, bald recht tief ein, bald ist ein hoher Occipitalhöcker vorhanden, bald fehlt er; an einzelnen Schädeln ist der Frontalwulst stark hinten übergreifend, an anderen schwach entwickelt; an einem zierlichen, schwach geramsten Schädel fehlt er vollkommen und das Hinterhaupt hat die Verhaltnisse des weiblichen Banteng getreu erhalten. Die Hornzapten zeigen den gleichen Bau, da sie wie wurmstichiges Holz aussehen. 
Der Stirnwulst, wo er vorkommt, ist somit ein neuer Erwerb, der erst wăhrend der Domestikation gemacht wurde.

Im übrigen gibt es schon in Asien neben langköpfigen Zebu mit schmaler Stime auch breitstirnige Formen. Auf afrikanischem Boden sehen wir die Schädelmetamorphose der Zebu deutlich drei verschiedene Richtungen einschlagen. Zunächst bleibt die lange, schmale, hinten verengte Schädelform mit schwach geramstem Profil vom Sundaochsen her erhalten, aber das Gehörn wird schwächer, oft schlapphörnig, zuletzt treten vollkommen hornlose Formen auf. Die Somalirinder weisen diese Verhälnisse recht typisch auf. Bei einer zweiten Gruppe, wie z. B. beim Hawaschrind und bei dem zentralafrikanischen Watussi-Rind wird das Gehörn mächtiger, oft geradezu kolossal, später ändert die Richtung, indem es sich über das Stirnprofil erhebt und zuletzt leierartig wird, Iland in Hand damit geht meistens eine Abtlachung der Stirn, so dass wir cine Konvergenz zum europäischen Primigenius erhalten. Ich habe diese Zeburinder unlängst als "riesenhörnige Sanga-Rasse“ bezeichnet; das altägyptische Langhornrind muss ihr zugerechnet werden.

Eine dritte Gruppe endlich erscheint mehr oder weniger breitstirnig, die Augenhöhlen treten über die Stirnfläche empor, das Gehörn bleibt kurz. Schon bei Madagaskar-Rindern konnte ich diese V'erhälnisse nachweisen, auffallender tritt die Erscheinung gegen den Norden Afrikas zu Tage, am extremsten bei den buckellosen kleinen Rindern von Algier und Marokko, deren Zebublut ja nicht zu leugnen ist, die aber vollständig den Charakter des Torfrindes oder Brachyceros-Rindes gewinnen.

Fassen wir schliesslich zusammen. welche Merkmale im Schädelbau dem weiblichen Banteng und dem Zebil gemeinsam sind, so ergiebt sich:

1. der allgemeine Umriss des Schädels, der bei beiden lang und schmal erscheint und nach hinten verengt ist:

2. das geramste P'rofil, das bei asiatischen Zebu sehr ausgesprochen, bei manchen afrikanischen Zebu (Somalrind) ebenfalls vorhanden ist;

3. der allseitige Abfall der Stirntläche;

4. die Beschaffenheit der Augenhöhlen, die beim weiblichen Banteng und bei vielen Zebu (nicht bei allen) fast gar nicht aus dem Umriss der Stirn heraustreten:

5. die Richtung des Gehörns bei südasiatischen Zebu:

6. die eigentümliche Beschaffenheit der Hornzapfen, die bei beiden wie wurmstichiges Holz aussehen:

7. die breite und flache Schläfengrube:

8. der abgerundete Rand der Schläfengrube nach der Stirn hin:

9. die Form der Thränenbeine, deren oberer Rand gerade oder nur schwach ausgebuchtet ist;

10. Die Knochenlücke an der Stelle, wo Thränenbein. Stirnbein und Nasenbein zusammenstossen: 
11. die Kürze des Nasenastes des Zivischenkiefers, der sehr häufig die Nasenbeine nicht erreicht:

12. die schiefe Stellung der Backenzähne:

13. der einfache Bau der Marken und die kraftige Entwicklung des Schmelzbleches:

14. der senkrecht aufsteigende Ast des Unterkiefers.

Dieser gemeinsame Betrag an wesentlichen analomischen Mlerkmalen ist also so gross, dass meiner Ansicht nach kein Zucifel bestelien kanin, dass der Zebu nichts anderes als cin durch Domestikation veründerter Banteng ist.

Die I)omestikation hat neben den früher hervorgehobenen Modifikationen den Gesichtsteil etwas verkürzt, wodurch die Stirnlänge relativ eine Zunahme erfahren musste. Die Stimlänge beträgt beim weiblichen Banteng meiner Sammlung nur $48 \%$ der Schädellänge (beim Stier aller-

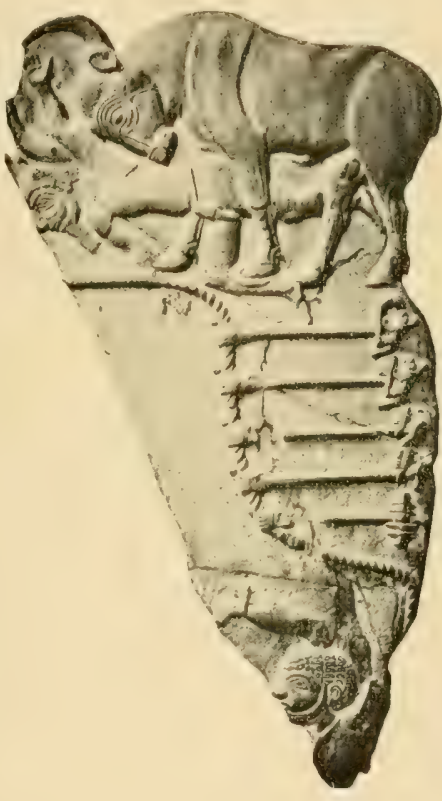

Fig. 5.5. steigt sie schon auf $50 \%$, beim Madagassenrind laält sie sich bereits über $50 \%$ und beim Somalirind fand ich in einem Fall sogar $54 \%$.

Für meine Auffassung der $\Lambda \mathrm{b}$ stammung des ZebuRindes kann ich noch einen bildlichen Beleg aus derfrühägyptischen Zeit anführen. Zwei Schieferplatten, die entweder den allerersten Dynastien oder der ihr unmittelbar vorhergehendenNegadahzeit angehören, weisen eigentümliche Rinderdarstellungenauf, dic unsere Archaeologen wiebengalischen Zebu Negadahzeit. (Musce du Lstuvre,) derholt beschäftigt haben. Die Schieferplatte von Gizeh lässt wegen einer Bruchstelle die offenbar zahmen Rinder etwas unvollkommen erkennen. Dagegen findet sich in Paris im Musée du Louvre eine zweite Platte mit einem vortreftlich gezeichneten Stierbild. ${ }^{1}$ ) Die Gestalt weicht von den Stierdarstellungen der $1 \mathrm{~V}$. und $\mathrm{V}$. Dynastie $a b$, ist aber denjenigen der Gizeh-Platte sehr ähnlich. An der ägyptischen Herkunft des Fundobjektes kann nicht gezweifelt werden. Als Büffelfigur kann das erwähnte Bild nicht

1) Vergl. Henzey. Revue archaeologique 1890, sowie 7 . de Morgan. Recherches sur les origines de l'Egypte. Paris. $189 \%$. 
aufgefasst werden, schon der Kopfbildung wegen. Der Stier auf der Platte des Louvre zeigt viehmehr in Verlauf des Gehörns, in der auffallenden Stirnbreite und in der Kürze der Schnauze die typischen Kennzeichen eines alten Banteng-Stieres. Wir sind daher zu der Annahme gezwungen. dass das Hausrind der frühägyptischen, vorpharaonischen Zeit der Bantengstammform noch sehr nahe stand.

Die heutige Verbreitung des \%ebu in Asien und Afrika mag hier etwas eingehender erörtert werden. II. M/arshall hat in seinem bekannten, Atlas

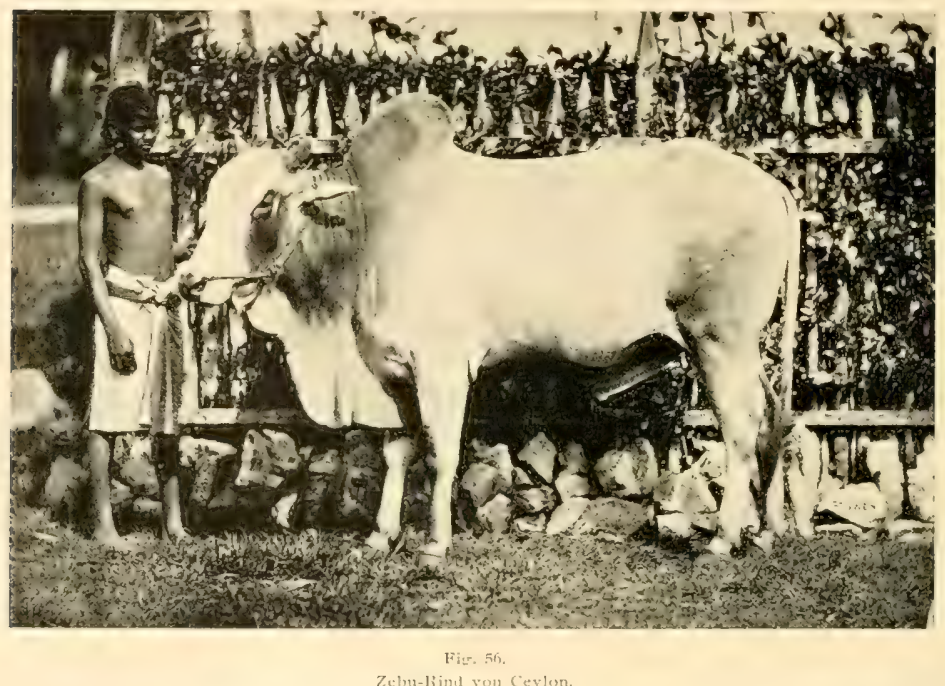

der Tierverbreitung “" die Grenzen offenbar etwas zu eng gezogen. ${ }^{1}$ ) In dem ursprünglichen asiatischen Stammgebiet sind es wohl die alten dravidischen Volkselemente gewesen, welche den Banteng zuerst in den Hausstand übergeführt haben, denn noch heute erscheint der Zebu am dichtesten in ihrer Heimat in Indien, Von Singapor bis Ceylon und Bombay wird eine bantengähnliche Rasse mit stark greamstem Kopf und nach hinten gewendeten, an der spitze eingebogenen Hörnern gehalten.

An den südlichen Abhängen des Himalaja ist der Kebu in einer starken, grossen Form vorhanden: seine Fürbung ist schwarz-weiss und die Herden der indischen Vorberge erinnern in ihrer Szenerie lebhaft an die schweiz-

1) W: Marshall. Atlas der Tierverbreitung (Berghaus phys. Atlas VI). Gotha. 1887. 
erischen Alpenthäler der freiburgischen Gruyere. In den Viederungen und Steppen ist das Rind schwächer gebaut.

Nach mündlichen Mitteilungen, die ich Herrn Max Ferrars verdanke, ist in Burma das Zeburind im Norden zahlreich und in einer grossen Form vertreten, in den Niederungen des Südens spärlicher vorhanden, weil der Büffel stark verbreitet ist.

In Ostasien tritt es stark zurück, reicht aber nach dem wärmeren China und mehr vereinzelt nach Japan, wo Rinder gelegentlich als Zugtiere verwendet werden. Der höckerlose Schlag ist klein und kurzhörnig, meist schwarzscheckig. Weisse Rinder hat als Seltenheit früher der kaiserliche Hof in Japan gehalten. Damals fütterte man diese Tiere mit Artemisia, sammelte Urin und Mist sorgfältig, um sie in dem Regierungsdepot als Medizin an das Volk zu verkaufen, was grosse linnahmen brachte. Jetzt ist man von dieser Sitte abgekommen.

In Neuguinea besitzen die Papua das Rind nicht, dagegen sind die Inseln Bali und Lombok ihres grossen Rinderreichtums wegen die Fleischkammer für Java und Sumatra geworden, wo meistens "Balivieh" eingefülnt wird. Nach der Beschreibung, die Axel Prever von diesem Balirind entwirft, ${ }^{1}$ ) handelt es sich um eine kleine, leichtgehaute Rasse, die dem marokkanischen Rind ähnlich ist. Das Kreuz ist hinten stark abtallend, die Beine verhältnismässig hoch, der Kopf schwer mit kurzen, etwas aufwärtsgebogenen Hörnerı: die Haarfarbe des Balirindes wird als braun oder schwarz bezeichnet. Daneben werden auch bengalische Rinder eingeführt.

Nach Westen hin findet man den Zebu in Persien, wo Pohlig prächtige schwarz und gelb getigerte Höckerrinder erwähnt. Nach demselben Autor geht eine kleine Zeburasse bis nach den kaspischen Küstendistrikten hinunter. In Mesopotamien und Kleinasien traten Buckelrinder bekanntlich frühzeitig aut, im heutigen Zweistromland sind sie durch den Büffel fast vollständig verdrängt worden.

Arabien besitzt nach meinen Beobachtungen ein ziemlich kleines, zartgebautes Rind von gelbbrauner Färbung, auch mit hellen Nuancen, aber kein eigentliches Fleckvieh. Der Fetthöcker ist klein, die Wamme stark entwickelt aber dünn. Die Hörner sind kurz und meist gerade unter einem Winkel von $45^{\circ}$ nach aussen gerichtet, zuveilen abwärts gebogen.

Wenden wir uns nach dem afrikanischen Wohngebiet, so ist dieses offenbar von Asien aus in einer sehr früheı Periode bevölkert worden, da wir Spuren des Rindes bereits in urägyptischer Zeit antreffen. Blyth ist sicher im Unrecht, wenn er die ursprüngliche Heimat des Zebu nach Afrika verlegt, da zu keiner Zeit ein Wildmaterial vorhanden war, an das der Phylogenetiker anknüpfen könnte. Da die älteste Kultur nicht im Norden des Nilthals, sondern umgekehrt in Oberägypten ansetzt, so hat unser Haus-

1) Axel Preyer. Die Rinder auf Java. Deutsche landw. Presse. August 1901. 
tier vermutlich zuerst im Südosten auf dem Boden Aethiopiens seinen Einzug grehalten und dürite über Südarabien vorgedrungen sein. Erst später d. h. zur P'haraonenzeit kamen auch von Westasien her Rinder nach Nordafrika.

Ich habe im Laufe der lahre die heutigen Rassen Afrikas an verschiedenen P'unkten untersucht und vor einiger Zeit eine Verbreitungskarte entworfen. ${ }^{1}$ )

Ueber die altagyptischen Rassen sind früher schon Angaben gemacht worden, die Physognomie hat sich gründlich geändert, indem Seuchen

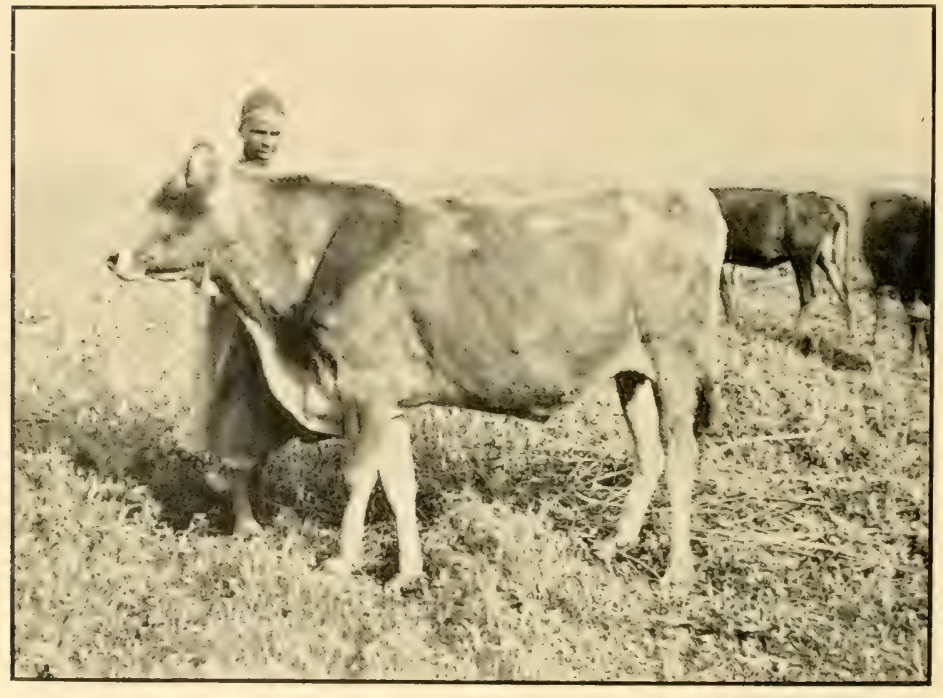

$1 \cdot 1,-=$

llausrind von Olerïgypten. Nach einer Aufnahme von $F$. Sormsin.

die Anwohner nötigten, sich nach einem widerstandsfähigeren Geschöpf umzusehen und der Büffel an die Stelle des Hausrindes trat. Was in Unterägrpten angetroflen wird, stammt aus Arabien oder aus dem südlichen Russland, ist also nicht mehr ursprünglich. In Oberägypten sind noch Bestiunde der alten Rassen da, ein feinköpfiges, kurzhörniges, ziemlich mageres Rind olne Fettbuckel.

Eine ähnliche Form von hellbrauner Färbung oder rotbunt oder getigert und ebenfalls ohne Höcker lernte ich vor Jahren in Nubien kennen; sic besitzt eine feine Sichnauze und erinnert im IIabitus an das kleine algerische Rind.

1) C. Keller. Das afrikanische Zeburind. Vierteljahresschrift der nat. Ges, in Zürich. 1896. 
In der Erythraea sind in der Neuzeit vielfach Rinder aus Arabien und aus Bombay eingeführt worden.

Der Ostsudan neben den Ländern am oberen Nil sind ihres Rinderreichtums wegen berühnt, die Tiere werden mit grosser Sorgfalt gehalten und der Stamm der Baggara gab sich die Ehre, seinen Namen von der Kuh zu entlehnen. Martmamn bemerkt, dass man in der Bajudawüste und in Süddongola Buckelochsen mit kurzem Gehörn antreffe; nach Schaeinfurth ist das Rind der Dinka lang- und schlankhörnig. weisslich mit Leo-

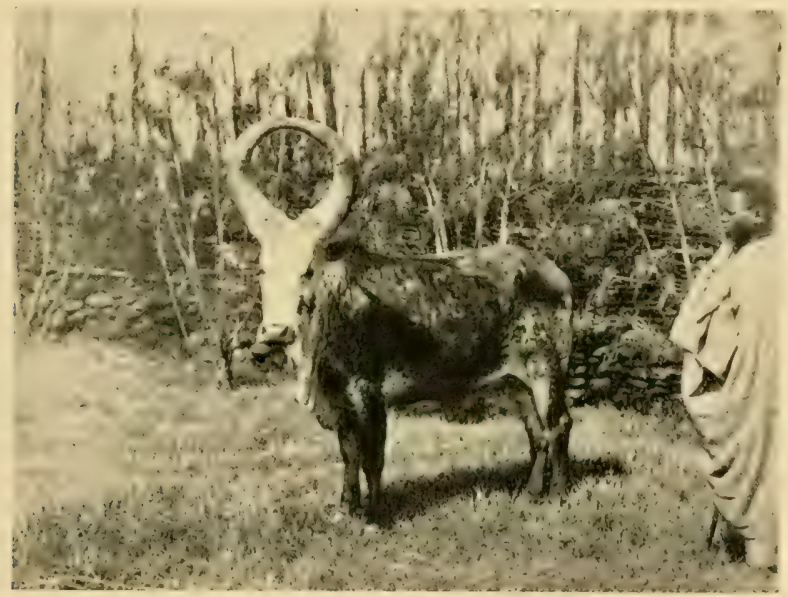

Fig. 5s,

Riesenhörnigres Rind aus Süd-Ahessinien.

(Nach einer verr. aethiopischen Ministerium in Adis-Abeba tibermittelten Originalaufnahme.)

pardenflecken. Westlich vom Nil findet man vielfach das Rind nur selten, die Niam-Niam kennen die Kühe nur vom Hörensagen.

Blühend ist die Viehzucht in Abessinien. Auf dem Hochplateau findet man grössere Tiere, die an unsere mittelschweren Rinder heranreichen. Die Stirn ist verhälnismässigg breit und flach, die Schnauze kurz und feingebaut; das drehrunde Gehörn aufwärtsgerichtet und leierförmig; am Grunde hell, an der Spitze schwarz, von ansehnlicher Grösse. Nach den Mitteilungen von Minister $A$. I/g wird in Tigré, Godjam und Schoa ein gleichförmiger Schlag gezüchtet, der bis zu Höhen von 3800 Neter verbreitet und meistens schwarz gefärbt ist, das Gehörn hat einen Durchmesser von S-9 Centimeter. In den tieferen Lagen Abessiniens kommen weissgraue und schwarzscheckige, seltener rotscheckige Rinder vor.

Im Sïdwesten, d. h. in Kaffa überwiegt die Kleinviehzucht, das Rind 
wird selten gehalten. An der westlichen Abdachung gegen den Nil hin findet man bei den Wolega-Galla ziemlich grosse Rinder mit einer Hornlänge von 40 Centimeter, bei den mehr nördlich wohnenden Berta ist das Rind kleiner, kleinhörnig oder hornlos.

In Tieflande und zwar hauptsächlich im Thal des Hawasch, ferner bei den I)schilli und Arussi-Galla in der Umgebung des Zuai-See wird ein rienenhomiger \% obuschlag gezüchtet, dessen Gehön gewaltige I)imensionen erreicht. Beispielsweise habe ich an einem Schädel eine Hornlänge von 115 Centimeter und 45 Centimeter Umfang gemessen. Bei den SidamaGalla tritt ein kurzhörniger Rinderschlag auf; im Wohngebiet der GadabursiundI ankali überwiegt ein langhörniges Sanga-Rind.

In den Somaliländern wird die Viehzucht sehr stark betrieben. Ich fand dort im Inneren überall ein kurzhörniges oder völlig hornloses Zeburind mit mässig stark entwickeltem Fettbuckel. Die Behaarung ist kurz, dicht anliegend, die Farbe grauweiss, gelbbraun oder rotscheckig.

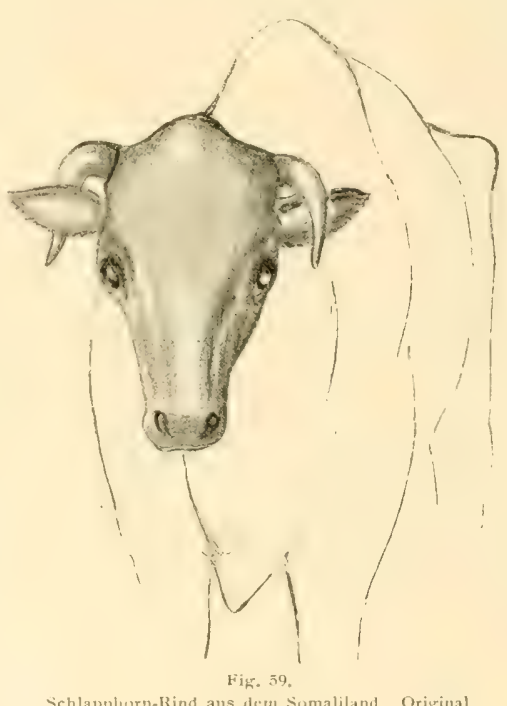

Schlappluorn-Kind aus dem Somaliland. Original.

Die schwarze Farbe ist verpönt. Die Kopfbildung unterliegt starken $\mathrm{Va}$ riationen, man findet schmalstirnige und breitstirnige Individuen. Die Hornlänge misst $7-10$ Centimeter, höchstens einmal 20 Centimeter. Die graugrünen Hornscheiden sind dickund aufgefasert. Schlapphornrinder mit beweglichen Hornscheiden kommen sehr häufig vor. Kurzhörnige Buckelrinder scheinen auch bei den Galla weit verbreitet; Deutsch-Ostafrika besitzt bis zum Kilimandscharogebiet ein ähnliches Rind, in Unjoro sind nach Stanley die Mehrzahl der Rinder hornlos.

Stuhlmann und $O$. Bammann berichten näheres über die zentralafrikanischen Rinder. Die Hirtenkolonien, die vermutlich von Abessinien her eingewandert sind, besitzen ein mittelgrosses Rind von kastanienbrauner Farbe und feinknochigen Gliedern, dessen Gehörn ähnlich wie das Hawaschrind Abessiniens eine kolossale Grösse erreicht und an der Basis einen Umfang von 40-50 Centimeter erlangt. Dieses "Watussi-Rind * oder "WahumaRind", obschonstark in Rückgang begriffen, findet sich bei Lijij. dam westlich und nördlich vom 'Tanganyika-See, sowie in Westen des Albert-Eduard-See. 
Im Norden vom Viktoria-Nyanza wird nach Fephson ein Höckerrind mit grossem Fettbuckel und mittelgrossem Gehörn gehalten.

Das Zambesigebiet beherbergt grosshönige Rinder, dagegen kommt auch eine eigentliche Zwergrasse vor, die reichlich Milch gibt. Beiden Makololo pflegt man die Hörner künstlich zu verunstalten.

Im ostafrikanischen Archipel ist Madagaskar berühmtwegenseines Reichtums an Rindern, die von den Howa und den Sakalaven des Westens trefflich gelialten werden. Dats Madagassenrind ist ziemlich tief gestellt, der Fettbuckel umfatngreich. I Die Farbe ist braumrot, dunkelbram. schwarz oder rotscheckis. I) als (jehörn erhebt sich über die Stirntläche, die Spitzen erscheinen nach iunen gebogen. In Ostmadagaskar

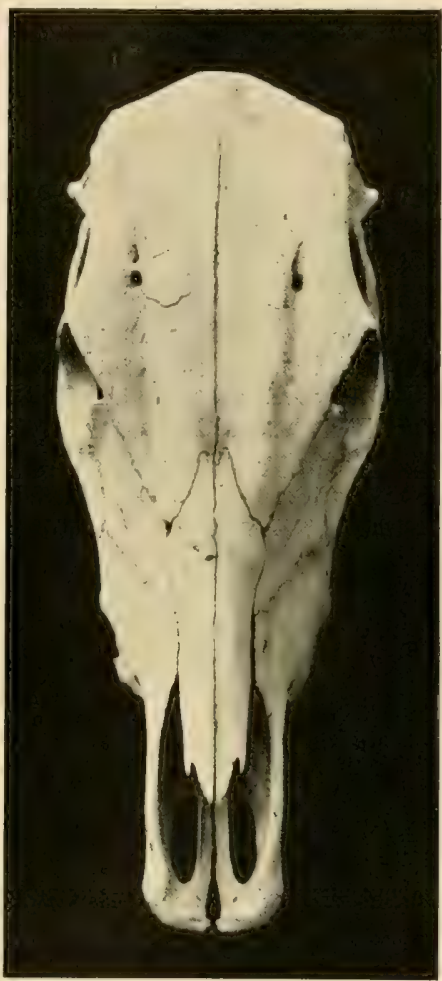

Jiis. 60

Schädel des Schlapphorntindes aus dem Somaliland. Original. (Landw. Sammlung Zïrich.) überwiegen breitstirnige und mittellärnige Rinder. Vestmadagaskar weist ein schmalstirniges, riesenhörniges Rind auf. das oflenbar von Atrika herübergebracht wurde und dem Sangarind Abessiniens verwandt ist. I)ie Maskarenen beherbergen kein eigenes Rind, die Bewohner beziehen ihren Bedart atlwächerutlich von den ostmatdachassischen Küntenplatzen.

lots breitstirnige TransvalRincl ist meist scheckigund gramshörnig. dast iehörn mehr nach der Seite auscrelegt. Auch Madagaskar. Rinder kommen gelegentlich vor, Mozambique hält meist madagassische Rinder, die von der Sakalavenküste eingeführt werden.

In Südwestafrika ist der frühere Reichtum der Hottentoten, die grosse Herden hielten, zerfallen. Nach Ilans Schinz ist dagegen die Rinderzucht bei den Herero sehr blühend. die Bullen haben oft einen stattlichen Fetthöcker, der den Ochsen und Kühen fehlt. Die Hörner sind weit ausgelegt und lang. Die in Südafrika weit verbreitete Rasse der Betschuanen. 


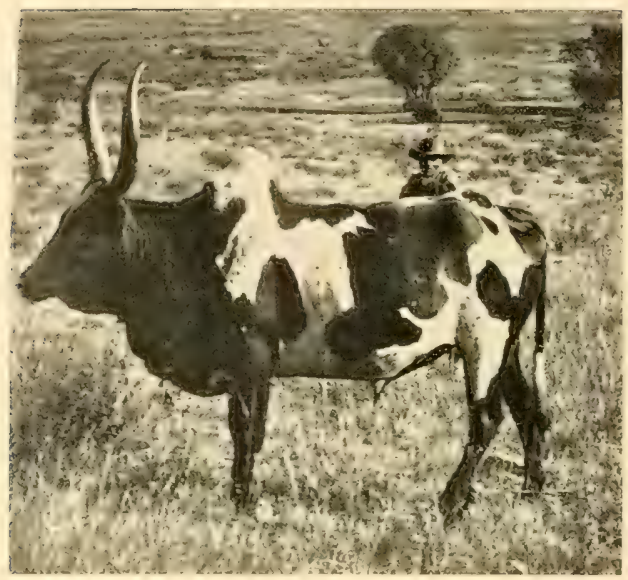

liig. 61

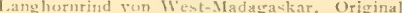

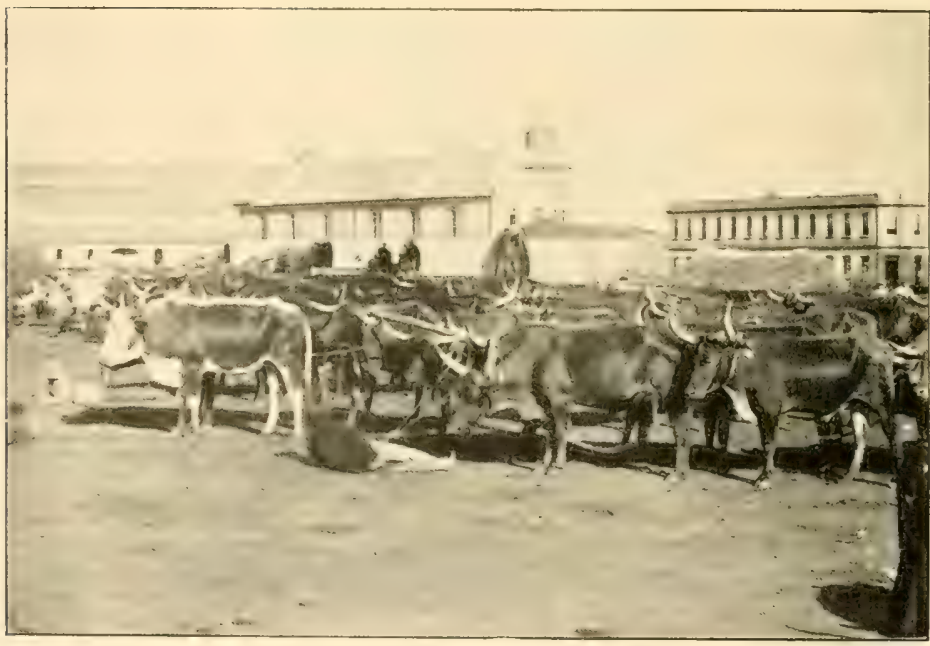

Fifir 62

$1+11101+1-1,4+1$ 
buckellos und meist rotscheckig, zeichnet sich durch ein kolossales, weitausgelegtes Gehörn aus.

Mehr im Norden, in Angola ist das Rind klein und kurzhörnig, besitzt aber einen Fetthöcker; es stammt vermutlich aus dem Zambesigebiet.

In Westafrika bis zum Senegalgebiet tritt die Rinderzucht ganz zurück: an der Loangoküste fehlt das Rind, bei den Krunegern tritt es sehr vereinzelt auf, dagegen ist es im mittleren Sudan wieder zahlreich und grosshörnig. Im Innern von Marokko, dann in Algier lebt eine kleine, kurz-

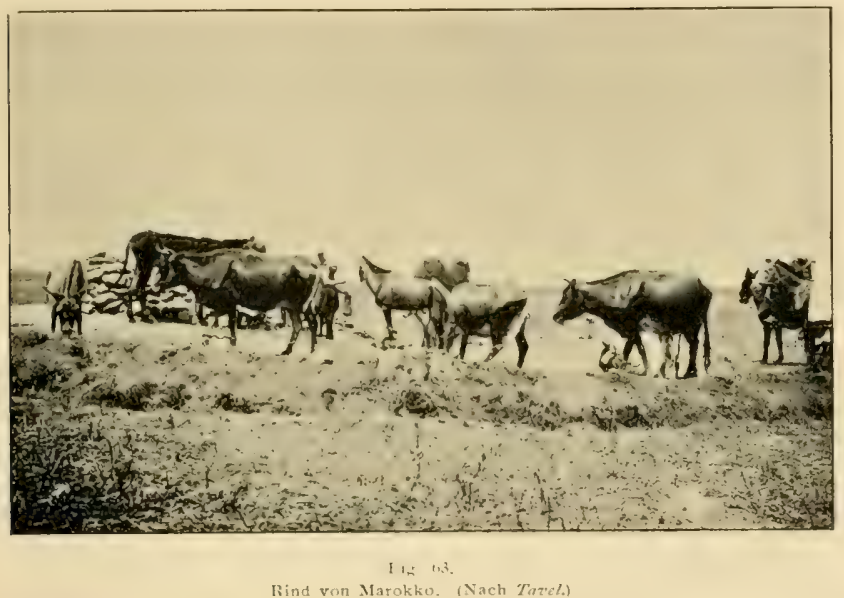

hörnigge Rassè (Race algérienne), dit sich unseren kleinen Braunviehschlägen auffallend nähert. Die Glieder sind fein gebaut, der Schwanz erreicht fast den Boden und ist am Ende buschig. Ein Fetthöcker ist nicht vorhanden. Von der Farbe wird angegeben, dass sie auf dem Rücken und Becken grau erscheint, unten aber in russiges Schwarz übergeht. In den algerischen Niederungen werden daneben grosshörnige Rinder gehalten.

\section{DIE BRACHYCEROS-RINDER EUROPAS ALS}

\section{ABKOEMMLIACE DER SLEDIILHEN ZEBU-RINDER.}

Die Frage nach der Abstammung der kleineren, kurzhörnigen Rinder Europas, wie sie uns im Braunvieh der Alpen, im illyrischen Rind, in manchen englischen und nordeuropäischen Rassen entgegentreten, ist vielfach Gegenstand der Kontroverse gewesen. Die nächstliegende Quelle in dem prähistorischen Torfrind zu suchen, war ganz naturgemäss. Allein die Frage erschien damit nicht vollständig gelöst, denn die Torfasse war ja bereits 
Haustier. Eine zugehörige wilde Stammform war mit Sicherheit in Europa nicht aufzufinden, da Bos primigenius hier nicht in Frage kommen kamn und so war man genötigt, eine aussereuropäische Herkunft für die alten Torfrinder und ihre heutigen Nachkommen anzunehmen.

Die afrikanische Abstammung und ein Zusammenhang mit dem Zebu ist in früherer Zeit mehrfach behauptet worden, aber ohne die anatomische Begründung liefern zu können. Man kannte eben die Zebuformen damals gerade da nicht, wo man die Antwort erwarten konnte.

Rütimever begnügte sich daher folgerichtig mit einer abwartenden Haltung, wies jedoch gelegentlich auf die Zeburinder hin.

Es ist naheliegend, dass ein so ampassungsfähiges Haustier, das sich über gewaltige Räume der beiden Nachbarkontinente verbreitet hat, schwerlich vor dem kleinen Europa Halt machte, das ja geographisch genommen nur eine bescheidene Dependenz Asiens darstellt.

Der Nachweis, dass eine dem Torfrind ganz nahe stehende Rasse sich auffallend rein in Nordafrika erhalten hat, ist gewiss bedeutungsvoll. Schwerlich handelt es sich um eine afrikanische Besiedelung mit alten europäischen Rindern, denn jene Rasse reicht bis tief nach Marokko hinein, also in ein seit langer Zeit abgeschlossenes Kulturgebiet. Der umgekehrte Fall ist also viel walıscheinlicher und auf Grund neuer Erhebungen habe ich 1896 darauf hingewiesen, dass die Annảherung des afrikanischen Zeburindes an unsere europäischen Braunviehschläge und Brachyceros-Rinder um so deutlicher wird, je mehr man in Afrika nach Norden vorschreitet. Schon Nubien besitzt eine feinköpfige und kurzhornige Rasse, die dem algerischen und marokkanischen Rind auffallend nahesteht. Es muss nun im einzelnen nachgewiesen werden, ob anatomische Uebereinstimmungen im Schädelbau nachweisbar sind.

Bei der ausserordentlichen Variationsfähigkeit des Zebu wird man sich weniger an ziffernmässige Erhebungen, sondern an das Gesamtgepräge zu halten haben.

Die lange und schmale Form des Brachycerosschädels ist bekanntlich auch eine Eigentümlichkeit der Zeburassen. Die Stirnlänge des Braunviehs hält sich äber $50 \%$ der schädellänge, das gleiche habe ich für ostafrikanische Zeburinder (bis zu $54 \%$ ) nachgewiesen.

Scheinbar ist der Hornansatz verschieden, unserem Brachyceros fehlen die dem Zebu eigentümlichen cylindrischen Hornstiele. Nun finde ich in dem kleinen Rind Sardiniens eine merkwürdige Form, die dem alten Torfrind wohl noch näher steht als das Albanesenrind. Der Schädel zeigt einen ungemein zierlichen Bau mit allen Merkmalen des typischen Brachyceros, aber zu meiner nicht geringen Ueberraschung bemerkte ich, dass die hinteren Ecken der Stirn wie beim Zebu in deutliche cylindrische Hornstiele ausgezogen sind und das aufsteigende Gehörn sich gegen das Ende zchuartig nach hinten wendet. Beim sardinischen Rind haben sich also neben den 
Braunviehmerkmalen, die sich namentlich auch in den stark aufgetriebenen Augenhöhlen zeigen, unzweideutige Zebumerkmale erhalten.

Beim Braunvieh sind die Hornscheiden abgeplattet, was auch bei vielen Höckerrindern der Fall ist. Die Neigung der kleinen Rinder Europas, hornlos zu werden, ist schon zur Pfahlbauzeit vorhanden (Akeratosform) und tritt vielfach beim Zebu auf (Somalirind, Rind von Unjoro und Berta, altägyptisches hornloses Rind.)

Beim Zebu verlăuft hâufig in der Stirnmitte, wo die beiden Stirnknochen

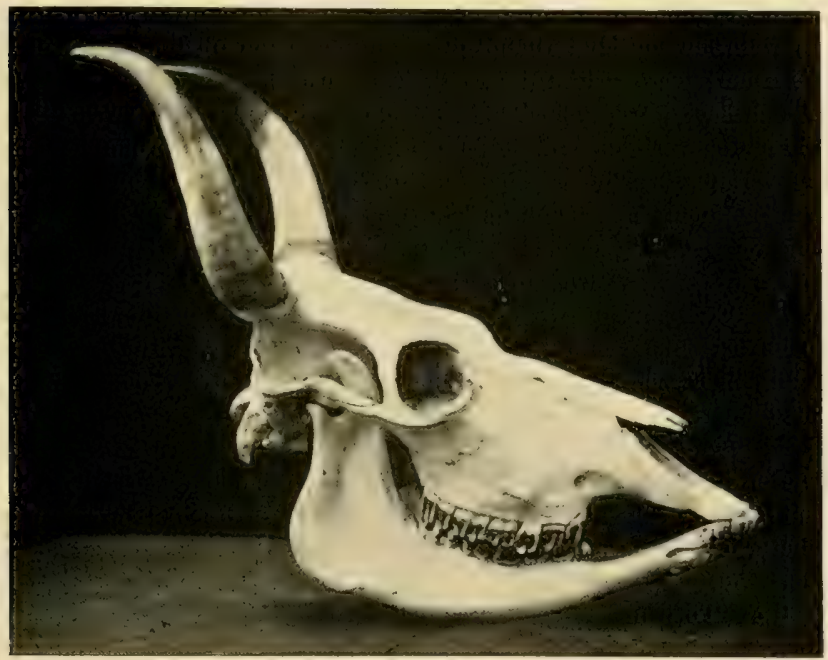

Fig 64

Schäidel des kindes von Sardinien. Oriminal, (Landw, Sammlung Zürich.)

zusammenstossen, eine feine Leiste. Das Merkmal ist zwar nicht konstant, aber es kommt auch bei europäischen Brachycerosrindern vor. Wenigstens zieht sich vom Hinterhauptshöcker eine kürzere oder längere Leiste nach vorn. Im. Bau der Augenhöhlen bestehen scheinbar die grössten Gegensätze. Bei den asiatischen und manchen afrikanischen \%ebu sind sie am Rand eingezogen und treten fast gar nicht aus den Umrissen der Stirn heraus, beim Torfrind und unseren europäischen Braunviehschlägen treten sie dagegen stark hervor und erheben sich mit ihrer Wölbung derart über die Stirntläche, dass letztere zwischen den Orbitae vertieft erscheint.

Diese starken Gegensätze werden aber in schönster Weise von gewissen afrikanischen Zeburindern überbrückt. Schon das Howarind in Ost- und Zentralmadagaskar ist breitstirnig mit vorgewölbten Orbitae, weit mehr ist das Transvaalrind, das offenbar vom Rind der Betschuanen abstammt, 
unserer Braunviehrasse angenähert, hier wird die Stirn hinten breit, die Augenhöhlen treten stark heraus und erheben sich derart über die Stirnfläche, dass diese eingesenkt wird. Bei dieser südafrikanischen Zebuform finde ich an einem Schädel die Hinterhauptsfläche mit der Stirnfläche einen spitzen Winkel bildend, genau wie es für unsere europäischen Brachycerosrinder angegeben wird.

Gegenüber dem Primigeniusrind ist die Schläfengrube beim Braunvieh breit und tlach, recht typisch sind die Schläfengruben beim Rind von Sardinien - ganz wie beim Zebu. Auch der Stirnrand ist häufig abgerundet, während am I Iinterhaupt die Kante üher der oft tief einschneidenden Schlafe scharf hervortritt (Moosrind, Sardenrind).

Die dreieckige Knochenlücke zwischen Thränen- und Nasenbein, beim Zebu so häufig vorkommend, findet sich auch bei unseren Braunviehschlägen. Ebenso verhält es sich mit dem kurzen Nasenast des Zwischenkiefers.

Der Zahnbau lässt wiederum Uebereinstimmungen erkennen. Die schiefe Stellung der Backenzähne in den Kiefern, der einfache Verlauf der Schmelzfalten, die kräftige Entwicklung des Schmelzbleches, so typisch für unsere reinen Brachycerosformen, sind Eigenschaften, die auch der Zebu besitzt. Rechnen wir hinzu, dass hier wie dort der Unterkieferast senkrecht aufsteigt und nicht schief wie beim Primigenius, so ist der gemeinsame Betrag an Schädelmerkmalen ein so hoher, dass wir in europäischen Brachycerosrind eben einfach einen Ausläufer der Zebugruppe zu erkennen haben.

Dieser Schluss ist im Hinblick aut die ungemeine Variationsfähigkeit des Zebu und in Anbetracht der für Afrika nachgewiesenen Zwischenformen ganz natürlich.

Der Umstand, dass am Nordrand des Nachbarkontinentes im Süden unser altes Torfrind gleichsam noch fortlebt und zwar in sehr abgeschlossenen Gebieten, deutet auf einen afrikanischen Import der ältesten Rinder, das Torfrind war in seinen Rasseneigentümlichkeiten gewissermassen schon fertig, bevor es auf südeuropäischen Boden übertrat.

Diesen Uebertritt erklären wir uns leicht aus den regen Wechselbeziehungen, die offenbar schon in einer sehr frühen Periode vorhanden waren. Dass sie später während des Mittelalters und bis in die Neuzeit hinein durch die feindselige Invasion des Islam für uns unterbrochen wurden, das alte Kulturland im Nilthal vor einem Jahrhundert gleichsam neu entdeckt werden musste, ist eine für unsere Frage rein nebensächliche Erscheinung.

Damit will ich nicht behanpten, dass uns Afrika allein Rinder geliefert hat. Die kleineren beweglichen Zeburinder haben noch eine zweite Wanderstrasse nach Europa eingeschlagen, die über Mesopotamien und Kleinasien führte. An historischen Belegen fehlt es ja nicht. Ich halte diesen direkten Import aus Asien für sekundär und nicht sehr ausgiebig und möchte zu Gunsten meiner Ansicht neben den früher angeführten anatomischen Be- 
funden bei den Rindern Afrikas auf die ausserordentliche Entwicklung der Rinderzucht hinweisen, die sich im Nilthal schon sehr früh, schon zur Zeit der ältesten Dynastien bemerbar macht.

In letzter Instanz ist freilich alles, auch der afrikanische Bestand, asiatischer Herkunft und wir haben auf einem langen Umweg die Fäden tunserer europäischen Brachycerosrinder bis zum südasiatischen Banteng (Bos sondaicus) verfolgen können.

Vielleicht darf anhangsweise noch einer kleinen Aeusserlichkeit gedacht werden, um sie für meine Beweisführung zu verwerten. Bekanntlich ist der Banteng durch eine umfangreiche weisse Stelle an den Hinterbacken (Spiegel) ausgezeichnet. Ich habe unter den einfärbigen Braunviehkühen um das Gotthardmassiv herum wiederholt Individuen beobachtet, die an den Hinterbacken sehr licht getärbt sind, also den Spiegel erkennbar angedeutet haben. Es ist dies wohl eine Rückschlagserscheinung.

Endlich mag noch hervorgehoben werden, dass beim kurzhörnigen Braunvieh $\mathrm{ab}$ und $\mathrm{zu}$ Individuen mit "Tigerfärbung" vorkommen, was ich ebenfalls als Rückschlag in die 7chufärbung ansehe. In den Alpen ist die Erscheinung sehr selten, tritt dagegen nach den Angaben von $L$. Adametz beim illyrischen Braunvieh zuweilen auf. Aus Agram berichtet mir O. Franges, dass unter den einfärbigen Kurzhornrindern Kroatiens etwa 2-3\% der Individuen tigerstreitig sind. Nach dem gleichen Beobachter besitzen manche kroatische Rinder auf dem Widerrist einen kleinen, aber deutlichen Buckel. der ohne Zweifel als atavistischer Anklang an den Zebu zu deuten ist.

Untersucht man das Verhalten des brachyceren Zebuzweiges in Europa auf den verschiedenen Wolngebieten, so erscheint das Gepräge durchaus nicht so einförmig wie man vielfach angenommen hat. Freilich sind die Bestände nach ihrer Rassenzugehörigkeit noch lange nicht mit der nötigen wissenschaftlichen sichärfe durchgearheitet, eine Vervollständigung unserer Kenntnisse ist daher noch Aufgabe der Zukunft. Aber was bisher vorliegt, deutet auf eine recht bedeutende Variationsfähigkeit.

Als bekannteste Vertreter brachycerer Rinder sind die einfärbigen Braunviehschläge der Zentralalpen hervorzuheben. Die Farbe variiert vom D unkelbraun bis zum hellen Mäusegrau, Aalstrich und Rehmaul sind hell. Dieser Alpen-Brachyceros ist ein direkter, aber doch etwas modifizierter Nachkomme der alten Torfrinder; am reinsten erhalten erscheint er um das Gothardmassiv herum; die schweren sichwyerschligge dürften etwas Primigeniusblut aufgenommen haben.

Durch die zahlreichen Untersuchungen von L. Adametz $z^{1}$ über die

1) L. Adametz. Studien zur Monographie des illyrischen Rindes. Journal für Landw. 1895, ferner: Untersuchungen über den Schädelbau des albanesischen Rindes 1898, und Studien üher Bos brachyceros europaeus, 1898 . 
österreichischen Rinder wurde der Nachweis erbracht, dass das polnische Rotvieh. sowie die litauischen und westrussischen Landrassen ebenfalls dem Brachycerosstamm zugerechnet werden müssen, ebenso das illyrische, montenegrinische und albanische Rind. Nach dem genannten Autor ist das auf der Balkanhalbinsel weit verbreitete Albanesenrind auf einer sehr niederen Entwicklungsstufe stehen geblieben und dem Typus des mitteleuropäischen Pfahlbaurindes nähet stehend als das schweizerische Braunvieh. Beachtenswert erscheint. dass der Schädel desselben meist auf der Mittellinie der Stirn einen kürzeren oder längeren Kamm wie beim Zebu aufweist.

Auch die insularen Gebiete des Mittelmeeres dürften bei ihrer Abgeschlossenheit noch vielfach solche primitive Brachycerosformen erhalten

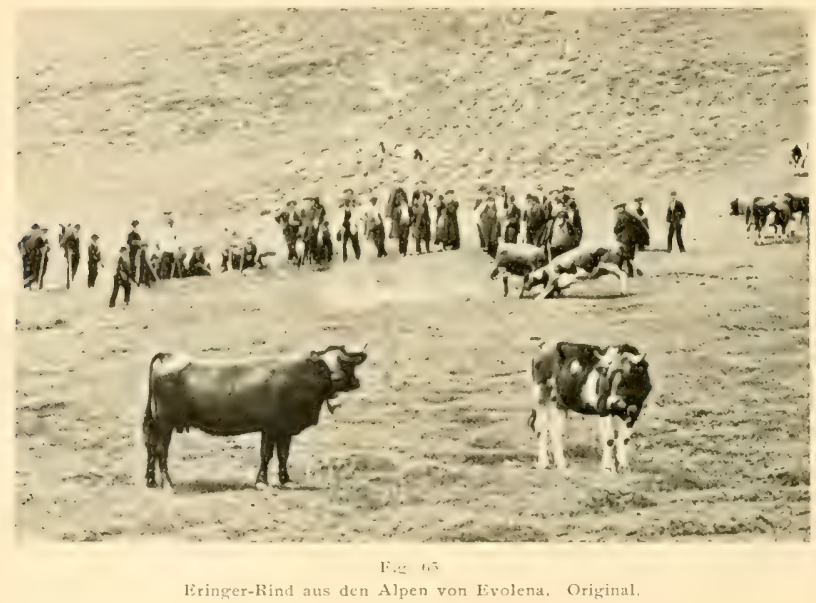

haben. Für Sardinien, dessen Rinder sehr klein sind, kann ich dies mit Bestimmtheit nachweisen. Es besitzt, wie das Albanesenrind, eine sehr breite und seichte Schläfengrube, ein I lauptmerkmal der brachyceren Rasse. Das Gehörn des Sardenrindes ist abweichend von allen mir bekannt gewordenen Formen, indem es sich aufwärts biegt, aber dann mit langen Spitzen sich nach hinten wendet.

Im Westen Europas sind ebenfalls Abkömmlinge der alten Torfrasse erhalten geblieben. Die kleinen Kanalrinder (Jersey-Vieh) müssen denselben zugerechnet werden, ebenso die Hereford-Rasse und das Sussex-Vieh.

Im Norden ist die Neigung zur Hornlosigkeit so stark ausgesprochen, dass man von einer in Bildung begrifienen Akeratos-Rasse reden kann. Arenander hat in seiner früher erwähnten monographischen Arbeit die weite 
Verbreitung ungehörnter Rinder nachgewiesen, so in Skandinavien (Fjellrasse). Lappland. Finnland, in Uralgebiet. Sikandinavische Rinder haben sich nach Island verbreitet und sind dort nach den vorliegenden Berichten meistens hornlos. In England kommt ungehöntes Rindvieh in überwiegender Zahl in den Grafschaften vom Norfolk und Suffolk vor, auch Wales besass vormals solches. Hornlose Rinder sind ferner in Schottland und Irland verbreitet, letztere Insel scheint vormals solche in grosser Zahl beherbergt zu haben, da in alten Ansiedelungen viele ungehörnte Schädel aufgefunden wurden. Aus den sehr gut ausgeführten Abbildungen, die Arenander von

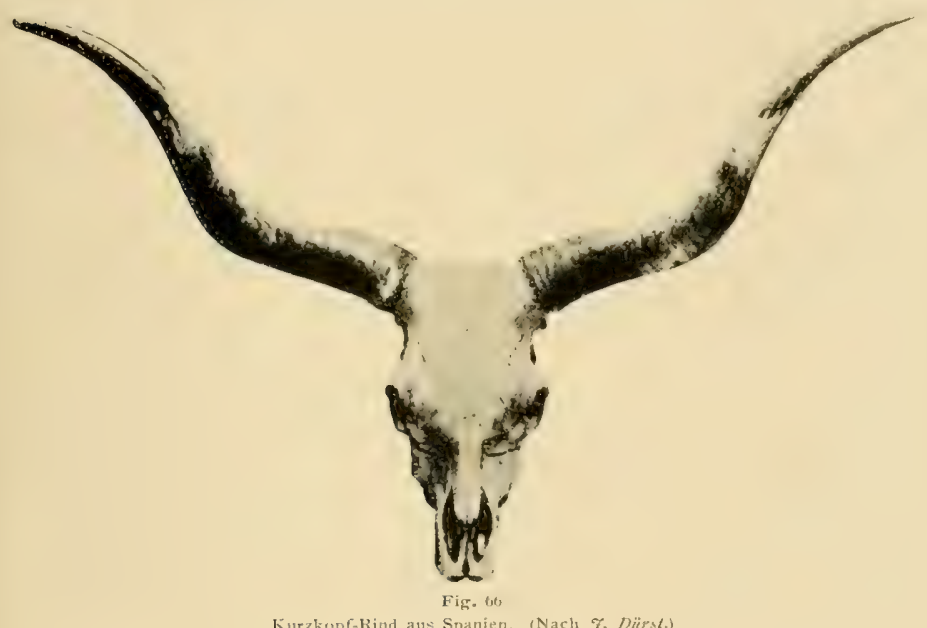

nordischen Akeratosschädeln veröffentlicht hat, spricht schon die so charakteristische Schläfengrube, die breit, seicht und nach hinten erweitert erscheint, deutlich genug für die Verwandtschaft mit den alten Brachycerosformen von Südeuropa (Albanien, Sardinien) und der genannte Autor musste gelegentlich die nahen Beziehungen zum hornlosen Zebu erwähnen.

Ueber die Stellung der eigentümlichen Kurzkopfiasse (Brachycephalus) hat sich Rütimejer dahin ausgesprochen, ${ }^{1}$ ) dass sie als ein Kurzhornrind mit beginnender Mopsbildung angesehen werden müsse und $L$. Adametz stimmte unlängst dieser. Iuffassung bei.-` Schon äussere Kennzeichen sprechen dafür. Das Eringer-Rind im Kanton Wallis ist in manchen Individuen dem Braunvieh in der Koptbildung doch sehr angenähert und kaum kurzköpfig

1) L. Rütimeyer. Ueber M. Wilckens' Brachycephalus-Rasse des Hausrindes. Verh. d. nat. Ges. in Basel. 1877.

$\left.{ }^{2}\right)$ L. Adametz. Journal für Landwirtschaft. 1898. Pag. 316. 
zu nennen, in andern dagegen wirklich der Mopsform entsprechend. Es ist vielfach schwarz mit weissen Abzeichen, doch wird es gegenwärtig einfärbig bei der Zucht vorgezogen, ist dann russig schwarz oder dunkelbraun mit rötlichem Schimmer, aber das Rehmaul und der Aalstrich hell kastanienbraun, ein Merkmal, das auf das Braunvieh hinweist.

Die insulare Verbreitung ist bemerkenswert; das Duxer-, Voigtländerund Eger-Rind werden diesem Formenkreis zugerechnet.

Die Kurzkopfrinder tauchen, soweit wir heute die Thatsachen übersehen, zuerst auf dem Boden Italiens auf und wurden vermutlich durch römische Kolonisten nach Norden gebracht. Die Reste aus der helvetischrömischen Zeit in Vindonissa und Aquae weisen auf ein sehr stattliches Tier hin, wie es sich heute noch im Südwesten von Europa vorfindet. So finden wir in Spanien und Portugal Schläge mit mächtigem Gehörn, deren Schädel vom podolischen Rind durchaus abweicht und extrem kurzköpfig erscheint. Es ist nicht unwahrscheinlich, dass diese Rinder schon in prähistorischer Zeit nach Europa gelangten, hier umgezüchtet wurden, ihrer Abstammung nach aber auf das altägyptische Langhornrind zurückzuführen sind. Spätere prähistorische Funde verbreiten vielleicht über diesen Punkt mehr Klarheit.

Im Anhang zu den Hausrindern mag hier noch kurz der zahme Büffel erwähnt werden. Dass derselbe auf asiatischem Boden in den Hausstand übergeführt wurde, kann keinem Zweifel unterliegen. Allein über die Zeit und den Ort der ältesten Domestikation befinden wir uns noch im Unklaren. Im Süden und Osten von Asien tritt der Hausbüffel überall stark in den Vordergrund, wo wasserreiche Niederungen vorhanden sind, denn an solchen Lokalitäten ist er widerstandsfähiger als das Rind.

Seine weite Verbreitung lässt die Vermutung aufkommen, dass er schon in prähistorischer Zeit domestiziert wurde. Doch sind bestimmte Anhaltspunkte zur Zeit in geringer Zahl vorhanden.

Layard giebt eine gute Abbildung eines altbabylonischen Cylinders, auf welchem eine männliche Figur aus einer Ampulle einem Büffel Wasser darreicht: dass es sich wirklich um einen Büffel handelt. lässt sich aus den sehr charakteristisch gezeichneten, deutlich gerippten Hörnern erkennen. Es dürfte sich um einen zahmen Büffel handeln. denn einen Wildbüffel zu tränken, wäre für einen Menschen wohl eine etwas schwierige Aufgabe.

Ob nun gerade Mesopotamien als Bildungsherd angesprochen werden darf, erscheint wenig sicher und genauere Aufklärung haben wir erst dann zu erwarten, wenn die Prähistorie des mittleren und südlichen Asien weiter fortgeschritten sein wird.

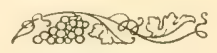




\section{DAS HAUSSCHAF.}

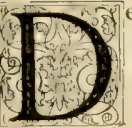

er Erwerb dieses genügsamen Haustieres, das besonders für den Bewohner trockener, steppenartiger Gebiete der alten Welt, später auch der neuen Welt, von ganz hervorragender wirtschaftlicher Bedeutung wurde, fand ohne Zwveifel in recht früher Zeit statt. Dafür spricht schon die weite geographische Verbreitung zu Beginn der historischen Periode, sodann die Spaltung in zahlreiche, von einander stark abweichende Rassen; endlich die psychische Eigenart der zahmen Schafe im Vergleich zu den Wildschafen, denu eine so völlige Umgestaltung des geistigen Charakters, durch Vererbung so sehr befestigt, dass Rückschläge geradezu ausgeschlosien sind, erforderte sicherlich ausserordentlich lange Zeiträume. In der That liegen positive Thatsachen zur Genüge vor, dass Hausschafe schon in der prähistorischen Zeit in verschiedenen Kulturkreisen vorhanden waren.

\section{PRAEHISTORISCHE SCHAFE.}

In Mitteleuropa scheint das Schaf während der älteren Steinzeit nirgends im zahmen Zustande vorhanden gewesen zu sein, wie denn überhaupt der Höhlenzeit alle Ilaustiere fehlen. Zwar liegen Angaben vor, dass bei den Ausgrabungen in der palaeolitischen Niederlassung beim Schveizerbild im Kanton Schaffhausen Schafknochen in der ältesten Kulturschicht zum Vorschein kamen. Dieselben sind jedoch so spärlich, dass die Vermutung nahe liegt, sie seien durch Zufall erst später in jene alte Kulturschicht gelangt, möglicherweise handelt es sich un Knochen des wilden siteppenschates oder Arkal, das sich als Seltenheit in die Gegend von Schweizerbild verirrte, wie das ja auch mit andern Steppentieren der Fall war.

Jedenfalls berechtigen die Angaben noch nicht zu positiven Schlussfolgerungen.

Unzweideutige Spuren wirklich zahmer Schafe tauchen erst zu Beginn der neolitischen Zeit in den Pfahlbauniederlassungen auf. Schon Rütimeyer fiel es auf, dass die Reste in den ältesten Pfahlbauten noch spärlich sind, später aber häufiger werden und $T \%$. Studer konnte dies bestätigen; erst mit der Bronzeperiode macht sich ein entschiedener. Iufschwung der Schafzucht bemerkbar. 
Anfänglich ist nur eine einzige und höchst eigentümliche Rasse vorhanden, das ziegenhörnige 'Torfschaf (Ovis aries palustris Rütineyer). Ihr unvermitteltes Erscheinen auf mitteleuropäischem Boden weist auf eine Einwanderung von aussen her; über ihre Entstehung wird an anderer Stelle meine Auffassung dargelegt werden. Dieses eigentümliche Schaf hat sich über die römische Zeit hinaus erhalten und lebt in spärlichen Relikten noch gegenwärtig in den Alpen des bündnerischen Oberlandes.

In der jüngeren Pfahlbauzeit erscheint eine neue, völlig hornlose Rasse, das Bronzeschaf. Da Zwischenformen fehlen, konte dieses nicht durch Umzüchtung aus dem vorhandenen Torfschafmaterial hervorgehen, sondern gelangte als fertiges Kulturprodukt aus einer nicht näher zu bezeichnenden Region nach Mitteleuropa. Die heutigen Marschschafe der nordeuropäischen Niederungen dürften direkte Abkömmlinge jenes Bronzeschafes sein.

Noch eine dritte, durchaus eigentümliche Rasse ist aus den prähistorischen Niederlassungen von Greng, Lattringen, Font, Lüscherz und Niederwyl bekannt geworden. Es ist ein auffallend grossgehörntes, merinoartiges Schaf, dessen mächtige Hornzapfen in der oberen Curvatur bis zu 26 Centimeter massen. ') Diese grosse Rasse war jedoch so selten, dass die Ansicht ausgesprochen wurde, die Gehörne seien möglicherweise nur als Trophäen in den Besitz der Pfahlbauer gelangt. Wahrscheinlich gehören diese Reste den ersten Vorläufern einer neuen eindringenden Rasse an, die erst mit Invasion der Römer im Norden der Alpen häufiger wird und deren Reste beispielsweise in der römischen Kolonie Vindonissa. zahlreich zum Vorschein kamen. ${ }^{2}$ )

\section{DAS SCHAF DER ALTEN KULTURKREISE.}

Die altassyrische Kunst hat uns recht gute Schafdarstellungen überliefert. Denselben können wir entnehmen, dass im Zweistromland die Rassenzucht offenbar schon frühe stark vorgeschritten war. So findet sich am S. W. Palast in Nimrod aus der Zeit Tiglatpilesar II (745 v. Chr.) eine Reliefdarstellung mit der Beute, die in einer eroberten jüdischen Stadt gemacht wurde. Aus dieser Stadt werden auch Schafe weggetrieben, die ganz unverkennbar der Fettschwanz-Rasse angehören und zwar besitzt der Schwanz einen recht beträchtlichen Umfang.

Auf den persischen Steinmonumenten, insbesondere auf den Relieffriesen von Persepolis kommt später das Schaf wiederum zur Darstellung. H. Pohlig ${ }^{-3}$ ) bemerkt darüber: „Die Widderbilder, welche dort eingemeisselt , sind, erinnern durch die kurzen, aufrecht stehenden Ohren an die wilden "Rassen oder an solche domestizierte, welche gegenwärtig in dem Orient

1) G. Glur. Beiträge zur Fauna der Pfahlbauten. Bern. 1894.

$\left.{ }^{2}\right)$ H. Krämer. Die Haustierfunde von Vindonissa. Revue suisse de zoologie. Genève. 1899.

$\left.{ }^{3}\right)$ H. Pohlig. Berichte des landwirtschaftichen Instituts Halle. Heft VII. 1887. 
"nicht mehr vorkommen." Es scheinen lang- und schmalschwänzige Rassen gewesen zu sein, welche heute in Persien fehlen.

In Palästina hatte die Schafzucht zu Salomon's Zeit eine gewaltige Höhe erreicht, wie denn das Tier in der Bibel hâufig Erwähnung findet.

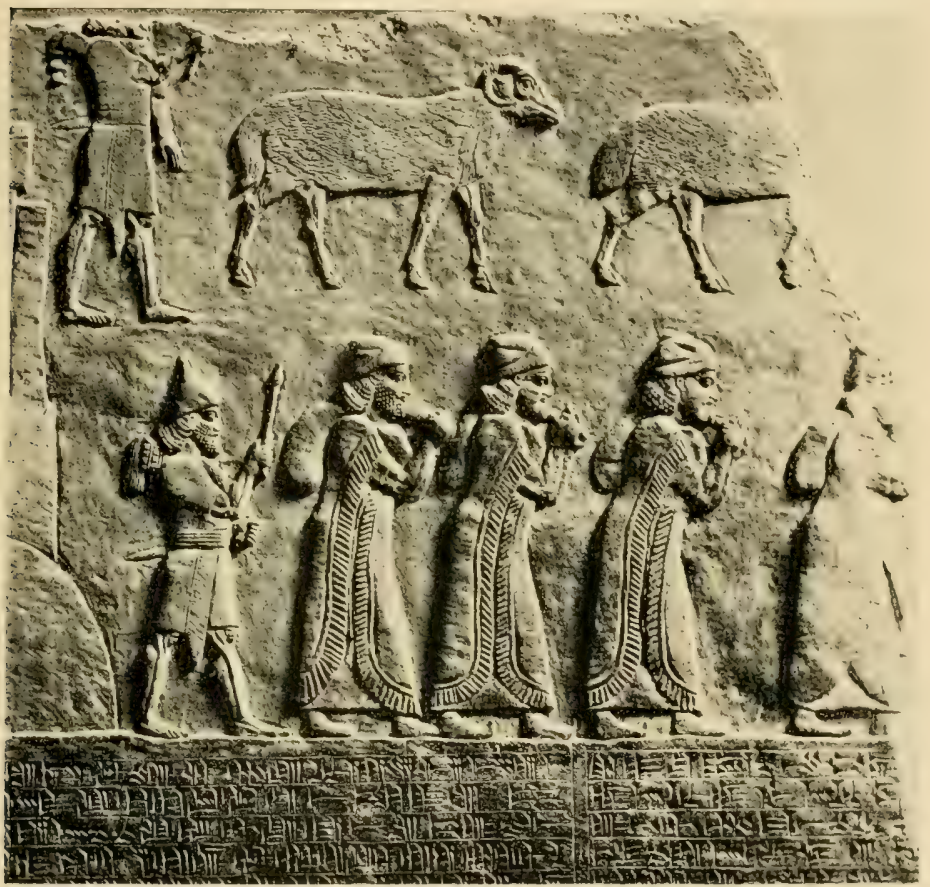

Fig. 67 .

Assyrische Fettschwanzschafe aus der Zeit Tiglatpilesar's, 745 v. Clir. (British Museum.)

Eigentümlich liegen die Verhältnisse in Acgypten. Mariette meint, dass das Hausschaf bei den Bewohnern des Nilthales noch zur Zeit der V. Dynastie fehlte und Dümichen bestätigt, dass gerade auf den alten Denkmälern mit ihren reichen Tierdarstellungen das Schaf völlig fehlt, also während der ältesten Zeit des Reiches offenbar nicht vorhanden war. Gegenüber dieser, in weit verbreiteten Werken niedergelegten Darstellung, die noch in jüngster Zeit wieder von M. Much aufrecht erhalten wird, muss ich das Gegenteil betonen und habe früher schon den Sachverhait richtig zu stellen versucht.')

1) C. Keller. Die Alostammung der Rassen unseres Hausschafes. Oesterreichische Molkereizeitung, Nr, 4 und 5. 1899. 
In Wirklichkeit hesass Aeguthen schon in zorpharaonischer Zeit eine cigcnartige Kasse zahmer Schafe. Der direkte Nachweis ist durch Knochenreste des Hausschafes geliefert, welche C\%. Gaillard aus den neolitischen Küchenabfallen von 'Tukh kürzlich beschrieben hat. ${ }^{1}$ ) Von der gleichen Lokalität kenne ich eine sehr alte, prähistorische Zeichnung des Mähnenschafes, die irrtümlicherweise als Antilope ausgegeben wurde. Es lässt sich freilich nicht entscheiden, ob diese Zeichnung ein domestiziertes Tier dar-

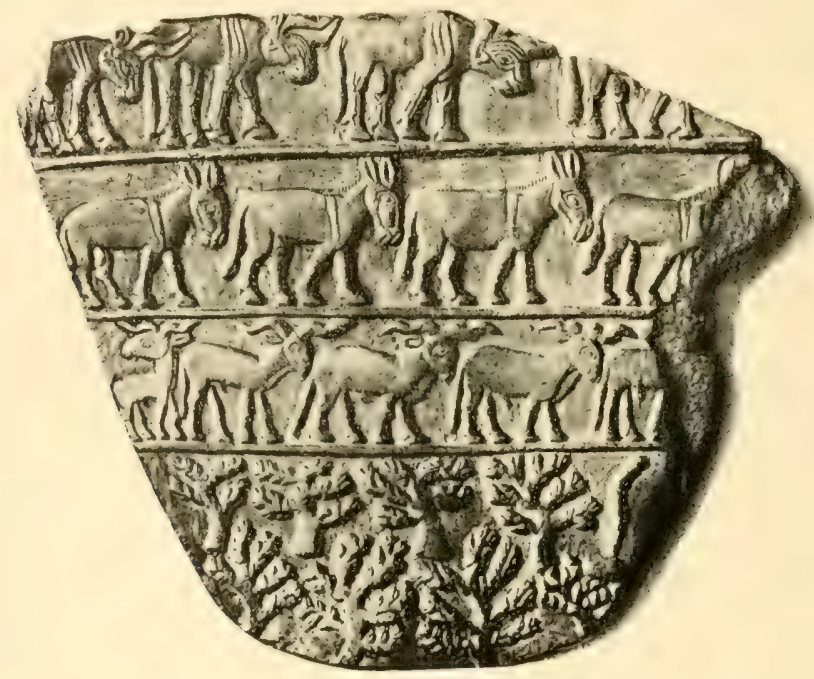

Fig. $6 \mathrm{~K}$

Urägyntische Hnusschafe aus der Nezradahzeit. (Schieforplatte des Museums in Gizeh.)

stellt. Dagegen findet sich eine vorpharaonische Bilderei auf der Schieferplatte von Negadah, welche im Museum von Gizeh aufbewahrt wird und von de llorgan veröfentlicht wurde."

Auf derselben erscheinen Hausschafe, die wegen der noch vorhandenen Halsmähne sofort als Abkömmlinge des Mähnenschafs (Ammotragus tragelaphus) erkennbar sind: die wagrecht abstehenden Zackelhörner verraten jedoch den Einfluss der Domestikation. Da die Negadahzeit der Pharaonenzeit unmittelbar vorausgeht, so leitet dieses Schaf direkt zum Hausschaf des alten Reiches hinüber. In den neuesten Veröfentlichungen von Flinders Petrie ${ }^{3}$ )

1) C\%. (inillard, Le bélier de Mendès ou le mouton domestique de l'ancienne Egypte. Société d'anthropologie de Lyon. 1901.

2) De Morman. Recherches sur les Origines de l'Egypte. Paris. 1897.

3) W. M. Flinders Petric. The Royal Tombs of the first Dynasty. Part. I. Pl. XXIII. London. $19(10$. 
lässt sich dieses wieder zur Zeit der I. Dynastie in Abydos nachweisen. Es ist dann später in (Gizeh und in Beni Hassan (XII. I) vnastie) mehrfach abgebildet.

Im mittleren Reich kommen bereits drei verschiedene Schläge dieser alten Rasse neben einander vor.

Im neuen Reich, da an die Stelle der früheren Abgeschlossenheit eine regere Fühlung mit Asien beginnt, wandert eine neue, asiatische Schafrasse ein, die nach und nach die Oberhand gewinnt. Die in Stein gehauenen Widder, welche reihenweise als Schmuck bei den Tempeln und an den Prozessionsstrassen aufgestellt wurden, sind offenbar diesen neuen asiatischen Ankömmlingen nachgebildet.

Wenden wir uns zum Boden des klassischen Altortums in Griechenland und Rom, so werden die Rassenspuren immer deutlicher.

Griechenland eignetesichseinesKlimas und seiner Bodenbeschaffenheit wegen ausgezeichnet für dic Schafzucht. In P'oesie und Prosa tritt der Träger des Wollvliesses und seine Bedeutung für die häusliche Industrie so

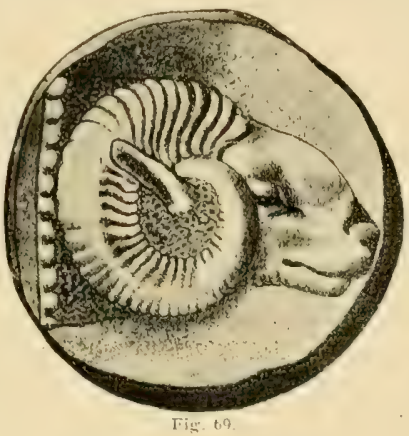

Sichat aut einer k]cinasiatischen Mïnze. (Nach Imhouf-Blumer.) hảufig auf, dass schon daraus auf eine grosse Ausdelunung seiner Zucht geschlossen werden darf.

Die mykenische Kunst hat bildliche Darstellungen von zahmen sichafen geliefert, atus denen wir aufverschiedene Rassenschliessenmüssen. Altgriechische Münzen weisen auf eine merinoartige Rasse hin. Die Sage, dass die Griechen das goldene Vliess, beziehungsweise dessen gelbwolligen Träger in Kolchis holten, griebt bedeutungsiolle Winke über die Herkunft gewisser wertvoller Schafe Griechenlands.

In Phönicien kannte man die Herstellung prachtvoller Wollstoffe, sowie die Kunst des Färbens. Tyrus trieb einen schwunghaften Wollhandel, mit ihm wetteiferte Milet. Ueber Samos fand ein lebhafter Import von Schafen nach Griecheuland statt, wo die epirotischen und attischen Zuchten später einen grossen Ruf erlangten. Griechische Kolonisten vermittelten über Sizilien ihre edlen Tiere der italischen Halbinsel und dem alten Gallien. wo an der Rhonemündung die griechische Kolonie Massilia entstand. Wenn Varra berichtet, dass die Schafe Apuliens vom Mai an herumwandern und die Hirten, um das Weidrecht auszüben, sich bei gewissen Beamten anmelden mussten, so passt dies noch ganz auf die späteren Verhältnisse in Spanien. Dass die Römer bei ihrem Vordringen nach dem Norden der Alpen stark umgestaltend aut die wirtschaftlichen V'erhältnisse Mitteleuropas einwirkten und auch die Schafzucht beeintlussten, lässt sich an der Hand der neuesten Funde unschwer nachweisen. 


\section{DIE WILDSCHAFE (NI) IHRE GEOGRAPHISCHE VERBREITUNG.}

Da geologisch gesprochen die Schafe eine verhältnismässig junge Gruppe darstellen, die offenbar erst in der gegenwärtigen Schöptung ihren Höhepunkt erreicht hat, so ist gerade hier die Wahrscheinlichkeit sehr gross, die vilden Stammformen noch unter den lebenden Arten anzutreffen. Bevor wir an die Abstammung der zahmen Rassen gehen können, müssen wir daher vorerst Umschau unter dem gegenwärtig vorhandenen Wildmaterial halten.

Zoologisch genommen, lässt sich die Familie der Oves gut umschreiben. Die im allgemeinen mittelgrossen, ausnahmsweise auch stattlichen Wiederkäuer von kräftigem, aber nicht plumpem Körperbau besitzen ein Haarkleid, das im Gesicht und an den Beinen kurz bleibt, am Hals und Körper länger erscheint. Unter dem Grammenhaar wächst im Herbst ein Unterwollkleid, das sich im Frühjahr in Fetzen oder Flocken abschenert. Das bleibende Wollvliess ist ein Resultat der künstlichen Züchtung und findet sich nur bei zahmen Rassen, aber nicht bei allen. Der Schädel ist in der Stirngegend eingesenkt, der Nasenteil bei den ächten Schafen mehr oder weniger konvex. Das Gehörn ist gewöhnlich dreikantig, im weiblichen Geschlecht schwächer entwickelt als beim Widder; es kann sogar ganz fehlen (Mouflon). Es entfernt sich vom Ursprung an ziemlich rasch von der Medianebene. 'Thränengruben sind nur bei den ächten Schafen vorhanden.

Die palaeontologische Vorgeschichte erscheint noch sehr lückenhaft. Die fossilen Reste beschränken sich auf vereinzelte Knochenfunde in diluvialen Ablagerungen Europas. Einen ziemlich grossen fossilen Schädel (Ovis antiqua) beschrieb Pommerol 1879; er stammt aus Südrankreich.

Die bisherigen Funde in posttertiären Ablagerungen Nordasiens haben keine Formen geliefert, die von den in der Gegenwart lebenden spezifisch verschieden sind. ${ }^{1}$ )

Weitere Aufschlüsse haben wir vermutlich von der palaeontologischen Erforschung Zentralasiens zu erwarten, weil dort wohl der wichtigste Bildungsherd der heutigen Wildschafe zu suchen ist.

Die Zahl der bisher in der Litteratur benannten Arten, die der Gegenwart angehören, beträgt über zwanzig. ${ }^{2}$ )

Die Artberechtigung derselben dürfte nicht durchweg gesichert sein: wir wollen nachher versuchen, dieselbe zu prüfen.

Ich möchte folgende natürliche Gruppen oder Formenkreise aufstellen:

1) F. D. Tscherski. Wissenschaftliche Ergebnisse. Mém. de l'Acad. d. St. P'etersbourg. 1892 .

2) W. Peters. Monatsbericht der kgl. Akad. d. Wissenschaft. Berlin. 1876, ferner:

A. Girinner. Ueber die Wildschafe. St. Gallen. 1898, und

E. L. Trouessart. Catalogus manmalium tam viventium quam fossilium. Berolini. 1898. 
a) Halbschafe. (Pseudoves.) Als Uebergangsstufe zwischen den Ziegen und echten Schafen besitzen sie einen noch stark an die Ziegen anklingenden Charakter, so fehlen ihnen die Thränengruben; ihr Gehörn wendet sich in weitem Bogen nach aussen.

1. Mähnenschaf. (Ammotragus tragelaphus.) Nordafrika, am zahlreichsten im Atlasgebirge und in Südtunesien.

2. Nahoor. (P'seudovis nahoor.) Im Himalaya, besonders im Quellgebiet des Ganges.

b) Mouflonartige Schafe. (Musimon.) Kleinere Wildschafe, die das westliche Asien und Südeuropa bewohnen. Ihr Gehörn bildet cine unvollkommene Spirale mit nach innen gebogener Spitze.

3. Mouflon. (Ovis musimon.) Gegenwärtig auf Sardinien beschränkt. Auf Korsika unlängst erloschen.

4. Cyprischer Mouflon. (Ovis ophion.) In den zentralen und westlichen Gebirgen von Cypern bis 2000 Meter Höhe. Kreta?

5. Persischer Mouflon. (Ovis gmelini und Ovis anatolica.) Von Kleinasien bis P'ersien.

6. Urial. (Ovis cycloceros.) Im nordwestlichen Himalaya.

7. Schapuschaf. (Ovis vignei.) Kleintibet und Hindukusch.

8. Steppenschaf. (Ovis arkal.) Steppen vom Kaspisee bis Persien.

c) Argalischafe. Diese auf Innerasien beschränkten Wildschafe besitzen einen in der Stirnzone stark verbreiterten Schädel mit dicken und relativ kurzen Stirnzapfen. Das dreikantige Gehörn nimmt von der Basis an in der Dicke rasch ab, bildet eine vollständige Spirale mit nach aussen gewendeter Spitze.

9. Argali. (Ovis ammon.) Vom Baikalsee bis Nordtibet.

10. Ovis hodgsoni. Nordabhang des Himalaya und 'Tibet.

11. Ovis blythi. Tibet.

12. Ovis jubata. Im Norden von Peking.

d) Kuschsare. (irosse innerasiatische Wildschate mit kolossal entwickeltem Gehörn, das eine vollkommene Spirale besitzt; die dreikantige Hornspitze nach aussen gewendet.

13. Pamirschaf. (Ovis polii.) Aut der Pamirhochebene.

14. Ovis karelini. Berge von 'Tian-Schau.

15. Ovis heinsii. Turkestan und oberer Amu.

16. Ovis nigrimontana. Karatau.

c) Dickhornschafe. Von den nahe verwandten Argali durch die auffallende Dicke der Hornschale abweichend. Das Gehörn beschreibt eine Spirale, die an Dicke langsam abnimmt; die Spitze nach vorn, kaum nach aussen gerrendet.

17. Eisschaf. (Ovis borealis.) Nordwestliches Sibirien.

18. Schneeschaf. (Ovis nivicola.) Kamtschatka.

19. Amerikanisches Dickhornschaf. (Ovis montana.) Nördliches Amerika. 
20. Kalifornisches Dickhornschaf. (Ovis californica.) Nördliches Kalifornien.

Dazu gesellen sich noch einige Arten ohne genügende Diagnose, daher wir sie am besten ganz weglassen.

Aber auch die zwanzig hier aufgeführten Arten lassen sich noch erheblich reduzitren, dat einzelne von ihnen nur auf geringtügigen L nterschieden im Gehörn beruhen.

Zunächst dürften die kleineren Wildschafe von Sardinien, Cvpern, Kleinasien und Persien bis zum Himalaya nur als geographische Abarten des Moutlon anzusehen sein; selbst Ovis cycloceros und Ovis Vignei können in ihrer Artberechtigung angezweifelt werden, Brandt hat wohl das richtige getroffen, wenn er zwei Abarten, eine Var. occidentalis und Var. orientalis des Moutlon aminmt. Dagegen bildet offenbar das Steppenschaf der Turkmenen (Ovis arkal) eine unanfechtbare Spezies, die den Moutlon an Grösse übertrifft und verhältnismässig langschwänzig ist. Die vier Argali-Arten lassen sich wohl ohne Not in eine zusammenfassen; das gleiche gilt für die Kaschgare.

Die Dickhornschafe Amerikas in zwei Arten zu spalten, hat keine Berechtigung, aber auch das Schneeschaf von Kamtschaka kann ich auf Grund eigener Untersuchungen nicht vom amerikanischen Bergschaf unterscheiden, dagegen scheint mir das Eisschaf mehr Artberechtigung zu haben.

Sehen wir ab von den ziegenähnlichen Halbschafen (Mähnenschaf und Nahoor), so lassen sich die gegenwärtig lebenden echten Wildschafe ohne Zwang auf ein halbes Dutzend Arten zurückführen (Ovis musimon, Ovis arkal, Ovis ammon, Ovis polii, Ovis borealis und Ovis montana).

In diesem Sinne kann Asien als das Zentrum und als Bildungsherd aller echten Wildschafe angesehen werden. Asien beherbergt alle Arten und es sind nur zwei davon, welche noch auf Nachbarkontinente hinübergreifen. Im Westen reicht der Mouflon nach den südeuropäischen Inselgebieten, wo er besondere Lokalformen erzeugte. Im Osten hat das Dickhornschaf von Kamtschaka aus zu einer \%eit. da noch alte Landverbindungen waren, einen Vorstoss nach dem nördlichen Amerika unternommen.

Diese tiergeographischen Thatsachen geben uns deutliche Winke bezüglich der ältesten Bildungsstätte gewisser zahmer Rassen.

\section{ABSTAMMUNG DER HAUSSCHAFE.}

Die bedauerliche Unklarheit, welche bis in die jüngste Zeit hinsichtlich der Herkunft der einzelnen Rassen herrschte, mag es rechtfertigen, etwas eingehender bei diesem Gegenstand zu verweilen und dies um so mehr, als meine Auffassung von meinen Vorgangern erheblich abweicht.

Eine genaue anatomische Durcharbeitung, wie wir sie beispielsweise für unsere Rinder besitzen, ist für manche Rassen noch nicht vorhanden, 
was mit der sichwierigkeit der Materialbeschaffung zusammenhängen mag. Immerhin lassen sich an der Hand der bisher gewonnenen Thatsachen wenigstens die Grundlinien der Stammesverhältnisse genauer feststellen.

Im Laufe der Zeit sind verschiedene Wildschafe als Stammväter der zahmen Formen erklärt worden, man hat besonders auf den Mouflon und das Argalischaf hingewiesen. Einzelne Forscher, wie z. B. Gervais dachten an eine bereits ausgestorbene IVildform - in dubio immer ein bequemes Auskunftsmittel! Ich stehe der Annahme ausgestorbener Stammformen Bos primigenius soll nicht ats Paradigma genommen werden - aus den früher dargelegten Gründen im allgemeinen skeptisch gegenüber.

Von denjenigen Autoren, die der Abstammung des Hausschafes mit wissenschaftlichen Methoden näher getreten sind, hebe ich aus der neueren Zeit Fulius Kühn ${ }^{1}$ ) und Alfred Nehring $g^{2}$ ) hervor.

Ersterer bediente sich der physiologischen Methode und berichtete 1888 über seine in Haustiergarten der Universität Halle angestellten Züchtungs-, beziehungsweise Kreuzungsversuche. Obschon gerade beim Hausschaf eine ausserordentlich starke Differenzierung in Rassen vorliegt, so gelang es \%. Kïhn dennoch, Mutterschafe der verschiedensten Rassen erfolgreich mit dem Mouflon Südeuropas zu paaren. Er erhielt Bastarde mit den verschiedenen Formen der Merinos (Elektorals, Negrettis, Rambouillets, Mauchamps), mit englischen Schafrassen, deutschen Landrassen, nordischen Kurzschwänzen, Zackelschafen, Graubündner Bergschafen, Bergamasker, ägyptischen Fettschwänzen, abessynischen Schafen, arabischen Stummelschwanzschafen, Senegalschafen u. s. w. Die Bastarde erwiesen sich als fruchtbar, selbst bei extremer Incestzucht. Halbblutböcke erzeugten Nachkommen bei Anpaarung mit Müttern der Hausschafrassen, waren aber auch fruchtbar bei Paarung mit Bastardmüttern.

"Es kamn durch diese Versuche," sagt $\mathscr{F}$. Kühn, "der Nachweis als sicher erbracht angesehen werden, dass Monflon und Hausschaf nicht verschiedener Art sind, dass also ersterer in. der That ein Stammvater des letzteren ist."

Die Zuchtergebnisse des verdienten Hallenser Forschers sind überraschend; aber wenn er daraus auf eine monophyletische Herkunft schliessen will und den Mouflon als gemeinsame Stammform hinstellt, so kann ich nicht beistimmen. Ich habe mich früher schon über den Wert der von ihm ausschliesslich in Anwendung gebrachten physiologischen Methode ausgesprochen und dabei betont, dass diese nicht ausschlaggebend sein kann. Sie bedarf einer Kontrolle durch die vergleichende Anatomie.

$\mathrm{Zu}$ abweichenden Ergebnissen ist 1 . Nehring gelangt. Aus zoologischen

1) Fulius Kühn. Festschrift zur Feier des 25-jährigen Restehens des landw. Institutes der Universität Halle. 1888.

2) A. Nehring. Deutsche landwirtschaftliche I'resse. 1891. 
Gründen befürwortet er eine polyphyletische Abstammung; die zahlreichen Rassen lassen sich auf mehrere Wildformen zurückführen und es haben seiner Meinung nach im Laufe der vorgeschichtlichen Zeit in verschiedenen Ländern der alten Welt, namentlich Europas und Asiens, vielfache Domestikationen von Wildschafen stattgefunden.

Als Stammquelle betrachtet zunächst den südeuropäischen Moutlon (Ovis musimon) auch Vehring; als eine zweite das vom Kaspisee bis Persien heimische Steppenschaf (Ovis arkal). Die Haidschnucken, sowie die kurzschwinzigen, dunkelhörnigen Schate Europas sind . Ibkömmlinge des Moutlon, withrend die hellhörnigen. langschwinzigen Rassen vom asiatischen siteppenschaf hergeleitet werden müssen. Aber auch innerasiatische Wildschafe, besonders das Argali haben Blut aut zahme Schafe vererbt.

Ich habe seither ${ }^{1}$ ) an der Hand des morphologischen Vergleiches und unter Zuhülfenahme der tiergeographischen, urgeschichtlichen und ethnographischen Thatsachen der Frage näher zu treten versucht. Ich nähere mich Nehring insofern, als ich einer polyphyletischen Abstammung der Rassen zustimme: anderseits weiche ich in wesentlichen Punkten von ihm $\mathrm{ab}$; namentlich muss ich die innerasiatischen Argalis von der Stammvaterschaft ausschliessen. Zwar ist diese Art schon von Pallas herangezogen worden, aber die relativ bedeutende Stimbreite, selbst beim weiblichen Schädel, dann die rasche Dickenabnahme des Gehörns beim Argali fehlen selbst bei den von mir untersuchten asiatischen Hausschafen so gut wie bei europäischen Rassen. Ich will damit nicht behaupten, dass wenn uns einmal die innerasiatischen Hausschafe genauer bekannt sind, da oder dort etwas Argaliblut fehlt; dann wären solche Vorkommnisse jedenfalls nur lokal. Einen irgendwie erheblichen Eintluss dieses IVildschafes bei der Entstehung zahmer Formen sind wir nicht berechtigt, zuzugeben.

Die Kaschgare und östlichen Dickhornschafe kommen schon aus tiergeographischen Gründen nicht in Betracht. Nach meinen Untersuchungen haben wir drei grosse Bildungsherde zahmer Schafe mit drei zugehörigen Stammformen anzunehmen und zwar einen europäischen, einen asiatischen und einen afrikanischen Bildungsherd. Wirtschaftlich mögen die drei von mir angenommenen Stämme ursprünglich sich das Gleichgewicht gehaiten haben: mit Beginn der historischen Zeit hat sich jedoch das Verhälnis in der Weise verschoben, dass der asiatische Stamm immer mächtiger wurde und die alten Rassen der Nachbarkontinente zurück drängte.

Der europäische Bildungsherd. In dem heutigen Rassenbestande Europas begegnen wir besonders im Norden auf den Gebieten, die wirtschaftlich noch am wenigsten beeinflusst sind, kurzschwänzigen Formen von meist geringer Körpergrösse, die aus anatomischen Gründen von mir in [ebereinstimmung mit . Vihing als. Joutlon- Ibkömmlinge angesehen werden.

1) C. Keller. Die Abstammung der Rassen unseres Hausschafes. Oesterreichische Molkereizeitung. Nr. 4 und 5.1899. 
Dafür spricht vor allem die Form des Gehörns, wo sich ein solches erhalten hat. An einem Haidschnuckenschädel erkenne ich nicht nur einen dem Mouflon analogen Verlauf, sonclern auch die Neigung der Hornspitzen, sich wie beim Mouflon nach innen zu wenden. Die starke Ausprägung der oberen Kante ist ein Merkmal, das uns auch beim Wildschaf Cyperns recht augenfâllig entgegentritt. Die gut entwickelten, jedoch nicht übermässig tiefen Thränengruben, dann die mit ihrer Achse fast senkrecht zum Stirndurchschnitt gestellten Augenhöhlen, deren Ränder sich vorn nur wenig verengen, weisen wiederum auf den Mouflon hin. Eine weitere Uebereinstimmung besteht in der Kürze des Schwanzes. Die prähistorischen Kulturverhältnisse wie die tiergeographischen Thatsachen weisen auf Südeuropa als Stammland hin. Mitteleuropa und Nordeuropa haben während der Diluvialzeit keine Mouflons besessen, während ihr Vorkommen für Cypern, Sardinien und Korsika allgemein bekannt ist; in neuester Zeit wird jedoch ihr Erlöschen auf Korsika signalisiert. Mehrfach ist behauptet worden, dass auf der Balkanhalbinsel noch Wildschafe vorkommen: nach meinen Erkundigungen scheint dies jedoch nicht der Fall zu sein. Da die Tiere, die im Sommer die Bergregion von 1500-1900 Meter bevorzugen, im Winter aber die tieferen Regionen aufsuchen, sich sehr leicht zähmen lassen, so wird die Ueberführung der Mouflons in den Hausstand leicht verständlich.

Als ältesten Bildungsherd haben wir vermutlich die östlichen Mittelmeerländer anzusehen, ob auf den griechischen Inseln oder auf der Balkanhalbinsel, das lässt sich zur Zeit nicht entscheiden; vielleicht kommt mehr Licht in die Frage, wenn einmal Cypern und Kreta gründlicher durchforscht sind. Da die Inselkultur des vorgeschichtlichen Griechenland angenscheinlich sehr alt ist und der Mouflon sich in jenen Gebieten bis heute als Wildschaf erhalten hat, ${ }^{1}$ ) so ist es nicht unwahrscheinlich, dass auf dem Inselgebiet die erste Domestikation desselben stattgefunden hat. Prähistorische Knochenfunde liefern vielleicht später den genaueren Nachweis für diese $\checkmark$ ermutung.

Der asiatische Bildungsherd. Die Hausschafe asiatischer Abkunft sind offenbar sehr alt, dafür spricht das hohe Alter asiatischer Kulturen, die Erwähnung in den altesten Schriftwerken (Genesis, Zend-Avesta, Veda) und die bildlichen Darstellungen, die weit zurückreichen, auch bereits die Merkmale starker Einwirkung durch künstliche Züchtung erkennen lassen. Der Reichtum Asiens an Wildschafen drängte geradezu dahin, daraus domestizierte Schafe zu gewinnen. Im Gegensatz zu den Mouflon-Abkömmlingen Europas sind die asiatischen IIasschafe ursprünglich alle langschwänzig.

Es wurde bereits bemerkt, dass sowohl die Argali-Schafe als auch die ihnen offenbar nahestehenden Dickhornschafe des östlichen Asiens von der Stammvaterschaft auszuschliessen sind, da die autlallende Breite der Stirn-

1) F. Biddulp/s. On the wild Sheep of Cyprus. Proc. Zool. Soc. 1884. 
region, sowie die starke Einsenkung im vorderen Teil derselben dem zahmen Schaf fehlt. Die Stammform wäre demnach im westlichen Teil von Asien z.u suchen.

Auf diesem Gebiet lebt ein ächtes Schaf im wilden Zustande, das langschwänziger als alle übrigen Wildschafe ist, nämlich das transkaspische Steppenschaf (Ovis arkal). Anatomische und physiologische Gründe sprechen dafür, dass wir im Arkal die eigentliche Stammquelle des asiatischen Hausschafmaterials vor uns haben.

An Grösse übertrifft er den Moutlon, wie demn auch die langschwảnzigen ITausschafe durchschnittlich grösser sind als die kurzschwänzigen. Nachdem

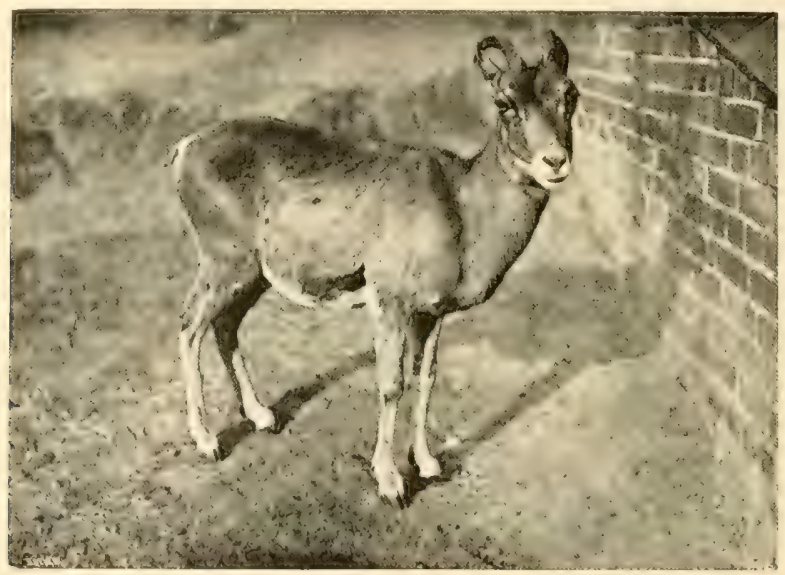

Fis: 70 ,

Steppenschaf (Ovis arkal). Originalaufnahme im zoolog. Garten Berlin.

ich den Arkalschãdel genauer untersucht habe, finde ich an ihm anatomische Eigentümlichkeiten, die sich auch am Schädel des Hausschafes asiatischer I Ierkunft wieder finden. So ist die Stirn verhältnismässig schmal, die Hornzapfen liegen an der Basis weiter auseinander als beim Mouflon, das dreikantige Gehörn ist hellfarbig, regelmässig gewulstet und tief eingeschnitten zwischen den starken Wülsteı, also mit dem Merinogehörn am meisten übereinstimmend. Die Thränengruben erscheinen tiefer als bei irgend einer anderen Art.

Die Augenhöhlen treten beim Arkal sehr stark hervor, sie erscheinen fast röhrenförmig, sind vorn verengt und mit ihrer Achse schief nach vorn gerichtet, ein Merkmal, das ich z. B. beim chinesischen Schaf sehr deutlich ausgesprochen finde. 
Ueber die Lebensweise sind wir durch Radde genauer unterrichtet. Der Arkal ist keineswegs ein Hochgebirgstier im Gegensatz zu den meisten andern Wildschafen Asiens. Er bewohnt die niederen Vorberge und geht selbst bis zur Küste des kaspischen Meeres herab, dessen Wasserspiegel bekanntlich unter dem Niveau des Mittelmeeres liegt. Als eigentliches Steppentier, dessen zahme Nachkommen ja vorzugsweise auch in trockenen Steppengebieten leben, auf feuchten Wohngebieten aber schwer fortkommen, lebt der Arkal mehr als alle andern Wildschafe in grösseren IIerden.

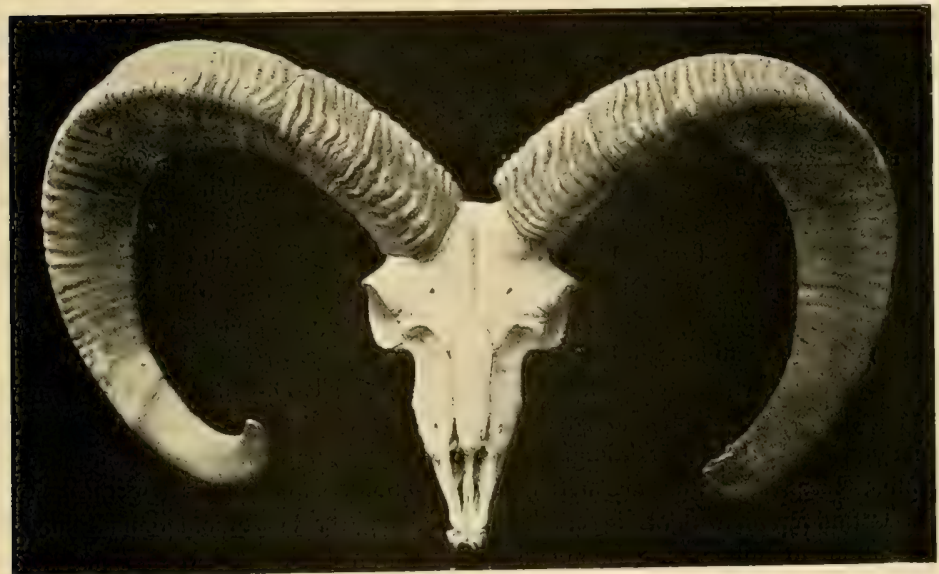

Fig. 71 .

Schäde) ven () vis arkal. (Landw. Sammlung Zürich.)

Vereinzelte Stücke werden nur selten angetroffen, meist leben 60-100 Stück beisammen: noch in neuerer Zeit sind ausnahmsweise auch Herden von 200 Stück gesehen worden.

Die Jagd ist so leicht, dass ein deutscher Wurstmacher in Askhabad im Winter 1886/87 hundert Arkalschafe aufkaufen und verarbeiten konnte.

Erwägt man ferner, dass der heutige Wohnbezirk des Steppenschafes räumlich den alten Kulturkreisen des westlichen Asiens nahe kommt, so ist die Annahme kaum gewagt, dass der Bildungsherd der asiatischen Hausschafe im alten Mesopotamien oder doch in nächster Nähe davon zu suchen ist.

Unterstiitzt wird dieselbe durch die früher schon erwähnte Thatsache, dass assyrische Reliefdarstellungen aus dem achten Jahrhundert v. Chr. schon eine hochgezüchtete Fettschwanz-Rasse erkennen lassen.

Von jenem Bildungsherd aus verbreiteten sich zahme Schafe nach 
Osten, drangen aber auch in namhafter Zahl in Südeuropa und Nordafrika ein.

Der afrikanische Bildungsherd. Derselbe ist früher meistens übersehen worden. Ich habe indessen nachgewiesen, dass Afrika eine auffallende Parallele zu Europa zeigt, dass wir auch dort scharf zu unterscheiden haben zwischen alten, offenbar autochthonen Rassen und den später zugewanderten asiatischen Elementen, die nach und nach überwucherten. Als Stammquelle der alten afrikanischen Hausschafe konnte ich mit genügender Sicherheit das Mähnenschaf nachweisen, das älteste Gebiet der Domestikation ist offenbar Oberägypten. In jüngster Zeit hat zwar, wie ich den Verhandlungen der Société d'anthropologie de Lyon (1901) entnehme, $\mathcal{F}$. U. Dïrst das afrikanische Mähnenschaf als Stammquelle abgelehnt und eine asiatische Herkunft befürwortet, indessen sind seine Beweisgründe stark anfechtbar. Meinen Irgumenten hat Thilenims neue und wichtige Thatsachen hinzugefügt.

Die epochemachenden, prähistorischen Funde, welche zu Ende des 19. Jahrhunderts im alten Nilthal bekannt geworden sind und einer vorpharaonischen oder urägyptischen Zeit angehören, vermochten die Verhältnisse aufzuklären. Die Schieferplatte von Gizeh, aus der Negadahzeit stammend, enthält bereits Abbildungen zahmer Mähnenschafe, an denen die Einwirkung menschlicher Kultur bemerkbar wird, da sie zackelhörnig erscheinen, aber noch eine Halsmăhne besitzen. Als Haustier erscheint somit das afrikanische Schaf um 5000-6000 v. Chr. Während der ersten Dynastien ist es ebenfalls zackelhörnig. dagegen schon hängeohrig. I)iese Tratgelaphus-Rasse, wie ich sie nennen will, scheint sich, nach den bildlichen Darstellungen von Beni-Hassan zu urteilen, später in verschiedene Schläge gespalten zu haben, von denen einer ziegenhörnig erscheint.

Vom Beginn des neuen Reiches an geht das Tragelaphus-Schaf zurück, da asiatische Rassen einwandern.

Räuberische Stämme haben offenbar schon während des alten Reiches den . legyptern häutig Kleinvith wegsenommen und es nach anderen Regionen verbreitet, wo es bei dem konservativen Charakter der Steppenvölker sich noch behaupten konnte, nachdem es im Nilthal längst durch anderes Material verdrängt war.

Ich habe darauf hingewiesen, dass das langschwänzige Dinkaschaf am oberen Nil, über welches namentlich $G$. Schweinfurth nähere Angaben gemacht hat, am Vorderkörper eine Mähne besitzt. Diese Mähne hat sich sicher nicht als Schutzmittel gegen klimatische Einflüsse ausgebildet, dazu lag ja in jener tropischen Region gar keine Veranlassung vor, wie das ebenfalls in jenem Gebiet heimische Fettsteissschaf beweist, das keine Wolle besitzt und kurzhaarig geblieben ist. Die Mähne kann daher nur als ein Erbstück des afrikanischen Mähnenschafes gedeutet werden.

Das Dinkaschaf weicht vom Fettsteissschaf erheblich ab, es ist klein und kurzbeinig. Der Kopf erscheint, wie mir Dr. $\mathscr{f}$. David, der unlängst 
von einer Reise nach dem weissen Nil zurückgekehrt ist, mitzuteilen die Güte hatte, autfallend ziegenartig, auch Schweinfurth stellt ihn spitz

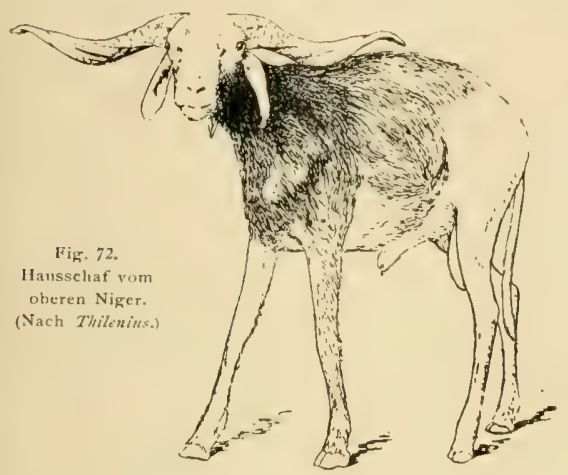
und stark in die Länge gezogen dar.

Der Hornverlauf erinnert an die später zu erörternden ziegenähnlichen Schafe, die auf mykenischen Figuren dargestellt werden. Im Süden von Tripolis haben sich ebenfalls alte Reste erhalten, denn das Fezzanschaf besitzt einen förmlichen Kuhschwanz mit deutlicher Quaste, ähulich wie beim wilden Mähnenschaf.

In neuester Zeit ist auch G. Thilenizs bei seinen Studien über das ägyptische Hausschaf zu dem überraschenden Ergebnis gelangt, dass die alte Tragelaphus-Rasse mit horizontal abstehenden Zackelhörnern, wie sie von den antiken Künstlern des Pharaonenlandes abgebildet wurde, noch heute in vollkommener Reinheit fortlebt. Es ist das Hausschaf am oberen Niger, von dem das Museum für Naturgeschichte in Berlin ein Exemplar besitzt und von welchem Thilenius eine Abbildung giebt. ${ }^{1}$ )

\section{DIE ABSTAMMUNG DES TORFSCHAFES UND BUENDNERSCHAFES.}

Eine durchaus eigenartige Stellung nimmt das alte Torfschaf (Ovis aries palustris Rïtimeyer) ein, das am frühesten d. h. schon zu Beginn der Pahlbauperiode auf mitteleuropäischem Boden erscheint und hier anfinglich die einzigre Rasse bildet. (Geringe ( Brösse, feine schlanke Extremitäten und aufrecht stehende, ziegenälnuliche Hörnchen lassen es von den heute allgemeiner verbreiteten Schafrassen als verschichen bezeichnen. ${ }^{2}$ ) Die Augenhöhlen treten verhältnismässig wenig vor. An einem ziemlich vollständigen Schadel aus der jüngeren Steinzeit, der in Font grefunden wurde, hat (r. G/ur ${ }^{3}$ ) noch weitere anatomische Eigentümlichkeiten feststellen können, so das Vorhandensein einer Thränengrube, eine flache Stirn, die als schmal zu be-

1) G. Thilenius. Das ägyptische Hausschaf in "Recueil de Travaux relatifs à la Philologie et à l'Archaeologie égyptiennes et assyriennes. Vol. XXII. Paris. 1900.

2) L. Rütimeyer. Die Fauna der Pfahlbauten in der Schweiz. 1862.

3) G. Glur. Beiträge zur Fauna der schweizerischen Pfahlbauten. Inaugural-Dissertation. Bern. 1894. 
zeichnen ist und ein verhälnnismässig langes, schmales Gesicht, das dem Torfschaf eine hirschartige Physiognomic verlieh.

L. Rütimeyer lnat 1862 die überraschende Thatsache bekannt gemacht, dass das Torfschat noch nicht völlig erloschen ist, sondern als lebendes Relikt aus der Pfahlbauzeit sich noch in einer eigentümlichen, ziegenähnlichen Schafrasse des bündnerischen Oberlandes erhalten hat, wo bekanntlich auch noch Nachkommen des Torfschweines leben.

Der Kopf der Bündnerschafe ist auffallend gestreckt, vorn spitz zulaufend, in Profil gerade oder zwischen Stirn und Nase etwas eingesenkt, nicht aber wie bei den meisten übrigen. Schafen ramsuasig.

Die osteologische Uebereinstimmung des Schädels, von dem die „Fauna der I'tahlhatuter" eine gute Abbildung enthält, ist eine so grosse, dass Ruiti mejer das Ober.

länderschaf als eisen nur wenig veränderten Abkömmling des Tort. schafeserklärt: die wichtigsten, wohl durch Domestikationsveränderungen zu erklärenden Ab. weichungen bestehen in einer ziem-

lich deutlichen

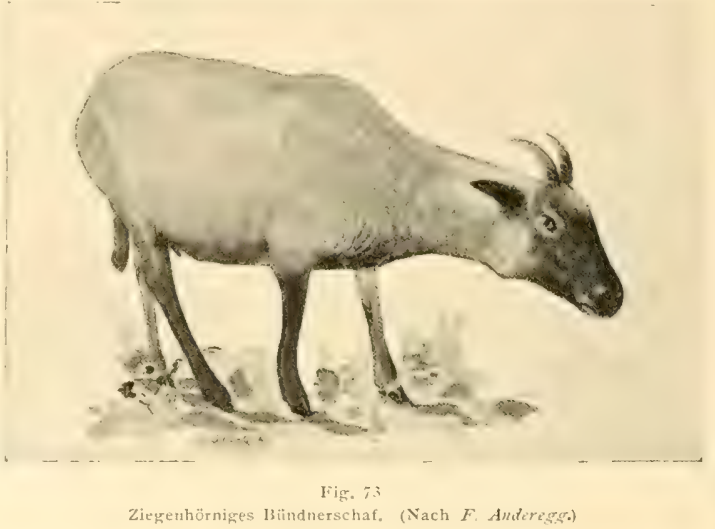
Wölbung der Stirn und einem weniger steilen Abfall des Hiuterhauptes. Die knöchernen Hornzapfen sind beim Bündnerschaf ebenfalls im Querschnitt linsenförmig mit ast ebener Innenseite und konvexer Aussenseite. Bei weiblichen Tieren ist das Gehörn gegenwärtig klein, scharf zweikantig und ziegenartig verlaufend; ich vermute, dass auch völlige Hornlosigkeit gelegentlich auftritt. Früher scheint das Gehörn grösser gewesen zu sein. Immerhin besitze ich den Schädel eines Widders aus Disentis, der noch ein recht ansehnliches Gehörn aufweist, das erst in der Flucht der Stirn verläuft, daun abwärts gebogen ist und sich langsam nach aussen wendet.

Die Ohren sind abstehend, relativ klein, aber sehr beweglich.

Den erganzenden Mitteilungen von $F$. Anderegg-1) entnehme icl, dass das Wollkleid dicht, aber wenig lang ist, so dass der Wollertrag ungünstig ausfällt. Die vorherrschende Färbung desselben ist silberweiss, eisengrau,

1) Felix Anderegg. Illustriertes Lehrbuch für die gesamte schweizerische Alpwirtschaft. Bern. 1898. 
dunkelbraun bis ganz schwarz. Dunkle Exemplare haben häufig einen weissen Kopfstern und weisse Abzeichen an Schwanz und Füssen. Das durchschnittliche Lebendgewicht beträgt 28 Kilogramm.

Den geistigen Charakter der Tiere finde ich der Ziege angenähert. Lebhaftigkeit in den Bewegungen, die \%utratulichkeit und natürliche Intelligenz. übertrifft andere Schafrassen.

Augenscheinlich ist diese tiergeschichtlich so interessante Rasse in starkem Rückgang begriffen, ja dem Verschwinden sehr nahe, da sie gekreuzt wird oder fremcte Rassen an ihre Stelle treten. Während Rü̈limejer noch Herden aus den Nalpseralpen erwähnt, hatte ich im Sommer 1900 Mühe,

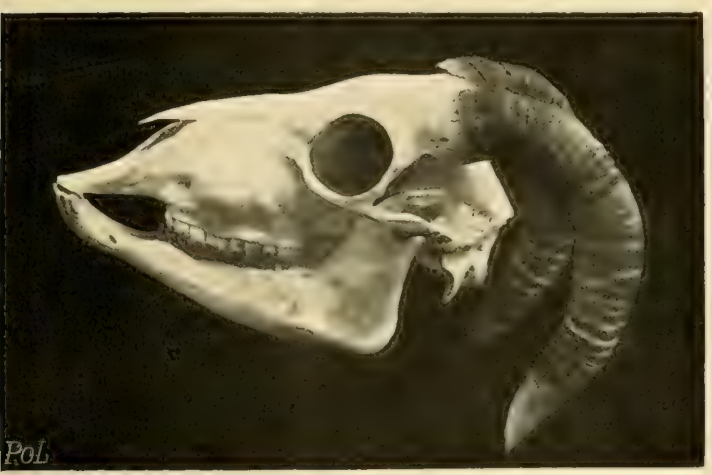

Fig if

Schädel des 13tindnerschafes aus Disentis. Original, (Landw. Sammlung Zürich.)

in Disentis noch ein gutes Exemplar reiner Rasse aufzutreiben. Am meisten soll sie zur \%eit noch in den V'rineralpen angetroffen wer(den. ${ }^{1}$ ) Es wird in der Litteratur mehrfach angegeben, dass einzelne primitive SchafrassenEnglands mit dem T'orfschaf zusammenhangen, was

keineswegs überraschend erscheint. Es wäre möglich, dass auch in den albanesischen Bergen noch lebende Reste des alten Torfschafes aufgefunden werden.

Ist die Abstammung der Schafe an und für sich nicht leicht aufzuklären gewesen, so blieb uns die Stammesgeschichte des Bünderschafes und Torfschafes rätselhaft. In der neueren geologischen Zeit haben wir nicht hinreichend zuverlässige Spuren, dass ein zugehöriges Wildschaf in Mitteleuropa vorkam. Bedenken wir, dass die palaeolitische Zeit keine Haustiere besass, sondern diese erst in der neolitischen Zeit erscheinen. so werden wir an eine Einwanderung von Aussen her zu denken haben.

1) Die Rasse geht auch dort dem Untergang entgegen. Nach den Mitteilungen des bündnerischen Alpinspektors, Herrı Solèr in Vrin, wird im Lugnezerthal gegenwärtig stark mit Walliser Schafen gekreuzt; nur wenige Ställe weisen reines Blut auf. Ich habe noch eine kleine Kolonie reinrassiger Tiere beztehen können, die gegenwärtig im Tierpark des Sihlwaldes bei Zürich angesiedelt sind. Eine zweite Kolonie dieser letzten Mohikaner hat man in Flims untergebracht, un auch in Bïnden noch eine Zuchtfamilie zu erhalten. 
Rütimejer deutet, aber nur als eine noch näher zu prüfende Vermutung, zwei mögliche Wege an. Es liesse sich denken, das Ovis primaeva, von welcher Spezies Knochenreste vereinzelt in den Höhlen Südeuropas angetroffen wurden, die Ausgangsform bildet. Ich stehe jedoch dieser Art skeptisch gegenüber, denn es handelt sich bei diesen Funden doch wohl nur um Moutlonreste. Anderseits wird auf das cyprische Wildschaf (Ovis ophion) hingewiesen. Ich möchte aber auch diese Stammquelle ablehnen, denn diese Lokalform der Mouflons konnte nur kurzschwänzige Rassen liefern, wihlend die ziegenhërnigen Bündnerschafe entschieden langschwänzig sind, wie ihre historischen Vorläufer, die Torfschafe.

Anatomische Momente schienen mir eine andere Lösung vorzuzeichnen. Es liegt nahe, an die Halbschafe (Pseudoves) als Stammquelle zu denken, da ja diese eine eigenartige Mittelstellung zwischen den echten Schafen und den Ziegen eimnehmen. Von ihren lebenden Vertretern kennen wir Ovis Nahoor als asiatische Art im Quellgebiet des Ganges. Es liegen aber keinerlei Anhaltspunkte vor, dass dieselbe je in den Hausstand des Menschen übergetreten ist.

Eine zweite, afrikanische Art, das Mähnenschaf (Ovis tragelaphus s. Ammotragus tragelaphus) liegt uns räumlich näher. Es wurde, wie wir den Berichten von Columella entnehmen müssen, im Altertum erfolgreich mit spanischen Hausschafen gekreuzt. Ich habe zudem den Nachweis geleistet, dass das altägyptische Hausschaf, das zuerst im Nilthal erscheint, von dem heute noch wildlebenden Mähnenschaf Afrikas abstammt.

Es gilt also, den Spuren des Bündnerschafes rückwärts bis nach Afrika nachzugehen. Den Zusammenhang mit dem Torfschaf hatte schon Rätime'ver betont. Sein Material war noch dürftig, namentlich fehlte der Nachweis in der Periode zwischen der Pfahlbauzeit und der Gegenwart. Seither ist dieser Beweis erbracht, in dem aus der römischen Periode Helvetiens Reste des Torfschafes in Vindonissa auftauchten. ${ }^{1}$ ) Von der Pfahlbauzeit an sind jedoch die weiter zurückführenden Fäden abgerissen. In Analogie mit der Herkunft so vieler Kulturerzeugnisse, die in vorgeschichtlicher Zeit ihren IVeg zu uns fanden, ist es naheliegend, nach Südosteuropa auszuschauen. Leider fehlen uns trotz der vielen archaeologischen Ausgrabungen Knochenfunde, die entscheidend sind.

Ich habe versucht, an der Hand antiker Tierdarstellungen Aufschlüsse zu gewinnen.

Bei der Durchmusterung mykenischer Kunstgegenstände stiess ich auf Darstellungen einer ganz eigenartigen Schafrasse, die mich in vielen Punkten an den Widder der Nalpseralpen. im Bündneroberland erinnerten. Auf einer mykenischen Elfenbeinschnitzerei, die dem Kuppelgrab von Menidi²) entstammt und $18,-1)$ in . Ittikatufgetunden wurde, sind zahme ichafe dargestellt.

3) Hermann hrämer. Die Haustierfunde von V'indonissa. Revue suisse de zoologie. 1899.

3) Perrot et Chifficz. Histoire de l'Art. La Grèce primitive. 
deren Kopf lang erscheint und meistens nicht geramst ist. Augenscheinlich hat man es mit einer langschwänzigen Rasse zu thun, deren Gehörn auf keinem einzigen Bilde spiralig aufgewunden ist, sondern mehr ziegenartig und zweikantig erscheint, offenbar auch stark entwickelt war.

Man kamn den Einwand erheben, dass diese Elfenbeinschnitzerei möglicherweise ausserhalb angefertigt, dann nach Griechenland eingeführt wurde. Aber an einer ganz anderen Lokalität sind Schafbilder mit ziegenartigen, abwärts gebogenen Hörnern ebenfalls zum Vorschein gekommen. Auf einem Amethyst, der von Vaphio stammt, finden sich vier Köpfe davon abgebildet, so dass die Annahme wohl berechtigt ist, dass im mykenischen

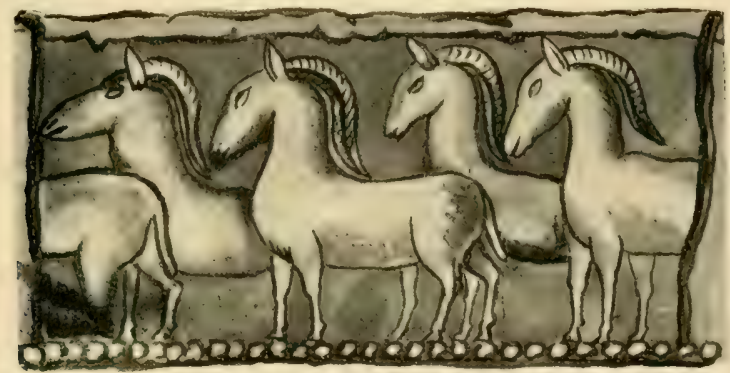

Fig. 75 .

Mykenische Schafe auf einer Flfenheinschnitzerei von Menidi. (Nach Perrot et Chiffiez.)

Kulturkreis ein dem 'Torfschaf sehr ähnliches Hausschaf vorkam. Daneben war aber auch eine andere Rasse mit merinoähnlichem Gehörn bekannt. wie ein geschnitzter Achat aus Vaphio beweist.

Es ist indessen unwahrscheinlich, dass ziegenhörnige Torfschafe auf südeuropäischem Boden entstanden, dat dort ein passendes Wildmaterial tehlte.

Die griechische Inselwelt mit ihrer beweglichen Bevölkerung vermittelte den Kulturbesitz des Orients zwischen dem europäischen Festlande und Aegypten, sowie Kleinasien. Nach den neuesten Ermittelungen sind die Beziehungen zu Aegypten weit älter als man bisher annahm, sie waren schon zu Beginn des alten Reiches vorhanden.

Es wurde früher schon betont, dass anfänglich im Nilthal eine einzige Rasse zahmer Schafe vorkam - ich habe sie Tragelaphus-Rasse genannt und vom Mähnenschaf abgeleitet.

Durchgehen wir jedoch die ãgyptischen Denkmäler ${ }^{-1}$ von der IV. bis zur XII. Dynastie, so werden die Schafe in verschiedenen Zuchtformen abgebildet, die offenbar neben einander vorkamen. Bei einer Form, die

1) Lepsius. Denkmäler aus Aegypten und Aethiopien. 
in Gizeh erscheint, ist das Gehörn zackelförmig. In Beni Hassan sind hängeohrige und zackethörnige neben ziegenhörnigen Schafen abgebildet, daneben aber auch ein Schaf mit kleinem, aufrecht stehendem Ohr. An Schafen, die mit dem mrkenischen Schaf übereinstimmen, fehlt es somit in Altägypten nicht. Freilich vermögen wir aus diesen Abbildungen nicht zu entnehmen, ob das Gehörn auch scharfkantig war. Der Nachweis lässt sich jedoch auf Umwegen erbringen, indem ja das Schaf des alten Reiches heute noch am oberen Niger vorkommt. Nach der Angabe von Thilenius ${ }^{1}$ ) ist es hier in der That scharfkantig.

In der urägyptischen Zeit vor den ältesten $\mathrm{D}_{\mathrm{Y}}$ nastien besass das Nilthal. wie ich früher an der Hand der Schieferplatte von Gizeh nachwies, ein Hausschaf. das seiner Herkunft nach direkt auf das Mähnenschaf zurückweist.

Die Bildereien der antiken Kunst weisen somit auf die \%wischen-Etappen hin, die auf dem $\mathrm{Weg}$ vom Nilthal bis zu den Pfahlbauern zurückgelegt wurden; wir hätteu nunmehr als die beiden Endglieder Mykenische Schafe auf einem Amethyst von Vaphis. Vergrössert. der Entwicklungsreihe an-

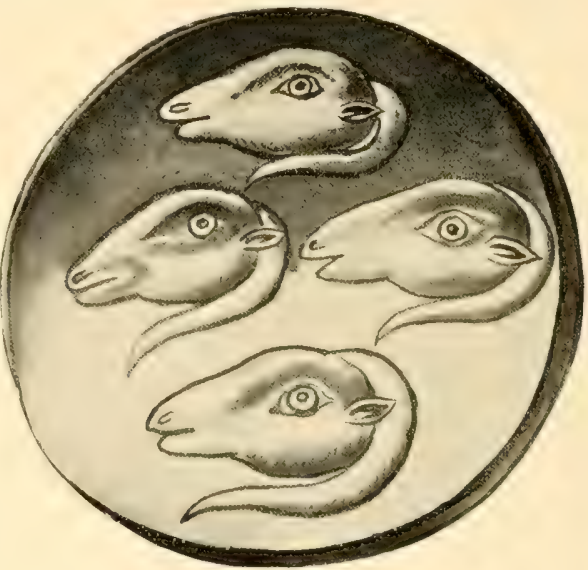

[ijir. 5 is

zusehen das Bündnerschaf einerseits und das wilde Mähnenschaf Afrikas anderseits.

In anatomischer Beziehung verglichen, ergiebt sich folgendes:

1. Die allgemeine Konfiguration des Schädels beim Bündnerschaf steht wegen seines ziegenartigen Charakters dem Mähnenschaf viel näher als irgend einem echten Wildschaf.

2. Bei beiden ist der Occipitalteil des Schädels auffallend lang gestreckt: beim Mähnenschaf jedoch steiler abfallend als beim Bündnerschaf.

3. Die Linea semicircularis des Ilinterhauptbeines ist bei beiden auffallend schwach hervortretend, während sie bei den übrigen Wildschafen (Mouflon, Arkal) und zahmen Rassen (Zackelschaf, Haidschnucke, Sardisches Schaf) weit kräftiger vortritt.

4. Die Orbitalränder treten beim Mähnenschaf und beim Nalpserschaf weniger stark hervor als bei den übrigen Schafen. Der obere Orbital-

1) (i. Thilenius. Das ägyptische Hausschaf. Paris. 1900. 
rand besitzt eine bis zu den Thränenbeinen reichende Einkerbung von auffallender Länge und rechteckiger Gestalt. Auch Rütimeyer hat diese eigenartige Einkerbung, die ich nur beim Mähnenschaf finde, beim Bündnerschaf deutlich gezeichnet.

5. Die Stimbeine sind beim Mähnenschaf flach, beim Nalpser gewölbt, was entweder Folge der Domestikation oder der Kreuzung sein kann.

6. Die Stirnzapfen zeigen bei beiden im Verlauf und in der Form eine auffallende Uebereinstimmung. Anfänglich in der Profilebene der Stirn verlaufend, wenden sie sich erst nach hinten und aussen, dann in weitem Bogen nach unten. Beim weiblichen Mähnenschaf, das mir zur Untersuchung vorlag, sind die Stirnzapfen wie beim Nalpser auf dem Querschnitt linsenförmig mit konvexer Aussenseite und fast ebener Innenseite. Beim Wildschaf sind sie natürlich grösser und waren auch beim Torfschaf der P'fahlbauer und der Römerzeit noch umfangreicher als beim Bündnerschaf.

Das Gehörn des Mähnenschafes ist im Grunde genommen zweikantig, indem die obere Kante bis zur Basis verläuft, wenigstens im weiblichen Geschlecht. Weniger deutlich ist diese beim Männchen: aber auch beim Nalpser Widder finde ich, dass die obere Kante sich gegen die Basis verliert.

7. Die Thränengrube fehlt dem Mähnenschaf gänzlich, während beim Bündnerschaf eine deutliche, wemn auch seichte Thränengrube vorkommt.

S. Die Nasenbeine sind in ihrem Verlauf gerade.

9. Die Zwischenkiefer erscheinen nach vorn allmählig verschmälert.

10. Das Mähnenschaf ist das langschwänzigste Wildschaf. Auch das Bündnerschat ist langschwänzig; an seinem Skelett zähle ich 17 Schwanzwirbel.

Daraus ergiebt sich ein so hoher Betrag gemeinsamer anatomischer Merkmale, dass die Ableitung des Torfschafes und Bündnerschafes von dem wilden Halbschaf Afrikas als ganz natürlich erscheinen muss.

Man kann zunächst allerdings einwenden, dass die Grössendifferenz erheblich ist. Das Mähnenschaf (1,55 Meter lang), ist ein ziemlich stattliches 'Tier, während das Oberländerschäfchen nach $F$. Anderegg nur eine Durchschnittsläinge von 84 Centimeter erreicht. Wir dürfen aber annehmen, dass die Auslese die kleinen Tiere begünstigte, weil sie für die Wanderung geeigneter waren. Andere Schafrassen zeigen ja auch starke Grössenunterschiede, asiatische und afrikanische Rinder weisen neben Riesenformen auch eigentliche Zwergformen auf.

Die wichtigste Differenz im Schädelbau betrifft eigentlich nur die Thränengrube, die dem Mähnenschaf durchaus fehlt.

Ich halte es für ausgeschlossen, dass sich diese während der Domestikation spontan entwickelt und nachher vererbt hat; ich muss als einzige 
mögliche Erklärung ihres Auftretens eine Kreuzung annehmen. Auf der Wanderung nach Europa war eine solche fast unvermeidlich, möglicherweise wurde etwas asiatisches Blut aufgenommen. Diese Deutung liegt um so näher, da ja beim Schwein analoge Thatsachen vorliegen und die Kreuzung des europäischen Landschweines mit asiatischem Blut sofort eine V eränderung des Thränenbeines hervorruft.

Ich halte also das Torfschaf, wie auch das ziegenhörnige mykenische Schaf für ein Kreuzungsprodukt, das aber der Hauptsache nach afrikanisches Blut besitzt und in dem sich die Durchschlagskraft des letzteren bei der Vererbung immer wirksamer hielt.

Den Gang der Dinge hat man sich so zu denken, dass im oberen Aegypten, als dort die Steinzeit zu Ende ging, das Mähnenschaf, das sich bekanntlich unschwer zähmen lässt, in den Hausstand überging und sich bis nach Unterägypten verbreitete. Die alte Inselkultur des griechischen Archipels hat es von dort her nach Europa gebracht. Es kann aber auch den Umweg über Syrien und Kleinasien genommen haben. Während der ersten Dynastien besassen die Aegypter bekanntlich Bergwerke am Sinai, die durch Truppen gegen die räuberischen Beduinen im Nordosten des Deltas geschützt werden mussten. ${ }^{1}$ ) Diese stahlen den Truppen, sowie den Iirten Aegyptens Rinder und Kleinvieh, woraus wohl das Vorkommen altägyptischer Schafe im inneren Arabien zu erklären ist.

Die Verbreitung derselben nach Westasien war also möglich. Ob die Wanderung nach Europa direkt oder auf dem Umwege über Kleinasien erfolgte, ist für unsere Frage völlig gleichgültig.

Die Wanderung des mykenischen Schafes, aus Aegypten stammend und wohl etwas gekreuzt, konnte damn nach den Pfahldörfern Mitteleuropas erfolgen. Sie erscheint um so verständlicher, als ich ja für die zahmen Primigenius-Rinder ebenfalls die Herkunft aus dem mykenischen Kulturkreis nachgewiesen habe.

\section{KLASSIFIKATION UND GEOGRAPHISCHE VERBREITUNG DER HEUTIGEN SCHAFRASSEN.}

Die menschliche Kunst hat aus dem früher genannten Wildmaterial eine erstaunliche Zahl von Kultur-Rassen herangezüchtet, die den verschiedenartigsten wirtschaftlichen Ansprüchen gerecht werden. Die wichtigste Umbildung besteht in einer völligen Veränderung des Haarkleides, die zur Gewinnung eines dauernden Wollvliesses führte; dazu kommen tiefgreifende Umgestaltungen des Gehörns und monströse Entwicklung des Schwanzes. Eine natürliche Klassifikation der Rassen auf Grund genetischer Verhältnisse fehlte uns bisher. Ich habe versucht, die Grundlinien eines solchen zu entwerfen. Das gegenseitige Verhältnis der Rassen wechselte

1) Adolf Erman. Aegypten und ägyptisches Leben im Altertum. 11. Bd. 
im Laufe der ( feschichte auf den verschiedenen Kulturgebieten. Wir sehen wie neue Rassen zuwandern oder Kreuzungen den ursprünglichen Charakter verwischen. Absterbende Rassen scheiden aus der Umgebung des Menschen; zuweilen vermögen sich vereinzelte Ueberreste bis in die Gegenwart fortzuerhalten. Wir berücksichtigen hier aus leicht verstandlichen Gründen vorzugsweise die heutige Verteilung in der alten Welt.

a) Die Monflon-Kassen. Sie scheinen stets auf Europa beschränkt gewesen zu sein und sind Abkömmlinge des südeuropäischen Mouflon (Ovis musimon). Ihre heutige Verbreitung erstreckt sich ïber die Niederungen und Bergländer des nördlichen Europa. Sie umfassen gehörnte oder hornlose Formen, die man als natürliche Gruppe der kurzschwänzigen Schafe (Ovis aries brachyura) zusammen gefasst hat. Den bisherigen Funden nach zu urteilen, sind diese Schafe bereits in vorgeschichtlicher Zeit im Norden der Alpen aufgetaucht. Schon in der späteren Steinzeit treten vereinzelte Spuren eines grossgehörnten sichates auf, zahlreicher jedoch erst im Gefolge der römischen Kolonisten. Die Hornzapfen stimmen in ihrem Bau mit dem Mouflon überein, indem sie in ihrem Innern entweder einen einzigen grossen Hohlraum oder mehrere grosszellige Räume enthalten. Daher weisen Th. Studer ${ }^{1}$ ) und H. Krämer ${ }^{2}$ ) jene Reste mit Recht der Mouflongruppe zu. Da die heutigen nordeuropäischen Rassen ein kleines Gehörn besitzen, müssen wir eine starke Abnahme desselben seit der Römerzeit annehmen, wie diese überhaupt mehr als Kümmerformen erscheinen.

Ganz unvermittelt erscheint mit der Bronzezeit ein hornloses Schaf. was auf eine Einwanderung von Süden her schliessen lässt. In der helvetischrömischen Niederlassung von Vindonissa fanden sich beide Rassen nebeneinander vor.

Wie $T h$. Studer auf osteologischem Wege nachgewiesen hat, ist das Bronzeschaf dem norddeutschen Marsch-Schat sehr nahe verwandt.

Als Ausgangsform des heute stark in den Hintergrund gedrängten europäischen Stammes mit Moutlonblut möchte ich die norddeutschen IIaidschmicken ansehen.

In ihnen tritt uns gleichsam eine im Dienst des Menschen entstandene Wwergform des Moutlon entgegen. Diese gehörnte Rasse wird in der Lüneburger- und Bremer-Haide, sow ie in Oidenburg und ()stfriesland gehalten: ihrer Genügsamkeit und Ausdauer wegen wird sie für die Anwohner jener Moor- und Sandflächen wertvoll.

Nahe verwandte, ebenfalls gehörnte Formen bewohnen die Bergländer von Skandinavien. Stammverwandt ist ferner das nordrussische und finnische Schaf, sowie das Hebridenschaf, das Farörschaf und das Shetlandschaf. Der westliche Ausläufer ist das isländische Schaf, dessen Herden ein elendes Dasein fristen.

1) Th. Studer. Mitteilungen der Naturf. Gesellschaft Bern. 1883.

2) H. Krämer. Die Haustierfunde von Vindonissa. 1899. 
Die zweite Gruppe, welche von dem alten Bronzeschaf ihren Ausgangspunkt nimmt, umfasst kurzschwänzige, hornlose Schate, welche die vorigen an Grösse übertreffen. Sie werden mehr des Fleisches als der Wolle wegen gehalten und kommen hauptsächlich in der norddeutschen Tiefebene, in Holland und Belgien vor. Zu diesen sogenannten MarschSchafen gehören die friesischen, holländischen, belgischen Schafe, sowie einige nordfranzösische, kurzschwänzige Formen. Ihnen wird auch das Roqucfortschaf beigezählt, das den weltberülmmten Schatkäse liefert.

b) Die Arkal-Rassen. Sie sind asiatischen Ursprungs und lassen sich alle auf das transkaspische Steppenschaf (Ovis arkal) zurückführen. Ursprünglich waren wohl alle zahmen Formen langschwänzig. Die Schwanzlänge übertrifft immerhin diejenige der Wildform, so dass wir annehmen müssen, dass unter dem Einfluss der künstlichen Züchtung eine Steigerung der Länge erfolgte. Indessen ist bei einer anderen Formenreihe das Gegenteil eingetreten, d. h. der Schwanz rudimentär geworden (Fettsteiss-Schafe). Das (jehörn ist bei einzelnen Rassen wohl ausgebildet, dann in der Regel durch kräftige Wülste ausgezeichnet; bei anderen ist es schwächer, auch völlig hornlose Rassen sind vorhanden.

Die hieher gehörenden Hausschafe haben sich über ganz Asien bis zum aussersten Osten ausgedehnt, sind aber auch schon sehr früh in Afrika und Europa eingedrungen. In Südeuropa haben sie die altangesessenen Rassen ganz verdrängt, aber auch in Mitteleuropa sich ausgebreitet. In Asien sind die Hausschafe durch die /ucht stark verändert worden, während die primitiveren Formen sich offenbar in Südeuropa, also in erheblicher Entfernung vom Stammlande, da und dort in starken Kolonien zu erhalten vermochten.

Betrachtet man zunächst den Arkalbestand in Europa, so uns tritt da als wichtigster Stamm die Reihe der Edelschafe entgegen. Als Ausgangsform, die dem Arkal noch nahe steht, betrachte ich das Sardenschaf, welches sich auf der Insel Sardinien in einer starken Kolonie erhalten hat und augenscheinlich sehr alt ist. In der Litteratur ist es sehr ungenügend charakterisiert, da es bald als gehörnt, bald als hornlos bezeichnet wird.

Nach dem mir vorliegenden Material besitzt dieses alte Landschaf ein starkes, wenig ausgezogenes Gehörn von heller Farbe und starken Wülsten; dasselbe beschreibt eine einzige weite Spiralwindung. Mit dem Moutlon vermischt sich das Sardenschaf nicht, auch wenn jenes in der Nähe weidet. Nahe verwandte Schläge dürften in Südeuropa sich vereinzelt erhalten haben.

Als höchstentwickeites Endglied der Reihe muss das Merinoschaf') (Ovis aries hispanica) angeschen werden. Der Weg, den dieses Schaf auf

$\left.{ }^{2}\right){ }_{n}$ Merino ${ }^{4}$ ist ein spanischer Name und bedeutet einen mit grossen Machtbefugnissen ausgestatteten Weiderichter, der allerlei Anstände zu schlichten hatte, wenn die Hirten mit ihren Wanderschafen das Land durchzogen. Ein Merino war gleichsam Schirmlerr der Herden und man übertrug später seinen Namen auf die Wanclerschafe. 
seiner Wanderung eingeschlagen hat, lässt sich ziemlich klar verfolgen. Aus Vorderasien erhalten wir die iltesten Nachrichten über Schafe mit feiner, gekräuselter Wolle. Die Beschaffenheit des Gehörns, das schon auf kleinasiatischen Münzen der ältesten historischen Zeit vortrefflich dargestellt wird, weist deutlich auf die Arkal-Abstammung hin. In Galatien und Phrygien nahm die Schafzucht einen starken Aufschwung, Milet wetteiferte mit Tyrus in der Wollfabrikation. IJeute ist das feine Wollschaf in Vorderasien bis auf wenige Reste am Ostufer des Schwarzen Meeres verschwunden. Griechenland hat es frühzeitig übernommen; griechische Kolonisten verbreiteten es nach Süditalien und Gallien, von wo aus es nach Spanien gelangte. Die iberische Halbiusel übertlïgelte schon zur Zeit von Columella alle Mittelmeerländer in der Schafzucht und frühzeitig wurde Corduba (Cordova) wegen seiner feinen Wolle berühmt. Als die Araber in Spanien erschienen, veredelten sie die Herden, später nahmen sich die Grossgrundbesitzer und klösterlichen Verwaltungen des blühenden Wirtschaftszweiges an. Ende des 18. Jahrhunderts breiteten sich die spanischen Merinos nach verschiedenen europäischen und aussereuropäischen Ländern aus, wobei das Produkt Spaniens zum Teil überholt wurde und berühmte Zuchten entstanden (Rambouillets, Electorals, Negrettis).

Grossartig hat sich die Merinozucht in überseeischen Ländern entwickelt, so im Kapland, in Australien, in Argentinien, Uruguay, Nordamerika, in Neuseeland und auf den Sandwichsinseln.

Einn zweite Reihe langschwänziger Schafe mit Arkalcharakter hat ilıren Ausgangspunkt in Südosteuropa und wird dort durch die Zackelschafe (Ovis aries strepsiceros) vertreten. Das Gehörn ist in beiden Geschlechtern vorhanden, bald merinoartig gewunden, bald in langgezogener Spirale abstehend. An gewissen Formen, die ich untersucht habe, treten Abweichungen auf, die eine Einwirkung altägyptischer Schafe nahelegen.

Die Zackelschafe sind heute über den griechischen Archipel, die Balkanländer, im Donaugebiet bis nach Ungarn verbreitet (kretische, macedonische, ungarische Schläge). Abkömmlinge des osteuropäischen Zackelschafes leben in steppenartigen Strichen Westeuropas, so das bajrische Zaupelschaf, das in der Neuzeit jedoch im Niedergang begriffen ist, dann das pommersche und hannoversche Landschaf; als westlichsten Ausläufer ist das englische Norfolkschaf zu bezeichnen, das früher wegen seiner Genügsamkeit eine grosse Verbreitung besass.

Als eine hieher gehörige Form, die augenscheinlich noch recht ursprünglich ist, betrachte ich von schweizerischen Schafen das W'alliserschuf, das in der Bergregion im Oberwallis stark verbreitet ist. Es erinnert an das Norfolkschaf, ist ganz schwarz oder schwarz und weiss gefleckt. Das ziemlich starke Gehörn ist spilalig ausgezogen. Auch hornlose Tiere kommen vor. Ion ihm stammt das hornlose Frattigerschaf des Kanton Bern ab. In diesen Formenkreis gehört auch ein starker Seitenzweig von horn- 
losen, langschwänzigen Schafen hinein. Er tritt uns in dem steirischen Schaf, in paduaner Schaf und Bergamaskerschaf entgegen. Entierntere Ausläufer sind die südfranzüsischen und englischen Bergschafe, dann das Thüringerschaf und das Rhönschaf.

Wenden wir uns nach den asiatischen Gebieten, so tritt uns zunächst die bemerkenswerte Erscheinung entgegen, dass dort die heutige Rassenzusammensetzung ausserordentlich viel einfacher erscheint als in Europa. Dieser Zustand ist sicher ein sekundärer. Die Arkal-Abkömmlinge, wie sie uns in feinen Wollschaf und im primitiven Zackelschaf entgegentreten, haben ihre östliche Heimat aufgegeben und sind nach Westen ausgewandert.

Von allgemeiner Bedeutung werden in Asien eigentlich nur zwei Schafrassen, nämlich das Fettschzanzschaf (Ovis aries platyura) und das Fethsteissschaf (Ovis aries steatopyga).

$\mathrm{Als}$ die ältere Form sehe ich das Fettschwanzschaf an, das in seinen heutigen Zuchtformen eine stattliche Grösse erreicht und das Merinoschaf übertrifft. Es ist ein Abkömmling des Arkal und in der That erscheint es anf den altassyrischen Darstellungen noch sehr arkalähnlich. Das Gehörn ist spiralig gewunden, bei weiblichen Tieren häufig fehlend; auch beim Widder ist es zuweilen kümmerlich entwickelt. Der durchweg lange Schwanz ist durch starke Fettwucherung ausgezeichnet. Pohlig bemerkt, dass beim persischen Schaf der Schwanz nicht selten den vierten Teil des Gesamtgewichtes des Tieres erreicht und dann zur unbequemen Last wird.

Augenscheinlich ist die Rasse sehr alt und wurde offenbar zuerst in Mesopotamien gezüchtet.

Nach Osten hin geht die Rasse nicht erheblich über Persien hinaus.

Von den bisher bekannt gewordenen Schlägen Asiens mag das anatolische und syrische Fettschwanzschaf hervorgehoben werden; der Fettschwanz ist bei diesen sehr lang und in der Höhe des Sprunggelenkes nach oben grekrümmt. Arabien hat sehr früh Fettschwanzschafe besessen, da sie bereits von Herodot und Diodor erwähnt werden. Der bucharische Schlag wird von den Kirgisen und Tartaren gehalten; die edelsten Zuchten scheint Persien zu besitzen, wo prächtige Zuchtwidder mit erstaunlichem Wollreichtum vorkommen.

Nach Westen sind nur vereinzelte Ausläufer bis nach Südeuropa gelangt, dagegen hat Afrika die Rasse in ziemlichem Umfang übernommen. Sie erscheint dort von Aegypten bis nach Abessinien, dann über ganz Nordafrika bis nach Marokko verbreitet: auch Südafrika hat das Fettschwanzschaf eingebürgert. Dem Schwanzende fehlen bei diesen Afrikanern häufig die Fettwucherungen, so namentlich beim algerischen Fettschwanzschaf.

Das Fettsteissschaf (Ovis aries steatopyga) besitzt in seiner asiatischen Heimat meistens ein Gehörn, selbst weibliche Tiere haben halbmondförmige, 
nach hinten gerichtete Iörnchen; sie können indessen auch fehlen. Der Schwanz ist verkümmert, der Steiss entwickelt zivei auffallende, schön gerundete Fettkissen, deren Inhalt mit Vorliebe von moslemitischen Völkern zum Gebrauch gelangt. Was die Abstammung dieser eigentümlichen Rasse. die namentlich die innerasiatischen Steppen erfüllt, anbetriftt, so sind die bisherigen Annahmen von einander abiveichend. Pallas will sie vom Argali ableiten, wogegen Fitzinger Widerspruch erhob. Ү. Bohm ${ }^{1}$ ) stellt sie zu

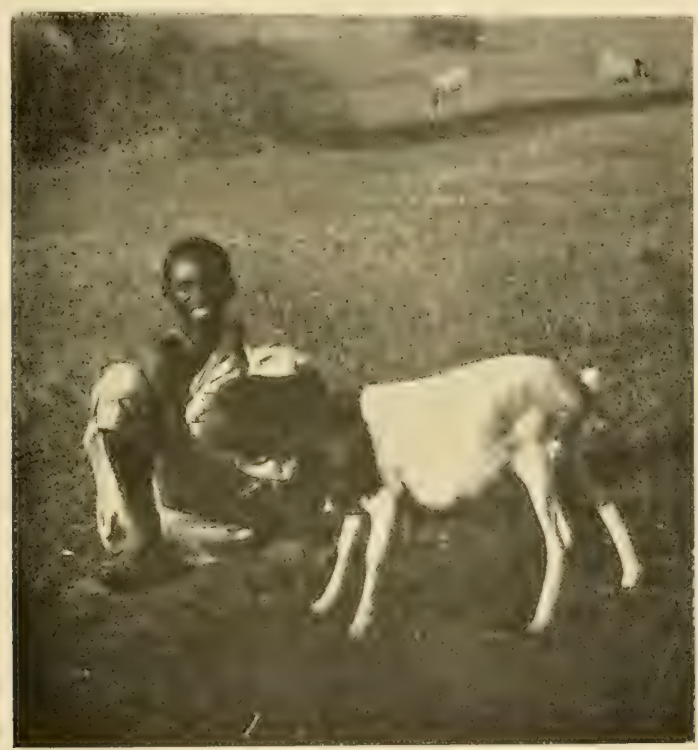

Vig. 77 .

Somali-Schaf. Origrinal.

den kurzschwänzigen Schafen von Nordeuropa, aber gegen eine Stammesverwandtschaft mit denselben lassen sich tiergeographische und anatomische Einwände machen. Leider geben uns assyrische und altpersische Denkmäler keine genügenden Aufschlüsse, Herodot erwähnt, dass die Rasse in Arabien vorkomme.

An einem aus China stammenden Schädel finde ich neben der auffallend schmalen Stirnzone röhrenförmige, stark vortretende Augenhöhlen mit schiefer Stellung, was auf den Arkal als Stammquelle schliessen lässt.

Es scheint mir daher naturgemäss, die Fettsteissschafe als Zuchtformen

1) 7. Bohm. Die Schafzucht. Zwei Bände. Berlin. 1883, 
zu betrachten, die aus Fettschwanzschafen hervorgingen. Die wesentlichste Umbildung besteht in einer Rückbildung der Schwanzwirbel, so dass die Fettlagen in die Steissgegend hinaufrücken mussten. Die Erscheinung ist nicht isoliert, da ja die Hauskatze in Ostasien ebenfalls stummelschwänzig geworden ist. Vielleicht ist das algerische Schaf eine uns erhalten gebliebene Zivischenstufe.

$\mathrm{Zu}$ den Fettsteissen gehört das Tartaren-Schaf, das vom Ostrand des Schwarzen Meeres bis zum Baikalsee reicht und fast das einzige Vermögen der dortigen Steppenvölker ausmacht. Die Widder sind stark gehörnt.

Fettsteisse leben auch in Persien und Arabien. Mehr nach Osten nehmen sie an Menge ab. Birma besitzt sie erst seit 1855 .

Das chinesische Schaf ist hornlos, der Fettsteiss nur wenig entwickelt. Nach Japan vermochte es nicht mehr vorzudringen; man hat zwar in der Neuzeit versucht, dort Schafe einzubürgen, musste aber darauf verzichten, da parasitäre Erkrankungen die Tiere dahinrafften.

Im Westen ist das Fettsteissschaf auf atrikanischem Boden stark verbreitet und dürfte von Arabien herstammen. Die gewöhnliche form ist weiss mit schwarzem Kopf und schwarzem Hals. In den Ländern am oberen Nil wird es in grosser Zahl gehalten; es reicht dort bis zum Gebiet der Dinka, wo es von dem ziegenartigen Dinkaschaf abgelöst wird. In der Gegend von Massaua fand ich neben schwarzköpfigen Schafen auch braungefärbte und gefleckte Tiere; häufig pflegt man ihnen die Ohren bis auf einen kurzen Stumpf abzuschneiden.

In den Somaliländern ist die Schafzucht sehr ausgedehnt und die Häute bilden einen nicht unwichtigen Exportartikel; die Tiere sind hornlos, der herzförmige Fettsteiss ist wenig entwickelt und verschwindet bei Abmagerung fast vollständig. Ausnahmsweise kommen in den Herden ganz schwarze Schafe vor, sowie solche mit schwarzem Steiss und weissem Fell; die Rasse bleibt auffallend klein.

Südafrika besitzt ebenfalls Fettsteissschafe, im ostafrikanischen Archipel sind sie nicht zahlreich. Im Innern von Madagaskar findet man sie bei den Howa, aber in einer etwas degenerierten Rasse, deren Fleisch trocken ist. An den Küsten der grossen Insel scheint sie nicht zu gedeihen.

c) Die afrikanischen Tragelaphus-Rassen. Auf dem Boden Afrikas haben von jeher starke Völkerverschiebungen stattgefunden, die naturgemäss auf die Verbreitung der Haustiere starken Einfluss gewomen haben; dazu kommt, dass im Norden von Afrika und im Nilthal die wirtschaftlichen Zustände eine raschere Entwicklung durchliefen als auf den übrigen Gebieten.

Daher finden wir den autochthonen Stamm der alten afrikanischen Hausschafe an ihrer Ursprungsstätte nicht mehr vor, sondern stark nach Süden und Westen abgedrängt. Es sind sozusagen weit versprengte Reste, deren wirtschaftliche Bedeutung längst im Rückgang begriffen ist. Seltsamerweise leben einzelne Rassentrümmer auch noch auf asiatischem und europäischem Boden, 
Wie früher bemerkt wurde. sind die ältesten Hausschafe Afrikas aus dem ziegenartigen Halbschaf (Ammotragus tragelaphus) hervorgegangen. Das mit langer Halsmähne gezierte zahme Tegadahschaf ist in seiner ursprünglichen Form erloschen, es bildet den Vorläufer zum altägyptischen

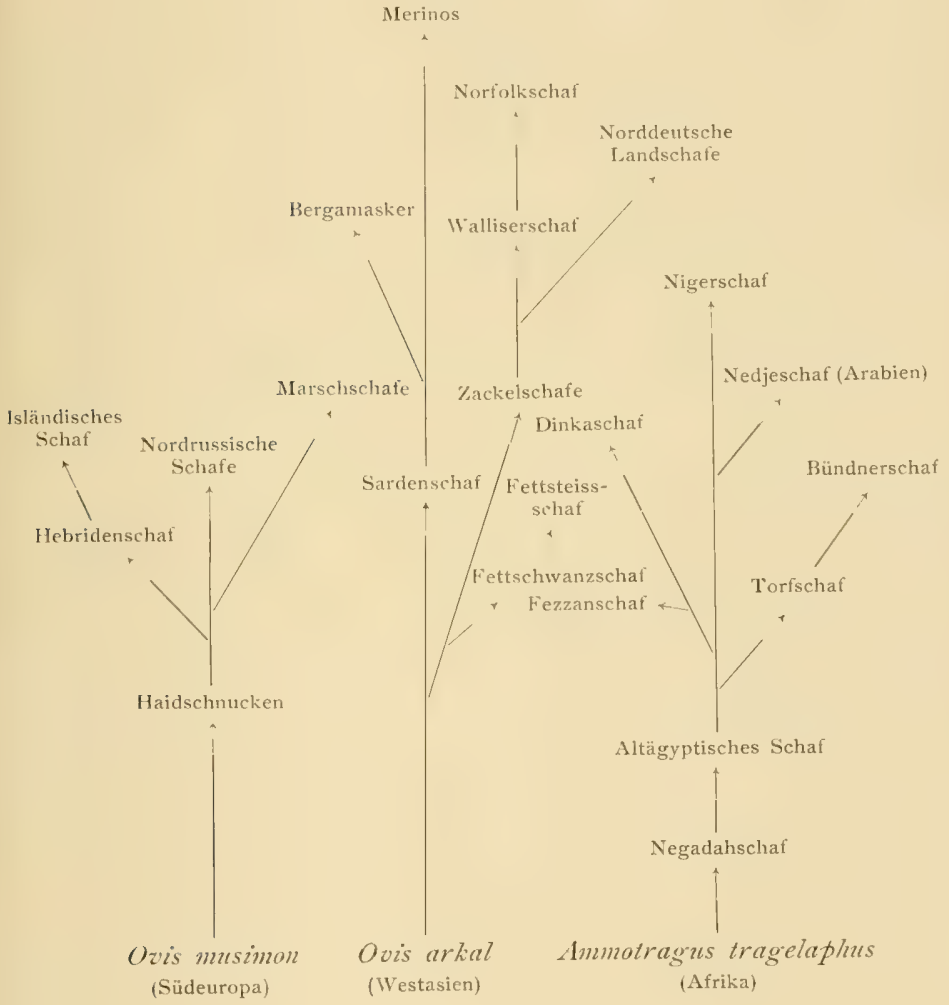

Hausschaf, das zum Teil hängeohrig war und in Schlägen gezüchtet wurde, von denen nur wenig verånderte Nachkommen jetzt noch leben.

Eines jener Rassenfragmente tritt uns beispielsweise am oberen Nil im Dinkaschaf entgegen. Es ist ausgezeichnet durch einen eigentümlichen Haarmantel, welcher mähnenartig an Hals und Vorderbrust herabfällt; der 
übrige Körper ist kurz behaart, ebenso der lange, dürre Schwanz. Das Dinkaschaf ist ziegenartig, indem die kurzen kräftigen Hörnchen sich scharf nach hinten wenden, um eine halbmondförmige Krümmung zu beschreiben. Die Färbung ist rein weiss, auch rotbraun oder weiss und schwarz gefleckt. Schucinfurth fand dieses Schaf bei den Dinka, Nuër und Schilluknegern.

Das Fezzanschaf oder lybische Schaf ist ebenfalls stark bemähnt und vorwiegend weiss grefärbt. Der dürre Schwanz trägrt am Ende eine grosse ( uaste, ahnelt also einem Kuhschivanz.

Am interessantesten ist wohl das Nigerschaf, vou dem unlängst ein Exemplar nach Berlin gelangte. Auch dieses besitzt am Vorderkörper verlängerte Haare; der Kopf ist hängeohrig und besitzt noch ganz den Charakter des altägyptischen Schafes, wie es in den Grabkammern und als hieroglyphisches \%eichen abgebildet wird. Die IIöner sind lang, horizontal abstehend und schraubenartig gewunden.

Dieses hochbeinige Schaf lebt am oberen Niger. Abkömmlinge davon verbreiten sich bis nach Senegambien und nach dem Golf von Guinea.

Meiner Auffassung nach enthalten die Senegalschafe, damn das hängeohrige, hochbeinige Guineuschaf, das Congoschaf und das kropfige Angolaschaf oder Zumi eine gute Dosis Tragelaphusblut, das aber mehr oder weniger stark mit solchem vom Fettschwanzschaf gemischt ist.

Auf asiatischem Boden hat sich die Tragelaphus-Rasse nach Innerarabien ausgebreitet und in den Schafen von Nedje bis heute erhalten.

Der Lebertritt auf europäisches Gebiet hat dem alten Torfschaf den Ursprung gegeben, wie ich nachgewiesen habe. ${ }^{1}$ ) Es hat sich in dem heutigen Bändnerschaf wenig veründert forterhalten, ist aber gegenwärtig am Erlöschen.

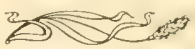

1) C. Feller. Dic Abstanmung des Bündnerschafes und Torfschafes. Vorgetragen in der 11. allg. Sitzung der Schweiz. Naturforscher-Versammlung in Thusis. Chur. 1900. 


\section{I)IL IIAUS\%ILGE: \\ (Capra Hircus.)}

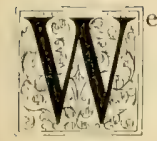

eder unsere europäischen zahmen Ziegen, noch diejenigen unserer Nachbarkontinente sind mit der wünschenswerten Vollständigkeit untersucht; immerhin gestatten die bisher ermittelten Thatsachen die Annahme eines polyphyletischen Ursprungs.

In Europa erscheint die Hausziege schon sehr früh, d. h. mit Beginn der P'fahlbauperiode. Wie Rütimeyer ${ }^{1}$ ) bereits hervorhob und andere seither bestätigt haben, sind die Reste der Ziege in den älteren Pfahlbauten weit häufiger als diejenigen des Schafes; in den jüngeren Pfahlbauten kehrt sich das Verhältnis freilich um. Die Ziege ist eben eine Begleiterscheinung primitiver Kultur; auch auf griechischem Boden wiederholt sich das anfängliche Ueberwiegen der Ziege und noch heute tritt dieses Geschöpf in den primitiven Kulturen Afrikas stark in den Vordergrund.

Bei der grossen Selbständigkeit, die es im Hausstande bewahrte, müssen wir annehmen, dass die P'ahlbauziege von unserer heutigen Hausziege nur wenig abwich, sie war nur etwas kleiner; schon während der Bronzezeit hat sie durch bessere Pllege und sorgfältigere Zucht an Grösse gewonnen, wie Glur hervorhebt. ${ }^{2}$ )

Mehrfache Funde weisen darauf hin, dass schon in prähistorischer Zeit nordwärts der Alpen auch eine auffallend grosse Rasse vorhanden war. Ebenso liess sich in den römisch-helvetischen Niederlassungen Vindonissa und Aquae neben der kleinhörnigen Hausziege das häufige Vorkommen einer grosshörnigen Rasse nachweisen. Beide zeigen in dem Verlauf und in der Oberflächenbeschaffenheit der ILornzalpen bestandige Lnterschiede. Die Häufigkeit der Relikte beweist, dass die grosse Ziegenrasse zur Römerzeit in der Schweiz allgemein verbreitet war, während sie heute auf das Oberıallis beschränkt ist.

Bildliche Darstellungen auf einer grossen Silberpfanne aus jener Niederlassung, zweifellos römische Arbeit, lassen diese grosshörnige, langbehaarte Ziege deutlich erkennen, sie begegnet uns vielfach auf römischen Darstellungen, sowie auf altgriechischen Münzen. Es handelt sich augenscheinlich um eine Kulturrasse der Mittelmeerländer, die frühzeitig, besonders zahlreich in Begleitung römischer Kultur, im Norden der Alpen eindrang.

1) L. Rïtimeyer. Fauna der I'fahlbauten. 1862.

") G. Glur. Beiträge zur Fauna der schweiz. P'fahlbauten. Bern. 1894. 
In Griechenland hatte die Ziege Kultbedeutung erlangt, die ägäischen Inseln erhielten von ihr den Namen, offenbar ihres Ziegenreichtums wegen, den auch die Odyssee wiederholt hervorhebt. Ihren Spuren begegnen wir auch frühzeitig im altägyptischen und altassyrischen Kulturkreis.

Der heutige Ziegenbestand der alten Welt weist eine grosse Zahl von

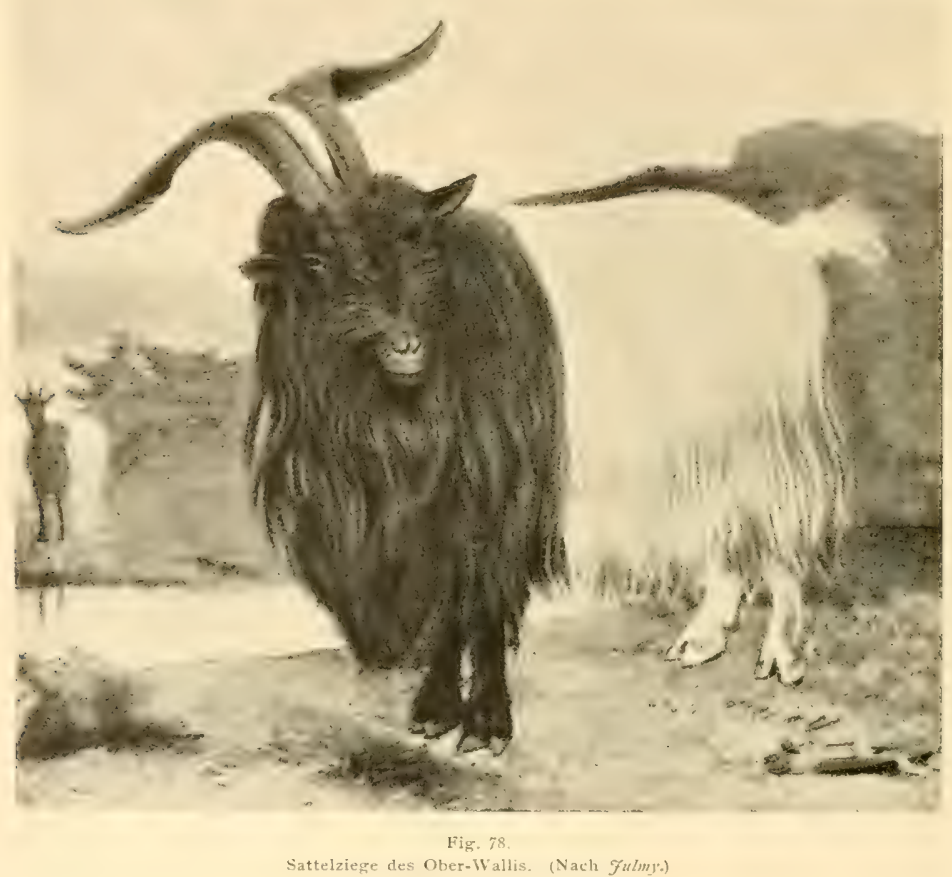

Formen auf, die sich durch Grösse, Art der Behaarung und Hornbildung stark unterscheiden. Wir kennen grosshömige, kleinhörnige und hornlose Rassen; dann ramsnasige, häugeohrige, kurz- und langhaarige Ziegen, deren Unterschiede zum Teil durch Zucht, zum Teil durch Abstammung bedingt sind. Am einfachsten ist die Rassenzusammensetzung in Europa. Für das Alpengebiet der Schweiz, in welchem wir noch ursprüngliche Verhältnisse zu erwarten haben, hat nach meiner Meinung 1 . Fulmy $y^{1}$ ) die natürlichste Einteilung vorgeschlagen, indem er vier Ratssen aufstellt: 1. die schwarz-

1) A. Fulmy. Die Ziegen-Rassen der Schweiz. 1896. 
halsige Walliserrasse; 2. die gemsfarbige Alpenrasse; 3. die weisse Sannenrasse und 4. die Toggenburgerrasse. Die beiden letztern sind ungehörnt. Es ist offenbar die weit verbreitete gemsfarbige Alpenrasse die Ausgangsform, von der alle übrigen abzuleiten sind; sie hat sich augenscheinlich in unseren Gebirgen seit der Pfahlbauzeit fast unverändert erhalten und nur in der Grösse etwas gewonnen. Die Pyrenäenziege und wohl die meisten Gebirgsziegen im übrigen Europa dürften dieser in beiden Geschlechtern gehörnten gemsfarbigen Rasse angehören, wenigstens funde ich bei Ludưg z'on Lorenz-Liburnau, dass ihr Iabitus bei Hausziegen in Griechenland und den Balkanländern vielfach wiederkehrt und in Bosnien überall auftritt. ${ }^{1}$ )

Die hornlosen Ziegen sind Abkümmlinge der alten Rassen, die Toggenburgerziege steht ihr wohl am nächsten, während die Saanenziege durch ihren Albinismus die jüngere Form darstellt.

Als eigenartige Kulturrasse muss die Walliserrasse (Sattelziege) aufgefasst werden: sie ist stattlich gebaut und sehr langhaarig, am Vorderkörper tiefschwarz, am Hinterkörper schneeweiss. Sie gehört zur Staffage der Bezirke um den Simplon herum und ist oberhalb Brieg sehr häufig. Ihr Vorkommen in der Nähe einer alten Gebirgsstrasse, die frühzeitig den Verkehr mit dem Norden der Alpen vermittelte, lässt sie unschwer als ein lebendes Relikt aus der Römerzeit erkennen, sie ist hier gleichsam hängen geblieben, wie die römischen Molosserhunde und die brachycephalen Rinder, die sich zum Bernhardinerhund und Eringerrind umgestalteten.

Viel verwickelter erscheinen die Rassenverhältnisse der asiatischen Formen. Die syrische Mamberziege ist gross, langhaarig und schlappohrig. Als edelste Rasse gilt die Angoraziege Kleinasiens mit langem, blendendweissem Wollhaar und grossem, spiralig nach aussen gedrehtem Gehörn. Ueber die persischen Ziegen bemerkt I/. Pohlig; ${ }^{2}$ ) dass am häufigsten eine kleine, schwarze Wollziege gehalten wird, deren Ohren hängend und deren Hörner spiralig nach auswärts gedreht sind. Daneben halten die persischen Bergvölker die der indischen Kaschmirziege nahe verwandte Murgusziege.

In Arabien ist die Ziege ausserordentlich verbreitet und vom primitiven Typus unserer gemsfarbigen Alpenziege, mit denen einzelne Individuen in der Färbung übereinstimmen; letztere variiert übrigens sehr, wie ich meinen Reisenotizen aus Südarabien entnehme. Man findet ganz weisse Tiere, andere sind weiss mit schwarzem Rückenstreif, schwarzbraun oder gelbbraun, das säbelförmige Gehörn ist nur ausnahmsweise gross. Das Euter ist ungewöhnlich gross und muss oft in einen Sack gebunden werden, damit es nicht auf dem Boden schleift. Das IJaar ist kurz, dicht anliegend, zuweilen auch etwas kraus.

Unter den südasiatischen Ziegen ist die ziemlich kleine Kaschmirziege

1) L. zon Lorenz-Liburneru. Wissenschaftl. Mitt. aus Bosnien und der Herzogowina. VI. Bd. 1899.

2) II. Pohlig. Berichte des landiv. Inst, der Universität Halle. VII. 1887. 
weit über IIochasien ausgebreitet; das Haarkleid ist ein Ianges Vliess, das scharfkantige Gehörn.schraubenförmig nach aussen gedreht; die Ohren häingend.

In Ostasien tritt die Ilausziege stark zurück. Eine eigentümliche Rasse bildet die Malayenziege, von der ich drei Schädel aus Sumatra erhielt. Das Gehorn ist auffallend dick, im Halbkreis nach hinten gebogen und im Verhältnis zur Dickenentwicklung sehr kurz. Eine chinesische Ziege der hiesigen Sammlungen zeigt nahe l'erwandtschaft zur malayischen Rasse.

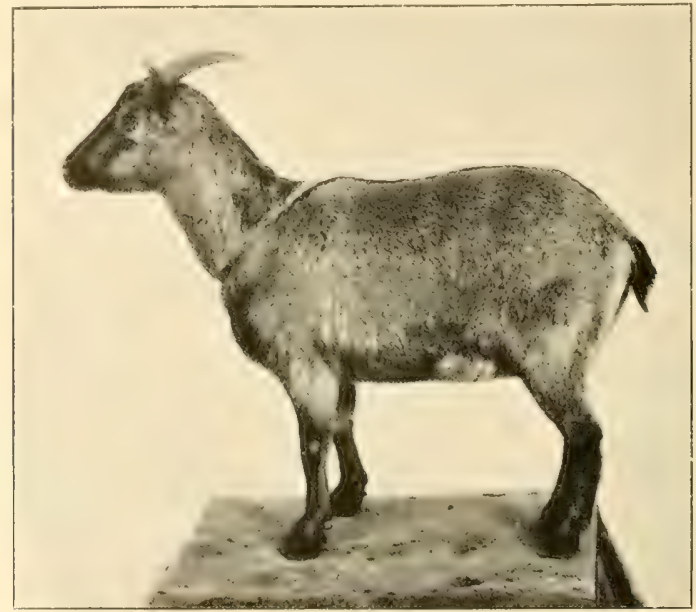

Hije. 70 .

Zwergziegre von Westafrika. (Original.)

Die afrikanischen Ziegen weisen im Nilthal zunächst enge Beziehungen zu Asien auf, in dem die schlappohrige, ramsnasige Nilziege mit der syrischen Form verwandt ist. Nordabessinien dürfte seine Rasse von Arabien her erhalten haben. In der Umgebung von Massaua fand ich am häufigsten eine kastanienbraune, mittelgrosse Ziege, die einen schwarzen Längsstreifen auf dem Rücken und dunkle Längsstreifen im Gesicht aufwies, die Hörner sind lang, flachgedrückt und von der Mitte an auseinandergebogen. Sie erinmert ganz an die gemsfarbige Ziege unserer Alpen. Es kommen auch braun und weissgetleckte, sowie schwarze Varietäten vor.

In den übrigen Gebieten des tropischen Afrika bis zur Westküste herrscht eine kleine Rasse mit kurzen Hörnern vor, die sogenannte Zwergziege mit verschiedenen Varietäten. Die schönste Form derselben ist wohl die Somaliziege. Bei den einzehnen Stämmen im Innern fand ich zahl- 
reiche Herden, die meist mit den kleinen Fettsteissschafen zusammen auf die Weide getrieben werden. Das Gehörn ist kurz, nach hinten und schwach nach aussen gekrümmt. Die Farbe ist meist blendend weiss, sehr beliebt ist auch weiss mit drei Längsstreifen von dunkelbrauner" Farbe im Gesicht und dunkeln Längsstreif über den Rücken. Die Somaliziege ist intelligent und gut gewöhnt, die Milchergiebigkeit ist entsprechend der geringen Ausdehnung des Euters nicht gross, das Fleisch fett und sehr schmackhaft.

\section{DIE WILDZIEGEN. \\ ABS'TAMMUNG DER HAUSZIEGEN.}

Die heutigen Wildziegen scheinen ihren Bildungsherd in der Gebirgswelt Asiens zu haben. Soweit die spärlichen palaeontologischen Funde einen Schluss zulassen, handelt es sich bei den Capriden um eine geologisch junge Gruppe, deren älteste Reste im oberen Pliocaen Frankreichs erscheinen; Funde aus Innerasien müssen wir noch abwarten. Die jetzt lebenden Arten lassen sich auf drei natürliche Gruppen verteilen:

I. Gruppe: Ture. Ihr Gehörn ist nach rückwärts und auswärts gebogen und im Querschnitt mehr oder weniger gerundet, so dass sie eine Mittelstellung \#wischen den Halbschafen und den echten Ziesen einnehmen.

Hieher gehören zunächst die beiden Ture des Kaukasus, nämlich Capra cylindricornis und Capra caucasica; letztere Art lässt am Vorderrand regelmässige Wülste erkennen, während solche bei Capra cylindricornis nur schwach angedeutet sind. Beide endemische Arten gehören dem Hochgebirge des grossen Kaukasus an, C. cylindricornis ist die östliche, C. caucasica die westliche Form. Auf dem Grenzgebiet beider fand G. Radde ${ }^{1}$ ) Gehörne, die einen Mischcharakter erkennen lassen und auf Bastardierung beider Arten hinweisen. Eine dritte Art, die Prof. Mensbier als Capra Sewertsowi unterschied, gehört offenbar in den Formenkreis von C. caucasica hinein.

Auf einem geographisch ziemlich weit entlegenen Gebiet, in Südspanien, lebt eine Wildziege, die "Cabra montes" der Sierra nevada, welche nach den Untersuchungen von $H$. Goll ${ }^{2}$ ) den kaukasischen Turen am nächsten steht.

II. Gruppe: Steinböcke. Auch sie sind echte Hochgebirgstiere, die man in einer besonderen Untergattung (Ibex) vereinigt. Ihr nach hinten gebogenes Gehörn entfernt sich von der Mittelebene durchschnittlich weniger als bei den Turen; auf dem Querschnitt erscheint es länglich viereckig, da es woht abgeplattet ist, aber keine scharfen Kanten aufweist. Der Vorderrand ist mit stark vorspringenden, regelmässig angeordneten Querwülsten besetzt.

Stammform der ganzen Gruppe ist augenscheinlich der Sibirische Steinbock (Capra sibirica), dessen Verbreitungsgebiet vom Ntai bis zum

1) G. Radde. Die Sammlungen des kaukasischen Museums. Tillis, 1894.

") 11. Groll. Le Globe. Tome XXXV11. Genève. 1898. 
Himalaja reicht und auch für Persien und Afghanistan angegeben wird. Von hier aus hat eine Ausstrahlung nach Süden und Westen stattgefunden. Der Steinbock der Alpen (Capra ibex), seit langer Zeit im Rückgang begriffen, ist gegenwärtig nur noch im Aostathal heimisch. Der Pyrenäensteinbock (Capra pyrenaica) gilt als selbständige Art, die in der Gehörnbildung vom Alpensteinbock abweicht.

Das Sinaigebiet wird wiederum von einer eigenen Spezies bewohnt (Capra sinaitica Hempr. und Ehr.), von welcher der Steinbock Nubiens (C. nubiana), derjenige Abessiniens (C. Walie Rüpp.) und der Maskatsteinbock in Südarabien (C. Mengesi Noack) wohl nur Lokalformen darstellen.

III. Gruppe: Ziegcn (im engeren Sime). Sie bilden das Endglied der Capriden und werden nach dem Vorgang von Gray in einer besonderen Untergattung llircus vereinigt. Ihre Grösse steht derjenigen der Siteinböcke etwas nach, der Kopf ist durch ein plattgedrücktes Gehörn ausgezeichnet. dieses ist scharfkantig und an der vorderen Kante mit unregelmässigen Knoten, aber niemals wie bei den Steinböcken mit regelmässigen Querwülsten versehen. Die Hornzapfen sind so stark genähert, dass zwischen denselben am IInterschädel eine Furche entsteht: die Hornscheiden wenden sich säbclförmig nach hinten oder sind schraubenförmig gedreht. Ihr eigentliches Wohngebiet ist Asien, dem afrikanischen Boden fehlen sie ganz, greifen aber in Südosteuropa auf die griechischen Inseln hinüber.

Als bekannteste Wildform mag hier zunächst die Bezoarziege (Capra aegagrus) angeführt werden, deren Verbreitungsgebiet sich über das mittlere und westliche Asien erstreckt. Oestlich reicht sie von Persien bis nach Beludschistan und dem westlichen Sind. Im Norden endet sie im grossen Kaukasus und Transkaspien. Sie ist in Armenien besonders auf dem Ararat verbreitet. Ihr bogenförmiges, am vorderen Rande mit Knoten besetztes Gehörn scheint bei allen asiatischen Formen sich erst langsam auswärts zu biegen, um gegen die Spitze hin wieder zu konvegieren, so dass die Enden gelegentlich gekreuzt erscheinen.

Wir müssen der Bezoarziege noch vermeintliche endemische Arten der griechischen Inselwelt anreihen. Seit langer Zeit kennt man das Vorkommen von Wildziegen auf Kreta, wo sie besonders zahlreich im Gebirge von Ida vorkommen. Brisson hat für diese den Namen Capra cretensis geschaffen. Von der Insel Erimomilos hat 1858 Erhard ${ }^{1}$ ) unter der Speziesbezeichnung "Aegocerus pictus" eine Wildziege beschrieben, die von C. aegagrus dadurch verschieden sein soll, dass sie eine geringere Grösse und ein mit den Spitzen nach atussen gedrehtes Gehörn besitzt. Die Bestände waren vor Dezennien noch sehr zahlreich, gegenwärtig aber sind sie wegen der schonungslosen Jagd stark zurückgegangen. Frühere spärliche Nachrichten erwähnter auch Wildziegen von den Sporadeninseln, ein an den zoologischen Garten nach Berlin gesandter wilder Bock von der Insel Joura hat Reichenow

1) Evlard. Fauna der Cykladen. 1858. Pag. 32. 
eingehender untersucht und darauf seine neue Art Capra dorcas gegründet. ${ }^{1}$ ) Bei derselben ist die Vorderkante des Gehörns nach innen gekehrt; die Hornscheiden entfernen sich von der Wurzel an, durch eine etwas spiralige Drehung erscheinen die Spitzen nach aussen gewendet.

Unlängst hat Lorenz-Liburnau eine sehr eingehende Untersuchung dieser griechischen Inselziegen veröfentlicht und vortrefliche Abbildungen der Joura-Ziegen und der Erimomilos-Ziegen geliefert.. ${ }^{2}$ ) Auf Grund sorgfältiger anatomischer Vergleiche kommt er zu dem jedenfalls sehr zutreffenden Schluss, dass die Kretaziege als echte Wildziege von der asiatischen Capra aegagrus im Schädelbau so wenig abweicht, dass sie mit ihr zusammen eine Art bildet. Auch die Erimomilosziege ist nur eine Lokalform der westasiatischen Bezoarziege und möglicherweise von Kreta importiert.

Anders verhält es sich mit Capra dorcas Reichenow der Insel Joura, die nichts weiter als eine verwilderte Hausziege ist, wofür neben dem Ilornverlauf besonders auch dic stärker aufgetriebene Stirn spricht. Dass sie in der Färbung des Haarkleides auffallend mit C. aegagrus übereinstimmt, ist eine Rückschlagserscheinung, die sich aus Abstammungsverhälnissen erklärt. Wir begegnen ja auf andern Inseln des Mittelmeeres verwilderten Ziegren; berühmt sind die Bestände von Tavolara im Norden von Sardinien, aber auch auf der Hauptinsel werden in den Bergen nach den mir zugekommenen Mitteilungen verwilderte Ziegen gejagt. ${ }^{3}$ )

Im Osten des asiatischen Kontinentes, im Himalajagebiet lebt eine andere, stattliche Wildziege, der Markhor (Capra Faiconeri) mit gerade gerichtetem Spiralgehörn, das beim Männchen meterlang werden kann. Diese Schraubenziege reicht von Kaschmir bis zum nördlichen Afghanistan. Man wollte in ihr gelegentlich die verwilderte form einer Hausziegenspielart erblicken (Blyth), allein nach dem ich den Schädel zu untersuchen Gelegenheit hatte, erscheint mir eine derartige Deutung ausgeschlossen; es handelt sich offenbar um eine echte Wildform.

Anhangsweise mag noch eine andere Himalaja-Wildziege, der Tahr (Capra jemlaica oder Hemitragus jemlaicus) Erwähnung finden. Er ist Vertreter der Halbziegen und bildet eine Uebergangsform zwischen den Antilopen und den echten Ziegen. Die langbehaarte Himalajaziege trägt ein kurzes, seitlich zusammengedrücktes Gehörn, dessen Kanten gerundet sind; die Iornspitzen sind einwärts gerichtet.

Untersuchen wir die Abstammungsverhältnisse der verschiedenen Hausziegen, so bleiben als wilde Stammformen jedenfalls die beiden Gruppen

1) Reichenoze. Zoolog. Jahrb. III. 1888.

2) Lorenz-Liburman. Die Wildziegen der griechischen Inseln. Wissensch. Mitt. aus Bosnien und der Herzogowina. VI, B3d. 1899.

$\left.{ }^{3}\right)$ C. Feller. Vervilderte Haustiere in Sardinien. Globus. 1849. 
der 'Ture und der Steiuböcke vollkommen ausgeschlossen. Zwar erfahren

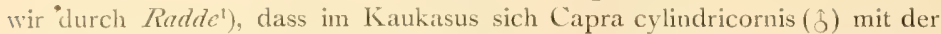
Hausziege (5) kreuzen kann und fruchtbare Bastarde erzeugt, ebenso ist längst bekannt, dass die Bastardierung zwischen Steinbock (Capra ibex) und der I Iansziege leicht grelingt und diese Bastardsteinböcke ebenfalls fruchtbar sind. Allein dieses physiologische Moment beweist für die Abstammung gar nichts. Man muss gegen die nähere Verwandtschaft einwenden, dass die Ilornbildung zunächst ganz verschieden ist. Die Hornzapfen als bestandteile des Sketettes und die I Jornscheiden als epidermoidale Bildungen gehören Organgebieten an, die sich sehr konservativ verhalten und daher phylogenetisch mit Nutzen verwendet werden können. Daher muss auch die Stammvaterschaft der Steinböcke abgelehnt werden.

An der Erzeugung der verschiedenen Hausziegen-Rassen sind offenbar drei wilde Arten beteiligt.

Die westlichen Ziegrenschläge, die Westasien und Arabien, dann Europa und ganz Afrika bewohnen, weisen im ganzen einen einförmigen Charakter auf, der auf eine einheitliche Abstammung hinweist. Als den primitivsten Typus sehe ich die gemstarbige Gebirgsziege an, die uns nicht nur in ganz Europa, sondern auch in Abessinien und Arabien begegnet. Die stärkste Unbildung, die unter dem Einfluss langer Domestikation entstand, sehen wir bei den hängeohrigen Schlägen Westasiens.

Diese westliche Gruppe stammt von der Bezoarziege (Capra aegagrus) ab, wotür eine Reihe von Gründen sprechen. Zunăchst liegt das Verbreitungsgebiet dieser Wildziege im Bereich der ältesten Kulturkreise, in welchen nachweisbar die Ziege als I Haustier sehr früh erscheint und durch Zucht am meisten abgeändert wurde.

Die zoologische Uebereinstimmung ist sehr gross. Das Gehörn unserer primitiveren Ziegenschläge ist scharfkantig und plattgedrückt, am Vorderrande beim Bock oft mit unregelmåssigen Knoten besetzt, wie bei der Bezoarziege; dass die Spitzen bei der zahmen Form sich nach aussen wenden, ist wohl eine nebensächliche, durch Domestikation bedingte Abweichung.

Der Bart, der sich in beiden Geschlechtern wohl entwickelt findet, ist auch bei C. aegagrus stark ausgesprochen. Besonders auffallend ist neben der Uebereinstimmung im allgemeinen Körperbau und in den Grössenverhältnissen die Aehnlichkeit in Färbung und Zeichnung des Haarkleides, die sich bekanntlich zähe vererbt und daher phylogenetisch von grossem Wert ist.

Viele Individuen unserer Nipenziegen stimmen in ihrer Gemsfarbe, dem schwarzen Aalstrich auf dem Rücken, der dunkelbraunen Stirn- und Halsfürbung, der dunkeln Aussenseite der Vorderläufe bis ins einzelne mit der

1) G. Iadde. 1)ie Sammlungen des kaukasischen Museums. 1899. 
westasiatischen Wildziege überein. Der charakteristische dunkle Rückenstreif des Aegagrus, sowie die dunkle Stirn und die dunkeln Streifen vor den Augen haben sich sogar bei den durch Albinismus ausgezeichneten Somaliziegen vielfach erhalten.

Wie H. Pohlig in Persien beobachten konnte, ${ }^{1}$ ) besitzt die Bezoarziege eine hohe Empfänglichkeit für die Domestikation. In Djulfa sah er eine Alte mit ihren beiden Jungen sich in einem Gehöfte einnisten und sich so an die Umgebung gewöhnen, dass sie von ihren Ausllügen pünktlich zur Fütterungszeit zurückkehrten.

Indessen ist dies nicht die einzige Stammform. Wir finden auf asiatischem Boden noch andere Rassen heimisch, die sich durch lange Behrarung

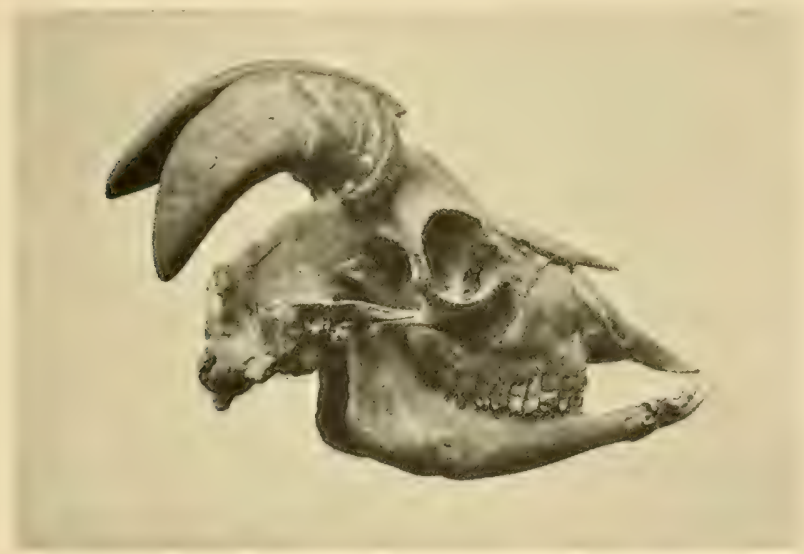

Fir.t. 80.

Schädel der Malayen-Ziege aus Sumatra, Original. (Landw, Sammlung Zürich.)

und schraubenartiges Gehörn auszeichnen. Diese enthalten offenbar Blut von der Schraubenziege (Capra Falconeri), deren Heimat das Himalajagebirge ist, die aber vor dem wohl bis Persien reichte. Die Falconeri-Rasse scheint in reinster Form im alten Mesopotamien vorhanden gewesen zu sein, wenigstens ist es mir auffallend, dass altassyrische Bilder eine hängeohrige und langbärtige Ziege darstellen ${ }^{2}{ }^{2}$ ) deren Schraubengehörn gerade verläuft, sich fast senkrecht vom Kopf erhebt und lang ist. Die Angoraziegen und die indischen Kaschmirziegen dürften mehr oder weniger als reine $\mathrm{Ab}$ kömmlinge der assyrischen Rasse, die langhaarig dargestellt wurde, anzusehen sein.

1) H. Pohlig. Loc. cit. Pag. 98.

2) Vergl. Layard. Monuments of Niniveh. 1849. Plate 58 und 60. 
Als dritte Wildziege, die meiner Auffassung nach Blut auf die Hausziege vererbt hat, bezeichne ich den Tahr (Capra jemlaica). Die betreffenden Rassen erscheinen auf Ostindien und die malavische Inselwelt beschränkt. Bei einem Bock aus Sumatra finde ich ein kurzes und auffallend dickes Gehörn, das zwar als zweikantig bezeichnet werden kanu, die Kanten erscheinen jedoch gerundet: es erhebt sich halbkreisfömig über der Stirn, wendet sich gar nicht nach aussen und endigt mit den Spitzen in der Ilöhe

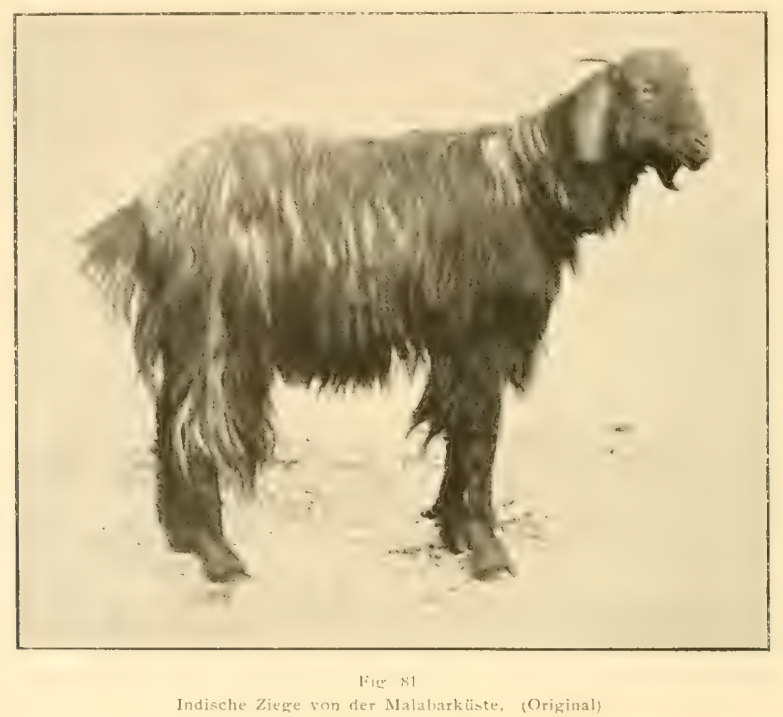

der Hinterhauptsschuppe. Zwei weibliche Schädel, ebenfalls aus Sumatra stammend, zeigen die IJomenden etwas nach aussen gedreht. Aus Tibet finde ich eine kreuzhörnige Ziege erwähnt, deren Gehörn oflenbar an den Tahr erinnert.

Wie bei Capra jemlaica (Hemitragus jemlaicus) sind au der Aussenseite der Hornscheiden regelmässig angeordnete. breite aber niedrige Querwülste vorhanden. Die Augenhöhlen treten nur wenig vor und erscheinen enger als bei andern IIausziegen.

Damit will ich durchaus nicht behaupten, dass ich die Malayenziege als domestizierten Tahr betrachte. denn in Schädol sind wiederum $\mathrm{Ib}$ weichungen vorhanden, die sich mit einer solchen dnnahne nicht vereinigen liessen.

Ich glaube vielmehr, dass es sich um ein Kreuzungsprodukt handelt, 
wobei allerdings eine erhebliche Menge Tahrblut vorhanden ist. Die wenigen Beobachtungen, die ich an lebenden Ziegen Ostasiens zu machen in der Lage war, deuten darauf hin, dass der Inteil von Tahrblut Schwankungen unterworfen ist.

I)as südasiatische Festland ist offenbar als IBildungsherd dieser BastardRasse anzusehen. Nan braucht nicht notwendig das Hochland von Tibet als solches anzmehnen, dat auch in den Gebirgsgegenden Südindiens eine dem Tahr nahestehende Form als geographische Varietät vorkommt. Die Iravidastämme Indiens besitzen eine I Iaumiege, die der Sumatraziege sehr nálhe steht. \%wei Ziegen von der Malabarküste, die ich untersuchte, stimmen in Gehörn vollkommen mit der Malayenziege Sumatras überein. Die langen und breiten Hängeohren erinnern an die Angoraziege, die Augen besitzen eine lichtgelbbraun gefärbte Iris. I)er Körper ist bei dem einen Exemplar fast überall kurz behaart und von tiefschwarzer Färbung, beim andern ist der Kopf tahrfarben, d. h. rötlich-kastanienbraun mit breiter. schwarzer Stimbinde und schwarz eingefassten, kastanienbranen Ohren. Der Körper ist in übrigen mit Ausnahme der kurzbehaarten Beine mit langem, grobem Grannenhaar bedeckt, dessen Farbe an den Seiten in Schiefergrau übergeht.

Also ein merkwürdiger, wenn auch bei den einzchen Individuen wechselnder Mischcharakter von Kaschmirziege und Tahr.

Das Auftreten solcher Bastarde, deren durchschnittliche Körperlänge 120 Centimeter betragen mag, darf nicht überraschen, da einmal nach den Beobachtungen von Ḱmlach Capra jemlaica sich leicht zähmen lässt und anderseits bekannt ist, dass der Tahr sich leicht mit der Hausziegre paart,') ja die Eingeborenen behaupten, dass für den Talırbock ein weibliches Moschustier sogar Gegenstand der Begehrlichkeit sein kann.

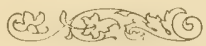

1) Brekms Tierleben. 3. Auflage. Bd. III. Pag. 213. 


\section{DAS KAMEL.}

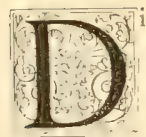

e Kameliden sind nach ihrer palaeontologischen Entwicklung von hohem Interesse geworden, indem sie sich am frühesten vom Stamm der Wiederkäuer ablösten und daher in ihren hentigen Repraisentanten cinen recht alten Zweig darstellen. Ihr konservativer Charakter spricht sich deutlich darin aus, dats sie die einzigen Wiederkäuer sind, welche im Oberkiefer noch Schneidezähne erhalten haben. Die völlige Abtrenumg von den selenodonten Huftieren erfolgte schon im Miocaen, bevor sich Geweihe oder Gehörne ausbildeten, denn diese Waffen fehlen den kamelartigen Tieren der Gegenwart wie den ausgestorbenen Gattungen, unter denen das mitteltertiäre Poëbrotherium die Stammform bildet.

Die ursprüngliche Heimat ist Nordamerika, wo während der jüngeren Tertiärzeit die reichste Entfaltung bemerkt wird, dort aber erlischt die Gruppe mit dem Diluvium, während die noch lebenden Nachkommen sich weit von ihrem ursprünglichen Wohnsitz entfernt haben. Die Schafkamele oder Llamas (Auchenia) wanderten nach Südamerika aus und sind schon in der präkolumbischen Zeit teilweise in den Dienst des Menschen eingetreten; sie sollen hier nicht weiter berücksichtigt werden.

Ein anderer Zweig, die Gattung Camelus bildend, siedelte sich in der alten Welt. in Asien, an und lebt heute noch auf den hochasiatischen Wüstenflächen zahlreich in ursprünglicher Wildheit. Aus diesem gewann der Mensch eines der brauchbarsten altweltlichen IIaustiere, dessen Domestikation nach den bisher gewonnenen Anhaltspunkten sich zweifellos in die prähistorische Zeit verliert.

Man ptlegte bisher ziemlich allgemein das zweihöckerige Kamel oder Trampeltier (Camelus bactrianus) artlich von dem einhöckerigen Dromedar (Camelus dromedarius) zu trennen. Morphologisch lässt sich ein Artunterschied nicht aufrecht erhalten. Der Fetthöcker allein ist nicht massgebend. Ob diejenigen Recht behalten, die ihn lediglich infolge der fortwährenden Belastung des Rückens entstehen lassen oder ob er in schwächerer Ausbildung schon beim Wildkamel vorhanden ist, wird eine genaue Untersuchung der letzteren lehren. In seiner heutigen Entwicklung ist er augenscheinlich ein Produkt künstlicher Züchtung; er lässt sich ähnlich wie beim Höckerrind bis zu extremen Dimensionen steigern, was ich oft an gemästeten Kamelen im afrikanischen Osthorn beobachten komte, oder durch lange 
Anstrengung bei knapper Nahrung in wenigen Wochen zum Verschwinden bringen. Bei Embryonen von Dromedaren fand ich die Rückenlinie zwar gebogen, den Höcker aber kaum angedeutet.

Lombardini hat nun den Nachweis geliefert, dass der Dromedar im Grunde genommen auch zweihöckerig ist und die erste Anlage beim Embryo doppelt erscheint. ${ }^{1}$ ) Für die Abstammungsgeschichte ist diese Thatsache von besonderer Wichtigkeit, dass wir nunmehr mit einer einzigen wilden Stammform auskommen, das zweihöckerige Kamel als die ursprünglichere zahme Rasse bezeichnen und davon den Dromedar als jüngere Zuchtrasse ableiten können.

Auch physiologische Gründe sprechen für die Zusammengehörigkeit beider Hauptrassen, da sich Camelus bactrianus und C. dromedarius leicht kreuzen lassen und fruchtbare Blendlinge liefern. ${ }^{2}$ ) Die geistigen Eigenschaften stimmen auffallend überein, beide Formen sind wenig begabt, wie es die tiefe Stellung der Familie mit sich bringt: beide zeigen neben störrischem Wesen eine auffallend geringe Anhänglichkeit an den Menschen.

Endlich sprechen auch tiergeographische Gründe für eine Zusammengehörigkeit beider Rassen, in dem sie schon zu einer Zeit in Asien neben einander vorkommen, da sie die Westgrenze ihres heimatlichen Kontinents noch nicht überschritten haben. Da der Dromedar in seiner Verbreitung mehr auf den Süden angewiesen ist, liegt die Vermutung nahe, dass er auf dem Boden Arabiens zuerst als Zuchtrasse entstanden ist.

Die Formenverhältnisse der Kamele lassen erwarten, dass die Nutzungsrichtung eine einseitige sei. Als Lasttiere und Reittiere leisten sie unter gewissen Bodenbedingungen unschätzbare Dienste und man kann sagen. dass der Mensch mit Hülfe des Kamels die gewaltigen Steppen und Wüsten Asiens und Afrikas eigentlich erschlossen und erobert hat. Aber auch als Zugtier findet das Geschöpf häufig V'erwendung. In Aegypten spannt es der Fellah - drollig genug - zusammen mit der Kuh vor den Pilug, um das Feld zu beackern: in Südarabien habe ich es den schweren Wasserkarren ziehen sehen. Die Kamelstuten liefern eine konzentrierte, wohlschmeckende Milch, die mit Wasser verdünnt, ein angenehmes Getränk bildet: die Wolle wird in Persien zu dauerhaften Filzdecken verarbeitet; in den Somaliländern versorgen gemästete Kamele den Fleischmarkt der grösseren Orte und das Kamelfleisch wird gerühmt; ich kamn nur sehr bedingt in dieses Lob einstimmen, denn der Geschmack ist wohl nicht unangenehm, das Fleisch jedoch recht zäh.

Die heutige Verbreitung zahmer Kamele lässt sofort erkennen, dass die zweibuckelige Rasse (Camelus bactrianus) tast ausschliesslich auf Asien beschränkt bleibt und hier die kühleren Distrikte bewohnt, indem sie in

1) Lombardini. Ricerche sui Camelli. Pisa. 1859 und Referat darüber im Kosmos. 1879. Pag. 144.

2) Brelims Tierleben. Bd. IHI. 
Innerasien. im südlichen Sibirien und bei den Mongolen Ostasiens die Alleinherrschaft erlangte. In China spielt das zweihöckerige Kamel eine wichtige Rolle im Karawanenverkehr mit sibirien und der Mongolei; im südwestlichen Sibirien wird dasselbe seit der raschen Entwicklung der Landwirtschaft häufig vor den Ptlug gespannt. Ueber den Ostrand Asiens vermochte es nicht hinauszudringen, weil für die insularen Gebiete der Büffel besser passt. In Japan, wo man alle möglichen Nutztiere einzubürgern versuchte, ist das Kamel erst vor kurzer Zeit eingetroffen. Im chinesischjapanesischen Krieg wurden den Chinesen eine Menge dieser Tiere abgenommen und nach Tokio gebracht. Sie wurden von der Regierung teils an das dortige l'eterinärinstitut, teils an l'rivatpersonen verschenkt, aber man wusste nirgends etwas damit anzufangen: hente dürfte dieser Fremdling auf japanischem Boden vollständig verschwunden sein.

In Westen kommen in Persien, Mesopotamien und Kleinasien beide Rassen neben einander vor, zweihöckerige Kinmele leben auch in den Landern des Kaukasus und sporadisch in Südrussland.

Der Dromedar, die südliche Rasse, erlangte die ausschliessliche IIerrschaft in dem arabischen und afrikanischen Gebiet, reicht aber auch bis nach Indien. In Arabien wird seine /ucht stark betrieben. Im nördlichen Teil von Afrika besorgt er überall den Karawanendienst bis nach Marokko und reicht selbst auf die kanarischen Insehn hinüber. In Aegypten und Nubien stark verbreitet, verengert sich sein Wohngebiet bei Massaua auf eine schmale \%one, da die Hochlander von tethiopien den Dromedar durch Esel und Maultier ersetzen. Im Osthom dagegen sind einzelne Bezirke mit zahlreichen Kamelherden erfüllt. Besonders stark wird das Kamel von den Somalen in den Ebenen des südlichen Ogadeen gezüchtet, ich habe in cler Nähe von Faf eine IJerde von etwa 10,000 Stück angetroffen. Auch im Gallagebiet ist der Dromedar eingebürgert, indem regelmässige Karawanen vom Djubathal aus über das Gebiet der Borangalla nach dem Rudolfsee und nach den grossen äquatorialen Seen verkehren. Nach Süden ist das Kamel bis Zanzibar vorgedrungen, dem waldreichen Westen tehlt es naturgemäss.

In Südeuropa vermochte es sich nicht in grösserer Zahl einzubürgern. Sporadisch trittit man den Dromedar auf der Balkanhalbinsel, in Sizilien und Südspanien war sein Erscheinen mehr vorübergehend, dagegen hat sich das Kamelgestüt von San Rassore bei Pisa erhalten, Die Einbürgerung ist auch in Nordamerika versucht worden, scheint aber nicht gelingen zu wollen, dagegen berichten neuere Reisende von seiner. Verwendbarkeit in dem steppenreichen Australien. Auf die zahlreichen Sichläge, dic von der einbuckeligen Rasse gehalten werden, kamn hier nicht näher eingetreten werden, da sie zum 'T'eil noch ungenau beschrieben sind. 
Die Frage nach der Abstammung der zahmen Kamele lässt sich heute ziemlich befriedigend beantworten, da wir nur eine einzige Wildform als Ausgangspunkt anzunehmen haben. Man hat mit Rücksicht auf das hohe Alter des Haustieres gelegentlich die seltsame Idee geäussert, das Kamel möchte ähnlich wie andere Haustiere bereits als zahmes Tier aus Amerika eingewandert sein. ${ }^{1}$ ) Diese Annahme bedarf kaum einer Widerlegung.

Die Angabe von Pomel, dass in Nordafrika, beziehungsweise in Algier, Knochenreste von Kamelen in quatärnären Ablagerungen angetroffen wurden, ${ }^{2}$ ) könnte die Vermutung nahelegen, dass wenigstens die Dromedare eine afrikanische IJerkunft besitzen. Aber die geschichtlichen Thatsachen sprechen durchaus dagegen. Wenn Pomel und Thomas Kamelreste (ein Schädel und zwei Unterkiefer) in pleistocaenen Ablagerungen Algiers nachweisen konnten, so handelt es sich um ein Wildkamel. das in Asien noch nicht erloschen ist. zur Quartärzeit aber wie andere asiatische Steppentiere sehr weit nach Westen vorgeschoben erschien, sich jedoch bereits in vorgeschichtlicher Zeit wieder zurückzog. Wir kennen ähnliche Funde von anderen Lokalitäten, so von Sarepta am linken Ufer der Wolga, aus Südsibirien und selbst aus Rumänien, wo G. Stefanescu unweit Slatina zwei Unterkiefer von Wildkamelen im diluvialen Sand sechs Meter unter der Oberfläche auffand. ${ }^{3}$ ) Er gründet darauf seine neue Art Camelus alutensis, sie ist aber wohl identisch mit dem noch lebenden innerasiatischen Wildkamel.

Die V'erbreitungsgeschichte, die ziemlich klar vor uns liegt, weist auf cinen asiatischen Bildungsherd der zahmen Kamele. Lristoteles kannte hereits beide Rassen und erwähnt. dass einzelne Besitzer Innerasiens Kamelherden halten, die nach Tausenden zählen. Die biblische Ueberlieferung: nennt das Kamel wiederholt und berichtet, dass die Königin von Saba, als sie Salomo besuchte, mit zahlreichen Kamelen in Jerusalem einzog. Sie müsste diese entweder aus Südarabien mitgebracht oder unterwegs gemietet haben.

Im Nilthal ist der Dromedar verhältnismässig spät eingetroffen und jedenfalls hatte: sich die wilden Kamele Nordafrikas längst vorher nach Osten z'irückgezogen, so dass keine Kontinuität angenommen werden kann.

Durchgeht man die bildlichen Darstellungen der Pharaonenzeit, so erscheint es auffallend. dass gerade während der klassischen Kunstepoche des alten Reiches unter den zahllosen Tierfiguren das Kamel niemals erscheint. Auch im mittleren Reich wird es nicht abgebildet. im nenen Reich erst zu einer Zeit, da ein Eindringen griechischen Einflusses bemerkbar wird. Man hat behaumten wollen. dass irgend eine religiöse Scheu die ägyptischen

1) Vergl. Kosmos. 1875 .

2) Nach A. de Lortillet. Origines de la chasse, de la pêche et de l'agriculture. Paris, 1890 .

3) Gregor Stefanescu. Camila Fosila din Rumania. Anuarulu Museului de Geologia si de Palaeontologia, Bucaresci. 1896. 
Künstlur abgehalten habe, das fremdartige ( jeschüpf abzubilden. Ich möchte jedoch dem entgegen halten, dass satyrische Papyrus aufgefunden wurden, deren Bildereien sich ganz von der herrschenden Kunstüberlieferung frei machen und es mit der guten Sitte wenig genau nehmen. Aber auch hier wird meines Wissens das Kamel nirgends abgebildet. Man darf daher annehmen, dass es als Haustier wirklich fehlte.

Das Eindringen des Dromedars in Afrika muss jedoch über Aegypten erfolgt sein. Wäre er frühzeitig vom Süden des Roten Meeres nach Aethiopien gelangt und dam von Süden her nach Norden vorgedrungen, so hätte man ihn vermutlich in Theben abgebildet, aber noch zur Zeit Ramses III. wird ausdrücklich der Esel als Transporttier für die Wüste erwähnt. Daher ist auch die Hypothese, dass während des mittleren Reiches der Einfall der Hyksos, d. h. der semitischen Hirtenvölker in Nordosten des Reiches das Kamel nach Aegypten verbreitet habe, nicht gerade wahrscheinlich.

Adolf Erman weist darauf hin, ${ }^{1}$ ) dass der Versuch, im Altagyptischen ein Fremdwort für das Kamel nachzuweisen, gescheitert sei und er hält dafür, dass die Pharaonenleute mit diesem Tier erst unter griechischer Herrschaft bekannt wurden, d. h. frühestens im vierten Jahrhundert vor unserer Zeitrechnung.

Weit früher begegnet man deutlichen Spuren beider Kamel-Rassen im 7wweistromland. In Niniveh fand Place ein Basrelief aus dem siebenten vorchristlichen Jahrhundert, ${ }^{2}$ ) auf dem ein assyrischer Bogenschütze auf einem 1)romedar reitend dargestellt wird. Layard hat in seinem zweibändigen monumentalen bilderwerk ${ }^{3}$ ) mehrfach altassirische I) arstellungen von Kamelen veröffentlicht, darunter einen beladenen Dromedar aus Kujundschik und einhöckerige Kamele aus Nimrod, ferner ein zweihöckeriges Kamel, das neben dem Elefanten auf einem im britischen Museum aufbewahrten Marmorobelisk abgebildet wird.

Wir finden daher beide Kamel-Rassen auf asiatischem Boden schon scharf ausgeprägt zu einer Zeit, da der Dromedar in Afrika noch nicht angelangt ist. Ihre erste Domestikation reicht jedenfalls in eine weit ältere Zeit zurück und wir werden kaum fehl gehen mit der Annahme, dass innerasiatische Völker das Kamel in Hochasien zur prähistorischen Zeit gezähmt haben. Diesen Auffassungen kommt die Entdeckung eines passenden WVildmaterials in jener Region sehr zu Gute.

Schon im vorigen Jahrhundert gelangten Nachrichten nach Europa, denen zufolge wilde Kamele in der Dsungarei leben sollen; sie waren zu unbestimmt, um vollkommen glaubwürdig zu erscheinen. Der russische Reisende Przerualski hat in der Neuzeit mit mehr Bestimmtheit ihr Vor-

1) Adolf Erman. Aegypten und ägyptisches Leben im Altertum. 1885.

2) Abgebildet in A. de Nortillet. Loc. cit. I'ag. 421 .

3) A. H. Layard. The monuments of Nineveh. London, 1849. 
kommen im Gebiet des Lob-nor, d. h. im westlichen Teil der Wüste Gobi signalisiert; es ist jedoch der Einwand erhoben worden, es möchten dies einzelne entlaufene und verwilderte Kamele gewesen sein.

In der jüngsten Zeit hat jedoch Sven Hedin so eingehende Angaben über zahlreiche Herden von Wildkamelen in jener Reginn auf ( Beobachtung veröffentlicht, dass Zweifel ausgeschlossen sind. In seinem Reisebrief ${ }^{1}$ ) aus Obdal vom Juni 1900 schreibt er über den westlichen Gobi: „In der Gegend, die wir durchwanderten, kamen wilde Kamele "in grosser Anzahl vor, und wir sahen und beobachteten sie täglich durch „unsere Ferngläser. Sie halten sich längrs des Fusses der Berge und in der "Wüste auf, begeben sich aber von Zeit zu Zeit zu den schirmenden Quellen, „um zu trinken und zu grasen. Es gewährt einen herrlichen Anblick, weñ "man eine solche Herde, nach dem man ihr den Wind abgefangen, unver"mutet überrascht. Einige der Kamele standen gewöhnlich aufgerichtet als "Späher da, während die andern sich in liegender Stellung ausruhten. Es "erweckte mein Staunen, dass wir diese Tiere immer nur in den unwirt„lichsten, sterilsten und wasserärmsten Wüsten antrafen, wo wir mit unseren „zahmen Kamelen Gefahr liefen, vor Durst umzukommen. Wunderschön ,ist auch der Anblick einer durch unsere Annäherung, oder noch vielmehr „durch einen Büchsenschuss erschreckten fliehenden Herde. Sie selıen sich "nicht um, sie fliehen blos und sie fliegen über die Wüste dahin wie der "Wind und verschwinden in einigen Minuten am Ilorizonte, um erst wieder „Halt zu machen, wenn sie sich ganz sicher fühlen, weit, weit hinten im Sande.

Diesen Schilderungen nach persönlichen Eindrücken hat Sien Hedin noch Notizen über die Lebensıveise beigefügt, die ihm die eingebornen Jäger machten. Aus allem geht hervor, dass es sich um Geschöpfe mit dem Betragen eines echten wilden Tieres handelt.

Die Verbreitungswege des Kamels liegen somit ziemlich klar vor uns. Die erste Zähmung dürfte nicht allzuweit von dem heutigen Wohngebiet der Wildkamele abliegen, also in Hochasien erfolgt sein; als Haustier stieg es in die warmen Ebenen von Mesopotamien herab, wo vermutlich die benachbarten Araber die südliche Rasse des Dromedars aus dem zweihöckerigen Kamel umgezüchtet haben. Kurz vor Beginn der heutigen Zeitrechnung setzte die Dromedar-Rasse nach dem afrikanischen Kontinent hinüber. Vieleicht ist sie in grösseren Kontingenten erst später angelangt und Mortillet hat möglicherweise Recht, wenn er annimmt, dass erst mit dem Eindringen der Araber in der zweiten Hälfte des ersten Jahrtausends n. Chr. der Dromedar sich allgemeiner in Nordafrika eingebürgert habe.

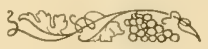

1) Reisebrief von Szen Hedin in der Zeitschrift "Die Umschau", herausgegeben von Dr. F. H. Bechhold. Nr. 44. Oktober 1900. 


\section{UEBERSICHT}

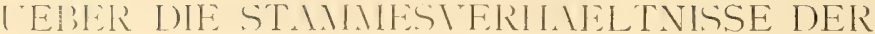 MELTESTEN HAUSTIERE.}

\begin{tabular}{|c|c|c|}
\hline Wildform & Urheimat & Zahme Abkömmlinge \\
\hline $\begin{array}{l}\text { 1. C'anis aureus } \\
\text { Sichakial }\end{array}$ & Westasien & $\begin{array}{l}\text { Torfhund. Spitzhunde, Pinscher. Tungusenspitz: } \\
\text { Tscliau. Battakhund. }\end{array}$ \\
\hline $\begin{array}{l}\text { 2. C'anis pallipes } \\
\text { Landga }\end{array}$ & Indien & Bronzehund, Schäterhund, Collie, I'udel. \\
\hline $\begin{array}{l}\therefore \text { Canis anthus } \\
\text { Scliakalwolt }\end{array}$ & Nordostafrika & Aegyptische und westasiatische Pariahunde. \\
\hline $\begin{array}{l}\text { 4. Canis simensis } \\
\text { Walgie }\end{array}$ & Aethiopien & $\begin{array}{l}\text { Altägyptischer Windhund. Slughi. Tasi, Barzoi, } \\
\text { Decrhound, Wolfhound, Windspiele. Jagdwind- } \\
\text { hunde. Haussahund. Taufhumd und Vorstehhund } \\
\text { (zum Teil gekreuzt). Dachshund. }\end{array}$ \\
\hline $\begin{array}{l}\text { 5. Canis niger } \\
\text { SchwarzerTibetwolf }\end{array}$ & 'libet & $\begin{array}{l}\text { Tihetdogge, Altassyrische Dogge, Molosserhund. } \\
\text { Veufundländer, Bernhardiner, Bulldoggen, Mops. }\end{array}$ \\
\hline $\begin{array}{l}\text { 1. Canis latrans } \\
\text { coyote }\end{array}$ & Nordamerika & (Bewisse Indianerhunde. Eskimohund.(?) \\
\hline $\begin{array}{l}\text { 7. C. occidentalis } \\
\text { Falbwolf }\end{array}$ & Nordameriki & Inkahund in drei verschiedenen Rassen. \\
\hline $\begin{array}{l}\text { \&. Felis maniculatil } \\
\text { fialbkatze }\end{array}$ & Nordustafrika & Ilauskatzen. \\
\hline $\begin{array}{l}\text { 4. Eqtus I'rze- } \\
\text { walskii } \\
\text { Przewalskisches } \\
\text { l'ferd }\end{array}$ & IJochasion & $\begin{array}{l}\text { ()rientalische Pferderassen, Mongolenpferd, } \\
\text { Araber, Gallapfert, nordafrikanische und ost- } \\
\text { curopäische P'fercle. }\end{array}$ \\
\hline $\begin{array}{l}\text { 11. Eyuus caballus } \\
\text { fossilis } \\
\text { Diluvialpferd }\end{array}$ & Europa & $\begin{array}{l}\text { ()ecidentale I'ferde, norisches P'ferd, deutscher } \\
\text { Karrengatul, Normännerpferde, engl. Karrenpferd. }\end{array}$ \\
\hline $\begin{array}{l}\text { 11. Equus taeniopus } \\
\text { Nubischer Steppen- } \\
\text { Esel }\end{array}$ & Nordostatrika & $\begin{array}{l}\text { Mltägyptischer Esel, kleinere Esel der Mittel- } \\
\text { mecrländer (Taeniopus-Kasse). }\end{array}$ \\
\hline $\begin{array}{l}\text { 12. Equus onager } \\
\text { Unager }\end{array}$ & Westasien & $\begin{array}{l}\text { Isabellfarbene und weisse Hausesel. Nedje- } \\
\text { Escl. (Onager-Rasse.) }\end{array}$ \\
\hline $\begin{array}{l}\text { 13. Sus vittatus } \\
\text { Bindenscluvein }\end{array}$ & ()stasien & $\begin{array}{l}\text { Chinesisches Schwein, Maskenschwein. Papua- } \\
\text { schwein. romanisches Schwein, englische Rassen, } \\
\text { Torfichwein. Bündnerschwein. }\end{array}$ \\
\hline
\end{tabular}




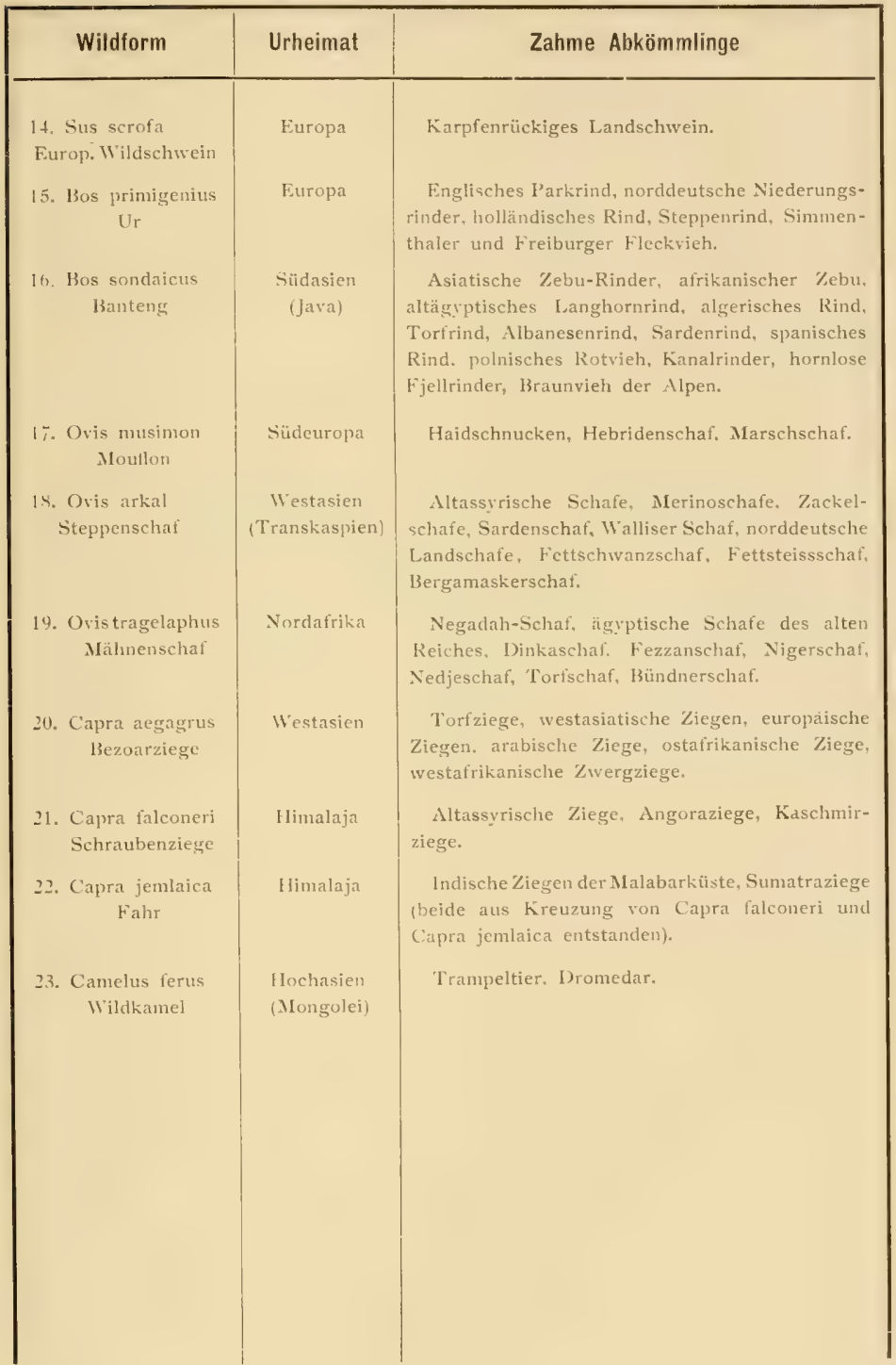




\section{NACHTRAG ZUM KAPITEL „HAUSRINDER“.}

Zeburind mit Aalstrich. Beim Braunvieh und beim einfarbigen Kurzkopfrind der Alpen verläuft ïber den Rücken ein heller Streifen, der sogenamnte Aalstrich. Ich suchte denselben auch beim Zebu nachzuweisen gemäss meiner Auffassung, dass der Braunviehstamm aus der Zebugruppe hervorging, doch standen mir einfarbige Höckerrinder früher nicht zu Gebote. Nach Drucklegung der vorigen Kapitel kommt mir ein indischer Zebu zu Gesicht, der einfarbig grauveiss ist. Das Flotzmaul ist schwarz, der Fettbuckel stark entwickelt und von demselben verläuft über den Rücken bis zur Schwanzwurzel ein breiter, vollkommen weisser und deutlich abgesetzter Aalstrich. Ich trage diese Thatsache nach, weil sie einen neuen Beleg für die Zebu-Abstammung unseres Alpen-Braunviehs liefert.

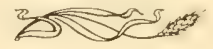




\section{RUECKBLICK.}

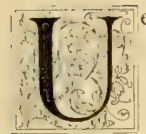

eberschauen wir die einzelnen Formenkreise derjenigen Ilaustiere, welche schon in den allerältesten Zeiten dem menschlichen Besitzstande einverleibt wurden, so drängen sich unwillkürlich eine Reihe von Fragen allgemeiner Natur auf, die entweder morphologische oder physiologische Thatsachen betreffen.

Dass die Ausgangsformen domestizierter Arten bei den wildlebenden Formen gesucht werden müssen und dass diese wilden Stammarten grösstenteils heute noch irgendwo ihr Freileben fortführen oder wenigstens noch in die historische Zeit hinein reichten, darüber herrscht wohl unter den Zoologen völliges Einverständnis.

Der Vergleich der Wildform mit den zahmen Deszendenten ergiebt ein für die Morphologie höchst wichtiges Ergebnis.

Jene so gut wie diese sind nach dem jetzigen Stand unserer wissenschaftlichen Erkenntnis in beständigem Formentluss begriffen. Dieser vollzieht sich aber in der freien Natur ausserordentlich langsam und zwar so langsam, dass wir für unsere phylogenetischen Zwecke keinen Fehler begehen, wenn wir annehmen, dass die Wildform vou dem. Punkte an, da sich die zahme Reike von ihr abgezweigt hat bis in die Gegenwart hinein keine erheblichen Umänderungen erlitten hat. Schon Cuvier konnte ja an dem von Creoffroy St. Ilitare Während der napoleonischen Expedition gesammelten Material aus der Pharaonenzeit den Nachweis liefern, dass die Veränderungen seit der altägyptischen Periode bei freilebenden Tieren gleich Null anzusetzen sind. Gegenwärtig verarbeitet Lortet, wie er mir schreibt, ein reiches Material von altägyptischen Tierresten und seine Ergebnisse dürften in der angedeuteten Richtung besondere Beachtung verdienen. Ich konnte schon früher als beachtenswerte Thatsache hervorheben, dass aus den ältesten Dynastien die Darstellung eines dem Canis simensis ungemein ähnlichen Hundes erhalten ist, die im wesentlichen übereinstimmt mit der Abbildung, welche uns Rïppel geliefert hat.

Sobald ein Geschöpf in den Hausstand des Menschen eintritt, so wird - Ausnahmen kommen vor - der Gang der Veränderungen in auffallender Weise beschleunigt.

Die Zeiträume, welche in Frage kommen, lassen sich heute selbst für die ältesten Haustiere annähernd übersehen. Die frühesten bildlichen 
Darstellungen von zahmen Arten reichen etwa in das sechste vorchristliche Jahrtausend zurück. Die primitiven, aber ofłenbar sehr naturwahren Bilder von Rind, Schat und Esel aus der urägyptischen Negadahzeit sind nach dieser Richtung Dokumente von hohem Wert. Man ersieht aus ihnen, dass der züchterische Eintluss damals erst begonnen hat, die Formen abzuändern. denn diese steht der wilden Stammform viel näher als dies in den folgenden Jahrtausenden der Fall ist. Geben wir mit Rücksicht auf das Rind, das in Altägypten offenbar von Asien her bezogen wurde, noch zwei Jahrtausende hinzu für die Periode der Migration, so dürften wir damit so ziemlich bei der äussersten Grenze angelangt sein, die wir zeitlich für die Entstehung der allerersten Haustiere ansetzen dürfen. Im Maximum würden wir also auf 10.000 Jahre kommen, die unsere Gegenwart von dem Beginn der ältesten Haustierwerdung trennen. Die Ziffer ist jedenfalls hoch genug angesetzt und ich glaube, dass zukünfige Funde im Gebiet der mesopotamischen Kultur dieselbe kaum wesentlich ändern werden.

Haben 8-10 Jahrtausende freilebende Arten, die hier in Betracht kommen, nicht erheblich umändern können, so vermochten sie dagegen die zahmen Abkömmlinge in manchen Fällen in weitgehendster Weise umzugestalten. Es ist somit der Einfluss des Menschen, der dem Umbildungsprozess ein rascheres Tempo verliehen hat und zwar in zwiefacher Weise. Einmal durch die Migration, die neue Lebensbedingungen zur Folge hatte. Indem der Mensch auf seinen ausgedehnten Wanderungen seine Haustiere nach nenen Gebieten verschleppte, haben die komplexen Reize, die wir unter dem Namen Klima und Wohnortsverhältnisse zusammenfassen, den ersten Anstoss zu Veränderungen gegreben.

Doch lehrt die Erfahrung, dass man diese Faktoren in gevissen Fällen nicht überschätzen darf. Nanche Rassen bleiben merkwürdig beständig: auch wenn sie in neue Wohngebiete versetzt werden. Beispielsweise hat sich dic Sus indicus-Form unserer Ilausschweine in Europa stellenweise, so in unseren Alpenthalern, stark konservativ verhalten. Das kleine Rind Sardiniens, ein Ausläufer der asiatischen Rindergruppe, weist noch Anklänge an die Zeburinder auf. Der russische Windhund ist in seiner Gesamterscheinung dem altägyptischen Windhund sehr nahestehend.

Von weit grösserem Einfluss erscheint die züchterische Auslese oder Selektion. Direkt vermag sie allerdings nichts neues zu schaffen, aber indirekt wird sie ausserordentlich schöpferisch, in dem sie über das Fortbestehen von zweckmässigen Abänderungen entscheidet und verhindert, dass dieselben bei unkontrollirter Vermischung der Haustiere wieder teilweise oder ganz verloren gehen. 'Thatsächlich kommt es auf dasselbe hinaus. ob die Selektion nur die sekundäre Führung übernimmt und primär noch andere Faktoren mitspielen - sie ist ein I lauptfaktor bei der Umgestaltung der IIaustierformen.

Die züchterische Auslese wird, was jedem denkenden Landwirt bekannt 
ist, in der gegenwärtigen Wirtschaftsperiode mit dem höchsten Raffinement betrieben. Jeder erzielte Erfolg lässt sich eben sofort in klingende Münze umsetzen und dieser Unstand giebt den Ausschlag im Kampf ums Dasein der Landwirte. Dic Fleckviehzüchter des Simmenthal wissen das sehr wohl: auch die Geschichte der Merino-Zucht liefert einen klassischen Beleg für das Gesagte.

Indessen hat bereits Darwin in seinem 1 ถูงิ9 erschienen Werke: "On the origin of Species" sehr richtig daraut hingeviesen, dass die Annahme unzutreffend sei, dass man erst in der neueren \%eit eine kunstgerechte Züchtung betreibe.

In der That lehrt uns das Studium der alten Kulturkreise, dass eine Selektion mit bestimmten Zuchtzielen schon sehr früh bewusst in Anwendung gebracht wurde. So sehen wir im Pharanenlande bereits während der altesten Dynastien eine ausgesprochene Reinzucht geübt. Die schönen Windhunde Altigyptens sind vollkommen reinblütig. Für die Aufzucht der Rinder wurden geeignete Kühe ausgesucht und untaugliche Stiere, wemn sie dieselben decken wollten, mit dem Stock verjagt. Für die ägyptischen Stiergefechte züchtete man eine besondere Rasse von Kampfstieren.

Die hochentwickelte Kultur im alten Nilthal war in mancher Hinsicht vorbildlich für die antike Kulturwelt in Griechenland und es ist zu vermuten, dass die züchterische Erfahrung von degypten aus sich nach Kleinasien und Griechenland verptlanzt hat, doch lässt sich zur \%eit noch nicht genatuer nachweisen, in welchem Umfang dies der Fall war. Sicher ist nur so viel, dass Nordafrika an Südeuropa an zahmen Rassen frühzeitig viel mehr abgegeben hat, als man bisher zugestehen wollte.

Im alten Griechenland sind die beiden Methoden der Reinzucht und der Kreuzungszucht sehr bewusst gehandhabt worden. Man scheute keine Ansgaben, um aus fremden Landern geeignete Znchttiere zu beschaffen. Die züchterischen Erfahrungen verbreiteten sich nach den griechischen Kolonien in Süditalien und wurden von den Römern verständnisvoll weiter entwickelt. Letztere waren es auch, die später in ihren Kolonien, namentlich im Norden der Alpen eine Ungestaltung und Verbesserung der Iaustier-Rassen herbeiführten.

Unabhängig von Kultureinflüssen der alten Welt wurde auch im präkolumbischen Amerika eine Rassenzucht mit Erfolg betrieben, wie Nchring am Beispiel der altamerikanischen Hunde nachgewiesen hat.

Freilich kennen wir selbst auf europäischem Boden Gebiete, wo der Mensch nur wenig in den Entwicklungsgang seiner domestizierten Tiere eingegriffen hat und die vorhandenen Rassen stabil geblieben sind. Auf geographisch wenig auseinander liegenden Distrikten finden sich merkwürdige Gegensätze. Man vergleiche in der Schweiz beispielsweise das Simmenthal mit seinem hochgezüchteten Fleckvich und das benachbarte Wallis, dessen Rinder, Schafe und Ziegen zum Teil recht alte, konservativ 
gebliebenen Rassentypen aufweisen. Und England beherbergt auf seinem Boden neben ganz modernen Zuchten noch solche, die offenbar seit langer Zeit unverïndert geblieben sind.

Die grossartigen Veränderungen, welche uns die Geschichte einzelner Haustiere vor Augen führt, hat Darwin bereits in richtiger Beleuchtung gezeigt: diese Veränderungen sind geeignet, das Verständnis für die viel langsameren Umbildungen in der freien Natur zu eroffnen. Es mag dies hier um so nachdrücklicher betont werden, da gerade in der Gegenwart an den Grundanschauungen des Darwinismus stark zu rütteln versucht wird.

Rein wissenschattlich betrachtet, ist die züchterische Arbeit. welche so tief eingreifende Umbildungen an unseren Haustieren hervorgerufen hat, nichts anderes als ein Fahrtansende hindurch fortgesetztes Exporiment, das die Richtigkeit der Transmutations- und Sclchtionslchre beweist. Die Geschichte der allerältesten Haustiere soll uns die verschiedenen Phasen vor Augen führen. welche von den einzelnen Rassen bei diesem naturwissenschaftlichen Experiment durchlaufen wurden.

Ich weiss, dass dieser Standpunkt neuerdings hart angefochten wird. Es wird von vielen Seiten darauf hingewiesen, dass man aus den Vorgängen der künstlichen Züchtung nicht so ohne weiteres Schlüsse auf die Vorgänge in der freien Natur ziehen dürfe, weil die natürliche Zuchtwahl mit anderen Nitteln arbeite wie die künstliche Auslese. Dieser Einwand ist unter den Botanikern erhoben worden, so von Higand, Nägeli, Reinke und neuerdings (1901) wieder von de Tries, welcher behauptet, die wahre Klippe der Darwin'schen 'Theorie sei der Uebergang von der künstlichen Zuchtwahl zu der natürlichen Zuchtwahl. Auch von zoologischer Seite wurden ähnliche Bedenken laut, so von Haacke, Emery und Ortmann.

Carl Vägeli betrachtet auffallenderweise die Haustiere und Kulturptlanzen als abnorme Produkte, deren vererbendes Plasma krankhaft geschwächt ist und Haacke scheint dieser Annahme ebenfalls zuzuneigen, wenn er bei Haustieren von einer Lockerung des Plasmagefüges spricht. In diese Allgemeinheit gefasst, kann ich obigen Sätzen nicht zustimmen. Dann wäre überhaupt jede V'eränderung an Lebewesen als krankhaft zu bezeichnen und in der That hat Rudolf Firchow diese Konsequenz gezogen und jede Veränderung als pathologisch bezeichnet. Die belebte Natur wäre somit nichts weiter als ein grosses Krankenlager!

Ich leugne keineswegs, dass die künstliche Züchtung unter Umständen Produkte erzeugt, die krankhaften Charakter an sich tragen. Jedem Tierzüchter ist bekannt, dass zu weit getriebene Inzucht oder gar Incestzucht eine Rasse verschlechtern kann. Aber das berechtigt noch nicht, jede Haustier-Rasse als ein abnormes, pathologisches Produkt aufzufassen.

Wer die Zuchten in unseren Alpen näher beobachtet, wird wohl rasch vom Gegenteil überzeugt werden. Esel und Rinder sind seit Jahrtausenden in den ostafrikanischen Steppen angesiedelt und erfreuen sich heute noch 
einer exemplarischen Vitalität. Der europäische Ur (Bos primigenius) erwies sich in der freien Natur nicht hinreichend lebensfähig; er ist untergegangen, während sich seine zahmen Nachkommen heute noch einer blühenden Gesundheit erfreuen, man braucht nur auf die stattlichen Steppenrinder und friesischen Rinder hinzuweisen.

Die Bildungsgesetze sind also in der freien Natur prinzipiell nicht verschieden von den Umbildungsgesetzen im Ilausstand oder dann müsste man die Richtigkeit und die Beweiskraft eines vom Menschen unternommenen naturwissenschaftlichen Experiments geradezu bezweifeln.

Ich darf vielleicht ein Bild gebrauchen.

Eine starke elektrische Entladung kam auf einen Organismus eine tötliche Wirkung ausüben. Ob ein Mensch vom I3litz erschlagen wird, oder ob in Nordamerika vom Elektrotechniker eine I linrichtungsmaschine erstellt wird, um einen Präsidentenmörder ins Jenseits zu befördern, kommt doch schliesslich in beiden Fällen auf die Elektrizität als Ursache hinaus. Die Natur schafft keine I Inrichtungsmaschinen, keine submarinen Kabel, keine elektrischen Tramwagen und keine Bogenlampen. Es ist der Mensch, der diese Dinge geschaffen hat - die Gesetze der Elektrizität sind dieselben wie in der freien Natur und niemand wird z. B. das elektrische Licht als krankhaften Ausfluss einer Naturkraft erklären wollen. Hier bemeistert der Mensch einfach die Naturgesetze und ebenso nimmt er die Bildungsgesetze der Natur in seine Hand, wenn er auf experimentellem Wege dem Haustier eine neue, ihm zusagende Form mit geeigneten Leistungen verleiht.

Verfolgen wir nun den Gang der Entwicklung, welcher zur Entstehung der einzelnen Rassen führte, so vollzog er sich nicht überall in gleicher Weise.

In gewissen Fällen ist die Umbildung langsam vor sich gegangen, jede sprunghafte Entwicklung erscheint ausgeschlossen.

Ein sehr lehrreiches Beispiel bietet sich uns in der Geschichte der Merino-Schafe, die wir in ihren einzelnen Phasen recht gut überblicken können. Jahrhunderte hindurch mussten viele Generationen von Züchtern mit aller Sorgfalt arbeiten, um nach und nach den edlen spanischen Stamm zu erzielen, von dem sich seit Ende des 18. Jahrhunderts einzelne Zweige abgelöst haben, um in Frankreich, in ()esterreich und in Sachsen wieder neue und eigenartige Zuchten zu begründen.

Das europäische Frontosusrind hat sich frühzeitig in einer nördlichen Region vom Primigeniusstamm abgezweigt. Auf dem Boden der Schweiz ist es in neuerer Zeit auffallend stark umgestaltet worden. Wenn ich mir vergegenwärtige, wie eine Simmenthalerzucht vor 30 Jahren aussah und damit die Zuchtprodukte vergleiche, welche gegenwärtig an die Ausstellungen gelangen, so muss ich bekennen, dass mit diesem jetzt hochgezüchteten Simmenthaler Fleckvieh erstaunliche Veränderungen in wenigen Dezennien vorgegangen sind. Im Norden von Europa vollzieht sich langsam ein Uebergang von kleinen brachyceren Rindern in völlig hornlose Formen. 
Wir dürfen wohl annehmen. dass in der freien Natur die Transmutation der Arten sich in ähnlicher Weise vollzog und immer wieder im Laufe der Entwichlung eine Stufe über die andere hinaus ging. Die Palaeontologie hat in der That solche zusammenhängende Ketten aufgedeckt - ich brauche nur an das klassische Beispiel der tertiären Pferde zu erinnern.

Aber auch in der gegenwärtigen Lebewelt sind auf einem verhältnismissig wenig ausgedehnten Areal ahnliche Entwicklungsreihen neben einander lebend nachgewiesen worden. Ausgezeichnete Beispiele haben I'aul und Fritz Sarasin in ihren tiergeographischen Untersuchungen bei den Landmollusken von Celebes nachgeviesen. Es giebt dort lange Ketten von Arten, von denen jede um einen Schritt über die vorhergehende hinaus reicht.

Derartige Thatsachen bestätigen für die freie Natur eine Annahme, zu der uns die Ergebnisse der experimentierenden Transmutation, d. h. die rationelle Tierzucht geführt haben. Damit stellen wir uns freilich in Gegensatz zu der jetzt viel besprochenen...Mutationstheorie“. wie sie 1901 von Ilugo de Vries zu begründen versucht worden ist und das Problem der Artbildung von einer ganz neuen Seite beleuchten will.

Der (redanke einer sprungweisen Entwicklung (Mutation) in der organischen Natur ist wiederholt ausgesprochen worden aber wohl nie so nachdrücklich und mit so gewichtigen Beweismitteln. wie dies bei $/$. de Vries der Fall ist. I)er genanute Amsterdamer Botaniker hat in sehr geschickter Weise die Gegensätze zwischen den früheren Anhängern der Konstanzlehre und der Transmutationstheorie zu vermitteln versucht, indem er die Spezies während einer langen Periode konstant sein lässt, bis diese in die sogenannte Mutationsperiode eintritt und in kurzer Zeit neue, beständige Arten liefert. Sind die Arten eimmal da, dann entscheidet der Kampf ums Dasein über deren Fortexistenz.

Im Gegensatz zu Darzin, welcher den Kampf ums Dasein als züchtendes Moment ansieht, soll dieser nicht neue Arten entstehen lassen. sondern umgekehrt gewisse Arten vernichten.

H. de Fries konnte an einer amerikanischen Nachtkerze (Oenothera Lamarckiana) ein Beispiel nachweisen, dass sich diese Art gegenwärtig im Zustand der Mutation befindet. Seit der Einführung nach Europa hat diese Płlanze in kurzer Zeit mehrere neue, formbeständige Arten geliefert.

Die beobachteten Thatsachen sind zweifelios höchst interessant. Aber die Induktionsreihe erscheint mir zunächst viel zu klein, um darauf gestützt eine allgemeine Theorie aufzubauen. Meiner Ansicht nach hätten vorerst ausgedehnte Parallelversuche mit den neuen Formen in Amerika angestellt werden sollen, um zu erfahren, wie sie sich in der alten Heimat verhalten. Vorlüufig kann man aus den mitgeteilten Thatsachen höchstens den Schluss ziehen, dass gelegentlich neue Arten infolge von Mutation einer schon vorhandenen Art auttauchen. Ob dies in der freien Natur Regel oder nur 
gelegentiche Ausnahme ist, bleibt dahingestellt. Ich möchte die Mutation als Ausuahme betrachten.

Wir kennen ja aus der Rassengeschichte einen berühmten und gut untersuchten Fall von plötzlicher Mutation, der zur Entstehung einer besonderen Schafrasse geführt hat. Es betrift derselbe das Mauchamp-Schaf. 1828 wurde in Nauchamp in einer Merino-Zucht ein Rocklamm beobachtet, das nicht das gewöhnliche gekräuselte Wollhaar, sondern ein langes, seidenartiges Vliess besass. Der P'áchter Graux erzog mit Hülfe dieses Bockes, der eine auffallend starke Individualpotenz aufwies, Nachkommen mit langer, fester und weicher Wolle (Seidenwollhaar), die schon 1835 auf einer landwirtschaftichen Ausstellung gezeigt wurden und später sehr gut vererbten. Die Merino-Schafe zeigen daher langsame und stetige Umbildung als Regel und Mutation als Ausnahme. Ich halte es für möglich, dass bei diesen plötzlichen Veränderungen primäre Ursachen im Keimplasma zu suchen sind.

Eine ungemein ergiebige und für die Iaustier-Norphologie bedeutsame Quelle zur Entstehung neuer Formen bildet die Kreuzung. Jedenfalls erzielt der Züchter damit rasche Erfolge, die aber nicht immer andauern.

Auf weiten Gebieten überwiegen die Kreuzungsprodukte gegenüber reinrassigen Tieren.

Schon wähend der prähistorischen Zeit lassen sich häufig Spuren von Kreuzungen erkennen. In den jüngeren P'fahlbauten der Westschweiz lassen sich solche für das Rind nachweisen, indem das kleine Torfrind mit dem später anlangenden grossen Rind gekreuzt wurde.

In der Bronzezeit taucht eine als Canis intermedius beschriebene Rasse auf, die augenscheinlich aus einer Kreuzung des kleinen Torfhundes mit dem grösseren Bronzehund hervorging. Auch das Torfschaf enthält vermutlich etwas Blut von fremder Rasse beigemischt. In der Gegenwart hat diese Erscheinung einen ungleich grösseren Unfang angenommen. Man durchmustere in unseren Städten nur eimmal das vorhandene Hundematerial, so ist vielfach von Rassereinheit keine Rede mehr und man wird oft Mühe haben, in dieser Mulattengesellschaft die Stammquelle sicher heraus zu finden.

Aehnlich verhält es sich mit unserem europäischen Pferdematerial. Orientalisches und abendländisches Blut ist auf weiten Gebieten in allen möglichen Abstufungen gemischt. Seit die asiatischen Schweinerassen sich immer mehr auf dem Kontinente einzubürgern beginnen, geht die früher stark verbreitete alte Landrasse immer mehr in derselben auf. In Mitteleuropa ist von einem Rinde reiner Rasse vielorts gar keine Rede mehr und nur einzelne Grossgrundbesitzer treiben Reinzucht.

In einzelnen Fällen gehen die Erzeugnisse der Kreuzung in einem allgemeinen Formen-Wirrwar auf, in anderen dagegen führten sie zur Entstehung von scharf umschriebenen Rassengruppen.

Das Bündnerschaf als direkter Abkömmling des alten Torfschafes, in welchem neben afrikanischem Blut vermutlich etwas europäisches oder 
asiatisches Blut vorhanden ist, bildet eine scharf gekennzeichnete Rasse. Im Osten Asiens erscheint die Malabarziege Indiens und die Malayen-Ziege als ein recht auffallendes Geschöpf. Die Behaarung scheint zu starken individuellen Abäuderungen geneigt, aber der gesamte Ilabitus des T'ieres und namentlich der Bau des Kopfes sind recht scharf markiert. Ich versuchte nachzuweisen, dass diese Rasse die eigentümliche Koptbildung dem eingeflossenen Tahrblut verdankt und daher als Bastard aufzufassen ist.

Unter den Ilunden ist die deutsche und die damit verwandte dänische Dogge trotz der Kreuzung zu einem sehr beständigen Typus geworden, der nun in Reinzucht fortgeführt wird.

Manche wollen die selır beständige Schwarzfleckrasse von Freiburg nicht als ganz reines Frontosus-Rind ansehen, sondern vermuten in ihr ein Kreuzungsprodukt. Wahrscheinlicher ist dies unter den Braunviehrindern tür den Schwyzer Schlag.

Mögen neue Formen so oder anders entstanden sein — im Wesentlichen handelt es sich um Einwirkungen von Seiten des Menschen, da klimatische und topographische Faktoren doch mehr sekundär sind.

Von menschlichen Einwirkungen kommen hauptsächlich in Betracht die Art der Ernährung, sodam die Uebung der Organe bei Haustieren, welche bestimmten nützlichen Leistungen angepasst werden und endlich die Regulierung der Fortptlanzung bei der züchterischen Auslese.

Der langsame ( mit dem ungemein raschen Tempo der Entwicklung der Tierwelt im Hausstande bereitet dem Zoologen eine grosse Verlegenheit, wo es sich um die Iandhabung des Spezieshegriffes handelt.

Im Sinne der herkömınlichen Schulzoologie muss für unsere Haustiere dieser Begriff entweder gänzlich fallen gelassen oder dann so modifiziert werden, dass man nur die genetische Seite, die gemeinsame Abstammung der Individuen, betont, dagegen anf die morphologische Forderung der Formenähnlichkeit ganz verzichtet.

Man hat früher infolge Unkenntnis der genetischen V'erhältnisse bei manchen Haustierarten die Variationsfahhigkeit überschätzt und manche körperlichen Unterschiede als Wirkung der Züchtung betrachtet, die heute aus einer V'erschiedenheit der Abstammung erklärt werden müssen. Aber trotzdem ist die Formenbiegsamkeit der einzelnen Reihen noch gross genug, um die morphologische Forderung des herkömmliclıen Speziesbegriffes einfach illusorisch zu machen.

Ueberschauen wir z. B, die Formenreihen der Hausrinder Asiens und Afrikas mit ihrer gemeinsamen südasiatischen Stammquelle, so kann man hier von einer Spezies in gewöhnlichem Sinne gar nicht mehr reden. Ebenso haben sich die Rinder europäischer Provenienz in ihren Endgliedera heute bereits soweit entfernt, dass man im Sinne der Schulzoologie die podolischen Rinder, die Niederungs-Rinder und die Frontosus-Rinder als drei gute Arten taxieren müsste. 
Der asiatische Stamm der Schafe erwies sich so ausserordentlich bild. sam, dass er in eine Reihe guter und mehrere weniger gute Arten zerspalten werden könnte.

Bis heute besitzen wir aber keine einheitliche und allgemein anerkannte Nomenklatur unserer Haustierformen.

Gegenwärtig noch von einem Canis familiaris im Sinne Linnés reden zu wollen, hat doch zoologisch genommen keinen Sinn mehr, denin die gut umschriebenen Formenreihen unserer Haushunde sind ja auf ganz verschiedene Wildspezies zurückzuführen, können also aus rein genetischen Gründen nicht zu einer einzigen Art verschmolzen werden.

Was sollen wir unter Ovis aries verstehen? Was gewöhnlich unter diesem Namen figuriert, ist ein Sammelsurium von heterogenen Formen zahmer Schafe, die drei ganz verschiedene Ausgangsformen haben.

Unsere Rinder zoologisch als Bos taurus zu bezeichnen, ist jedenfalls unzulässig, da sie zwei morphologisch und geographisch auseinander liegenden Arten entsprungen sind.

Es wird also eine Aufgabe der Zukunft sein, für die domestizierten Tiere eine brauchbare Nomenklatur zu schaffen. Es lassen sich verschiedene Wege denken. Entweder befolgt man die gleichen Regeln, wie man sie bei freilebenden Formen angenommen hat, d. h. man verwendet die binäre Nomenklatur im Sinne der Systematik und wird dann, ohne eine scharfe Abgrenzung vornehmen zu können, eine Masse neuer Arten kreieren müssen, oder man sieht von diesem konsequenten Verfahren ab und macht bei den Haustieren eine Ausnahme.

Dann könnte man, wic es von L. Fitzinger seinerzeit versucht, aber leider sehr wenig rationell durchgeführt wurde, bei der wissenschaftlichen Nomenklatur drei Namen verwenden, wobei gleichzeitig die Stammiorm aufgenommen wird.

Es setzt dies naturgemäss eine gesicherte I'hylogenie voraus und eine derartige Nomenklatur müsste also ganz neu geschaflen werden.

Bei Formen, die sich von der wilden Stammart noch wenig entfernt haben, genügte es, dem bisherigen Speziesnamen einfach beizufügen, dass es sich um die domestizierte Form handelt.

Die Hauskatze würde man somit als Felis maniculata domestica, das europäische Landschwein als Sus scrofa domesticus, das chinesische Hausschwein als Sus vittatus domesticus bezeichnen. Wo die Umbildung der Formen weiter gediehen ist, kommen andere Benennungen zur Verwendung. Das eigentümliche Maskenschwein Ostasien erhielte etwa den Namen Sus vittatus pliciceps.

Im asiatischen Stamm der Schafe würde ich etwa als Arten aufstellen: 1. Das Fettschwanzschat (Ovis arkal platyura); 2. das Fettsteissschaf (Ovis arkal steatoprga): 3. das Zackelschaf (Ovis arkal strepsiceros) und 4 , das Merinoschaf (Ovis arkal hispanica) mit seinen verschiedenen Varietäten. 
Für das Rind wird der Name Bos taurus ganz hinfällig, die bisher hïufig zur Verwendung gelangten Bezeichnungen Bos taurus primigenius, Bos taurus frontosus, Bos taurus brachyceros und Bos taurus brachycephalus sind wiederum nicht ganz glücklich.

Will man die einzelnen Formenkreise nach ihren Stammesbeziehungen wruppieren, so liessen sich für die altweltlichen Hausrinder etwa folgende Speziesformen aufstellen: 1. Steppenrinder (Bos primigenius podolicus): 2. Marschrinder (Bos primigenius hollandicus); 3. Grosstimrinder (Bos primigenius frontosus); 4. Grosshörnige Zeburinder (Bos sondaicus macroceros); 5. Kurzhornrinder (Bos sondaicus brachyceros) und 6. Hornlose Rinder (Bos sondaicus akeratos). Es sind das vorläufig nur Andeutungen, wie man vorgehen sollte und ich begnüge mich an dieser Stelle damit.

Die bisher berührten Umbildungen im Hausstande drängen uns auch eine physiologische Betrachtungsweise auf. Es entsteht die Frage, wo sie ihre erste Entstehung genommen haben. Sind sie primär im somatischen Gebiet aufgetaucht und hinterher auf die Keimsphäre übertragen worden oder entstanden sie zuerst im Keimplasma.

In der Neuzeit hat sich in der Vererbungslehre bekanntlich der Gegensatz zwischen beiden Anschauungen stark zugespitzt. Der altere Lamarkismms, der eine Uebertragung aus dem somatischen Gebiet auf das Keimplasma annimmt, ist von dem modernen Weismannismus, der diese Uebertragungsmöglichkeit leugnet, zu erschüttern versucht worden.

Mir scheint, dass die Haustiergeschichte neben dem physiologischen Experiment in erster Linie dazu berufen ist, zur Klärung der Streitfrage beizutragen.

Sie gewährt uns einen weiten Ueberblick über die Erfolge der Tierzucht und diese ist ja auch ein Experiment auf dem Gebiet der Vererbungsphysiologie. Sie sollte daher heute eine Aufklärung liefern können.

Schon die oben berührte Thatsache, dass mit dem Uebertritt einer Wildform in den Hausstand die Umbildung, beziehungsweise Entwicklung ein viel schnelleres Tempo anschlägt als bei den unter gleichen örtichen Bedingungen lebenden Vervandten in der freien Natur, giebt uns deutliche Winke.

Vom Wildstande her werden eine grosse Zahl vererbbarer Eigenschaften in die neuen Verhälnisse herübergenommen. Um diesen eisernen Bestand gruppieren sich im Laufe vieler Generationen neue Eigenschaften, die sich entweder schon regelmässig vererben oder deren Vererbung erst noch befestigt werden muss. Dieselben besitzen ein verschiedenes Alter, da ja die Aufnahme in das vererbende Inventar nicht gleichzeitig, sondern nach und nach erfolgt. Dahin rechne ich vorab die Rassenmerkmale, die Eigentümlichkeiten einzelner Schläge und Zuchtfamilien. Diese sind es, welche 
wir als die vom I Iaustier cruorbenen Eigenschaften bezeichnen können und auf deren Weitervererbung der Züchter rechnet.

Wenn die neuen Eigenschaften zuerst im somatischen Gebiet auftauchen, wie der Lamarckismus annimmt, dann setzt deren Vererbung einen Mechanismus voraus, der äussere Veränderungen auf das Keimplasma übertragen kann.

Indem A. Weismann alle Abänderungen zuerst im Keimplasma erscheinen lässt, macht er diesen übertragenden Mechanismus entbehrlich. Nun scheint mir der scharfsinnige Carl Nägeli durch seine wenigstens im Prinzip richtige Idioplasmalehre die Art angedeutet zu haben, wie wir uns einen bis zur Keimzelle reichenden Uebertragungs-Mechanismus vorstellen können. Setzen wir an Stelle seines im Körper verzweigten Plasmanetzes, das zur Vererbung bestimmt ist, ein System von Punkten, resp. Zellkernen, die gegenseitig Fühlung besitzen, wenn auch nur in drnamischem Sinne, so ist der Nägclische Gedanke in eine Form gebracht, die unseren heutigen cellular-physiologischen Anschauungen entspricht.

Bei dem geordneten Ineinandergreifen der einzelnen Gewebe müssen wir eine solche gregenseitige Fühlung als vorhanden annehmen und die mikroskopische Anatomie hat auch durch zahlreiche Beobachtungen nachgewiesen, dass gerade bei den physiologisch sehr energischen Geweben (Epithelien, Muskeln, Nerven) die einzelnen Zellen unter sich in Verbindung stehen und besondere Nervenbahnen überall regulierend eingreifen. Die V orstellung, dass dies nur für Körperzellen der Fall sei, die Keimzellen dagegen eine lusnahme bilden und sozusagen eine getrennte Buchführung besitzen, erscheint mir vom physiologischen Gesichtspunkte aus betrachtet doch etwas gewagt, anderseits will ich der Weismann'schen Richtung zugeben, dass in gewissen Fällen auch Anlagen zu neuen Eigenschaften zuerst im Keimplasma auftauchen können, da die Keimzellen ebenso gut der Veränderung fähig sind wie die übrigen Zellen. Wahrscheinlich sind sprungweise Abänderungen wie plötzlicher Albinismus, Melanismus u. s. w. primär im Keimplasma entstanden.

Anhänger wie Gegner der Lamarck'schen Ansichten haben vorwiegend Wahrscheinlichkeitsbeweise ins Feld geführt. In jüngster Zeit hat jedoch der Entomologe Dr. E. Fischer experimentelle Studien an Insekten veröflentlicht ${ }^{1}$ ), die mir eine Uebertragung neuerworbener Eigenschaften des somatischen Gebietes auf das Keimplasma als zweifellos erscheinen lassen. Er verfuhr in der Weise, dass er aus einer Zucht des bekannten Bärenspimners (Arctia caja) eine Anzahl Raupen sich normal entwickeln liess, die andern nach der Verpuppung einer Kälte von $8^{\circ} \mathrm{C}$ aussetzte und damit Falter mit auffallenden Aberrationen gewann. Während die normalen Falter durchweg normale Nachkommen lieferten, haben die durch das

1) Dieselben wurden öffentlich bekannt gegeben anlässlich der Versammlung der schweiz. Naturforscher in Thusis (1900). 
Experiment abgeänderten Falter, welche zur Fortpllanzung gebracht werden konuten und deren Brut jetzt unter normalen Verhältnissen aufgezogen wurde, die Abänderung unzweideutig vererbt.

Der Einwand, dass dies wohl für Insekten richtig sei, aber daraus kein verbindlicher Schluss auf höhere Tiere z. B. auf unsere Haustiere gezogen werden dürfte, ist nicht stichhaltig. Es handelt sich bei solchen Erscheinungen un ganz allgemein verbindliche Gesetze.

Der T'ierzüchter setzt denn auch die Uebertragbarkeit der im somatischen Gebiete neu erworbenen Eigenschaften voraus und W. Witckens sagt wohl zutreflend, dass jeder Fortschritt auf dem Gebiet der Tierzucht unmöglich wäre, wemn jene Uebertragbarkeit auf das Keimplasma nicht stattfände.

Er beweist dies an dem Beispiel des englischen Rennpferdes, bei dem seit etwa 200 Jahren durch fortwährende Uebung auf der Renubahn der Kopf kleiner, der Hals länger, das Gestell höher geworden ist. A. II cismann will dagegen diese Veränderungen lediglich auf Selektion zurückführen.

Iir scheinen in dieser Streitfrage die Thatsachen entscheidend, die wir hinsichtlich der ausserordentlichen Veränderungen im psychischen Charakter unserer Haustiere unter dem Eintluss des Menschen beobachten köunen.

Der psychische Vergleich zwischen einer Wildform und der zugehörigen zahmen Form lässt oft eine tiefe Kluft im geistigen Wesen erkennen, deren Entstehung nicht durch blosse Auslese erklärt werden kann, wenn wir auch zugeben, dass die Auslese unterstützend gewirkt hat. Sie that dies nur sekundär.

Alle unsere ältesten Iaustiere stammen von Wildarten ab, die gesellig gelebt haben, somit schon in Freileben der Suggestion zugänglich waren. Mit dem Eintritt in den Hausstand hat der erzieherische Eintluss des Menschen diese Suggestionsfähigheit henutzt und dem geistigen Wesen seiner Haustiere eine neue Richtung gegeben, die sich im Laufe der Zeit sehr streng vererbt hat.

Soweit die Psychologie das Wesen der Suggestion ermittelt hat, handelt es sich stets um äussere Einwirkungen, welche die psychische Funktion abändern. In unserem Fall wirkt der Mensch durch allerlei Suggestivmittel auf das Nervensystem ein, wodurch Veränderungen im Grosshirn hervorgerufen werden. Gewisse Vorstellungen werden beseitigt, andere treten ganz zwangsmässig in den Vordergrund. Wie $O$. Stoll in seinem ideenreichen Werke "Suggestion und Hypnotismus" ungemein treffend bemerkt, ist die Suggestion die "Zwangsjacke des Gedankens". Handelt es sich um Dressur der Haustiere, so wird die Suggestion systematisch gesteigert und ein aut den Mann dressierter Hund lässt sich auf einen völlig imaginären Gegenstand hetzen, so bald man bestimmte Suggestivmittel in Anwendung bringt. Die Haustiergeschichte sagt uns nun ungemein klar, dass diese äusseren Einwirkungen im Laufe der Zeit sich durch Vererbung hefestigt haben. 
Merkwürdigerweise ist das Resultat dieser Einwirkungen bei den einzelnen Arten sehr verschieden ausgefallen; einige haben geistig ungemein viel gewonnen, andere dagegen verloren.

Am merkwürdigsten verhält sich die I Iauskatze. Von Ilaus aus intelligent, behielt sie ihre Selbstïndigkeit mehr wie irggend ein anderes Geschöpf. Suggestiv sehr empfänglich, verlangt sie gute Behandlung, ist dies nicht der Fall, so antwortet sie sofort durch eine Konträr-Suggestion. Der Umstand, dass sie in ihrer ursprünglichen Heimat, in Aegypten, sehr lange als Kultgegenstand behandelt wurde, düfte diesces selbstündige und aristokratische WVesen gesteigert haben.

Durchaus entgegengesetzt verhielt sich der Hund, der übrigens im Verkehr mit dem Nenschen ausserordentlich an Intelligenz gewonnen hat.

Geistig verloren hat der Esel, wenigstens in den romanischen Ländern Südeuropas, was der schlechten Behandlung zugeschrieben werden muss. Im Orient, wo man auf ihn viel mehr Sorgfalt verwendet, ist sein Charakter weit angenehmer.

Der Büffel, im wilden Zustand sehr agressiv, hat sich im Hausstand zum gutmütigsten Wesen entwickelt, das sich von jedem Kinde lenken lässt.

Das Schwein ist nicht ohne Intelligenz und wie einzelne Beispiele lehren, erziehungsfähig, aber es ist vom Menschen immer vernachlässigt worden.

Weitaus die grössten Veränderungen weist das Schaf auf. Seine Zucht ist sehr alt, aber psychisch hat es gewaltig eingebüsst. Die Wildschafe sind vorwiegend Gebirg: Es wird von allen Beobachtern hervorgehoben, dass sie Gefahren n.t Klugheit zu erkennen wissen und sich durch Mut und Kampflust auszeichnen. Im Hausstand ist zwar die starke Suggestionsfähigkeit geblieben, aber an die Stelle der Klugheit ist eine unslaubliche Willenlosigkeit und I nummheit getreten. der Mut ist einer grenzlosen Feigheit gewichen.

Diese neuen Erwerbungen haben sich durch Vererbung so streng befestigt, dass unsere Hausschafe wegen ihrer Unbeholfenheit gar nicht mehr verwildern können: der Freiheit überlassen würden sie aus Mangel an Verteidigungsfähigkeil dem ersten besten Raubtier zum Opfer fallen.

Sollen wir nun annehmen, dass mit dem Eintritt in den Hausstand im Keimplasma bei allen drei Stammreihen (denn das Hausschaf lässt sich ja auf drei verschiedene Stammformen zurückführen) plötzlich Feigheitsdeterminanten autgetreten seien, die der Mensch ihrer Zweckmässigkeit wegen weiter züchtete und zur Vererbung brachte? Eine solche Annahme erschiene durchaus unnatürlich, dagegen liegt die auf das Keimplasma übertragene Veränderung, die durch suggestive Einflüsse zuerst im somatischen Gebiet erworben wurde, auf der Iland. Dass die züchterische Auslese hinterher noch unterstützend eingriff, soll deswegen nicht geleugnet werden.

Was für das Nervensystem gilt, trifft auch für andere Organgebiete 
zu, ihr Gebrauch oder Nichtgebrauch bewirkt Veränderungen, die erblich übertragen werden können.

Lehrreich sind auch jene Fälle, wo ein Haustier sein Verhältnis zum Menschen löst und zum Wildieben zurückkehrt. Dieses Verwildern kemen wir bei den meisten IJaustieren, so bei Katzen, IJunden, Rindern, P'ferden, Schweinen, Ziegen und Kaninchen. Dann steigen die im Iausstande neu erworbenen Eigenschaften vou der Höhe ihrer Entwicklung herab, sie betreten eine rückläufige Bahn, un sich der wilden Stammform wieder anzunähern. Ich habe früher darauf hingewiesen, dass die asiatischen Schweine Sardiniens den Wilcharakter wieder so vollkommen angenommen haben, dass im Schädel die Spuren der Jomestikation völlig verwischt werden und der Sus vittatus-Charakter zurückerobert wurde.

So lluktuiert die Körperform, durch wechselnde änssere Einwirkungen getroffen, im Laufe längerer Zeitperioden hin und her.

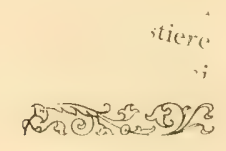







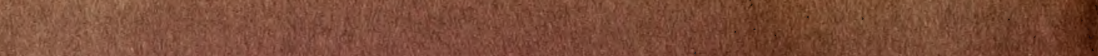

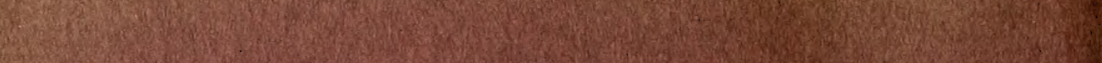
Thes.

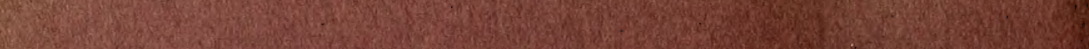
A Wing

Whe 1.1. Sor.t. 

